\author{
UNIVERSIDADE DE SÃO PAULO \\ ESCOLA DE ENGENHARIA DE SÃO CARLOS \\ PROGRAMA DE PÓS-GRADUAÇÃO EM ENGENHARIA DE PRODUÇÃo
}

\title{
MODELO DE REFERÊNCIA PARA A FORMAÇÃO E OPERAÇÃO DE REDES DE INOVAÇÃO AUTO-ORGANIZADAS NA ÁREA DE UTILIDADES DOMÉSTICAS NO BRASIL
}

\section{Adauto Lucas da Silva}

Tese apresentada à Escola de Engenharia de São Carlos da Universidade de São Paulo, como parte dos requisitos para a obtenção do Título de Doutor em Engenharia de Produção.

Área de concentração: Processos e Gestão de Operações

Linha de pesquisa: Redes Produtivas e Logística Integrada

Orientador: Prof. Associado Dr. Fábio Müller Guerrini 


\section{MODELO DE REFERÊNCIA PARA A FORMAÇÃO E OPERAÇÃO DE REDES DE INOVAÇÃO AUTO-ORGANIZADAS NA ÁREA DE UTILIZADADES DOMÉSTICAS} NO BRASIL

Tese apresentada à Escola de Engenharia de São Carlos da Universidade de São Paulo, como parte dos requisitos para a obtenção do Título de Doutor em Engenharia de Produção.

Área de concentração: Processos e Gestão de Operações

Orientador: Prof. Associado Dr. Fábio Müller Guerrini 
AUTORIZO A REPRODUÇÃO E DIVULGAÇÃO TOTAL OU PARCIAL DESTE TRABALHO, POR QUALQUER MEIO CONVENCIONAL OU ELETRÔNICO, PARA FINS DE ESTUDO E PESQUISA, DESDE QUE CITADA A FONTE.

Silva, Adauto Lucas da

Modelo de referência para a formação e operação de redes de inovaçăo auto-organizadas na área de utilidades

domésticas no Brasil / Adauto Lucas da Silva ; orientador Fábio Müller Guerrini. -- São Carlos, 2015.

Tese (Doutorado) - Programa de Pós-Graduação em Ciências e Engenharia de Produção e Área de Concentração em Processos e Gestão de Operações -- Escola de Engenharia de São Carlos da Universidade de Săo Paulo, 2015.

1. Redes de inovaçāo. 2. Sistemas complexos. 3. Autoorganização. 4. Redes de inovação auto-organizadas. I. Titulo. 
Candidato: Bacharel ADAUTO LUCAS DA SILVA.

Título da tese: "Modelo de referência para a formação e operação de redes de inovação auto-organizadas na área de utilidades domésticas no Brasil".

Data da defesa: 26/10/2015

\section{Comissão Julgadora:}

Prof. Associado Fábio Müller Guerrini (Orientador)

(Escola de Engenharia de São Carlos/EESC)

Prof. Dr. Edson Walmir Cazarini

(Escola de Engenharia de São Carlos/EESC)

Prof. Dr. Kleber Francisco Êsposto

(Escola de Engenharia de São Carlos/EESC)

Prof. Dr. Kleber Francisco Êsposto

(Escola de Engenharia de São Carlos/EESC)

Prof. Dr. Alceu Gomes Alves Filho

(Universidade Federal de São Carlos/UFSCar)

Profa. Dra. Rosane Lucia Chicarelli Alcantara

(Universidade Federal de São Carlos/UFSCar)

\section{Resultado:}
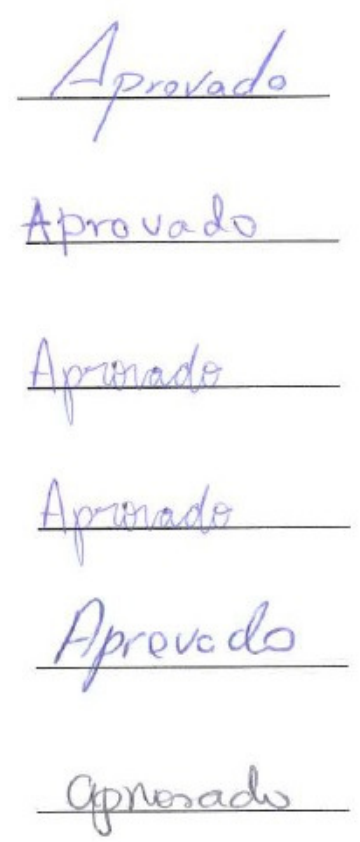

Coordenador do Programa de Pós-Graduação em Engenharia de Produção Profa. Associada Daisy Aparecida do Nascimento Rebelatto

Presidente da Comissão de Pós-Graduação: Prof. Associado Paulo César Lima Segantine 

DEDICATÓRIA

Aos meus amados pais por me oferecer oportunidades com as quais eles nunca sequer puderam sonhar. À minha amada esposa pela compreensão e companheirismo. À minha amada filha pela inspiração para continuar caminhando sempre para frente. 


\section{AGRADECIMENTOS}

A Deus pela paciência comigo ao longo de todos esses anos.

À minha querida esposa pelo amor, compreensão e apoio incondicional. Por me ajudar a avaliar, enfrentar e aliviar todos os desafios cotidianos. Por acreditar em mim e, mais que isso, me fazer acreditar em mim.

Ao meu orientador prof. Dr. Fábio Müller Guerrini pela excelente orientação acadêmica, pelo profissionalismo durante as intervenções precisas, pela cordialidade e incentivo indispensáveis para a conclusão deste trabalho.

A todos os colegas do grupo de pesquisa pelo companheirismo e pelas valiosas contribuições.

Aos professores e funcionários do departamento de Engenharia de Produção da EESC e à Universidade de São Paulo pela infra-estrutura e condições disponibilizadas. 
SILVA, A.L. Modelo de referência para a formação e operação de redes de inovação autoorganizadas na área de utilidades domésticas no Brasil. 2015. 283 p. Tese (Doutorado em Engenharia de Produção). Escola de Engenharia de São Carlos, Universidade de São Paulo, São Carlos, 2015.

\section{RESUMO}

A inovação é um desafio cada vez mais importante e recorrente no nosso contexto econômico. A formação e operação de redes de inovação entre empresas constituem parte do esforço para enfrentar esse desafio. Esta pesquisa tem como propósito apresentar um modelo de referência para apoiar a formação e operação de redes de inovação auto-organizadas. A metodologia de pesquisa é composta de um estudo bibliográfico para a discussão dos principais constructos sobre redes de inovação e sistemas complexos, e de um estudo de caso múltiplo para a coleta de dados em campo. A análise e discussão do cruzamento entre as evidências teóricas e os dados práticos visa propor um modelo de referência para apoiar a formação e operação de redes de inovação auto-organizadas. O modelo de referência é desenvolvido com a metodologia Enterprise Knowledge Development (EKD). O resultado da pesquisa contribui para ampliar a compreensão dos elementos envolvidos no processo de formação e operação de redes autoorganizadas. Espera-se dessa forma estender a aplicação da auto-organização, enquanto constructo teórico de sistemas complexos, para a área de redes de inovação.

Palavras-chave: redes de inovação, sistemas complexos, auto-organização, redes de inovação auto-organizadas 


\title{
SILVA, A.L. Reference model for the formation and operation of self-organized innovation
} networks in the area of household appliances in Brazil. 2015. 283 p. Tese (Doutorado em Engenharia de Produção). Escola de Engenharia de São Carlos, Universidade de São Paulo, São Carlos, 2015.

\begin{abstract}
Innovation is an increasingly important challenge and recurrent in our economic context. The formation and operation of innovation networks between companies are part of the effort to meet this challenge. This research is intented to provide a reference model to support the formation and operation of self-organized innovation networks. The research methodology consists of a literature study for the discussion of the main constructs of innovation networks and complex systems, and a case study analysis with multiple units to collect field data. Analysis and discussion of the intersection between theoretical evidence and practical data aims to propose a reference model to support the formation and operation of self-organized innovation networks. The reference model will be developed with the Enterprise Knowledge Development methodology (EKD). The search result helps to broaden the understanding of the elements involved in the formation and operation of self-organized networks. It is hoped in this way to extend the application of self-organization, while theoretical construct of complex systems, to the innovation networks area.
\end{abstract}

Keywords: innovation networks, complex systems, self-organization, self-organizing innovation network. 


\section{LISTA DE QUADROS}

Quadro 1 - Protocolo de pesquisa .16

Quadro 2 - Empresas que centralizam as unidades de análise estudadas .................................18

Quadro 3 - Metodologias de modelagem ...........................................................................22

Quadro 4 - Conceitos associados com auto-organização segundo o recorte analítico de redes ..37

Quadro 5 - Conceitos associados à auto-organização pela teoria de sistemas complexos ...........38

Quadro 6 - Elementos do Modelo de Objetivos relacionados às parcerias .................................75

Quadro 7 - Elementos need for change para o Modelo de Objetivos .........................................77

Quadro 8 - Elementos do Modelo de Regras de Negócios .......................................................78

Quadro 9 - Elementos need for change para o Modelo de Regras de Negócios .........................80

Quadro 10 - Elementos do Modelo de Processos de Negócios .................................................82

Quadro 11 - Elementos need for change para o Modelo de Processos de Negócios ...................83

Quadro 12 - Elementos do Modelo de Atores e Recursos .......................................................84

Quadro 13: Elementos need for change para o Modelo de Atores e Recursos ..........................85

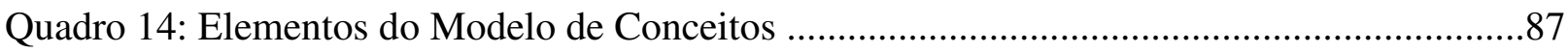

Quadro 15 - Elementos need for change para o Modelo de Conceitos .....................................89

Quadro 16 - Comparativo da revisão bibliográfica com o estudo de caso ...............................126

Quadro 17 - Formulário relativo à validação do Modelo de Objetivos ...................................231

Quadro 18 - Formulário relativo à validação do Modelo de Regras de Negócios .....................231

Quadro 19 - Formulário relativo à validação do Modelo de Atores e Recursos ........................232

Quadro 20 - Formulário relativo à validação do Modelo de Processos de Negócios ................232

Quadro 21 - Formulário relativo validação do Modelo Componentes e Requisitos Técnicos ..233 


\section{LISTA DE FIGURAS}

Figura 1: Os sub-modelos da metodologia EKD ...............................................................24

Figura $2:$ A visão da mudança organizacional através do EKD-CMM ..................................25

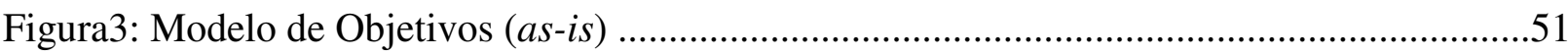

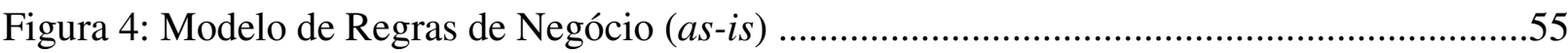

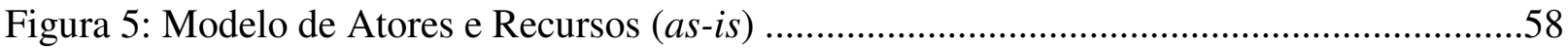

Figura 6: Modelo Macro de Processos de Negócios (as-is) ....................................................60

Figura 7: Modelo de Processos de Negócios: processo 1- gerar a concepção do produto (as-is)

Figura 8: Modelo de Processos de Negócios: processo 2- desenvolver fornecedores (as-is) .....64 Figura 9: Modelo de Processos de Negócios: processo 3- desenvolver protótipos (físico e/ou virtual) (as-is) .66

Figura 10: Modelo de Processos de Negócios: processo 4- desenvolver material de apoio (as-is) 68

Figura 11: Modelo de Processos de Negócios: processo 5- desenvolver e homologar o processo e certificar o produto (as-is) .70

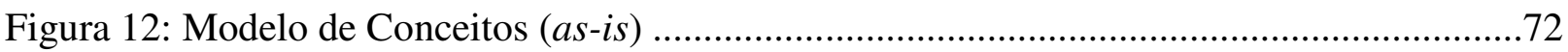

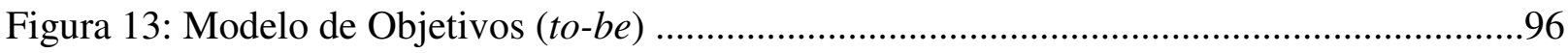

Figura 14: Modelo de regras de Negócios (to-be) - parte A .....................................................99

Figura 14: Modelo de regras de Negócios (to-be) - parte B .....................................................100

Figura 15: Modelo de Atores e Recursos (to-be) ......................................................................103

Figura 16: Modelo de Processos de Negócios - Macro Processos (to-be).................................105

Figura 17: Modelo de Processos de Negócios - Gerar colaborativamente a concepção do produto (to-be) 106

Figura 18: Modelo de Processos de Negócios - Desenvolver protótipos físico e/ou virtuais (tobe) 108

Figura 19: Modelo de Processos de Negócios - Desenvolver material de apoio (to-be) 110

Figura 20: Modelo de Processos de Negócios - Desenvolver e homologar processo e certificar produto (to-be)

Figura 21: Modelo de Componentes e Requisitos Técnicos 


\section{LISTA DE SIGLAS}

ARIS - Architecture of Integrated Information Systems

CIMOSA - Computer Integrated Manufacturing Open System Architecture

CRM - Customer Relationship Management

EKD - Enterprise Knowledge Development

EKD - CMM - Enterprise Knowledge Development - Change Management Method

EM - Enterprise Modelling

OCDE - Organisation for Economic Co-operation and Development

PERA - Purdue Enterprise Reference Architecture

P\&D - Pesquisa e Desenvolvimento

TI - Tecnologia da Informação 


\section{SUMÁRIO}

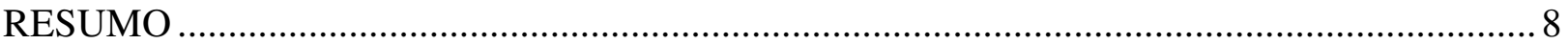

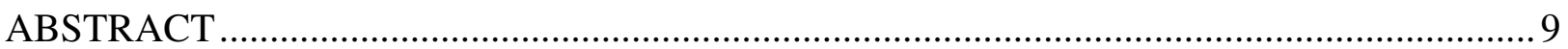

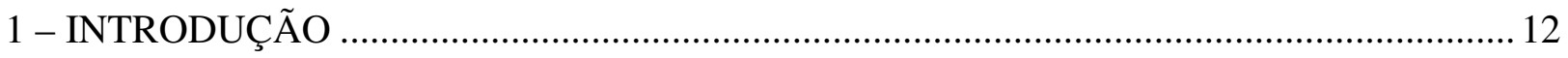

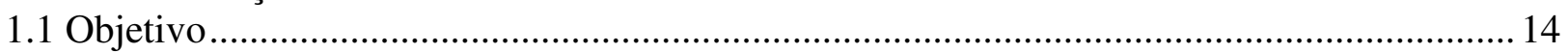

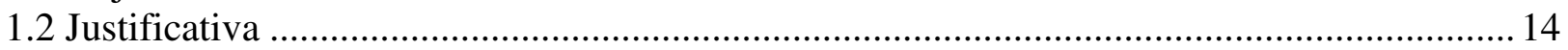

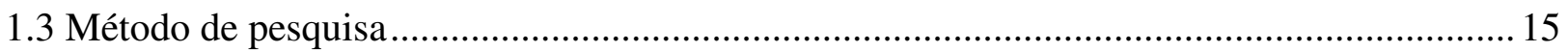

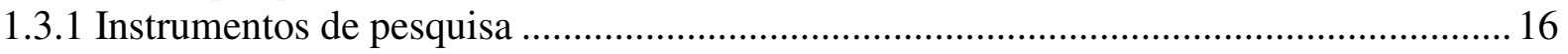

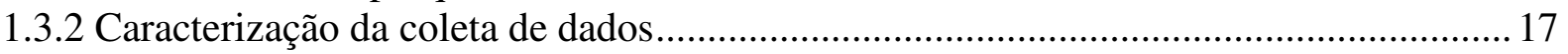

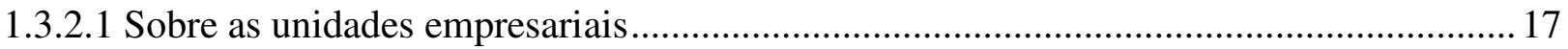

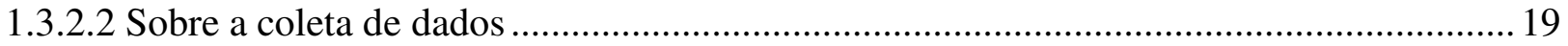

1.4 Caracterização e conceituação do modelo de referência.....................................................20

1.4.1 Passos para a elaboração do modelo de referência ....................................................... 21

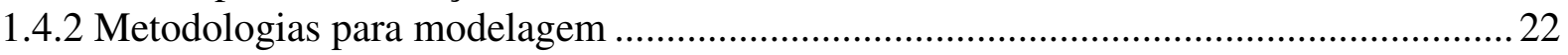

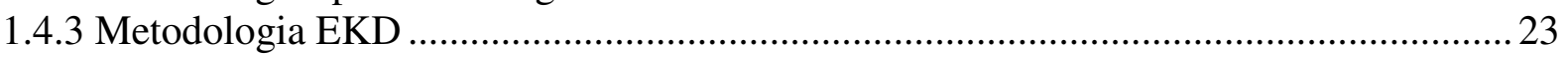

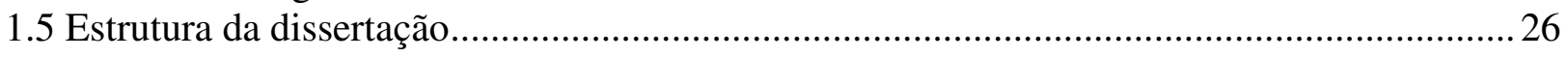

2 - REVISÃO BIBLIOGRÁFICA: REDES DE INOVAÇÃO AUTO-ORGANIZADAS NA PERSPECTIVA DE SISTEMAS COMPLEXOS, UMA REVISÃO CONCEITUAL

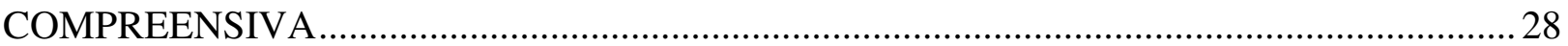

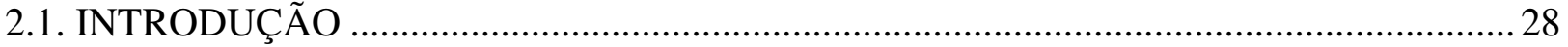

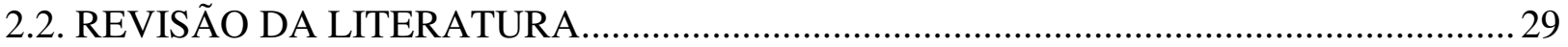

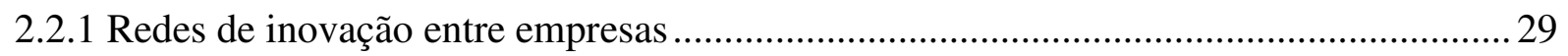

2.2.1.1 Estrutura de uma rede de inovação ....................................................................... 30

2.2.1.2. Requisitos na gestão de uma rede de inovação ......................................................... 31

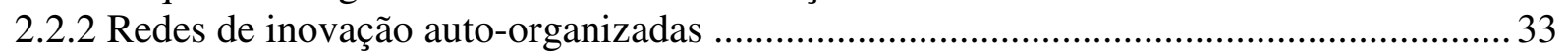

2.2.3 Redes de inovação auto-organizadas na perspectiva de sistemas complexos................. 34

2.2.3.1 A propriedade de auto-organização sob a perspectiva de sistemas complexos ............... 36

2.3. ANÁLISE CRÍTICA PARA SISTEMATIZAÇÃO DO ESTADO DA ARTE.................... 37

2.3.1 Auto-organização: perspectiva do recorte analítico de redes de inovação........................37

2.3.2 Auto-organização: perspectiva de sistemas complexos …............................................... 39

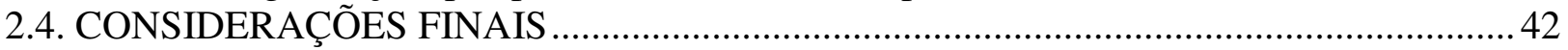

\section{3 - MODELO ATUAL (“AS-IS”) E IDENTIFICAÇÃO DAS NECESSIDADES DE}

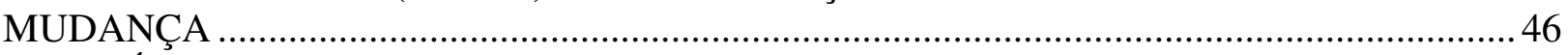

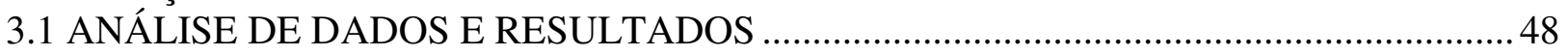

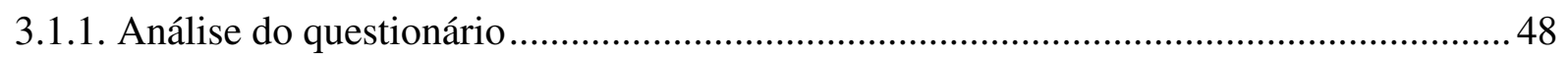

3.1.2 Modelagem consolidada do estudo de caso com 08 unidades empresariais (modelo atual

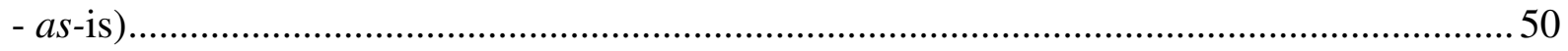

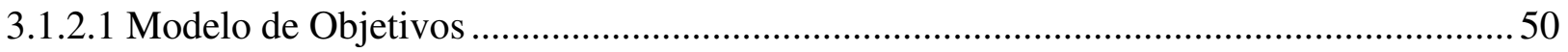

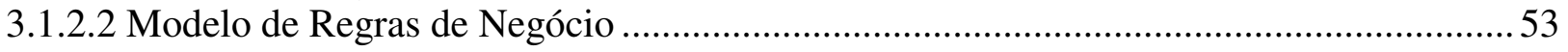

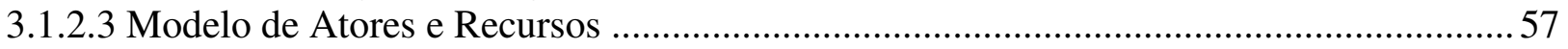

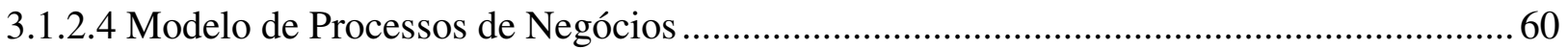

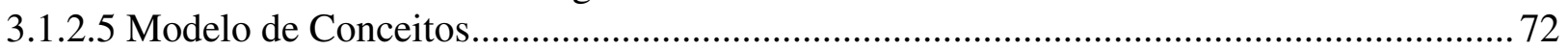

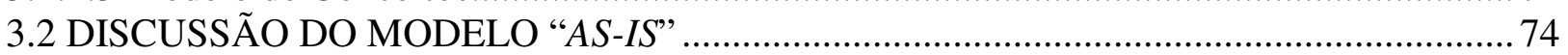

3.3 ANÁLISE DA NECESSIDADE DE MUDANÇA (NEED FOR CHANGE) ........................ 76

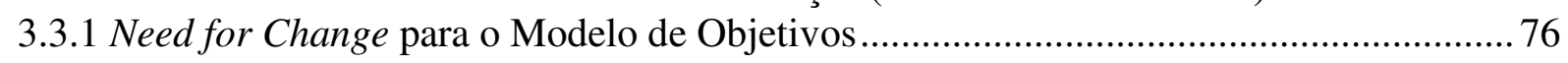

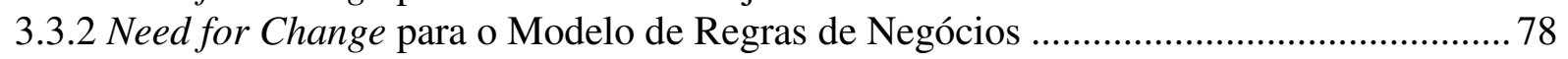

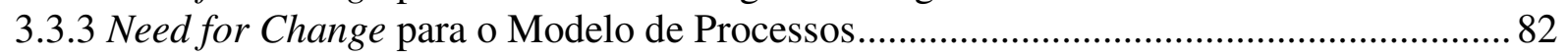

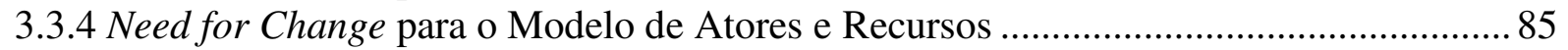

3.3.5 Need for Change para o Modelo de Conceitos .................................................................. 88 
4 - MODELO DE REFERÊNCIA PARA A FORMAÇÃO E OPERAÇÃO DE REDES DE INOVAÇÃO AUTO-ORGANIZADAS NA ÁREA DE UTILIZADADES DOMÉSTICAS NO

BRASIL

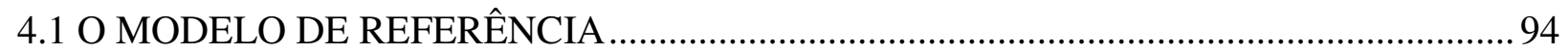

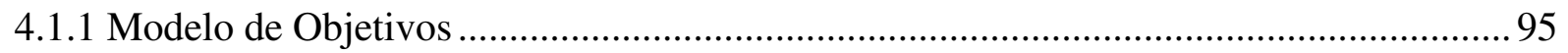

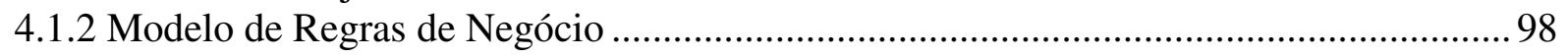

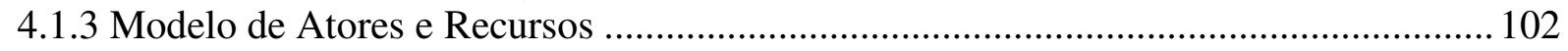

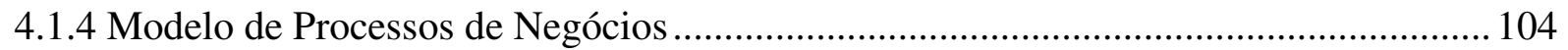

4.1.5 Modelo de Componentes e Requisitos Técnicos ...................................................... 112

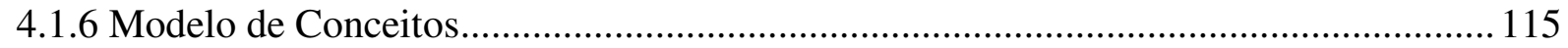

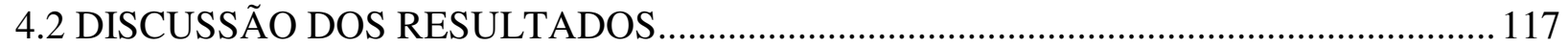

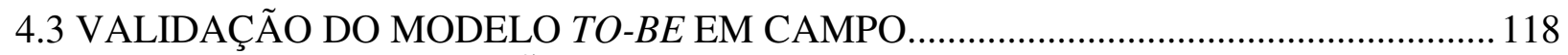

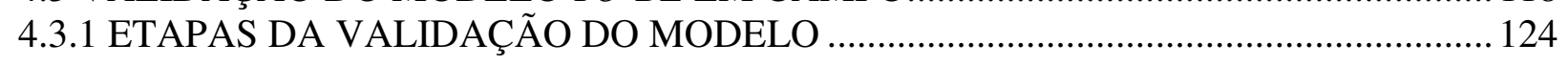

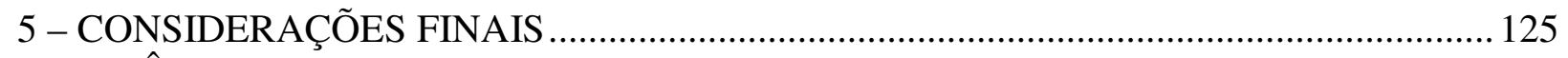

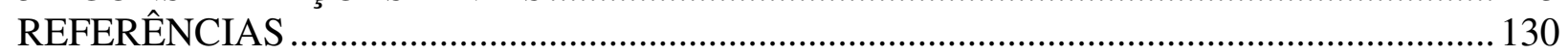

ANEXO A - EKD (Enterprise Knowledge Development) como metodologia de modelagem para

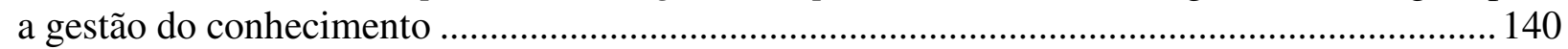

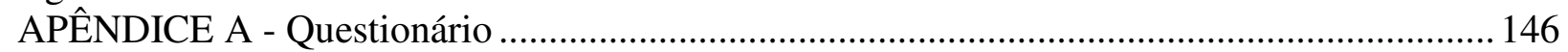

APÊNDICE B - Método de escolha dos elementos presentes nos modelos ............................. 156

APÊNDICE C - Os modelos em cada unidade empresarial .................................................. 162

APÊNDICE D - Questionário de validação do modelo de referência..................................... 230 


\section{1 - INTRODUÇÃO}

A corrente schumpeteriana de pensamento formada por pesquisadores como Fagerberg e Verspagen (2009), Becheikh et al. (2006) e Stock et al. (2002) sugerem uma relação entre inovação e desenvolvimento sócio-econômico. Para eles, a inovação permite que as empresas empreendedoras aumentem seus lucros por intermédio da criação de vantagens temporárias, ao mesmo tempo em que consolidam uma fonte de sucesso empresarial de longo prazo.

Apesar da alta taxa de incerteza/risco associada com a inovação, Berggren e Nacher, 2001), Rosenbusch et al. (2011) e Wang e Ahmed (2007) sugerem que o processo de inovar pode ser gerenciado, sistematizado e replicado internamente nas organizações, pois os processos bem sucedidos de inovação contêm elementos em comum.

A inovação se beneficia basicamente da contribuição oferecida pela heterogeneidade da fonte de conhecimento e competência (Chesbrough, 2008), das características da estrutura de colaboração que conecta as empresas (Zeng et al., 2010) e da habilidade das firmas de criar, combinar, reter, compartilhar e utilizar o conhecimento (Cohen e Levinthal, 1990). Para Rycroft e Kash (2004) e Tzeng (2009), a inovação sistêmica e institucionalizada depende da capacidade dinâmica da firma integrar, construir e re-configurar competências internas e externas.

Nesse contexto, há uma percepção (Hausman, 2005; Prajogo e Ahmed, 2006) de que a inovação é cada vez menos o produto de um esforço isolado, ou seja, inovar é um processo que pressupõe a interação entre diferentes atores (Zeng et al., 2010; Freel e Harrison, 2006).

Isso motiva a formação das redes de empresas, as quais, segundo Britto (2002), constituem arranjos baseados em vínculos sistemáticos de caráter colaborativo entre empresas formalmente independentes com vistas à coordenação de esforços econômicos, compartilhamento de conhecimentos, diminuição do tempo de lançamento de novos produtos, ou integração de competências necessárias para atender novas oportunidades de negócio. As fronteiras entre as empresas dentro da rede são porosas o suficiente para os parceiros complementarem suas competências (Cowan et al., 2005).

Em determinadas redes há a presença de um agente centralizador (Liu e Madhavan, 2005; Ting e Chiu, 2009; Roxenhall, 2013; Valk e Chappin, 2011) que em muitos casos utiliza sua posição privilegiada para impor regras aos parceiros (Christopherson e Clark, 2007; Ting e 
Chiu, 2009). O conceito de auto-organização ganha relevância nesse contexto porque a complexidade do processo de inovação requer cada vez mais um nível de comprometimento, engajamento e pró-atividade que ultrapassa as relações caracterizadas pela imposição de diretrizes por parte de um agente centralizador.

As redes de inovação auto-organizadas constituem uma vertente do conceito de redes de empresas, sendo caracterizadas por Li e Zhou (2010) como redes capazes de, sob condições apropriadas, combinar e rearranjar espontaneamente suas competências sem a necessária intervenção de um controle central, com o objetivo de ampliar o seu núcleo de capacidades e os seus ativos complementares. Para Rycroft e Kash (2004), a auto-organização nas redes ocorre quando o aprendizado e a criação de novos conhecimentos, chaves para a inovação, conduzem a novos processos e estruturas organizacionais que superam desafios e aproveitam oportunidades.

No entanto, apesar de todo o interesse que a área de redes de inovação entre empresas tem despertado na comunidade científica, o corpo de conhecimento produzido tendo como foco de análise uma perspectiva sistêmica da própria rede, ainda é bastante modesto, e isso em boa parte deve-se ao fato de que a observação de fenômenos no âmbito de redes é algo complicado e demorado (Provan et al., 2007; Dahlander e Gann, 2010).

De acordo com Tongming (2010), as redes de inovação apresentam comportamento complexo como decorrência das interações dos elos colaborativos entre si e com o ambiente externo. Uma das propriedades que os sistemas complexos apresentam é a auto-organização, que tem relação direta com a capacidade de adaptação desses sistemas. Em muitas circunstâncias, a ordem e o controle nestes sistemas não são pré-determinados, sendo o controle gerado através de regras comportamentais simples, muitas vezes baseadas em informações locais devido a autonomia e distribuição do controle nos agentes.

Diante da possibilidade das redes de inovação serem analisadas como sistemas complexos, o presente trabalho se propõe a estudar o fenômeno da auto-organização no contexto das redes de inovação na área de utilidades domésticas no Brasil. Usando o recorte analítico de redes e a teoria de sistemas complexos, a pesquisa procura responder as seguintes questões:

(1) As redes de inovação apresentam características de sistemas complexos?

(2) Como surge a auto-organização (como ela se manifesta)?

(3) Como criar condições para que a auto-organização ocorra?

(4) Como garantir que a auto-organização traga benefícios para a rede? 


\subsection{Objetivo}

O objetivo geral desta tese é propor um modelo de referência para a formação e operação de redes de inovação auto-organizadas no contexto das relações de colaboração entre empresas envolvidas no processo de inovação de produtos na área de utilidades domésticas no Brasil.

Como objetivos específicos, a pesquisa visa:

(1) Discutir os principais constructos associados com redes de inovação e autoorganização a partir do recorte analítico de redes de inovação e da teoria de sistemas complexos.

(2) Discutir o estado atual (as-is) da operação do processo colaborativo entre empresas para a inovação de produtos na área de utilidades domésticas no Brasil. Esse trabalho é apresentado através da modelagem organizacional em um estudo de caso múltiplo composto por oito unidades empresariais analisadas, sistematizado de acordo com a metodologia Enterprise Knowledge Development (EKD).

(3) Identificar, através do estudo de caso, as lacunas que podem comprometer a manifestação de comportamentos auto-organizados, assim como apontar através da literatura os principais elementos de apoio para a auto-organização.

\subsection{Justificativa}

Cada vez mais a inovação tem sido considerada uma alternativa para manter a competitividade sustentável das empresas (Armoutis et al.,2008; Katzy et al. 2008). O desafio de inovar tem forçado as empresas a ampliarem suas competências, e isso tem provocado cada vez mais o estabelecimento de alianças inter-organizacionais de caráter colaborativo para o compartilhamento de know-how, capital humano, tecnologia, infra-estrutura e recursos financeiros (Sari et al., 2007; Gilbert et al., 2007; Emden et al., 2006; Schoonmaker e Carayannis, 2010; Molina-Morales e Mertínez-Fernández, 2010). As redes de inovação constituem uma especificidade das redes de empresas, na forma de um arranjo voluntário entre organizações independentes ligadas por vínculos colaborativos com o propósito de superar em parceria as incertezas do processo de inovação, envolvendo-se na geração, comercialização e difusão de produtos, processos e serviços novos ou melhorados (Freel e Harrison, 2006; Sammarra e Biggiero, 2008).

Em várias dessas redes de inovação há a presença de uma empresa focal centralizadora (Liu e Madhavan, 2005; Ting e Chiu, 2009; Roxenhall, 2013; Valk e Chappin, 2011; Dhanaraj e Parkhe, 2006). Quanto mais vulnerável julgar-se a empresa focal, mais ela tenderá a proteger-se usando uma combinação de garantias contratuais diretas e indiretas para controlar os demais 
parceiros da rede (Gardet e Mothe, 2011). A questão é que os desafios impostos pelo processo de inovação requerem uma intensidade de comprometimento e de trocas entre os parceiros que não pode ser assegurada simplesmente através de obrigações contratuais impostas por uma empresa centralizadora.

Diante desse cenário, ambientes auto-organizados mostram-se abertos para acolher ideias potencialmente inovadoras, e não apenas as diretrizes de uma empresa focal, a qual também não tem todas as soluções para as incertezas e desafios do processo de inovação. A propriedade de auto-organização se caracteriza por comportamentos coletivos espontâneos que surgem a partir de movimentos gerados pelos próprios agentes do sistema em resposta aos estímulos externos e internos (Pathaket et al., 2007; Manson, 2001; McCarthy et al., 2000). Essa propriedade é importante porque tem relação direta com a capacidade de adaptação desses sistemas (Schneider e Somers, 2006).

\subsection{Método de pesquisa}

Nesta pesquisa foi adotada uma abordagem qualitativa a fim de viabilizar a análise e a compreensão dos fenômenos envolvidos com o objeto de pesquisa. As principais características dos métodos qualitativos são a imersão do pesquisador no contexto em estudo e a perspectiva interpretativa de condução da pesquisa (Kaplan e Duchon, 1988). Em relação aos fins, a pesquisa realizada será do tipo exploratório, pois o objetivo é proporcionar maior familiaridade com um problema ainda pouco explorado pela literatura acadêmica.

O método de pesquisa adotado para planejar, coletar e analisar os dados é o estudo de caso. Segundo Yin (2005), este método é indicado para uma pesquisa detalhada, que tenha cunho empírico e esteja circunscrita ao estudo de poucos objetos. De acordo com Yin (2005), um protocolo de investigação concorre para aumentar a confiabilidade de uma pesquisa, pois fornece os procedimentos padronizados seguidos pelo pesquisador e que podem ser repetidos em outras situações por outros pesquisadores.

O protocolo do estudo de caso deve conter alguns elementos essenciais como o objetivo de pesquisa, a identificação das fontes de informação e a definição das questões para orientar o pesquisador na conduta da coleta de dados (Yin, 2005). O protocolo de estudo de caso apresentado no Quadro 1 mostra a sinopse geral da pesquisa. 
Quadro 1: Protocolo de pesquisa

\begin{tabular}{|c|c|}
\hline \multicolumn{2}{|c|}{ Componentes do Projeto de Pesquisa de Campo } \\
\hline Tipo de pesquisa & Exploratória. \\
\hline $\begin{array}{l}\text { Objetivo da pesquisa } \\
\text { de campo }\end{array}$ & $\begin{array}{l}\text { Propor um modelo de referência para a formação e operação de redes de } \\
\text { inovação auto-organizadas no contexto das relações de colaboração entre } \\
\text { empresas envolvidas no processo de inovação de produtos na área de utilidades } \\
\text { domésticas no Brasil. }\end{array}$ \\
\hline Questões de estudo & $\begin{array}{l}\text { (1) As redes de inovação apresentam características de sistemas complexos? } \\
\text { (2) Como surge a auto-organização (como ela se manifesta)? } \\
\text { (3) Como criar condições para que a auto-organização ocorra? } \\
\text { (4) Como garantir que a auto-organização traga benefícios para a rede? }\end{array}$ \\
\hline Unidade de Análise & Agrupamentos de empresas centralizados por uma empresa líder. \\
\hline Unidade de Tempo & De 2013 a 2014. \\
\hline Local & Brasil (SP, PR, CE) \\
\hline $\begin{array}{l}\text { Validade do } \\
\text { Constructo }\end{array}$ & $\begin{array}{l}\text { A convergência das várias fontes de evidência (revisão bibliográfica; estudo de } \\
\text { caso, e metodologia de modelagem) permite a consolidação das várias } \\
\text { perspectivas de avaliação do objeto de estudo. }\end{array}$ \\
\hline Validade Externa & $\begin{array}{l}\text { Como as unidades de análise desenvolvem projetos de inovação a partir de } \\
\text { parcerias estabelecidas entre empresas do mercado pode-se pensar numa } \\
\text { generalização analítica para outras unidades de análise de porte similar, } \\
\text { tomando-se como base a replicação dos resultados apresentados pelo estudo de } \\
\text { caso. }\end{array}$ \\
\hline Confiabilidade & Utilização de um protocolo de estudo de caso. \\
\hline
\end{tabular}

Yin (2005) sugere que a validade do constructo pode ser evidenciada a partir da busca pela convergência entre as várias fontes de informação que compõem a pesquisa. A revisão bibliográfica, a avaliação do estudo de caso (apoiado pelo questionário gerado a partir da revisão teórica), e a metodologia de modelagem fornecem várias perspectivas de avaliação do objeto de estudo, cuja convergência apoia a validade do constructo. Em relação à validade externa, pode-se sugerir que ela se limita às redes de inovação de porte organizacional semelhante.

\subsubsection{Instrumentos de pesquisa}

O primeiro instrumento de pesquisa elaborado foi um questionário com base na revisão bibliográfica, o qual abordou quatro pontos principais: (1) se a unidade de análise apresentou características de sistemas complexos; (2) se a auto-organização manifestou-se durante os projetos; (3) se havia elementos para permitir que o fenômeno da auto-organização ocorresse; (4) se a auto-organização trouxe benefícios para os objetivos das unidades de análise.

O questionário foi elaborado com base no referencial teórico. Após ser utilizado no estudo de caso da primeira unidade empresarial, algumas questões foram re-elaboradas a fim de melhorar a compreensão dos entrevistados. O intuito foi avaliar o nível de compreensão do entrevistado em relação às questões, coletar sugestões, e fazer as melhorias necessárias. 
O segundo instrumento de pesquisa utilizado no estudo de caso foi a entrevista com os responsáveis diretos pela inovação de produtos de cada unidade empresarial. Embora o nome do cargo de cada um deles varie, todos possuem a atribuição de coordenar o complexo processo de colaboração entre as empresas durante os projetos de inovação de produtos. O objetivo da entrevista foi coletar informações para realizar a modelagem do estado atual (as-is) do cenário que envolve a inovação de produtos em cada unidade empresarial para levantar os objetivos, regras de negócio, processos, e atores e recursos envolvidos. Antes de iniciar o processo de modelagem propriamente dito, cada entrevistado teve uma visão geral da metodologia EKD a fim de facilitar a compreensão dos modelos a serem produzidos. Consequentemente, eles poderiam ajudar a refinar esses modelos.

A partir do cruzamento entre os dados coletados através do questionário e os modelos desenvolvidos por intermédio das entrevistas foram identificados os elementos de apoio para a propriedade de auto-organização.

\subsubsection{Caracterização da coleta de dados}

Com o objetivo de verificar em campo a presença dos elementos indicados pela literatura como necessários para a formação e operação de redes de inovação auto-organizadas, apresenta-se um estudo de caso múltiplo com 08 unidades empresariais. O propósito do trabalho de campo foi estudar o processo de formação e operação do conjunto de parcerias que cada unidade empresarial estabelece dentro dos projetos de inovação de produtos. Como a determinação de inovar e o controle sobre todo o processo é exercido pela empresa focal, estudou-se esse processo a partir da perspectiva da empresa líder.

Outro fato que influenciou na condução da pesquisa é que a configuração das parcerias para apoiar o processo de inovação não ocorre isoladamente, ou seja, ela ocorre dentro do processo de desenvolvimento de produtos (PDP). Por essa razão são identificados os elementos referentes à formação e operação das redes de inovação dentro do cenário de PDP de cada unidade estudada.

\subsubsection{Sobre as unidades empresariais}

As unidades selecionadas pertencem ao setor de eletrônicos, e cada uma delas individualmente participa de um conjunto de empresas vinculadas por parcerias do tipo clientefornecedor. De acordo com relatório disponibilizado pela ABINEE (2013), esse setor é composto por 08 áreas de bens de capital: automação industrial, componentes, equipamentos industriais, GTD (Geração, Transmissão e Distribuição de Energia Elétrica), informática, material de instalação, telecomunicações, e utilidades domésticas. A área de utilidades 
domésticas representa $12 \%$ do faturamento desse setor, posicionando-se individualmente como a quarta área do setor em termos de faturamento. A área de utilidades domésticas também é responsável por ajudar a movimentar duas outras áreas importantes desse setor: informática e equipamentos industriais, que são responsáveis por $45 \%$ do faturamento do setor (ABINEE, 2013).

Conforme a ABINEE, a área de utilidades domésticas está subdividida em: aparelhos eletroeletrônicos domésticos e ferramentas manuais, baterias automotivas, eletroeletrônica embarcada, motocompressores, pilhas e lanternas elétricas portáteis. A subdivisão escolhida é a de aparelhos eletroeletrônicos domésticos e que agrega 53 empresas diretamente concorrentes. E nesse estudo de caso foram consideradas todas as empresas líderes e todas as marcas com penetração nacional.

Quadro 2: Empresas no território nacional que centralizam as unidades empresariais estudadas.

\begin{tabular}{|c|c|c|c|c|}
\hline $\begin{array}{c}\text { Empre- } \\
\text { sas }\end{array}$ & $\begin{array}{c}\text { Porte (\$) } \\
\text { Fatur. anual }\end{array}$ & Produtos & $\begin{array}{l}\text { Funda- } \\
\text { ção }\end{array}$ & $\begin{array}{l}\text { Entre- } \\
\text { vistado }\end{array}$ \\
\hline 1 & $\begin{array}{c}\text { Grande } \\
\text { (2 bilhões) }\end{array}$ & $\begin{array}{l}\text { Lavadora, secadora, fogão, } \\
\text { refrigerador, micro-ondas, ar- } \\
\text { condicionado }\end{array}$ & 1926 & $\begin{array}{l}\text { Gerente de } \\
\text { inovação }\end{array}$ \\
\hline 2 & $\begin{array}{c}\text { Médio } \\
\text { (160 milhões) }\end{array}$ & $\begin{array}{c}\text { Lavadora, secadora, } \\
\text { purificador, bebedouro } \\
\text { refrigerado }\end{array}$ & 1994 & $\begin{array}{l}\text { Coordenador } \\
\text { de projetos }\end{array}$ \\
\hline 3 & $\begin{array}{c}\text { Grande } \\
\text { (1 bilhão) }\end{array}$ & $\begin{array}{l}\text { Lavadora, secadora, freezer, } \\
\text { refrigerador, frigobar, forno } \\
\text { elétrico }\end{array}$ & 1954 & $\begin{array}{l}\text { Gerente de } \\
\text { inovação }\end{array}$ \\
\hline 4 & $\begin{array}{c}\text { Médio } \\
\text { (200 milhões) }\end{array}$ & $\begin{array}{l}\text { Tanquinho, lavadora, } \\
\text { purificador, bebedouro }\end{array}$ & 1976 & $\begin{array}{l}\text { Gerente de } \\
\text { marketing }\end{array}$ \\
\hline 5 & $\begin{array}{c}\text { Grande } \\
\text { (800 milhões) }\end{array}$ & $\begin{array}{l}\text { Purificador, ducha e chuveiro, } \\
\text { aquecedor de água }\end{array}$ & 1923 & $\begin{array}{l}\text { Gerente de } \\
\text { P\&D }\end{array}$ \\
\hline 6 & $\begin{array}{c}\text { Grande } \\
\text { (650 milhões) }\end{array}$ & $\begin{array}{c}\text { Refrigerador, lavadora, } \\
\text { freezer, fogão, purificador, } \\
\text { bebedouro }\end{array}$ & 1963 & $\begin{array}{l}\text { Supervisor de } \\
\text { produtos }\end{array}$ \\
\hline 7 & $\begin{array}{l}\text { Grande } \\
500 \mathrm{~m} .\end{array}$ & $\begin{array}{c}\text { Forno elétrico, liquidificador, } \\
\text { centrífuga, microondas, } \\
\text { panificador, aspirador }\end{array}$ & 1956 & $\begin{array}{l}\text { Gerente de } \\
\text { produtos }\end{array}$ \\
\hline 8 & $\begin{array}{l}\text { Grande } \\
800 \mathrm{~m} .\end{array}$ & $\begin{array}{l}\text { Liquidificador, centrífuga, } \\
\text { aspirador, batedeira, cafeteira }\end{array}$ & 1940 & $\begin{array}{l}\text { Gerente de } \\
\text { P\&D }\end{array}$ \\
\hline
\end{tabular}


Todas as unidades empresariais são centralizadas por uma empresa líder dedicada ao desenvolvimento, manufatura e comercialização de produtos da área de utilidades domésticas. As demais empresas parceiras que integram cada unidade estão relacionadas com o desenvolvimento e o fornecimento de componentes mecânicos, hidráulicos, plásticos, metálicos, elétricos, eletroeletrônicos, embalagens e tecnologia em geral para a empresa focal e para o mercado. Dependendo do produto a ser desenvolvido (inovação), os arranjos podem sofrer reconfiguração, e mesmo no caso de inovação de um mesmo produto, as parcerias formadas em projetos anteriores podem sofrer modificações.

\subsubsection{Sobre a coleta de dados}

Em cada unidade empresarial o questionário foi o primeiro instrumento de pesquisa utilizado. O uso do questionário como primeira abordagem teve como objetivo verificar se havia uma relação entre essas unidades e os sistemas complexos, e também permitir uma compreensão geral do contexto de cada unidade empresarial. Isso foi verificado utilizando-se os conceitos obtidos na revisão bibliográfica sobre redes de inovação e sistemas complexos. O trabalho de coleta de dados para compor os modelos organizacionais foi o próximo passo. Ele foi antecedido em cada unidade por uma explicação introdutória sobre a metodologia Enterprise Knowledge Development (EKD) e a lógica de conexão dos seus sub-modelos. O objetivo do trabalho de modelagem foi mapear o estado atual (as-is) da formação e operação do conjunto de parcerias estabelecido dentro do PDP de cada unidade empresarial.

Essa etapa da coleta de dados foi realizada por meio de entrevistas semi-estruturadas com os responsáveis diretos pelo desenvolvimento de novos produtos, consequentemente responsáveis pela articulação e/ou acompanhamento das ligações e fluxos entre os parceiros. Cada entrevista teve duração de aproximadamente 2 horas, sendo realizadas de 02 a 03 visitas para cada unidade empresarial. Além disso, foi realizado contato telefônico e através de email a fim de esclarecer algumas dúvidas. O período de coleta de dados ocorreu entre agosto/2014 e outubro/2014.

O resultado da pesquisa de campo foi representado através de um modelo de referência que foi denominado modelo " $a s$-is", ou modelo do estado atual. Utilizando-se o recorte analítico de redes de inovação e a teoria de sistemas complexos foram identificadas as lacunas presentes nesse modelo, e organizadas e discutidas através de quadros as necessidades de mudança. Do cruzamento do modelo "as-is" com as necessidades de mudança foi desenvolvido o modelo "to$b e$ ", ou modelo do estado futuro. Esse modelo representa uma sistematização dos elementos 
necessários para a formação e operação de redes de inovação auto-organizadas na área de utilidades domésticas no Brasil.

\subsection{Caracterização e conceituação do modelo de referência}

O principal objetivo da modelagem organizacional é apoiar a análise sistematizada de um objeto em estudo, oferecendo mecanismos para o mapeamento do conhecimento (processos, objetivos, recursos), funcionando como uma ferramenta de unificação semântica, reduzindo a complexidade do sistema mapeado e facilitando o uso do conhecimento e know-how da própria organização (Vernadat, 2002). Ainda de acordo com esse autor, a modelagem pode ser realizada a partir de situações reais (melhores práticas) com o apoio da perspectiva teórica.

Conforme Bubenko et al. (2001), um modelo oferece uma forma estruturada de representar o conhecimento de uma empresa, facilitando a compreensão do seu contexto interno e externo, e fortalecendo a comunicação entre os agentes envolvidos. Kirikova (2000) destaca a importância de um modelo ao sugerir que a compreensão adequada de uma organização requer a identificação dos seus principais elementos, como estes estão relacionados, como eles funcionam em conjunto, assim como o papel da organização no seu ambiente de atuação.

Para Schuh et al. (2008), modelo de referência é uma classe especial de modelos, mais abrangente e genérica, que pode ser usada como base para o desenvolvimento de modelos específicos (instanciação). Ele pode ser usado como base para modelar (especificar e sistematizar) um determinado domínio, funcionando como ferramenta para sua análise (Ahlemann, 2009; Reinhartz-Berger et al., 2010).

Segundo Ermilova e Afsarmanesh (2010), um modelo de referência precisa ser abrangente a fim de contemplar os sistemas similares ao ambiente originalmente mapeado. Para isso, Romero e Molina (2010) sugerem que esse tipo de modelo precisa fornecer um conjunto padronizado de diretrizes que permitam sua instanciação em vários ambientes.

Indulska e Matook (2009) e Fettke e Loos (2007) também indicam algumas condições básicas para um modelo ser considerado de referência:

(a) Generalidade: capacidade intrínseca de cobertura das funções em cada situação e de atender diferentes casos (o modelo não representa um negócio particular).

(b) Flexibilidade: capacidade de adaptação do modelo para atender situações fora do seu escopo original.

(c) Uso completo: utilização próxima ao total dos componentes do modelo.

(d) Usabilidade: facilidade para operar, implementar e utilizar.

(e) Compreensibilidade: facilidade de compreensão dos conceitos e da sua estrutura. 
O uso de um modelo de referência permite o compartilhamento de conceitos entre os agentes, a construção de um painel com os pontos fortes e fracos do objeto modelado, e o aumento da eficiência do próprio processo de modelagem através da reutilização sistematizada dos modelos (Goepp et al., 2014). A reutilização acelera a modelagem e produz soluções com melhor qualidade devido a possibilidade de se adotar melhores práticas e alternativas consensuais (Haddar et al., 2014). Outros benefícios são: padronização de processos de negócio para serem utilizados em várias organizações; condução de projetos de novos processos de negócio; redução de tempo, custo e risco na implantação de mudanças; apoio na comunicação de novas ideias e de melhores práticas (Ahlemann, 2009). A modelagem estrutura o conhecimento de e sobre um determinado domínio, apoiando as melhorias de processos bem como a integração, coordenação e tomada de decisão intra e entre empresas.

\subsubsection{Passos para a elaboração do modelo de referência}

De acordo com Ahlemann e Gastl (2007), o desenvolvimento dos modelos de referência precisa seguir alguns passos específicos a fim de assegurar a consistência em relação ao domínio modelado. São eles:

- $\quad$ Planejamento: essa etapa envolve a identificação do objeto a ser modelado, a avaliação do método de modelagem mais adequado, a escolha das ferramentas computacionais de apoio, e o planejamento das atividades (identificação, cronogramas, envolvidos);

- Construção: algumas atividades dessa etapa compreendem a investigação do domínio de conhecimento a ser modelado, a preparação da primeira investigação empírica, a execução da primeira investigação empírica, e a construção do modelo inicial;

- Validação: uma vez desenhado o modelo inicial, torna-se necessário avaliar sua consistência. Essa etapa envolve alguns passos como planejamento das atividades da segunda investigação empírica, execução das atividades da segunda investigação empírica, refinamento do modelo inicial (inclusão e/ou exclusão de elementos);

- Teste: essa etapa envolve a aplicação do modelo obtido nas etapas anteriores. A partir das informações obtidas nos testes pode-se proceder ao refinamento do modelo.

- Documentação do modelo de referência: o modelo precisa ser estuturado por meio de alguma representação esquemática que facilite sua compreensão, e seus 
elementos precisam ser descritos detalhadamente para que sua compreensão seja clara em futuras aplicações.

\subsubsection{Metodologias para modelagem}

Há várias metodologias de modelagem organizacional disponíveis, no entanto, normalmente elas se restringem à representação dos processos operacionais. De acordo com Loucopoulos e Kavakli (1999), vários aspectos importantes são desconsiderados, como os objetivos da organização, os principais papéis, as razões que definem a estrutura e os processos organizacionais, e a visão holística da organização.

Vernadat (1996) e Bubenko et al. (2001) indicam diferentes perspectivas que a modelagem organizacional pode abordar (Quadro 3):

- Visão de objetivo: justifica o motivo da presença de uma determinada atividade, seus pontos fracos e fortes, assim como os problemas e oportunidades.

- Visão de decisão: refere-se à definição e manutenção das regras de negócio que determinam as ações executadas.

- Visão de atividade: relaciona os processos e tarefas para a transformação de materiais e geração de informação, assim como o estabelecimento de metas e indicadores.

- Visão de dados: trata-se dos eventos e informações que inicializam ou finalizam atividades relacionadas aos processos.

- Visão de organização: refere-se à estrutura organizacional como papéis, responsabilidades e recursos.

- Visão de informação: tem relação com as entradas tangíveis e intangíveis para a execução de um processo, bem como as saídas resultantes de uma atividade.

- Visão de processo: ou de controle, descreve as relações sistemáticas entre as demais visões possibilitando a visão completa de um determinado processo de negócio.

Para a metodologia CIMOSA (Computer Integrated Manufacturing Open System) toda empresa pode ser analisada como um conjunto de processos controlados por agentes através de eventos e mensagens (Kosanke, 1995), podendo-se modelar funções, informações e aspectos organizacionais (Kosanke, 1995; Vernadat, 1996). A metodologia ARIS (Architecture of Integrated Information Systems) também está focada na modelagem de processos, representado as visões de função, de dados, de organização, e controle, sendo bastante utilizada na área de 
engenharia de software por abordar aspectos organizacionais em projetos de sistemas integrados (Vernadat, 1996). Essas duas metodologias apresentam caências em termos das visões objetivo e decisão.

A metodologia PERA (Purdue Enterprise Reference Architecture) foi desenvolvida para permitir a modelagem do ciclo de vida completo de uma empresa, cobrindo desde a definição da missão até sua obsolescência. Sua deficiência reside na visão de processo ou controle, mostrando-se como uma metodologia mais voltada para planejamento.

A metodologia EKD (Enterprise Knowledge Development) mostra-se mais completa em comparação com as demais. Nurcan e Rolland (2003) e Pádua et al. (2004) sustentam que a metodologia Enterprise Knowlodge Development (EKD) apresenta uma forma para organizar o conhecimento disperso pela organização. O conjunto de sub-modelos que formam essa metodologia permite que seja registrada uma imagem do estado atual do objeto estudado, que sejam construídos cenários futuros alternativos, e que haja fácil compreensão e justificativa das decisões tomadas rumo à implantação das mudanças desejadas.

Quadro 3 - Metodologias de modelagem

\begin{tabular}{|l|c|c|c|c|c|c|c|}
\hline \multirow{2}{*}{$\begin{array}{l}\text { Metodologias } \\
\text { de odelagem }\end{array}$} & \multicolumn{7}{|c|}{ Conceitos } \\
\cline { 2 - 8 } & Objetivo & Decisão & Atividade & Dados & Organização & Informação & Processo \\
\hline ARIS & - & - & $\mathrm{x}$ & $\mathrm{x}$ & $\mathrm{x}$ & $\mathrm{x}$ & $\mathrm{x}$ \\
\hline CIMOSA & - & - & $\mathrm{x}$ & $\mathrm{x}$ & $\mathrm{x}$ & $\mathrm{x}$ & $\mathrm{x}$ \\
\hline PERA & $\mathrm{x}$ & $\mathrm{x}$ & $\mathrm{x}$ & $\mathrm{x}$ & $\mathrm{x}$ & $\mathrm{x}$ & - \\
\hline EKD & $\mathrm{x}$ & $\mathrm{x}$ & $\mathrm{x}$ & $\mathrm{x}$ & $\mathrm{x}$ & $\mathrm{x}$ & $\mathrm{x}$ \\
\hline
\end{tabular}

De maneira geral, as metodologias de modelagem privilegiam a identificação, integração e visualização dos processos principalmente com o auxílio de ferramentas computacionais. Nesta pesquisa foi adotado o EKD como metodologia de modelagem organizacional para o desenvolvimento do modelo de referência devido sua maior abrangência em relação às visões organizacionais.

\subsubsection{Metodologia EKD}

Conforme Bubenko et al. (2001), a saída do EKD é um conjunto de modelos conceituais inter-relacionados que fornecem uma visão multifacetada do objeto modelado. O Modelo de Objetivos descreve aquilo que os agentes precisam alcançar por intermédio do esforço de colaboração. O Modelo de Regras de Negócios define e mantém as regras que ajudam a tornar 
possível o Modelo de Objetivos. O Modelo de Processos de Negócios mapeia os processos responsáveis por movimentar a organização na busca pelos objetivos. O Modelo de Atores e Recursos descreve como os agentes e os recursos relacionam-se entre si no âmbito da organização. O modelo de Requisitos e Componentes Técnicos define os requisitos necessários para o desenvolvimento de um sistema de informação que apóie os objetivos, processos e atores. O Modelo de Conceitos reúne os principais constructos presentes nos demais modelos, ajudando na compreensão geral do resultado da modelagem. A Figura 1 mostra a estrutura da metodologia EKD.

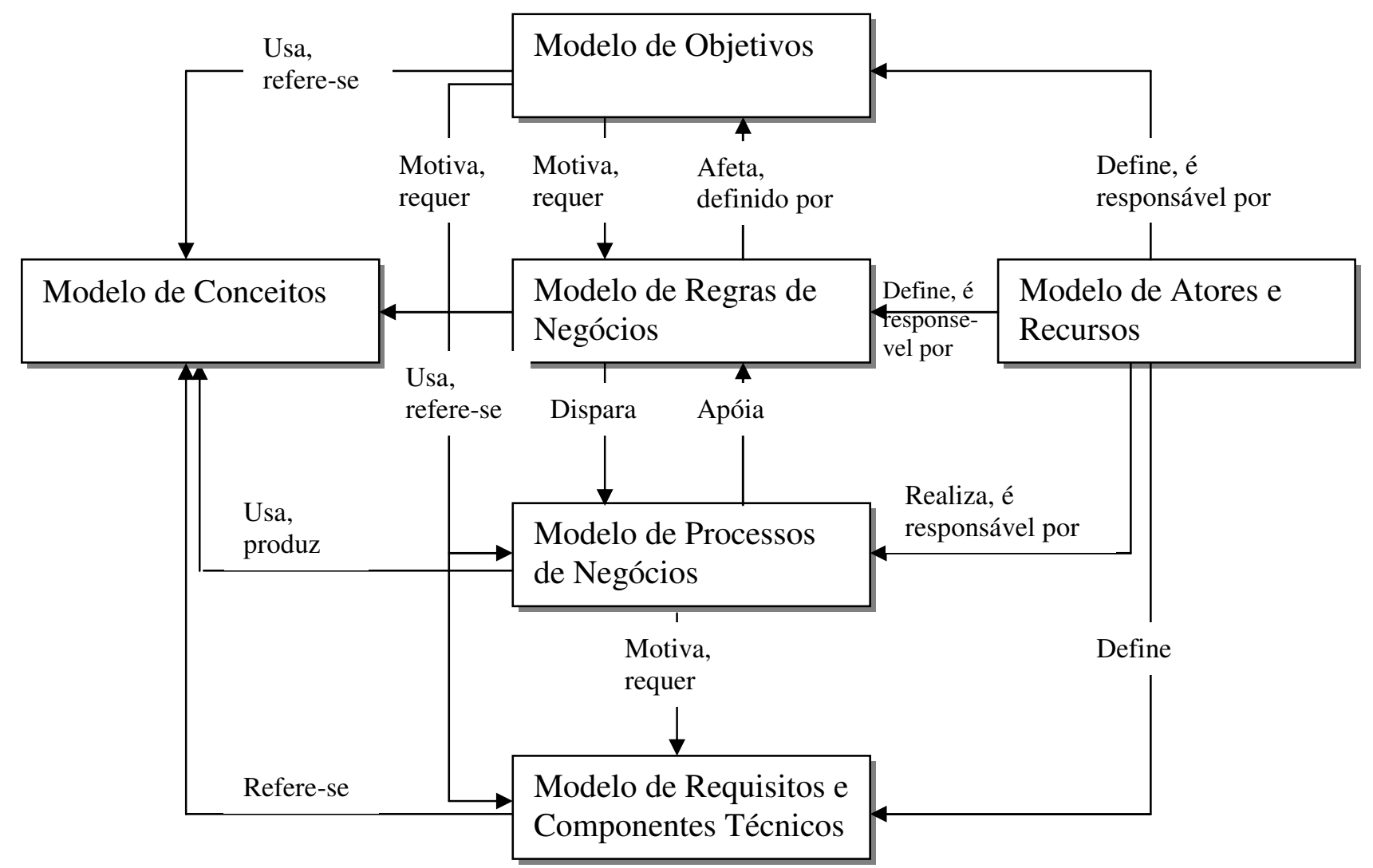

Figura 1: Os sub-modelos da metodologia EKD. Fonte: com Bubenko et al. (2001).

De acordo com Bubenko et al. (2001), a modelagem organizacional através da metodologia EKD envolve três grandes processos: diagnóstico, que consiste em modelar a situação atual do objeto estudado e identificar os requisitos para a mudança; compreensão, que envolve interpretar, discutir, compreender, e deliberar sobre os estados atual e futuro da empresa; e desenvolvimento, que trata da discussão e modelagem das alternativas e dos possíveis cenários futuros.

Algumas características da metodologia EKD envolvem: participação de pessoas de diferentes posições hierárquicas no trabalho de modelagem, identificação das necessidades de mudança, e identificação das alternativas e dos critérios disponíveis para as escolhas. 
A seguir estão relacionados alguns procedimentos indicados por Bubenko et al. (2001) e que foram utilizados nesta pesquisa:

a) definir claramente os objetivos e cronograma de cada seção de modelagem.

b) empregar uma abordagem participativa que permita ao entrevistado ajudar a construir os modelos.

c) documentar os modelos através de ferramentas computacionais.

d) validar os modelos com os participantes.

e) iniciar novas sessões de modelagem a partir dos modelos desenvolvidos, de modo a refinar os modelos.

Nurcan e Rolland (2003) defendem que o ferramental oferecido pela metodologia EKD para o processo de modelagem está contido numa estrutura conceitual que estende suas contribuições. Essa estrutura oferece uma perspectiva de como a empresa está funcionando num certo momento, quais são as razões e os requisitos para a mudança, quais as alternativas mais adequadas, e quais os critérios para avaliar essas alternativas. Esses autores definem essa estrutura conceitual da metodologia como EKD-CMM (Enterprise Knowledge DevelopmentChange Management Method).

De acordo com a Figura 2, na perspectiva do EKD-CMM o domínio sobre a mudança em uma organização requer quatro grandes passos:

a) Análise reversa: abstração de um modelo a partir da realidade atual (modelo "as-is").

b) Definição da mudança: integração da definição de mudança no modelo "as-is" gerando o novo modelo organizacional (modelo "to-be").

c) Implantação da mudança: execução das mudanças baseadas no modelo "to-be".

d) Integração legada: avaliação do contexto existente sobre a implantação da mudança.

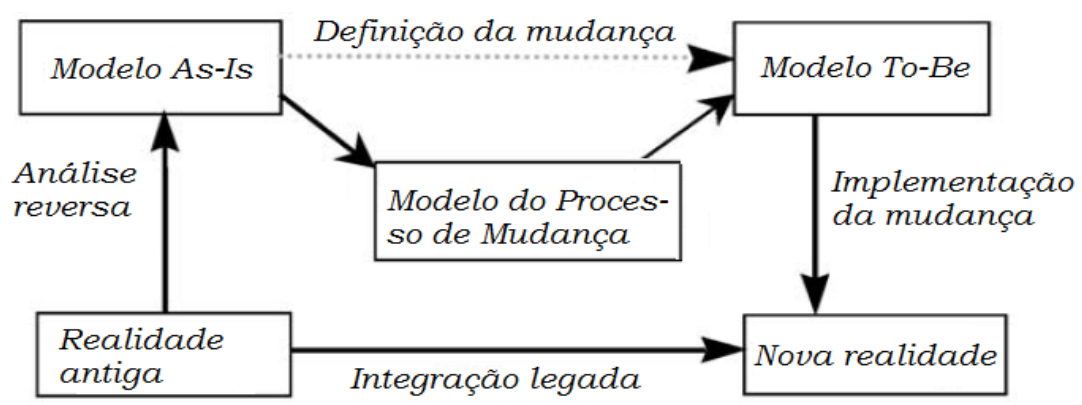

Figura 2: A visão da mudança organizacional através do EKD-CMM. Fonte: Nurcan e Rolland (2003) 
A metodologia EKD permite a representação da realidade organizacional através do modelo "as-is", o qual será modificado com o apoio da definição da mudança desejada para gerar o modelo "to-be".

\subsection{Estrutura da dissertação}

A estrutura da dissertação é composta pelos seguintes capítulos:

(1) Introdução: apresenta o contexto da pesquisa, os objetivos, a justificativa e o método de pesquisa.

(2) Revisão bibliográfica: identifica os constructos associados com redes de inovação e autoorganização a partir da literatura de redes e de sistemas complexos.

(3) Modelagem organizacional do estado atual (as-is): apresenta a sistematização do cenário de colaboração entre empresas para a inovação de produtos na área de utilidades domésticas no Brasil. A partir dessa modelagem é apresentada uma análise sobre as necessidades de mudança (rotulada como need for change de acordo com a metodologia EKD) a fim de se atender o conceito de auto-organização. Para tanto, avalia-se o apoio de elementos presentes no recorte analítico de redes e na teoria de sistemas complexos.

(4) Modelagem organizacional do estado futuro (to-be): apresenta um modelo de referência para apoiar a formação e operação de redes de inovação auto-organizadas. Para isso utiliza os conceitos identificados no capítulo 3 sobre auto-organização.

(5) Considerações finais: apresenta as conclusões e contribuições do trabalho. Também são apontadas as limitações da pesquisa e sugestões para o desenvolvimento de trabalhos futuros.

(6) Apêndices: a primeira seção apresenta a metodologia EKD; a segunda seção registra o questionário utilizado nas entrevistas como apoio para responder as questões de pesquisa; a terceira seção mostra o critério utilizado para selecionar os elementos presentes nos modelos sistematizados no capítulo 3; a quarta seção apresenta os modelos organizacionais desenvolvidos para cada unidade empresarial; a quinta seção apresenta os formulários utilizados na vlidação do modelo "to-be". 


\section{2 - REVISÃO BIBLIOGRÁFICA: REDES DE INOVAÇÃO AUTO-ORGANIZADAS NA PERSPECTIVA DE SISTEMAS COMPLEXOS, UMA REVISÃO CONCEITUAL COMPREENSIVA}

\subsection{INTRODUÇÃO}

A inovação representa a força motriz da mudança econômica e social de longo prazo (Fagerberg e Verspagen, 2009; Becheikh et al., 2006; Stock et al., 2002) e as empresas inovam a partir de novos produtos, novos métodos de produção ou transporte, novos modos de organização industrial, e novos mercados (OECD, 2010).

Amara e Landry (2005), Nieto e SantaMaria (2007), Andersson et al. (2008), Patrakosol (2007), Thorgren et al. (2009) e Tsai (2009) destacam que a inovação esbarra em fatores como a natureza multidisciplinar das novas tecnologias, a complexidade dos processos de negócio, a exigência de novos conhecimentos, e a contínua necessidade de mitigar custos e riscos. Por essa razão, a inovação é cada vez menos o produto de um esforço isolado, ou seja, pressupõe a interação entre diferentes atores (Zeng et al., 2010; Freel e Harrison, 2006; Chesbrough, 2003; Palmberg, 2006; Faems et al., 2005; Hausman, 2005; Prajogo e Ahmed, 2006).

Conforme Becker e Dietz (2004), Freel e Harrison (2006), Iyer et al. (2006), Patrakosol (2007), as redes de inovação têm se mostrado eficazes no apoio aos empreendimentos inovadores, por intermédio do estabelecimento de parcerias bem estruturadas. Em determinadas redes de inovação, observa-se a presença de um agente centralizador (Liu e Madhavan, 2005; Ting e Chiu, 2009; Roxenhall, 2013; Valk e Chappin, 2011), que deveria reunir as fontes dispersas de conhecimentos e recursos (Dhanaraj e Parkhe, 2006), mas, normalmente, acaba usando sua posição privilegiada para impor diretrizes e regras aos parceiros da rede (Christopherson e Clark, 2007; Ting e Chiu, 2009). Entretanto, a complexidade do processo de inovação faz com que a empresa focal não detenha sozinha todas as respostas para os desafios e incertezas que surgem. 
Diante desse cenário, a revisão da literatura analisa a propriedade de auto-organização dos sistemas complexos no contexto das redes de inovação. A pesquisa tem como propósito caracterizar o fenômeno da auto-organização, discutir sua proveniência, assim como as condições para ela ocorrer e trazer benefícios para os negócios.

A auto-organização é uma propriedade dos sistemas complexos, e tem relação direta com a capacidade de adaptação desse tipo de sistema (Lichtenstein, 2000; Marion e Uhl-Bien, 2001; Grabowski e Strzalka, 2008; Surana 2005). De acordo com Mccarthy et al. (2000), Regine e Lewin (2000) e Rose Anderssen et al., (2005) muitos sistemas industriais e de negócios apresentam comportamentos que somente podem ser compreendidos através da perspectiva da teoria de sistemas complexos.

\subsection{REVISÃO DA LITERATURA}

Para identificar os artigos relacionados à pesquisa foram selecionadas as bases de periódicos Web of Science e Scopus. As palavras-chaves pesquisadas nos títulos dos artigos foram innovation networks (544 artigos), complex systems (225 artigos), self-organization (85 artigos), e self-organizing (178 artigos). Foram considerados os artigos publicados a partir do ano 2000 até 2014 (com exceções feitas a alguns artigos considerados clássicos), e que estavam associados às áreas de Engineering, Science Technology e Social Sciences.

Através da leitura e análise dos títulos das publicações foram selecionados 195 artigos associados com innovation networks, 205 com complex systems, 38 com self-organization, e 91 com self-organizing. O terceiro passo incluiu a leitura dos resumos dos artigos, e foram selecionados 133 artigos associados com innovation networks, 63 com complex systems, 13 com self-organization, e 17 com self-organizing. Através da leitura completa desses textos foram selecionados 75 artigos relacionados com innovation networks, e 36 artigos com sistemas complexos (complex systems, self-organization, self-organizing).

\subsubsection{Redes de inovação entre empresas}

As empresas buscam alternativas eficazes para responder com agilidade às incertezas e oportunidades oferecidas por ambientes cada vez mais turbulentos (Armoutis et al., 2008; Katzy et al., 2008). De acordo com Chen e Tsou (2007), Patrakosol (2007), Prajogo e Ahmed (2006) a inovação é uma alternativa para manter a competitividade sustentável das empresas diante de um cenário de mudanças constantes. Para Christopherson e Kitson (2008), inovação é o aproveitamento bem sucedido de novas ideias em termos de produtos, processos, serviços e práticas de negócios. Para ser considerada inovação é requisito que a nova ideia ou concepção 
seja introduzida no mercado ou usada no processo de produção (OECD, 2010; Garcia e Calantone, 2002).

As empresas normalmente apresentam vínculos fortes com o paradigma da inovação fechada, ou modelo integrado vertical, no qual as atividades de pesquisa e desenvolvimento são consideradas processos estritamente internos (Westergren e Holmström, 2012). Esse laço tem raiz no modelo tradicional de gestão baseado nas garantias que o controle hierárquico interno apresenta, como controle rígido das variáveis e baixo risco de evasão de conhecimento. No entanto, a inovação tem estimulado a busca pela ampliação das competências, o que tem provocado o estabelecimento de alianças inter-organizacionais de caráter colaborativo para o compartilhamento de know-how, capital humano, tecnologia, infraestrutura e recursos financeiros (Sari et al., 2007; Gilbert et al. 2007; Emden et al., 2006; Schoonmaker e Carayannis, 2010; Molina-Morales e Mertínez-Fernández, 2010).

Como reação à necessidade de recursos e conhecimentos heterogêneos têm-se observado a formação das redes de empresas. Conforme Freel e Harrison (2006) e Sammarra e Biggiero (2008), as redes de inovação constituem uma especificidade das redes de empresas, na forma de um arranjo voluntário entre organizações independentes ligadas por vínculos colaborativos com o propósito de superar em parceria as incertezas do processo de inovação, envolvendo-se na geração, comercialização e difusão de produtos, processos e serviços. A superação dos desafios é possível porque, segundo Rycroft e Kash (2004) e Corsaro et al. (2012), as redes de inovação são organizações que desenvolvem, adquirem, e integram o conhecimento e as habilidades necessárias para criar e entregar ao mercado soluções inovadoras.

\subsubsection{Estrutura de uma rede de inovação}

Um importante aspecto morfológico a ser discutido é a posição dentro da estrutura da rede. Um agente geralmente está numa posição central na rede quando possui um grande número de conexões com outros agentes, ou quando ocupa uma posição estratégica na estrutura da rede (Liu e Madhavan, 2005). Posições centrais na rede estão associadas ao alto grau de poder, o que facilita a imposição de diretrizes de uma empresa focal para os demais agentes (Roxenhall, 2013; Valk e Chappin, 2011).

A competência em rede ajuda a empresa a mover-se para uma posição mais central na estrutura (Ting e Chiu, 2009), e também o poder econômico concede a força necessária para ela para estabelecer as diretrizes de inovação aos parceiros (Christopherson e Clark, 2007). De acordo com Dhanaraj e Parkhe (2006), a empresa focal tem o papel de reunir as fontes dispersas de conhecimentos por intermédio de um controle que permita a gestão da mobilidade do 
conhecimento (facilidade com que o conhecimento é compartilhado, adquirido e desenvolvido dentro da rede), da apropriação da inovação (habilidade de capturar os benefícios gerados como patentes e marcas registradas), e da estabilidade da rede (controle da entrada, da saída, e dos relacionamentos).

Outro importante aspecto morfológico a ser considerado são as ligações (relacionamentos) que podem ser fracas ou fortes. Para Fukugawa (2006), as ligações fracas são aquelas de curto prazo, mais dinâmicas, que normalmente envolvem apenas a troca de conhecimento explícito. Em contrapartida, as ligações fortes caracterizam-se por serem estáveis e de longo prazo, por envolverem a troca de conhecimentos explícitos e tácitos, e por requererem alto nível de confiança e comprometimento entre as partes. Existe um impasse na escolha desses tipos de ligações que surge do fato de que a confiança aumenta com o tempo, com o volume de interações, com o nível de integração e com o nível de maturidade da interação com os parceiros (Camarinha-Matos et al., 2009), no entanto o relacionamento quando restrito ao mesmo grupo pode provocar a perda de oportunidade de obter novos conhecimentos (Cowan et al., 2005).

Em pesquisa anterior Harryson et al. (2008) sugerem que esses dois tipos de ligações, apesar de conflitantes à primeira vista, são complementares e não excludentes. Eles alertam para o fato de que toda inovação requer duas etapas distintas, a exploração de novos conhecimentos e depois o aproveitamento deles na prática. Esses pesquisadores sugerem que as ligações fracas são mais adequadas para acelerar as fases iniciais de um projeto de desenvolvimento (fases nas quais o conhecimento requerido não é tão complexo). No entanto, quanto mais o projeto caminha maior a importância das ligações fortes, pois mais tácito torna-se o conhecimento requerido e maior a dificuldade para codificá-lo, consequentemente maior a dificuldade para transferi-lo entre os parceiros (Martin e Salomon, 2003; Gooderham e Ulset, 2002).

Com o propósito de abordar adequadamente estas duas situações de conflito ganha força a perspectiva de Granoveter (1973), Burt (1992), Cowana e Jonard (2004), Capaldo (2006), Fritsch e Kauffeld-Monz (2010), Büchel et al. (2013) de que uma estrutura de rede adequada para a inovação é a de núcleo coeso, marcada por um número limitado de ligações fortes e de confiança, vinculada a uma ampla periferia de ligações fracas, responsáveis por informações novas e não redundantes.

\subsubsection{Requisitos na gestão de uma rede de inovação}

O requisito apontado de forma mais recorrente na literatura para a gestão de uma rede de inovação é a confiança, baseada na comunicação aberta, transparente e eficaz (Ritter e 
Gemünden, 2003; Ojasalo, 2008; Kotilla et al., 2008; Ollus et al., 2011; Alin et al., 2013; Westergren e Holmström, 2012).

Ojasalo (2008) alerta que numa rede de inovação centralizada nem todos os aspectos e/ou situações podem ser controlados pela empresa focal. No entanto, mesmo enfrentando mudanças inesperadas, essas redes podem ser gerenciadas por intermédio da atenção a alguns elementos fundamentais. Para esse autor, a confiança e o comprometimento dentro dos relacionamentos de longo-prazo são importantes e podem ser alcançados com: apoio do sistema de recompensas; compartilhamento do planejamento, do controle e das informações; consistência na interação; termos contratuais; e resolução compartilhada de conflitos. De acordo com Gardet e Mothe (2011), a confiança é ainda mais importante que o grau de formalização contratual, e que ela se beneficia do compartilhamento de benefícios, das garantias para evitar comportamento oportunista, e da resolução conjunta de conflitos.

Ollus et al. (2011) e Alin et al. (2013) sugerem que a confiança tem relação com o sucesso no esforço de inovar, mas que ela necessita o alinhamento dos parceiros em relação ao projeto (objetivos, processos, tarefas) e dos parceiros entre si (competências e comprometimento). Esse alinhamento precisa ser freqüente e requer um processo eficiente de comunicação (Lee e Yong, 2010), pois os interesses, as capacidades, e as estratégias das empresas podem ser conflitantes (Christopherson e Clark, 2007). A tecnologia pode ajudar a manter a consistência da informação nos nós de uma rede, assegurando a atualização, padronizão e distribuição (Held e Blochinger, 2009). Wu et al. (2006), Chung et al. (2009) e Andersson et al. (2008) defendem que uma plataforma tecnológica integrada pode permitir que os parceiros trabalhem colaborativamente como uma organização virtual utilizando um espaço digital compartilhado.

A partir de um estudo realizado em três redes pertencentes a três setores distintos da economia, Ulbrich et al. (2011) também apresentam alguns fatores considerados críticos para a gestão de um processo colaborativo entre empresas: comunicação aberta e transparente, alto nível de comprometimento, acordo sobre regras de cooperação, e expectativa razoável de sucesso. Para Bititci et al. (2007) e Corsaro et al. (2012) a gestão bem sucedida dos parceiros numa rede de inovação depende de estabelecimento de objetivos realistas e direcionados, base de conhecimentos heterogênea, competências complementares, planejamento compartilhado, alinhamento das expectativas em relação aos benefícios, e política de governança.

Para Gnyawali e Srivastava (2013), alguns catalisadores que influenciam a gestão de uma rede de inovação são estado de alerta (capacidade de perceber o desenvolvimento de novas tecnologias e o surgimento de novas tendências de mercado), motivação (disposição para se 
engajar em novos desafios/oportunidades), disponibilidade de recursos (quantidade, diversidade e qualidade), flexibilidade organizacional.

\subsubsection{Redes de inovação auto-organizadas}

Lowe et al. (2012) definem redes auto-organizadas como sendo aquelas compostas por entidades que escolhem voluntariamente participar de práticas compartilhadas para a obtenção de vantagem mútua, usando compartilhamento de capital social coletivo em um ambiente com confiança mútua, na ausência de um controle central. Nesse tipo de sistema o controle é policêntrico (distribuído), pois cada entidade se auto-coordena e ajuda a manter o controle do sistema com foco no objetivo principal (Walker e Dooley, 1999). Para serem consideradas verdadeiramente auto-organizadas, as redes devem monitorar o ambiente, aprender e se adaptar às mudanças externas (Tharumarajah, 2003).

Analisando a estrutura interna das redes, Eschenbacher et al. (2011) sugerem que o comportamento auto-organizado passa pela avaliação e reconhecimento dos diferentes tipos de relacionamentos (legal, financeiro, pessoal, promotor de inovação), e da identificação da intensidade das trocas e controle adequados. Esse esforço diminui a complexidade do processo de auto-organização por intermédio do estabelecimento de prioridades nos relacionamentos.

Para Kash e Rycroft (2002) a auto-organização refere-se à capacidade que as redes têm de se reorganizarem em estruturas mais complexas, e de usarem processos mais complexos, sem uma diretriz gerencial centralizada. Para eles, cinco elementos influenciam a capacidade de auto-organização:

- Aprendizagem organizacional: está no centro da auto-organização, sendo caracterizada pelo desenvolvimento, acúmulo, e transferência de conhecimentos e habilidades.

- Capacidades centrais: capacidade tecnológica (P\&D) e organizacional (gestão, estrutura).

- Ativos complementares: corpo de conhecimentos e habilidades suplementares que as redes têm acesso a fim de tirar o máximo de proveito das capacidades centrais.

- Dependência do caminho: acontecimentos e ações passadas podem acabar indicando novas alternativas, funcionando como base para gerar novos conhecimentos (aprendizagem).

- Influência do ambiente: concorrência, tecnologias, consumidores, políticas governamentais. 
Outras pesquisas também destacam a relevância do aprendizado para a propriedade de auto-organização. Tharumarajah (2003) sugere que a capacidade de auto-organização das redes de inovação manifesta-se como a habilidade das entidades autônomas usarem a capacidade de aprendizagem para adaptar-se às condições prevalecentes, ao mesmo tempo em que a proximidade dos vínculos organizacionais garante a unidade das ações. Para Rycroft e Kash (2004) e Tzeng (2009) a propriedade de auto-organização tem relação direta com a capacidade de aprendizagem (caracterizada pela geração e uso do conhecimento produzido). A capacidade de aprendizagem permite que novas competências e habilidades sejam identificadas, compartilhadas e continuamente atualizadas, o que provoca movimentos de auto-organização dentro de relacionamentos formais e informais das redes.

\subsubsection{Redes de inovação auto-organizadas na perspectiva de sistemas complexos}

Para Wadhawan (2009) um sistema complexo é formado por um grande número de agentes que interagem formando uma rede: os nós são os agentes e as ligações representam as interações. Marion (1999), Regine e Lewin (2000), e Mccarthy et al. (2000) sugerem que a teoria de sistemas complexos propõe que as organizações sejam vistas como sistemas complexos capazes de se adaptar, formados por uma ampla diversidade de agentes cujos comportamentos afetam uns aos outros. Rose-Anderssen (2005) é mais específico ao reconhecer que as empresas ao se organizarem para desenvolver novos produtos podem ser vistas como sistemas complexos, e a diversidade de conhecimentos e perspectivas de cada agente contribui para a aprendizagem coletiva.

Sistemas complexos além de serem constituídos por certo número de elementos denominados agentes (firmas, consumidores, fornecedores, governo), operam sem um controle centralizado, e interagem de maneira não linear seguindo regras simples (Vasileiadou e Safarzynska, 2010; Pathak et al., 2007). Estas interações não lineares geram comportamento não proporcional às mudanças nos estímulos recebidos, e produzem respostas que não seguem um padrão linear (Choi et al., 2001; Rose-Anderssen, 2005). Como conseqüência, observa-se que mesmo pequenas oscilações nas condições iniciais podem provocar grandes diferenças nas saídas do sistema (Dooley e Van de Ven, 1999).

Para Surana et al. (2005), esse tipo de sistema pode formar redes de elementos dinâmicos nas quais os estados dos nós e das ligações podem mudar, e a topologia frequentemente pode evoluir de maneira não linear. A ordem e o controle nesses sistemas não são pré-determinados, sendo o controle gerado através de regras comportamentais simples, muitas vezes baseadas em informações locais devido à autonomia e distribuição dos agentes. Essas interações são tão 
importantes que Tongming (2010) considera que as redes de inovação comportam-se como sistemas complexos como decorrência das interações (relacionamentos formais e informais) entre os elos colaborativos da rede (agentes).

Uma das propriedades que os sistemas complexos apresentam é a capacidade de adaptação, caracterizando-se como mutantes e inovadores, capazes de obter flexibilidade a partir de uma estrutura de relacionamentos interdependentes, moderadamente acoplados, unidos através de uma dinâmica colaborativa que visa atender objetivos em comum, necessidades compartilhadas, e pontos de vista compatíveis (Uhl-Bien et al., 2007). Esse conceito remete às características das estruturas das redes de empresas discutidas por Granoveter (1973), Burt (1992), Cowana e Jonard (2004), Fritsch e Kauffeld-Monz (2010), Sari et al. (2007), Gilbert et al. (2007), Schoonmaker e Carayannis (2010), e Molina-Morales e Mertínez-Fernández (2010).

Lichtenstein (2000) apresenta quatro pressupostos subjacentes aos sistemas complexos: mudança constante, não redutibilidade, dependência mútua e não linearidade. Para Smith (2005), a mudança é uma força pervasiva na vida organizacional, e a estabilidade e a inércia são inimigas da prosperidade. A instabilidade é uma pré-condição para a mudança e o papel dos líderes organizacionais é remover as barreiras artificiais a fim de tornar a organização menos estável. Quando uma oportunidade de mercado é reconhecida surge uma instabilidade no sistema na forma de pressão para aproveitá-la, e isso motiva a capacidade de auto-organização.

Os sistemas complexos não são redutíveis às suas partes básicas (Lyons, 2005). A compreensão desses sistemas precisa considerar que a agregação dos relacionamentos locais pode gerar padrões, estruturas, e comportamentos a nível global (Frenken, 2000). Como não é possível a compreensão avaliando isoladamente os agentes, Batty e Torrens (2005) sustentam que o desafio está em identificar como simplificar e compactar o sistema preservando sua essência.

$\mathrm{Na}$ dependência mútua um agente afeta e é afetado pelo desempenho de outro agente. A criação e o fluxo de conhecimento constituem um caso onde dois elementos são mutuamente constituintes e dependentes. Para Nonaka (1994) o conhecimento organizacional é criado por intermédio de um diálogo ou fluxo contínuo entre o conhecimento tácito e o conhecimento explícito, através de um processo cíclico e contínuo.

Lichtenstein (2000) destaca que os sistemas complexos comportam-se de maneira não proporcional aos estímulos de entrada, sendo que acima do valor de treshold (estágio no qual a mudança é inevitável) as perturbações são amplificadas, e uma simples idéia ou perturbação pode fomentar o surgimento de uma nova estrutura. A quebra da linearidade implica que 
mudanças na comunicação e nas trocas entre agentes individuais tornam não proporcional e difícil de prever as mudanças nas saídas do sistema (Vasileiadou e Safarzynska, 2010).

\subsubsection{A propriedade de auto-organização sob a perspectiva de sistemas complexos}

De acordo com Choi et al. (2001) e Surana et al. (2005), a auto-organização é uma propriedade de sistemas complexos que se caracteriza pelo comportamento coletivo espontâneo do sistema como decorrência de movimentos de base (bottom-up) estabelecidos entre os próprios agentes. Esses relacionamentos disparam mudanças espontâneas provocando o surgimento de novas estruturas, padrões e propriedades sem a necessidade de imposições externas e com o objetivo de melhor interagir com o ambiente e responder aos estímulos recebidos (Pathak et al., 2007; Manson, 2001; McCarthy et al., 2000).

A importância dos relacionamentos em sistemas complexos tem relevância porque a interdependência entre os agentes, consolidada pelo conjunto de relacionamentos, provoca movimentos auto-organizados responsáveis pela capacidade de adaptação (Schneider e Somers, 2006). A topologia das relações entre os agentes de inovação pode afetar a taxa de produção e difusão de conhecimento, com implicações para a eficiência e efetividade do processo de aprendizagem coletiva (Frenken, 2006).

Um desafio é como tratar esses relacionamentos de modo a fomentar propositadamente comportamentos auto-organizados capazes de gerar inovação. Uhl-Bien et al. (2007) sugerem que num sistema complexo capaz de adaptar-se o controle hierárquico tradicional, de cima para baixo (top-down), pode prejudicar o seu funcionamento. Como os novos comportamentos podem emergir das camadas mais internas do sistema, sempre que ocorre a imposição de uma ideia, acaba-se inibindo comportamentos que poderiam gerar soluções mais eficazes e inovadoras (Marion e Uhl-Bien, 2001). Para Ollus et al. (2011), em atividades colaborativas o mais adequado não é o uso de autoridade para impor respostas, mas a criação de condições para que novos comportamentos gerem inovação.

Ainda segundo essa visão, Schneider e Somers (2006) defendem que na perspectiva de sistemas complexos capazes de se adaptarem o controle é um processo indireto (não depende de autoridade, mas de influência) e catalítico (que proporciona o contexto e os cenários de aprendizado). O controle ocorre influenciando de modo indireto a auto-organização e a adaptação do sistema através da inserção de novos agentes, incentivando o aumento do relacionamento, e também apoiando a divulgação das regras compartilhadas pelos agentes.

Outra fonte de apoio para a auto-organização nos sistemas complexos é a habilidade de reter informação e transformá-la em conhecimento para ser aplicado. Vasileiadou e Safarzynska 
(2010) propõem que os sistemas complexos possuem memória, porque as interações anteriores ocorridas nas dinâmicas locais podem influenciar futuras possibilidades e gerar novas trajetórias no desenvolvimento do sistema. Para Manson (2001), a intensidade dessas interações determina a estrutura interna do sistema, sendo que sua memória reside na própria estrutura interna e a aprendizagem está na capacidade de variar as configurações e a densidade dos relacionamentos.

\subsection{ANÁLISE CRÍTICA PARA SISTEMATIZAÇÃO DO ESTADO DA ARTE}

A discussão dos principais constructos sobre redes de inovação e sobre teoria de sistemas complexos evidencia uma região conceitual comum entre essas duas áreas de pesquisa. Ambas reconhecem a importância do ambiente (Armoutis et al.,2008; Katzy et al. 2008; Chen e Tsou, 2007, Patrakosol, 2007; Prajogo e Ahmed, 2006; Pathak et al. 2007; Manson, 2001; McCarthy et al. 2000), dos agentes (Freel e Harrison, 2006; OECD, 2010; Vasileiadou e Safarzynska, 2010; Pathak et al., 2007; Marion, 1999; Regine e Lewin, 2000; Mccarthy et al., 2000; Frenken, 2006; Choi et al., 2001; Schneider e Somers, 2006), da morfologia ou estrutura (Uhl-Bien et al., 2007; Frenken, 2006; Surana et al. 2005; Pathak et al. 2007), da densidade (Choi et al., 2001; Mccarthy et al., 2000; Manson, 2001; Frenken, 2006), de políticas ou regras de governança (Bititci et al., 2007; Ulbrich et al., 2011; Camarinha-Matos et al., 2009; Vasileiadou e Safarzynska, 2010; Pathak et al., 2007, Surana et al., 2005), e da perspectiva sistêmica (Ollus et al. 2011; Grabowski e Strzalka, 2008; Lechstentein, 2000; Frenken, 2000).

Outros constructos compartilhados pelas áreas de redes e de sistemas complexos são os relacionamentos e a auto-organização. As duas áreas de pesquisas reconhecem que os relacionamentos estão no centro da capacidade de se auto-organizar (Fukugawa, 2006; Cowan et al. 2005; Tongming, 2010; Lichtenstein, 2000; Manson, 2001), e que essa última tem relação direta com a capacidade de adaptação (McCarthy et al., 2000; Tharumarajah, 2003; Kash e Rycroft, 2002).

\subsubsection{Auto-organização: perspectiva do recorte analítico de redes de inovação}

Para o recorte analítico de redes, a auto-organização manifesta-se como a capacidade das redes de se reorganizarem em estruturas mais complexas (Kash e Rycroft, 2002). Esse fenômeno, enquanto esforço de adaptação às mudanças prevalecentes no ambiente (Tharumarajah, 2003; Rycroft e Kash, 2004), decorre da capacidade que as alianças organizacionais têm de produzir novos relacionamentos e, consequentemente, novos processos de negócio a partir da aprendizagem enquanto geração e uso do conhecimento. 
O Quadro 4 resume os principais conceitos relacionados com auto-organização que foram discutidos sob a perspectiva do recorte analítico de redes de inovação.

Quadro 4: conceitos associados com auto-organização segundo o recorte analítico de redes

\begin{tabular}{|c|c|}
\hline Conceitos & Autores \\
\hline $\begin{array}{l}\text { Monitorar o ambiente (estado de } \\
\text { alerta) }\end{array}$ & Tharumarajah (2003), Gnyawali e Srivastava (2013) \\
\hline Relacionamentos & $\begin{array}{l}\text { Granoveter (1973), Burt (1992), Cowana e Jonard (2004), } \\
\text { Capaldo (2006), Fritsch e Kauffeld-Monz (2010), Büchel et. } \\
\text { al (2013), Fukugawa (2006), Cowan et al. (2005), Tongming } \\
\text { (2010), Lichtenstein (2000), Manson (2001) }\end{array}$ \\
\hline $\begin{array}{l}\text { Identificação do tipo e intensi- } \\
\text { dade dos relacionamentos }\end{array}$ & Eschenbacher et al. (2011), Camarinha-Matos (2009) \\
\hline Controle distribuído & $\begin{array}{l}\text { Lowe et al. (2012), Kash e Rycroft (2002), Ollus et al. } \\
\text { (2011) }\end{array}$ \\
\hline Participação voluntária & Lowe et al. (2012) \\
\hline $\begin{array}{l}\text { Compartilhamento de práticas e } \\
\text { conhecimentos }\end{array}$ & Lowe et al. (2012) \\
\hline Confiança mútua & Lowe et al. (2012) \\
\hline $\begin{array}{l}\text { Aprendizagem organizacional } \\
\text { (geração / uso do conhecimento) }\end{array}$ & $\begin{array}{l}\text { Kash e Rycroft (2002), Tharumarajah (2003), Rycroft e } \\
\text { Kash (2004) e Tzeng (2009) }\end{array}$ \\
\hline Alinhamento dos parceiros & $\begin{array}{l}\text { Ollus et al. (2011), Alin et al. (2013), Bititci et al. (2007) e } \\
\text { Corsaro et al. (2012) }\end{array}$ \\
\hline Comunicação & $\begin{array}{l}\text { Lee e Yong (2010), Ulbrich et al. (2011), Ritter e Gemünden } \\
\text { (2003) }\end{array}$ \\
\hline Tecnologia & $\begin{array}{l}\text { Held e Blochinger (2009), Wu et al. (2006), Chung et al. } \\
\text { (2009) e Andersson et al. (2008) }\end{array}$ \\
\hline
\end{tabular}

O recorte analítico de redes destaca que os desafios enfrentados pelas redes são atribuídos às diversas forças que compõem o ambiente e que o monitoramento contínuo dessas forças (Tharumarajah, 2003; Gnyawali e Srivastava, 2013) estimula o fenômeno da autoorganização. Essas forças são geradas pela intensificação da competição, diminuição do ciclo de vida dos produtos, customização dos mercados, e distribuição do conhecimento pelo mundo. 
Os relacionamentos têm o papel de manter a coesão entre os membros da rede e de permitir o fluxo de conhecimentos entre eles, sendo que o nível de intensidade desses relacionamentos determina o tipo de conhecimento transacionado, explícito ou tácito (Eschenbacher et al., 2011; Nonaka, 1994). A capacidade das redes se reorganizarem em estruturas mais complexas está diretamente associada a esses relacionamentos e ao tipo de conhecimento compartilhado (Kash e Rycroft, 2002; Martin e Salomon, 2003; Gooderham e Ulset, 2002).

A distribuição do controle é considerada um requisito importante para a autoorganização (Lowe et al., 2012; Kash e Rycroft, 2002; Ollus et al., 2011). Ela, por sua vez, requer relacionamentos fortes que motivem a participação voluntária e o compartilhamento de práticas e conhecimentos dentro de um ambiente de confiança recíproca (Lowe et al., 2012). Esse compartilhamento permite a aprendizagem organizacional da rede, considerado elemento importante na auto-organização (Kash e Rycroft, 2002; Tharumarajah, 2003; Rycroft e Kash, 2004; Tzeng, 2009).

Embora não associados diretamente pela literatura com a auto-organização, os três últimos conceitos funcionam como elementos de apoio para os demais. $\mathrm{O}$ alinhamento dos parceiros consolida o esforço coletivo, permitindo a participação voluntária e a distribuição do controle dentro de uma expectativa única de objetivos e resultados. Nesse cenário, a comunicação desempenha papel fundamental no alinhamento dos agentes, bem como a tecnologia apresenta os recursos indispensáveis para uma comunicação eficiente.

\subsubsection{Auto-organização: perspectiva de sistemas complexos}

O recorte analítico de redes de inovação não caracteriza o fenômeno da autoorganização, não explora sua proveniência, nem as condições para ela ocorrer e trazer benefícios para os negócios. Essas lacunas podem ser preenchidas com conceitos definidos na teoria de sistemas complexos. O Quadro 5 resume os principais conceitos relacionados com autoorganização que foram discutidos sob a perspectiva de sistemas complexos.

Quadro 5: conceitos associados à auto-organização pela teoria de sistemas complexos

\begin{tabular}{|l|l|}
\hline Conceitos & Autores \\
\hline Controle descentralizado & Vasileiadou e Safarzynska (2010); Pathak et al. (2007), Uhl- \\
& Bien et al. (2009); Marion e Uhl-Bien (2001); Walker e \\
& Dooley (1999) \\
\hline Relacionamentos & Tongming (2010), Manson (2001), McCarthy et al. (2000) \\
\hline
\end{tabular}




\begin{tabular}{|l|l|}
\hline Interdependência & Schneider e Somers (2006), Lichtenstein (2000) \\
\hline Controle indireto e catalítico & Schneider e Somers (2006) \\
\hline Aprendizado/memória & Vasileiadou e Safarzynska (2010), Manson (2001) \\
\hline Apoio a movimentos bottom up & Marion e Uhl-Bien (2001) e Ollus et al. (2011) \\
\hline Instabilidade/mudança constante & Lichtenstein (2000), Smith (2005) \\
\hline $\begin{array}{l}\text { Não linearidade no comporta- } \\
\text { mento e/ou saída }\end{array}$ & $\begin{array}{l}\text { Choi et al.(2001), Rose-Anderssen(2005), Dooley e Van de } \\
\text { Ven (1999), Surana et al. (2005) }\end{array}$ \\
\hline Não redutibilidade & $\begin{array}{l}\text { Frenken (2000), Frenken (2006), Lichtenstein (2000), Lyons } \\
\text { (2005), Batty e Torrens (2005) }\end{array}$ \\
\hline
\end{tabular}

Para a teoria de sistemas complexos a auto-organização é um comportamento coletivo espontâneo (Choi et al., 2001; Surana et al., 2005), que pode se manifestar na mudança espontânea da estrutura do sistema (Manson, 2001; McCarthy et al., 2000), e que contribui para a adaptação do próprio sistema (Uhl-Bien et al., 2007). A espontaneidade desse comportamento nasce da interdependência entre os agentes (Lichtenstein, 2000; Schneider e Somers, 2006), dos movimentos bottom up (Marion e Uhl-Bien, 2001; Ollus et al., 2011) que surgem em determinados locais e se espalham pelo sistema, e do aprendizado acumulado ao longo do tempo (Vasileiadou e Safarzynska, 2010; Manson, 2001) que retro-alimenta os relacionamentos. Cada agente na rede influencia e é influenciado e, dessa forma, movimentos locais podem propagar-se através dos relacionamentos e acabar conduzindo a comportamentos globais. O recorte analítico de redes negligencia esses movimentos internos provenientes dos relacionamentos que surgem em pontos específicos da rede e que podem alterar o comportamento do sistema.

Sob a perspectiva de sistemas complexos, os movimentos locais bottom up dos agentes estão associados a um controle descentralizado, indireto e catalítico (Schneider e Somers, 2006). Isso implica na ausência de um controle centralizador rígido que possa inibir iniciativas inovadoras. Essa visão é importante para as redes de inovação e pode ser concretizada a partir de alguns elementos apresentados pelo recorte analítico de redes como política de governança clara, comunicação aberta, e alinhamento e comprometimento entre as partes (Bititci et al., 2007 e Corsaro et al., 2012). A política de governança e a comunicação precisam permitir o alinhamento dos agentes em relação ao objetivo global. Dessa forma, mesmo com um controle descentralizado, com iniciativas localizadas e com idéias novas e diferentes, será possível manter o mesmo foco e comprometimento.

Essa nova perspectiva de controle não constitui conflito com o conceito de empresa focal porque, de acordo com Dhanaraj e Parkle (2006) e Ojasalo (2008), o papel da empresa focal é 
atuar na gestão da estabilidade da rede, na gestão da mobilidade do conhecimento, e na gestão da apropriação da inovação. Essas frentes de gerenciamento promovem a aprendizagem da rede enquanto organização estruturada e isso reforça a capacidade de inovar, pois, segundo Rycroft e Kash (2004) e Tzeng (2009), a capacidade sistêmica e institucionalizada de inovação das redes está diretamente associada com a habilidade delas para integrar conhecimentos, e construir e reconfigurar competências. No entanto, embora a presença de uma empresa focal e o conceito de descentralização não sejam mutuamente excludentes, o fenômeno da auto-organização no contexto das redes de inovação enquanto entidades complexas impõe um novo desafio gerencial. A operação das redes precisa ocorrer sob uma nova forma de controle, apontada por Walker e Dooley (1999) como descentralizada. Neste sentido, a forma clássica de gestão organizacional, baseada essencialmente em concentração de poder hierárquico, ainda mantém seu papel, porém sozinha torna-se insuficiente e limitada.

Um importante elemento associado com a auto-organização é a interdependência. Numa rede de inovação a interdependência é gerada a partir da própria morfologia da rede e constitui uma força motriz por trás do surgimento de novos comportamentos para o sistema (Marion, 1999; Lichtenstein, 2000; Regine e Lewin, 2000; Mccarthy et al., 2000). Essa perspectiva sobre dependência e influência recíprocas ajuda a compreender porque a imitação entre empresas é uma estratégia cuja perpetração muitas vezes apresenta um baixo índice de sucesso: não basta fazer uma cópia da estrutura do concorrente, também é necessário reproduzir sua teia de relacionamentos.

A teoria de sistemas complexos também contribui ao apresentar propriedades sistêmicas que ainda não foram abordadas pelo recorte analítico de redes. A instabilidade, caracterizada pela mudança constante (Smith, 2005; Lichtenstein, 2000) intercalada por momentos de estabilidade, mostra que esses sistemas se alteram dinamicamente. Como a instabilidade é uma condição para a mudança, ao invés de perseguir estabilidade e previsibilidade, sugere-se encorajar a fase de transição na qual as perturbações podem induzir a caminhos inovadores (Smith, 2005). Soluções criativas ocorrerão quando o sistema organizacional for colocado entre uma posição de equilíbrio e desequilíbrio (Surana et al., 2005; Lichtenstein, 2000). Nesse ponto, a função do controle do sistema passa essencialmente pelo gerenciamento das fronteiras que governam esse equilíbrio (Smith, 2005).

Outra contribuição relevante da teoria de sistemas complexos para o estudo das redes de inovação é o conceito de não linearidade no comportamento e na saída desses sistemas (Vasileiadou e Safarzynska, 2010). Sob a perspectiva dos sistemas complexos não existe uma correlação direta entre o tamanho da causa e o efeito produzido (Choi et al., 2001; Lichtenstein, 
2000), porque podem ocorrer diferenças significativas nas saídas observadas a partir de pequenas oscilações nas condições iniciais (Dooley e Van de Ven, 1999). Nesse caso, uma rede, ainda que formada basicamente pelos mesmos parceiros, mas submetida a estímulos diferentes, ou então duas redes distintas submetidas aos mesmos estímulos podem apresentar comportamentos significativamente divergentes a cada nova situação. Isso ocorre porque diferentes conjuntos de estímulos podem induzir diferentes intensidades de auto-organização.

Por fim, a não redutibilidade ou decomposição funcional limitada (Batty e Torrens, 2005) é uma propriedade que dificulta a compreensão global dos sistemas complexos analisando-se apenas seus componentes isoladamente. Schneider e Somers (2006) sugerem uma mudança de foco do reducionismo para a compreensão do tipo e do nível de interação entre os agentes, e da interação deles com outros sistemas, pois os relacionamentos locais podem produzir novos comportamentos globais não previstos inicialmente (Frenken, 2000).

\subsection{CONSIDERAÇÕES FINAIS}

A literatura indica que as redes de inovação tem se mostrado como uma possível alternativa ao contínuo desafio das empresas diante da necessidade de inovar. Uma das manifestações desse tipo de rede é aquela centralizada por uma empresa focal com poder suficiente para influenciar e impor diretrizes aos demais agentes da rede. O problema é que a empresa focal não detém sozinha todas as respostas para os desafios do processo de inovação.

Este trabalho analisa a possibilidade de aplicação da propriedade de auto-organização dos sistemas complexos nas redes de inovação. Essa propriedade está diretamente associada com a capacidade de adaptação dos sistemas complexos. As dificuldades impostas pelo desafio de inovar geram um estado de desequilíbrio no sistema formado pela rede de parceiros. Essa situação de desequilíbrio estimula a auto-organização dos agentes num movimento voluntário, e não necessariamente forçado pela empresa focal, com potencial para transferir conhecimentos dentro da rede, providenciar recursos e, dessa forma, gerar inovação.

As organizações podem ser analisadas como sistemas complexos porque elas apresentam características típicas desses sistemas: ambiente marcado por mudança constante, ampla diversidade de agentes envolvidos, capacidade de se adaptar, e interdependência nos comportamentos. A complexidade das redes reside na sua estrutura e na força das interações entre os agentes. A ampla diversidade de conhecimentos e habilidades de cada agente contribui para o aprendizado coletivo, base para retroalimentar a capacidade de adaptação ao longo do tempo. 
A auto-organização se manifesta como um comportamento coletivo e espontâneo dos agentes, que podem se reorganizar em estruturas mais complexas sem a necessária intervenção de um elemento centralizador. A fonte dos comportamentos auto-organizados está nos movimentos bottom up estabelecidos pelos próprios agentes a partir da teia de relacionamentos que os conecta. Através dos relacionamentos fluem os conhecimentos e demais recursos necessários ao esforço de adaptação do sistema. A força desses relacionamentos determina a estrutura interna do sistema, sendo que a habilidade do sistema aprender (requisito para a autoorganização) está na capacidade de se variar as configurações dessa estrutura, e a memória, na capacidade de se recorrer a configurações anteriores.

Vários elementos concorrem para apoiar a auto-organização. O uso de um controle descentralizado e indireto aumenta o comprometimento dos agentes por não se utilizar da imposição de respostas, mas da criação compartilhada de condições para o surgimento de novos comportamentos coletivos com potencial para apresentar alternativas inovadoras.

A distribuição do controle requer, por sua vez, o reforço dos relacionamentos, que pode ser fomentado através de três elementos de apoio: comprometimento, participação voluntária, e aprendizado. A motivação para o comprometimento pode advir da interdependência entre os agentes, ou seja, da noção de que a complementariedade de competências na rede impõe a necessidade de colaboração. A percepção de que o sucesso coletivo está diretamente atrelado ao desempenho individual de cada agente fornece a motivação necessária para o engajamento próativo dos agentes na rede, motivando-os a colaborar além de suas metas e/ou eventuais obrigações.

Outro elemento importante para o comprometimento entre os agentes é a definição clara de uma política de governança (regras, bônus e ônus). A motivação para a participação voluntária surge da abertura para a propagação de movimentos bottom up, e do incentivo para uma comunicação clara, para o aumento da confiança, e para o apoio à distribuição justa dos benefícios.

Os comportamentos auto-organizados dentro da rede podem agregar valor aos negócios, mas é necessário o alinhamento dos agentes em relação aos objetivos globais da rede; que a aprendizagem, enquanto geração e uso do conhecimento, funcione como pivô central para a condução dos relacionamentos; que ocorram iniciativas espontâneas a partir de problemas e/ou oportunidades isolados ligados aos macro objetivos; e que haja incentivos para apoiar a propagação de movimentos isolados e com potencial inovador através da rede. Nesse caso, mesmo que os esforços locais sejam momentaneamente divergentes entre si, eles estarão alinhados com o objetivo global. 
A contribuição da pesquisa para o mercado está na sugestão de que a forma clássica de gestão organizacional, baseada essencialmente na força da hierarquia, apresenta limitações quando aplicada às redes de inovação. A própria estrutura da rede (formada por agentes formalmente independentes), associada à impossibilidade de um único agente apontar todas as respostas às demandas impostas pelo desafio de inovar, sugere a necessidade de uma nova forma de controle, essencialmente descentralizado e indireto, a fim de apoiar a mobilidade do conhecimento, a estabilidade da rede, e a apropriação adequada dos benefícios do processo de inovação. Um controle descentralizado tem mais potencial para reconhecer ideias e soluções locais, e dessa forma incentivar comportamentos espontâneos que possam gerar soluções mais eficazes e inovadoras.

A contribuição acadêmica da pesquisa está na intersecção dos principais constructos provenientes do recorte analítico de redes de inovação com os principais conceitos da área de sistemas complexos. Procurou-se evidenciar a existência de uma região conceitual entre essas duas áreas de pesquisas, e dessa forma estender a teoria de redes incorporando elementos de sistemas complexos.

Algumas contribuições para o mercado decorrentes da intersecção dessas duas áreas:

(a) Pode-se explicar o motivo da aplicação direta do conceito de "melhores práticas" nas redes de inovação apresentar flutuações, ou seja, ser bem sucedida em certas situações e mal sucedida em outras. O comportamento não linear presente nos sistemas complexos enseja que os mesmos estímulos aplicados a sistemas ligeiramente diferentes induzam diferentes níveis de intensidades de movimentos auto-organizados. Em outras palavras, duas redes distintas submetidas aos mesmos estímulos ou então uma rede ainda que formada basicamente pelos mesmos parceiros, mas submetida a estímulos diferentes, podem apresentar comportamentos significativamente divergentes a cada nova situação;

(b) Outro ponto importante da pesquisa está na identificação proporcionada pela teoria de sistemas complexos da fonte dos comportamentos auto-organizados: os movimentos bottom up. Essa origem não tem sido tratada pelo recorte analítico de redes de inovação.

Como limitação da pesquisa teórica, não se explora a possibilidade dos agentes serem concorrentes. Nesse caso, como ficaria a relação de confiança e comprometimento? Outra limitação dessa parte da pesquisa é que ela não leva em consideração o impacto da proposta de mudança e as dificuldades de implantação. 


\section{$\underline{3}$ - MODELO ATUAL (“AS-IS") E IDENTIFICAÇÃO DAS NECESSIDADES DE MUDANÇA}

Inovação significa transformação bem sucedida de novas ideias em produtos, processos, serviços e práticas de negócios (Christopherson e Kitson, 2008; OECD, 2010; Garcia e Calantone, 2002). E cada vez mais a inovação tem sido considerada uma alternativa para manter a competitividade sustentável das empresas (Armoutis et al.,2008; Katzy et al. 2008).

O desafio de inovar tem forçado as empresas a ampliarem suas competências, e isso tem provocado cada vez mais o estabelecimento de alianças inter-organizacionais de caráter colaborativo para o compartilhamento de know-how, capital humano, tecnologia, infra-estrutura e recursos financeiros (Sari et al., 2007; Gilbert et al. 2007; Emden et al., 2006; Schoonmaker e Carayannis, 2010; Molina-Morales e Mertínez-Fernández, 2010). As redes de inovação constituem uma especificidade das redes de empresas, na forma de um arranjo voluntário entre organizações independentes ligadas por vínculos colaborativos com o propósito de superar em parceria as incertezas do processo de inovação, envolvendo-se na geração, comercialização e difusão de produtos, processos e serviços novos ou melhorados (Freel e Harrison, 2006; Sammarra e Biggiero, 2008).

Em várias dessas redes de inovação há a presença de uma empresa focal centralizadora (Liu e Madhavan, 2005; Ting e Chiu, 2009; Roxenhall, 2013; Valk e Chappin, 2011; Dhanaraj e Parkhe, 2006). Quanto mais vulnerável julgar-se a empresa focal, mais ela tenderá a proteger-se usando uma combinação de garantias contratuais diretas e indiretas para controlar os demais parceiros da rede (Gardet e Mothe, 2011). A questão é que os desafios impostos pelo processo de inovação requerem uma intensidade de comprometimento e de trocas entre os parceiros que não pode ser assegurada simplesmente através de obrigações contratuais impostas por uma empresa centralizadora.

Ambientes auto-organizados mostram-se abertos para acolher idéias potencialmente inovadoras, e não apenas as diretrizes de uma empresa focal, a qual também não tem todas as soluções para as incertezas e desafios do processo de inovação. A propriedade de auto- 
organização se caracteriza por comportamentos coletivos espontâneos que surgem a partir de movimentos gerados pelos próprios agentes do sistema em resposta aos estímulos externos e internos (Pathaket et al., 2007; Manson, 2001; McCarthy et al., 2000). Essa propriedade é importante porque tem relação direta com a capacidade de adaptação desses sistemas (Schneider e Somers, 2006).

Para serem consideradas auto-organizadas, as redes precisam ter a habilidade de monitorar o ambiente, de aprender e de se adaptar às mudanças externas (Tharumarajah, 2003; Rycroft e Kash,2004). Neste tipo de sistema o controle é policêntrico (distribuído), pois cada entidade se auto-coordena e ajuda a manter o controle do sistema olhando para o objetivo principal estabelecido.

Esta parte da pesquisa tem como propósito identificar os elementos de apoio à propriedade de auto-organização nos agrupamentos formados por empresas envolvidas nos processos de inovação de produtos na área de utilidades domésticas no Brasil. O setor de eletrônicos foi escolhido devido a sua importância para a economia do país. A área de utilidades domésticas representa o quarto faturamento desse setor (cerca de $12 \%$ do faturamento), sendo ainda responsável por apoiar as áreas de informática e de equipamentos industriais que, juntas, contribuem com $45 \%$ do faturamento do setor (ABINEE, 2013).

A identificação desses elementos está apoiada na revisão da literatura sobre o recorte analítico de redes de inovação e sobre a área de sistemas complexos (capítulo 2), assim como na realização de um estudo de caso múltiplo constituído por oito unidades empresariais que resultou na consolidação de um conjunto de modelos baseados na metodologia Enterprise Knowledge Development (EKD).

De acordo com Bubenko et al. (2001), um modelo é uma maneira estruturada de representar o conhecimento, a estrutura e o contexto de uma empresa com vistas a facilitar a comunicação entre os agentes envolvidos. Ainda de acordo com este autor, a metodologia EKD oferece um método sistematizado para as empresas desenvolverem modelos organizacionais. Esses modelos revelam o atual estado de funcionamento da empresa, quais as necessidades de mudanças (need for change), quais os requisitos necessários, quais as alternativas podem ser visualizadas a fim de atingir estes requisitos, e quais os critérios e argumentos para avaliar estas alternativas (Nurcan e Rolland, 2003). 


\subsection{ANÁLISE DE DADOS E RESULTADOS}

A seguir, na seção 3.1.1, são apresentados os resultados e a análise do questionário. $\mathrm{Na}$ seção 3.1.2 é apresentada a modelagem compilada da formação e operação das parcerias dentro da área de utilidades domésticas. Como resultados dessa modelagem são apresentados os modelos de Objetivos, Regras de Negócio, Processos de Negócios, Atores e Recursos, e Conceitos representados através da metodologia Enterprise Knowledge Development (EKD). Como a formação dessas parcerias ocorre dentro de um contexto de PDP, a modelagem também reflete essa situação. A seleção de cada elemento que integra o modelo compilado atende o critério da recorrência no estudo de caso. Apenas os elementos que aparecem em três ou mais unidades empresariais foram levados em consideração. Essa repetição de elementos nas diversas unidades estudadas tem relação com o conceito de melhores práticas, que é amplamente adotado no ambiente empresarial.

\subsubsection{Análise do questionário}

A Tabela 1 apresenta o resultado do questionário aplicado no estudo de caso. $\mathrm{O}$ questionário foi dividido em quatro seções, com cinco questões por seção, onde cada questão recebeu a pontuação máxima de 5 pontos.

\begin{tabular}{|c|c|c|c|}
\hline Seções & Tópicos das questões & $\begin{array}{l}\text { Pontos } \\
\text { (0-5 por } \\
\text { questão) }\end{array}$ & $\begin{array}{l}\text { Total } \\
(0-25)\end{array}$ \\
\hline \multirow{5}{*}{$\begin{array}{c}1 \\
\text { Características } \\
\text { de sistemas } \\
\text { complexos }\end{array}$} & Mudança constante & 4,7 & \multirow{5}{*}{16,9} \\
\hline & Comportamento não proporcional & 3,4 & \\
\hline & 1.3. Evolução não linear da topologia & 3,1 & \\
\hline & Não redutibilidade & 3,6 & \\
\hline & Controle descentralizado, indireto e catalítico & 2,1 & \\
\hline \multirow{5}{*}{$\begin{array}{c}2 \\
\text { Auto- } \\
\text { organização } \\
\text { nos projetos }\end{array}$} & 2.1. Comportamento coletivo espontâneo & 0,6 & \multirow{5}{*}{8,7} \\
\hline & 2.2. Mudança espontânea na estrutura & 0,9 & \\
\hline & 2.3. Aprendizagem e/ou relacionamentos & 2,5 & \\
\hline & 2.4. Movimentos locais espontâneos (bottomup) & 1,9 & \\
\hline & 2.5. Influência e/ou interdependência & 2,8 & \\
\hline \multirow{5}{*}{$\begin{array}{c}3 \\
\text { Facilitadores } \\
\text { da auto- } \\
\text { organização }\end{array}$} & 3.1. Controle descentralizado & 1,6 & \multirow{5}{*}{11,7} \\
\hline & 3.2. Controle indireto: motivar relacionamentos & 1,8 & \\
\hline & 3.3. Controle indireto: motivar metas & 2,1 & \\
\hline & 3.4. Controle catalítico: motivar comunicação & 2,9 & \\
\hline & 3.5. Controle catalítico: recursos e responsabilidade & 3,3 & \\
\hline \multirow{5}{*}{$\begin{array}{c}4 \\
\text { Benefícios da } \\
\text { auto- } \\
\text { organização }\end{array}$} & 4.1. Alinhamento de agentes com os objetivos gerais & 1,4 & \multirow{5}{*}{8,2} \\
\hline & 4.2. Geração e uso do conhecimento & 1,8 & \\
\hline & 4.3. Incentivos para propagar movimentos & 1,6 & \\
\hline & 4.4. Núcleo coeso cercado por ligações fracas & 3,3 & \\
\hline & 4.5. Iniciativas espontâneas relativas aos objetivos & 0,1 & \\
\hline & & TOTAL & 45.5 \\
\hline
\end{tabular}


Observa-se na Tabela 1 que as características de sistemas complexos estão de certa forma presentes nas empresas do estudo de caso. Os tópicos relacionados à mudança constante, comportamento proporcional, evolução não linear da topologia e não redutibilidade são particularmente representativos para as empresas. Entretanto, o controle descentralizado, indireto e catalítico é afetado pelo papel centralizador da empresa focal. Esse fato permite inferir que apesar dos relacionamentos entre as empresas apresentarem características de sistemas complexos, o controle centralizado da empresa focal ainda é determinante na gestão dos parceiros.

A auto-organização não é uma prática efetiva no desenvolvimento de projetos, considerando o comportamento coletivo espontâneo, a mudança espontânea na estrutura e os movimentos locais espontâneos. Somente a aprendizagem e os relacionamentos baseados nos vínculos entre os parceiros foram relativamente reconhecidos na auto-organização nos projetos. Ao apresentar esse resultado aos entrevistados, mencionou-se que a confiança entre os parceiros estava condicionada a relações contratuais, cujas cláusulas permitem assegurar um nível mínimo de serviço entre os parceiros, mas não garantem o comprometimento necessário para fomentar a troca de conhecimentos a ponto de gerar novas ideias e iniciativas individuais do tipo bottom-up.

Os elementos facilitadores da auto-organização não receberam o reconhecimento adequado no tocante ao controle indireto, no sentido de motivar os relacionamentos entre os parceiros e o atingimento de metas, e no controle catalítico, no tocante a distribuir recursos e responsabilidades. $\mathrm{O}$ reconhecimento ficou restrito às condições para a comunicação aberta e transparente. A constatação referente aos elementos facilitadores da auto-organização corrobora a não detecção do fenômeno da auto-organização relativo a seção 2 do questionário.

Finalmente, não foram identificados os benefícios gerados pela auto-organização, produzidos pelo alinhamento de agentes com os objetivos gerais, geração e uso do conhecimento, incentivos para propagar movimentos e iniciativas espontâneas relativas aos objetivos. Houve somente a constatação da existência de uma estrutura baseada em núcleo coeso cercado por ligações fracas. A estabilidade do núcleo coeso permite a troca de conhecimentos tácitos entre as partes, ao mesmo tempo em que uma periferia de ligações fracas facilita o acesso dos parceiros a novos conhecimentos.

Em síntese, pode-se depreender pela análise dos dados coletados que as unidades empresariais apresentaram comportamento complexo, mas, no entanto, não se identificou a propriedade de auto-organização, caracterizada pelo comportamento coletivo espontâneo e pela mudança espontânea na estrutura. A causa está relacionada à falta dos elementos de apoio como controle descentralizado e indireto, e à falta de incentivo para iniciativas próprias dos parceiros. 
Como consequência, não foi possível verificar a relação entre o fenômeno de auto-organização e seus eventuais benefícios para as unidades emrpesariais.

A partir dos resultados obtidos, desenvolveu-se um modelo organizacional baseado na metodologia EKD, no sentido de sistematizar a dinâmica de relacionamentos entre os parceiros para o desenvolvimento de novos produtos na área de utilidades domésticas, evidenciando as causas que impediram a manifestação da auto-organização.

O modelo organizacional sintetiza a modelagem específica da realidade das 8 unidades empresariais (Apêndice D), cujos dados foram consolidados seguindo o critério da recorrência dos elementos (Apêndice C). Os modelos específicos foram apresentados e validados pelos entrevistados de cada unidade.

\subsubsection{Modelagem consolidada do estudo de caso com 08 unidades empresariais (modelo atual - $a s$-is)}

A seguir apresenta-se a sistematização do atual cenário geral de formação de parcerias para o desenvolvimento de novos produtos na área de utilidades domésticas no setor de eletrônicos a partir da consolidação dos dados individuais (modelos) de cada unidade empresarial que compõe o estudo de caso. A metodologia EKD foi utilizada para representar e estruturar os dados na forma de um Modelo de Objetivos, de Regras de Negócio, de Atores e Recursos, de Conceitos e de Processos de Negócios.

\subsubsection{Modelo de Objetivos}

O principal objetivo estabelecido pelas empresas focais que centralizam as unidades de analise estudadas é a ampliação da liderança no segmento de eletrodomésticos (Objetivo 1). Cinco objetivos secundários apoiam o Objetivo 1: melhorar a capacidade de inovação (Objetivo 1.1), entregar benefícios para consumidores, acionistas e comunidade (Objetivo 1.2), diminuir o impacto ambiental do negócio (Objetivo 1.3), reforçar os laços de parcerias com terceiros (Objetivo 1.4), e selecionar profissionais capacitados para integrar o PDP (Objetivo 1.5).

O esforço para melhorar a capacidade de inovação (Objetivo 1.1) permite aumentar o percentual de faturamento relativo à fatia de novos produtos (Oportunidade 1), no entanto ele encontra resistência na limitação técnica dos laboratórios (Ameaça 1) e nas ingerências administrativas entre diferentes áreas (Ameaça 2) principalmente no caso das empresas de base familiar. Esse mesmo Objetivo 1.1 encontra apoio em outros quatro objetivos: acelerar o processo de desenvolvimento de produtos (Objetivo 1.1.1), ameaçado pelo risco de se sacrificar etapas do PDP (Ameaça 3); padronizar o PDP nas diversas plantas e integrar as diferentes áreas (Objetivo 1.1.2), ameaçado pelo risco de engessar o processo (Ameaça 4); ampliar a validação 
digital dos produtos (Objetivo 1.1.3); e utilizar Engenharia Simultânea (Objetivo 1.1.4), a qual permite antecipar mudanças e o tempo da concepção à manufatura (Oportunidade 2), mas que sofre com a estrutura tradicionalmente funcional para a gestão de projetos (Ameaça 5).

A busca pela entrega de benefícios para consumidores, acionistas e comunidade (Objetivo 1.2) encontra resistência para se equilibrar os diferentes interesses envolvidos (Ameaça 6) e está sustentada por quatro objetivos de apoio: reduzir custos operacionais do ciclo de vida do produto (Objetivo 1.2.1); buscar originalidade (Objetivo 1.2.2), que sofre ameaça do excesso de foco no custo (Ameaça 8); equilibrar qualidade e custo (Objetivo 1.2.3); e diminuir reclamações de clientes e acelerar respostas (Objetivo 1.2.4), o que pode ajudar a fortalecer a marca (Oportunidade 3).

O esforço para diminuir o impacto ambiental do negócio (Objetivo 1.3) acha resistência na visão de lucro a curto prazo (Ameaça 7), e encontra apoio em três outros objetivos: reduzir impacto operacional dos produtos (Objetivo 1.3.1); reduzir impacto do processo produtivo (Objetivo 1.3.2); e desenvolver e/ou explorar novas tecnologias (Objetivo 1.3.3), que permite tornar os produtos mais eficazes (Oportunidade 4), mas que esbarra no aumento dos custos (Ameaça 8).

O objetivo de reforçar os laços de parcerias com terceiros (Objetivo 1.4) esbarra nas diferenças culturais (Ameaça 9) e nas diferenças de objetivos estratégicos (Ameaça 10), mas pode contribuir para a redução dos prazos e custos relacionados ao processo de desenvolvimento de produtos (Oportunidade 5). Cinco objetivos apoiam o Objetivo 5: aumentar o nível de confiança entre os parceiros (Objetivo 1.4.1); extrair novos conhecimentos dos parceiros (Objetivo 1.4.2); estabelecer parcerias de longo prazo (Objetivo 1.4.3), que encontra resistência na dificuldade para controlar os parceiros (Ameaça 11); integrar os parceiros chaves ao PDP (Objetivo 1.4.4), objetivo que sofre com o risco de se perder conhecimento estratégico (Ameaça 12); e transferir desafios técnicos para parceiros especializados (Objetivo 1.4.5), o que pode provocar conflitos por propriedade intelectual (Ameaça 13) além de uma excessiva dependência do know-how dos parceiros (Ameaça 14).

E o último objetivo de apoio ao objetivo principal é selecionar profissionais capacitados para integrar o PDP (Objetivo 1.5). Esse objetivo é apoiado por dois objetivos: integrar ao PDP representantes de todas as áreas da empresa (Objetivo 1.5.1), o que permite acessar as práticas e conhecimentos dispersos pela organização (Oportunidade 6); e investir em treinamento (Objetivo 1.5.2), que é dificultado pela falta de comprometimento devido a conflitos de prioridades (Ameaça 15).

A Figura 3 apresenta o Modelo de Objetivos (as-is). 


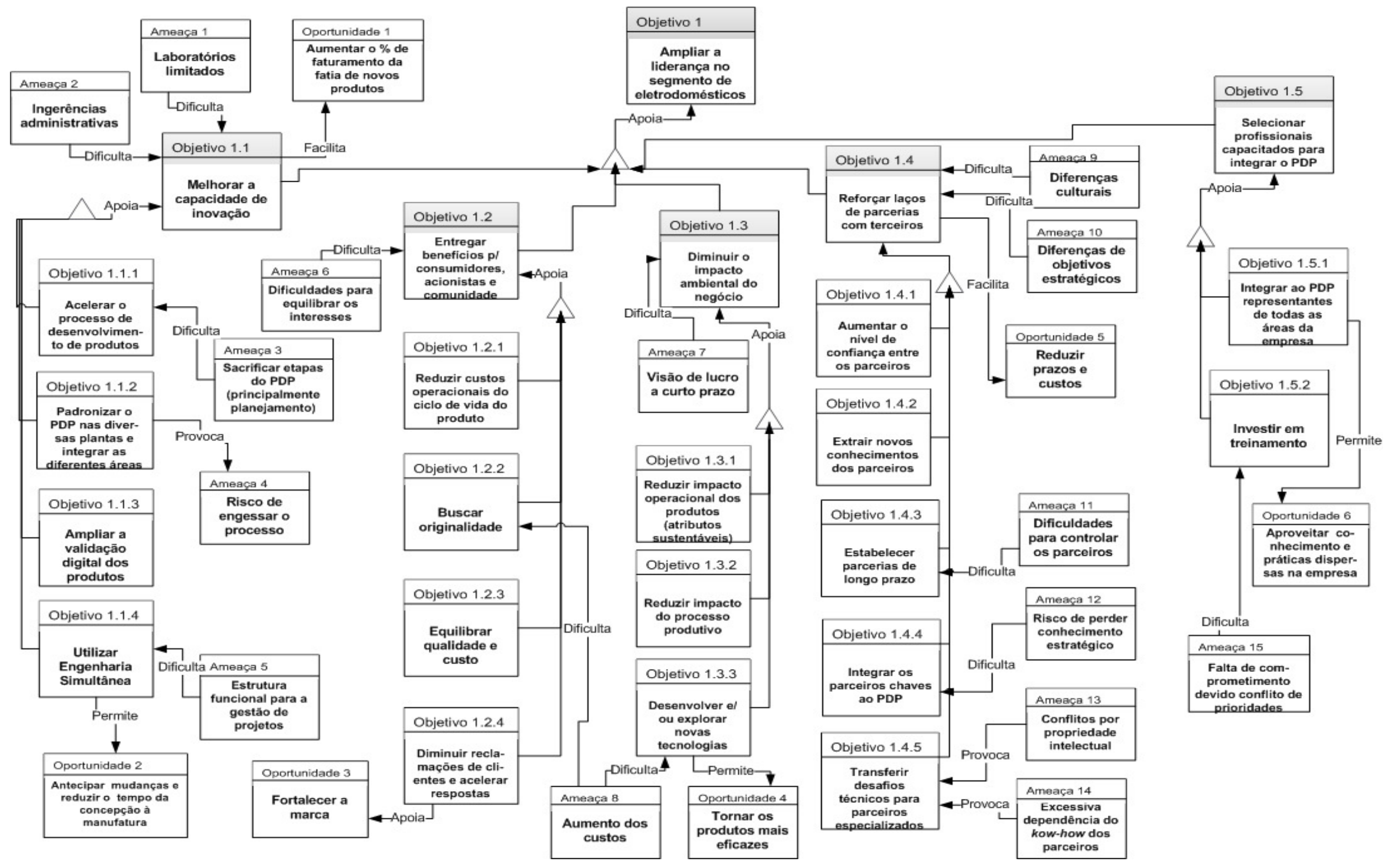

Figura3: Modelo de Objetivos (as-is) 


\subsubsection{Modelo de Regras de Negócio}

O Modelo consolidado de Regras de Negócio evidencia que há várias regras definidas para apoiar os objetivos diretamente associados com o estabelecimento de parcerias (objetivos 1.4, 1.4.1, 1.4.2, 1.4.3, 1.4.4 e 1.4.5 da figura 3). Todas essas regras identificadas no estudo de caso são importantes para as unidades empresariais estudadas. Questiona-se, no entanto, a relevância delas para apoiar a formação e operação de redes de inovação auto-organizadas, pelo fato delas estarem mais direcionadas para o controle da empresa focal sobre as demais empresas parceiras.

A fim de reforçar os laços de parcerias com terceiros (Objetivo 1.4) foram estabelecidas três regras: priorizar o desenvolvimento de produtos com o apoio de terceiros (Regra 9), exigir qualificação e/ou certificação comprovada dos parceiros (Regra 10), e avaliar os vínculos dos parceiros com os concorrentes (Regra 11). A regra 9 define que mais projetos terão a participação de parceiros, e as regras 10 e 11 apoiam a ideia de selecionar melhor esses parceiros (competentes e sem vínculos com concorrentes), ou seja, nenhuma delas trata de reforçar o relacionamento entre as partes envolvidas, que é a base da propriedade de autoorganização. Para aumentar o nível de confiança entre os parceiros (Objetivo 1.4.1) trabalha-se com duas regras: contrato rigoroso sobre as responsabilidades de cada parte (Regra 26), e nenhum fornecedor tem acesso ao projeto completo (Regra 27). A primeira regra define o escopo de atuação dos parceiros e a segunda regra protege os interesses da empresa focal. Para extrair novos conhecimentos dos parceiros (Objetivo 1.4.2) é necessário documentar a participação desses parceiros (Regra 28) e assinar o termo de confidencialidade com eles (Regra 29). O próprio objetivo 1.4.2 tem uma perspectiva unilateral que difere da visão de se efetuar trocas com os parceiros, para isso documenta-se as informações produzidas em parceria, mas usa-se um termo de confidencialidade para proteger a empresa focal da evasão de seus próprios conhecimentos. O objetivo de estabelecer parcerias de longo prazo (Objetivo 1.4.3) tem apoio em três regras: premiar os parceiros mais eficazes com maior número de contratos (Regra 30), $80 \%$ dos fornecedores precisam estar dentro de um raio de $80 \mathrm{~km}$ (Regra 31), e avaliar e atribuir notas para cada parceiro (Regra 32). As regras 30 e 32 fornecem estímulos para reforçar o relacionamento com os parceiros, já a regra 31 pode acabar conduzindo à manutenção de relacionamentos pouco eficazes apenas por conta do critério localização. A integração dos parceiros chaves ao PDP (Objetivo 1.4.4) está apoiada em duas regras: a primeira determina que se integre os parceiros nas etapas iniciais (Regra 33) e a segunda que se priorize parceiros com histórico de colaboração (Regra 34); essa segunda regra reforça os vínculos de colaboração ao longo do tempo. Por fim, o objetivo de transferir desafios técnicos para parceiros especializados 
(Objetivo 1.4.5) está apoiado em duas regras: a primeira justifica o motivo dessa transferência de responsabilidade ao determinar que se mantenha foco no core business da empresa (Regra 36), e a segunda ajuda na qualidade do resultado produzido por essa transferência, propondo a realização de auditorias nesses parceiros (Regra 35).

As demais regras desse modelo apóiam outros objetivos que não se relacionam diretamente com as parcerias. A fim de apoiar o objetivo de ampliar a liderança no segmento de eletrodomésticos (Objetivo 1), fica determinado que o PDP precisa permanecer alinhado com as diretrizes da empresa (Regra 1) e que sejam utilizados Brokers para identificar oportunidades de mercado (Regra 2). Para melhorar a capacidade de inovação (Objetivo 1.1) ficam estabelecidos que pelo menos $25 \%$ do faturamento precisa vir de novos produtos (Regra 3), que é obrigatório o registro da documentação técnica do projeto (Regra 4), e que serão privilegiados os investimentos em novas tecnologias (Regra 5). O objetivo de entregar benefícios para consumidores, acionistas e comunidade (Objetivo 1.2) está apoiado em duas regras: priorizar ideias inovadoras (Regra 6) e novas funcionalidades precisam ser prospectadas pelo CRM (Customer Relationship Management - Regra 7). A fim de diminuir o impacto ambiental do negócio (Objetivo 1.3) respeita-se a regra de atender as políticas públicas de emissão de gases e resíduos sólidos (Regra 8). O objetivo de selecionar profissionais capacitados para integrar o PDP (Objetivo 1.5) está apoiado em duas regras: a área de recursos humanos $(\mathrm{RH})$ precisa participar do PDP (Regra 12), e a equipe de projetos precisa ser multifuncional (Regra 13). O objetivo de acelerar o processo de desenvolvimento de produtos (Objetivo 1.1.1) está apoiado na regra que determina que o ciclo de início de novos projetos seja semestral (Regra 14), e na regra que define como prioridade o uso de componentes intercambiáveis (Regra 15). Para padronizar o PDP nas diversas plantas e integrar as diferentes áreas (Objetivo 1.1.2) é preciso usar um modelo sistematizado para o PDP (Regra 16), e envolver todos os participantes e trabalhar com indicadores de desempenho (Regra 17). Para ampliar a validação digital dos produtos (Objetivo 1.1.3) está definido que serão elaborados protótipos virtuais para a maioria dos produtos (Regra 18), e que os laboratórios receberão atenção e investimentos (Regra 19). O objetivo de utilizar a engenharia simultânea (Objetivo 1.1.4) está apoiado na regra que exige que seja feito planejamento para antecipar o máximo possível de atividades do PDP (Regra 20). O objetivo de reduzir custos operacionais do ciclo de vida do produto (Objetivo 1.2.1) encontra apoio na regra que obriga a realização de estudos de viabilidade financeira para as etapas intermediarias do PDP e para o ciclo de vida completo do produto (Regra 21). Os objetivos "buscar originalidade" (Objetivo 1.2.2), "equilibrar qualidade e custo" (Objetivo 1.2.3), "diminuir reclamações de clientes e acelerar respostas" (Objetivo 1.2.4) estão ancorados na regra que determina que as 
expectativas dos clientes sejam levantadas corretamente (Regra 22). Os objetivos de reduzir o impacto operacional dos produtos (Objetivo 1.3.1) e de reduzir o impacto do processo produtivo (Objetivo 1.3.2) estão apoiados em duas regras: focar no design for excellence e no design for environment (Regra 23), e focar na reciclabilidade e na redução de insumos (Regra 24). Para desenvolver e/ou explorar novas tecnologias (Objetivo 1.3.3) é necessário manter a vigilância tecnológica e investir em pesquisa (Regra 25). O objetivo de integrar ao PDP representantes de todas as áreas da empresa (Objetivo 1.5.1) está apoiado na regra que define que as atividades de projeto têm prioridade sobre as atividades consideradas funcionais (Regra 37). E o objetivo de investir em treinamento (Objetivo 1.5.2) tem apoio na regra que define que um percentual do faturamento gerado pelos novos produtos será revertido para treinamento do pessoal interno (Regra 38).

A Figura 4 apresenta o modelo de Regras de Negócio (as-is). 


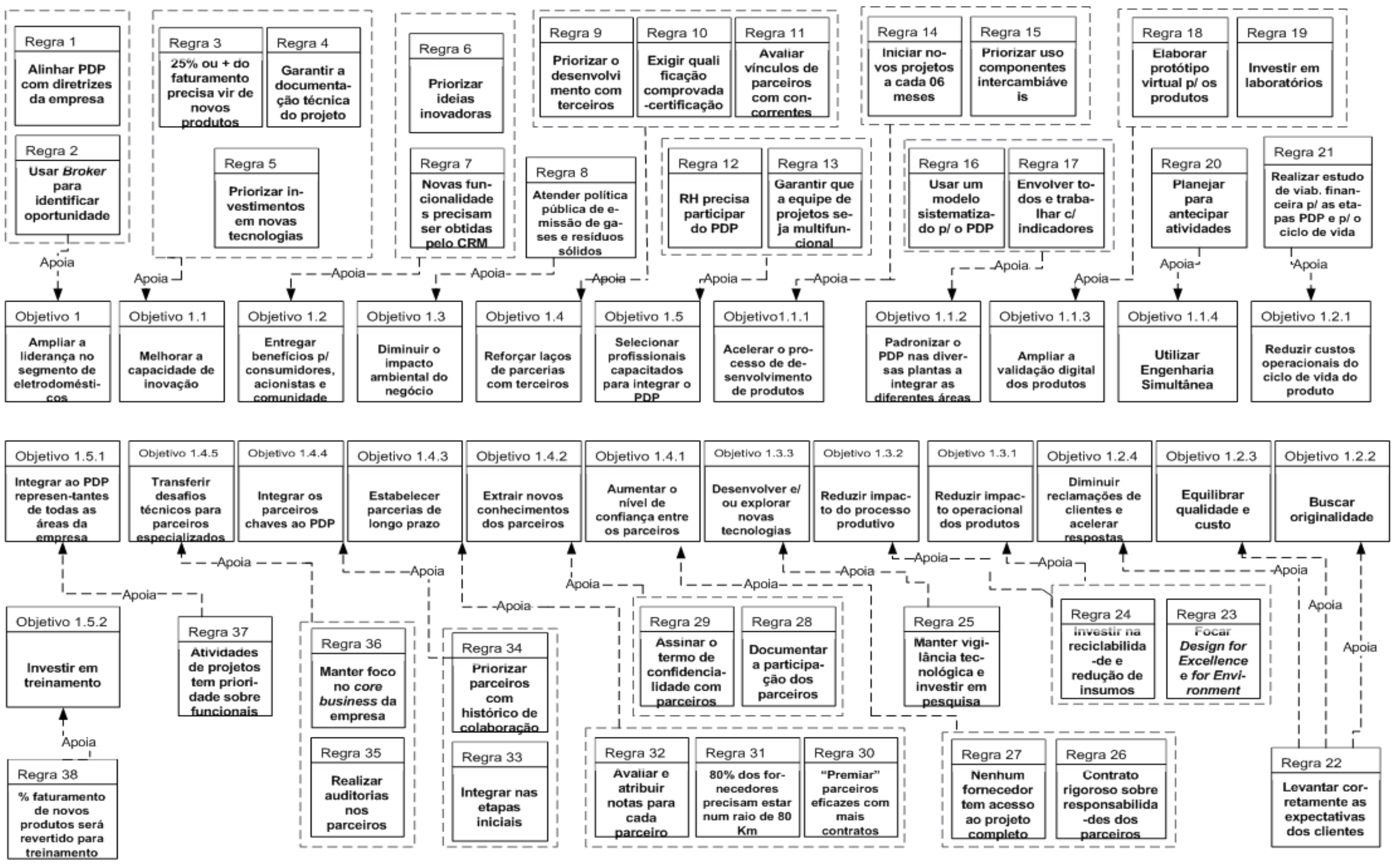

Figura 4: Modelo de Regras de Negócio (as-is). 


\subsubsection{Modelo de Atores e Recursos}

As Unidades Organizacionais de 1 a 4 (departamento de inteligência de mercado, gerência de processos, gerência de manufatura, gerência de qualidade) fornecem pessoas e recursos para os projetos. Há 7 Unidades Individuais (gerente de projeto, analista de mercado, engenheiro de processo, engenheiro de produto, engenheiro de qualidade, técnico de laboratório, engenheiro de manufatura) que integram a equipe de projeto (Unidade Organizacional 6). Essa equipe acessa os recursos disponibilizados pelas Unidades Organizacionais (de 1 a 5): diretrizes, normas e procedimentos (Recurso 1); banco de projetos (Recurso 2); laboratórios de desenvolvimento (Recurso 3); ERP, CAD, softwares em geral (Recurso 4); e ferramentas, máquinas e equipamentos (Recurso 5).

O gerente de projeto (Unidade Individual 1) assume a coordenação da equipe de projetos (Papel 1). $\mathrm{O}$ analista de mercado (Unidade Individual 2) acessas as diretrizes organizacionais estratégicas (Recurso 7) a fim de manter os projetos conectados às metas comerciais. $\mathrm{O}$ engenheiro de processo (Unidade Individual 3) é responsável pelo planejamento do processo de produção, trabalhando em sintonia com o engenheiro de produto (Unidade Organizacional 4). Todos esses atores tem acesso ao banco de projetos como fonte de pesquisa (Recurso 2) além dos softwares disponíveis como o ERP e o CAD (Recurso 4). O engenheiro de qualidade (Unidade Organizacional 5) acessa as normas e procedimentos (Recurso 1) para ajudar a elaborar, por exemplo, o estudo de impacto ambiental (Recurso 14). Os laboratórios de desenvolvimento (Recurso 3) são de responsabilidade do técnico de laboratório (Unidade Organizacional 7), designado para realizar ensaios técnicos e elaborar relatórios com as informações de desempenho (Recurso 17). O engenheiro de manufatura (Unidade Organizacional 8) verifica se o projeto é exeqüível no chão de fábrica e para isso analisa as máquinas, ferramentas e equipamentos disponíveis (Recurso 5), emitindo laudo técnico de manufaturabilidade (Recurso 16).

A equipe de projeto (Unidade Organizacional 6) assume a elaboração dos principais componentes que integram o documento de descrição geral do produto (Recurso 8): lista técnica com os SSC's (Sistemas, Sub-sistemas e Componentes - Recurso 10), roteiro de fabricação (Recurso 11), cronogramas (Recurso 12), estudos de viabilidade técnica e financeira (Recurso 13), estudo de impacto ambiental (Recurso 14), atas de aprovações (Recurso 15), laudo técnico de manufaturabilidade (Recurso 16), e informações de desempenho (Recurso 17). O parceiro de desenvolvimento (Unidade Organizacional 9) não está integrado como membro da equipe de projeto (Unidade Organizacional 6), por esse motivo ele não participa da elaboração do documento de descrição geral do produto (Recurso 8). Os contratos (Recurso 9) 
elaborados pela equipe de projeto limitam o acesso dos parceiros a apenas parte da lista de componentes técnicos (Recurso 10). Os parceiros recebem da equipe de projeto instruções prontas sobre suas atribuições e, dessa forma, não participam do processo decisório.

O diretor comercial (Unidade Individual 9), o diretor industrial (Unidade Individual 10), e o diretor de pesquisa e desenvolvimento (Unidade Individual 11) assumem a tarefa de elaboração e aprovação (Papel 2) do plano de diretrizes estratégicas (Recurso 7) que será acessado pelo coordenador (Papel 1) e pela própria equipe de projeto. Esse coordenador tem a função de fazer a ponte entre a diretoria e a equipe de projetos. Em muitos casos observa-se que um parceiro especializado em marketing de mercado (Unidade Organizacional 8) assume o papel de um Broker (Papel 3) para apoiar a elaboração desse plano estratégico.

A Figura 5 apresenta o modelo de atores e recursos (as-is). 


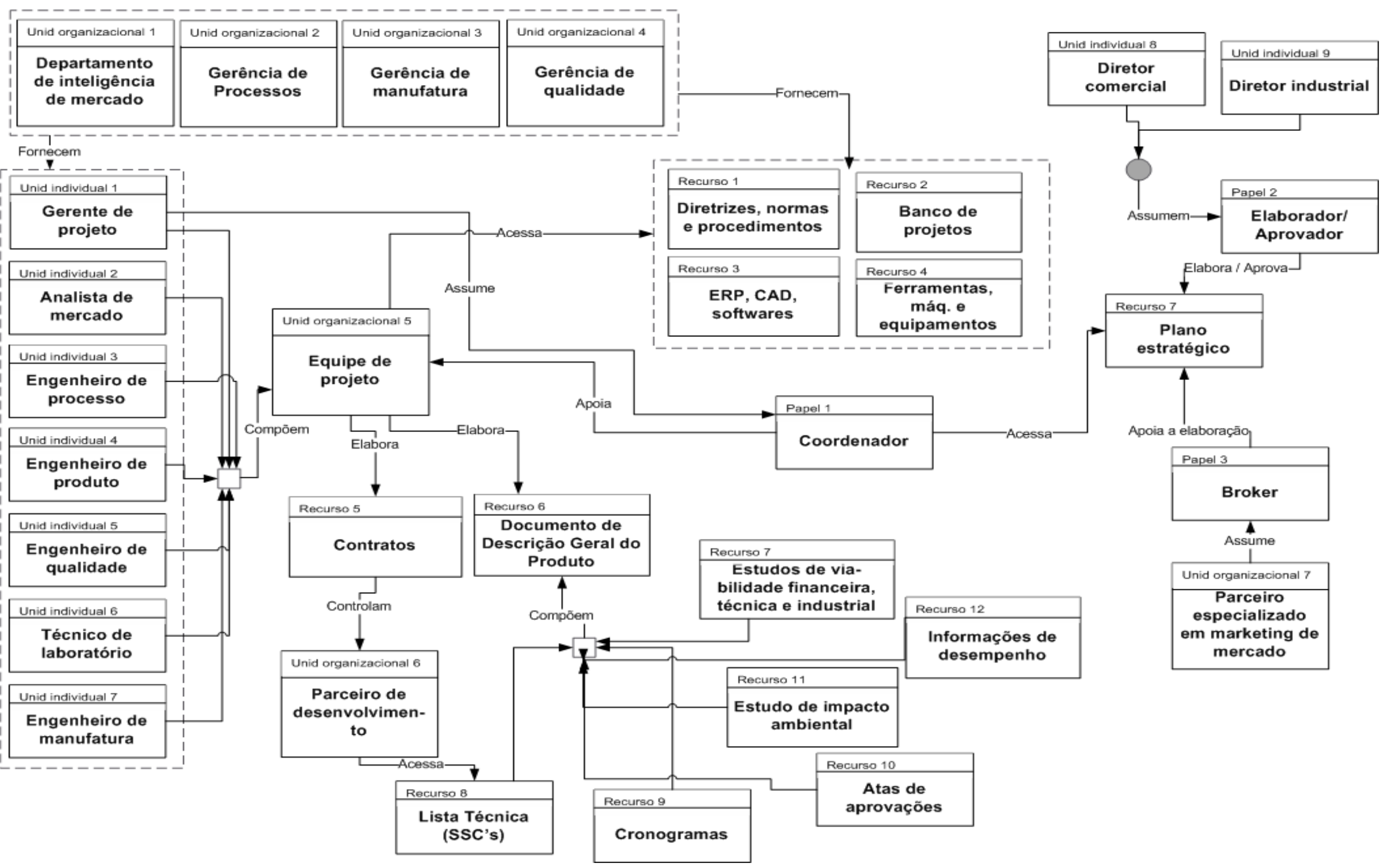

Figura 5: Modelo de Atores e Recursos (as-is). 


\subsubsection{Modelo de Processos de Negócios}

O processo relacionado com o estabelecimento das parcerias está inserido dentro do Processo de Desenvolvimento de Produtos (PDP). Para facilitar a apresentação do resultado da modelagem foi feito um modelo macro do processo de desenvolvimento de produtos, o qual contém o processo de desenvolvimento de fornecedores (Processo 2). É preciso ficar claro que o esforço realizado pela empresa focal para estabelecer as suas parcerias não tem fim em si próprio, mas que ele ocorre como apoio ao PDP.

O processo de desenvolvimento de produto inicia-se com a definição estratégica do portfólio de produtos para o mercado (Processo Externo 1). Esse processo gera a identificação de oportunidades no mercado e a consequente definição do posicionamento do produto na carteira/mercado (Infoset Externo 1). A concepção do produto (Processo 1) nasce a partir dessas definições estratégicas e tem como saída as especificações técnicas, a definição da arquitetura do produto, e os estudos de viabilidade técnica, financeira, industrial e ambiental (InfoSet 1). Esse conjunto de informações serve como entrada para o processo de desenvolvimento de fornecedores (Processo 2), cuja saída é formada pelos contratos elaborados e informações provenientes dos processos anteriores (InfoSet 2). A terceira etapa é o desenvolvimento de protótipos físicos e/ou virtuais (Processo 3), cuja saída é formada pelos protótipos e também pela lista técnica e roteiro de fabricação (InfoSet 3). A próxima etapa compreende o desenvolvimento do material de apoio (Processo 4), gerando como saída o manual técnico e o manual do usuário, a arte e a faca da embalagem, e a documentação do projeto (InfoSet 4). Por fim, a última etapa envolve o desenvolvimento e a homologação do processo de manufatura, e a certificação do produto (Processo 5), cuja saída é o processo de produção definitivo aprovado, o produto certificado, e as equipes de manufatura e de apoio/suporte (SAC e autorizadas) treinadas (InfoSet 5).

A Figura 6 apresenta o Modelo de Processos de Negócios (as-is). 


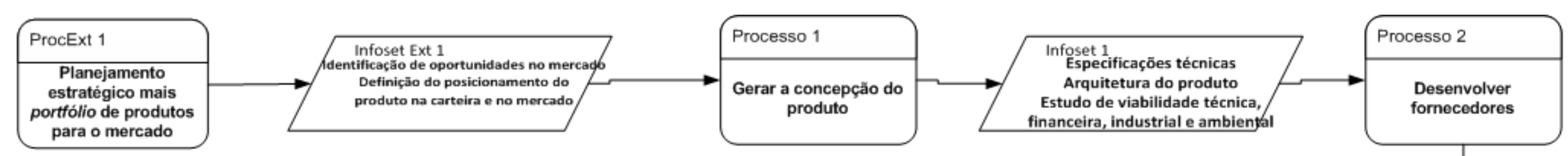

anceira, industrial e ambienta

fornecedores
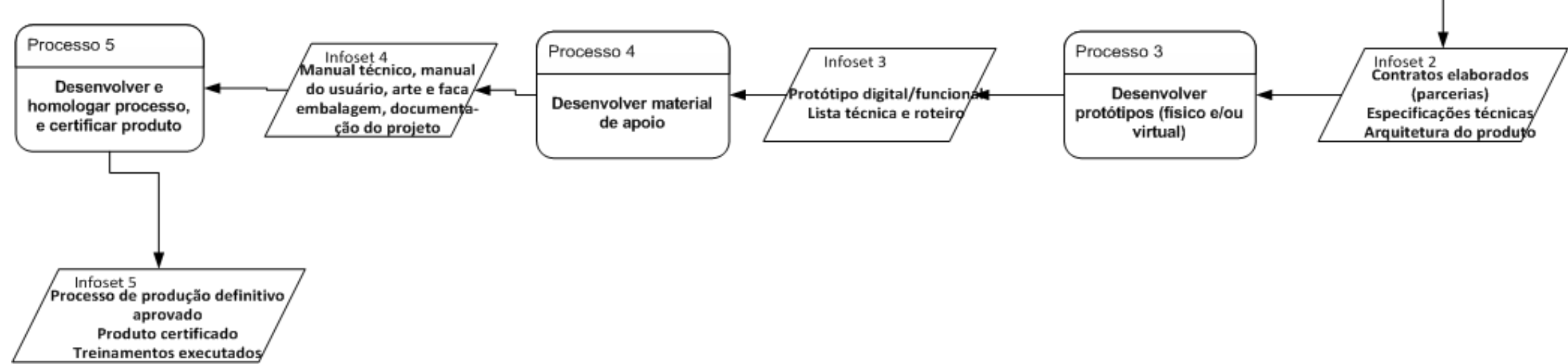

Figura 6: Modelo Macro de Processos de Negócios (as-is). 


\section{Processo 1: Gerar a concepção do produto}

A geração da concepção do produto (Processo 1) inicia-se a partir da identificação de oportunidades no mercado e da definição do posicionamento do produto na carteira e no mercado (InfoSetExt 1). O primeiro passo desse processo é a definição dos requisitos do cliente (Processo 1.1), cuja saída é formada pelo conjunto de necessidades e desejos do cliente (InfoSet 1.1). Esses requisitos coletados juntos aos clientes estão numa linguagem coloquial e precisam ser traduzidas em requisitos técnicos do produto (Processo 1.2). Esse processo gera uma lista de requisitos técnicos e de parâmetros de desempenho (InforSet 1.2) que alimentará a realização dos estudo de viabilidade técnica, financeira e industrial (Processo 1.3). Com os resultados desses estudos a diretoria emite seu parecer (InfoSet 3). Os próximos passos compreendem a modelagem funcional do produto (Processo 1.4) e o desenvolvimento de soluções alternativas para cada função do novo produto (Processo 1.5). Com a lista de soluções alternativas pronta, define-se a arquitetura do produto (Processo 1.6), e novamente é realizado um estudo de viabilidade técnica, financeira e industrial (Processo 1.7) para assegurar à diretoria condições de tomada de decisão quanto ao prosseguimento do projeto (InfoSet 1.7).

A Figura 7 apresenta o processo "Gerar a concepção do produto" do Modelo de Processos de Negócios (as-is). 


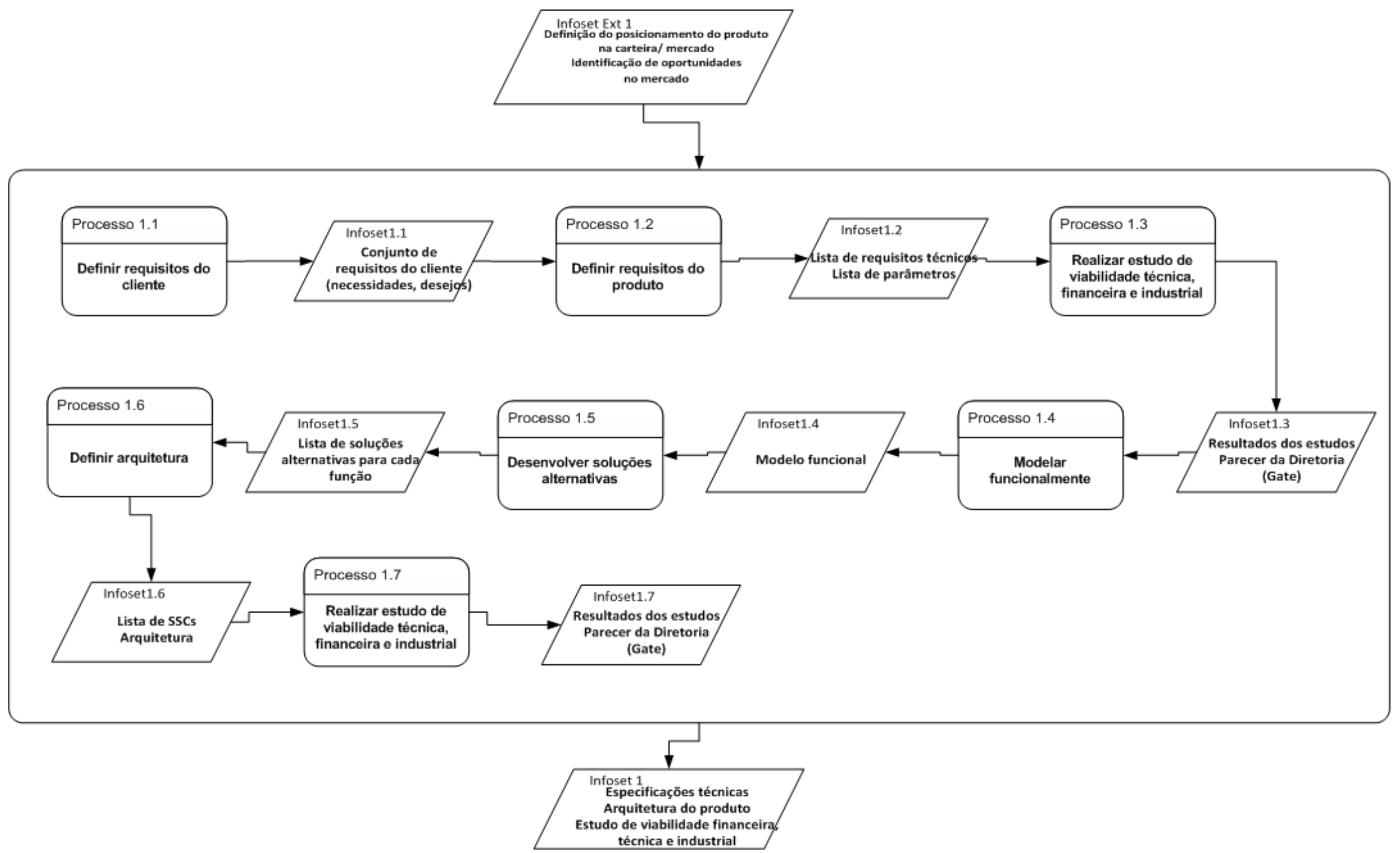

Figura 7: Modelo de Processos de Negócios: processo 1- gerar a concepção do produto (as-is). 


\section{Processo 2: Desenvolver fornecedores}

O desenvolvimento de parcerias com fornecedores (Processo 2) somente pode ser iniciado após a definição das especificações técnicas, da arquitetura do produto e dos resultados dos estudos de viabilidade técnica, financeira e industrial (InfoSet 1). O primeiro subprocesso do Processo 2 é a definição de quais SSC's serão desenvolvidos internamente e quais serão terceirizados (Processo 2.1), e essa lista (InfoSet 2.1) serve de base para a prospecção dos parceiros mais adequados para cada caso (Processo 2.2). Os próximos passos são a definição dos objetivos e metas a serem alcançados (Processo 2.3), e a definição dos recursos a serem compartilhados durante o projeto (Processo 2.4), sendo que tanto as métricas de desempenho (InfoSet 2.3) quanto a definição sobre as instalações, máquinas, equipamentos e pessoal (InfoSet 2.4) constituem referência para a determinação das condições contratuais (Processo 2.5) que estabelecerão as condições relacionadas com propriedade intelectual, prazos, custos, e condições de confidencialidade (InfoSet 2.5). Novamente ocorre um novo estudo de viabilidade técnica, financeira e industrial (Processo 2.6) a fim de posicionar a diretoria sobre a viabilidade do projeto e assim obter aprovação para a continuidade do mesmo.

A Figura 8 apresenta o processo "Desenvolver fornecedores" do modelo de processos de negócios (as-is). 

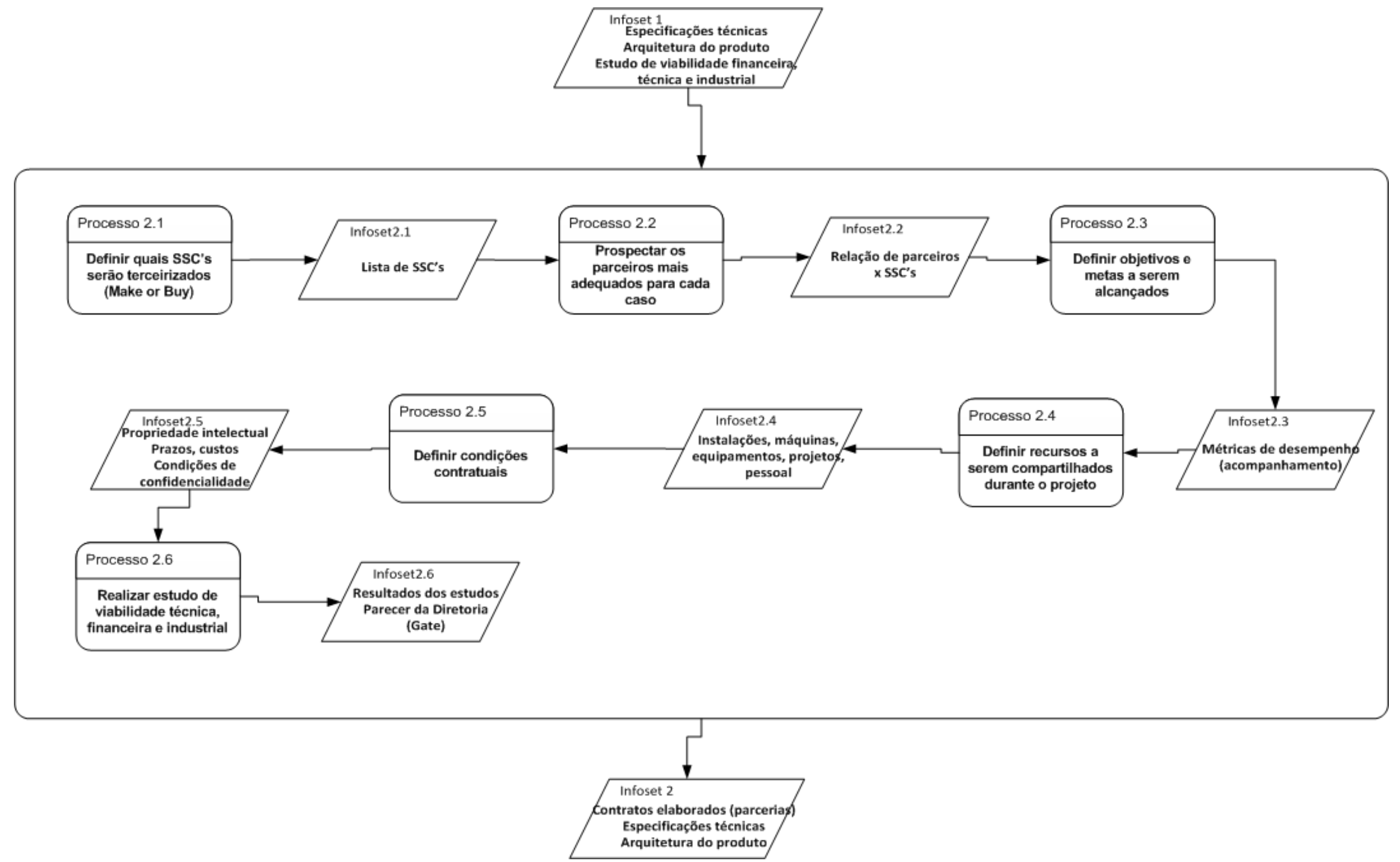

Figura 8: Modelo de Processos de Negócios: processo 2- desenvolver fornecedores (as-is). 


\section{Processo 3: Desenvolver protótipos}

Uma vez definidas as parcerias para apoiar o desenvolvimento do produto procede-se ao desenvolvimento do protótipo (Processo 3). O primeiro passo refere-se à integração dos parceiros ao PDP (Processo 3.1), o que resulta no compartilhamento parcial do projeto com terceiros (InfoSet 3.1). A partir disso é desenvolvido o modelo virtual (Processo 3.2) com o apoio de informações técnicas fornecidas pelos parceiros e, em seguida, são realizados os testes de operação e desempenho (Processo 3.3). O modelo virtual permite criar vários cenários de simulação e dessa forma gerar informações consistentes sobre funcionalidade, robustez, durabilidade e usabilidade (InfoSet 3.3), as quais servirão para ajudar a desenvolver um modelo físico muito próximo do ideal (Processo 3.4). Novamente os parceiros darão apoio fornecendo tecnologia e componentes para o modelo físico (InfoSet 3.4). Em seguida são realizados os testes de operação e desempenho (Processo 3.5), cuja saída (InfoSet 3.5) alimentará o subprocesso que realiza os estudos de viabilidade técnica, financeira e industrial (Processo 3.6). Esse subprocesso fornece os subsídios para que a diretoria emita seu parecer sobre o projeto (InfoSet 3.6).

A Figura 9 apresenta o processo "Desenvolver protótipos físico e/ou virtual" do modelo de processos de negócios (as-is). 


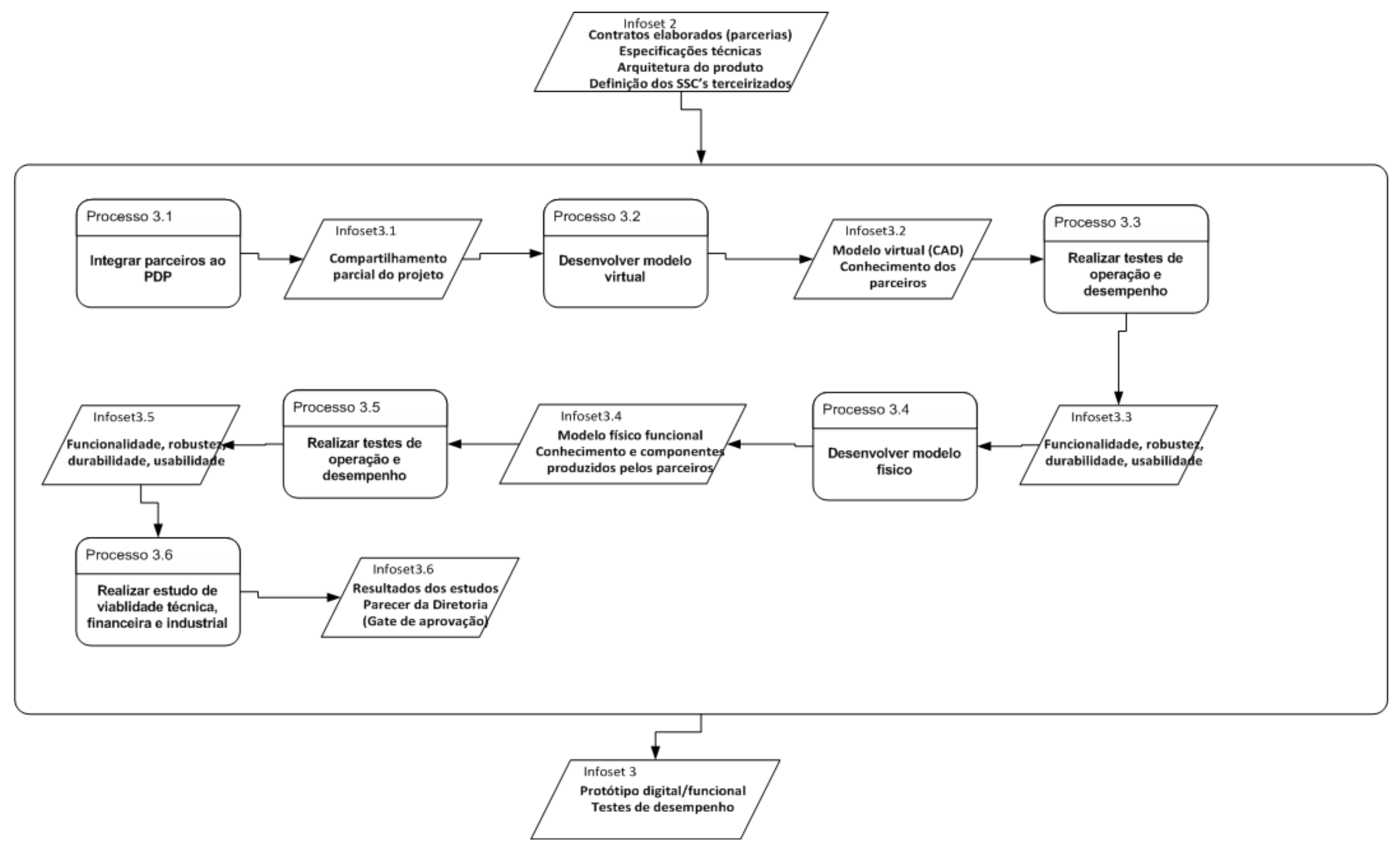

Figura 9: Modelo de Processos de Negócios: processo 3- desenvolver protótipos (físico e/ou virtual) (as-is). 


\section{Processo 4: Desenvolver material de apoio}

Com as informações geradas pelos protótipos virtual e/ou físico pode-se iniciar o desenvolvimento do material de apoio (Processo 4). A partir das especificações técnicas como dimensões e peso, e informações sobre fragilidade, pode-se iniciar o projeto da embalagem (Processo 4.1), sendo que a saída produzida é constituída pelos desenhos, gráficos e pela faca da embalagem (InfoSet 4.1). Outros materiais precisam ser produzidos neste ponto do processo de desenvolvimento do produto como manuais técnicos, manuais do usuário, guias de suporte para o serviço de atendimento ao cliente, e cadastros no ERP (Enterprise Resource Planning, Processo 4.2). E, por fim, são realizados os processos relacionados aos treinamentos: treinar pessoal das assistências técnicas (Processo 4.3) e treinar pessoal do SAC (Processo 4.4).

A Figura 10 apresenta o processo "Desenvolver material de apoio" do modelo de processos de negócios (as-is). 


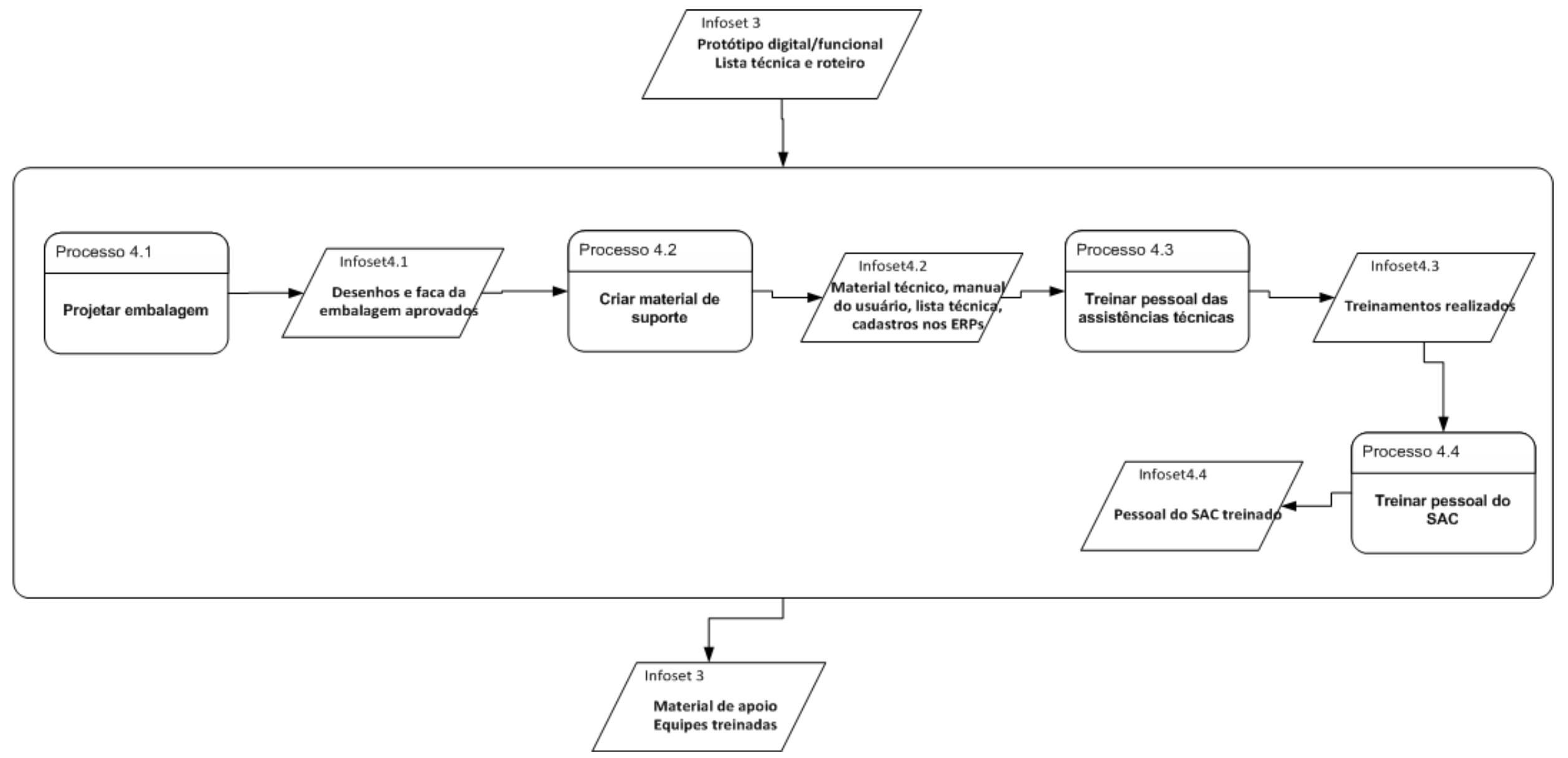

Figura 10: Modelo de Processos de Negócios: processo 4- desenvolver material de apoio (as-is). 


\section{Processo 5: Desenvolver e homologar processo e certificar produto}

Com a lista técnica, roteiro, protótipo físico/funcional, e material de apoio prontos, procede-se ao desenvolvimento e homologação do processo de manufatura e à certificação do produto (Processo 5). A partir das informações de lista técnica e roteiro, determina-se um processo produtivo acordado entre os setores produtivos (InfoSet 5.1). Esse processo produtivo precisa mostrar desempenho em relação a parâmetros como tempo, custo, e desperdícios, por essa razão procede-se à homologação do processo produtivo (Processo 5.2). Esta homologação ocorre por intermédio da geração de try outs, lotes pilotos, testes de armazenamento e de transporte (InfoSet 5.2). Após a validação do processo produtivo é realizado um estudo de viabilidade financeira (Processo 5.3) para permitir que a diretoria se posicione sobre o andamento do projeto (InfoSet 5.3). Apesar do processo estar homologado neste ponto, ainda é necessário que o produto manufaturado pelo processo receba a certificação (Processo 5.4) necessária tanto da área interna de qualidade quanto dos órgãos públicos como INMETRO. Depois que processo e produto estão aprovados, inicia-se a etapa de fase out com a área de manufatura (Processo 5.5), sendo que aqui ocorre o treinamento das equipes de funcionários e o acompanhamento por um determinado prazo do processo de manufatura (InfoSet 5.5).

A Figura 11 apresenta o processo "Desenvolver e homologar o processo e certificar o produto" do modelo de processos de negócios (as-is). 


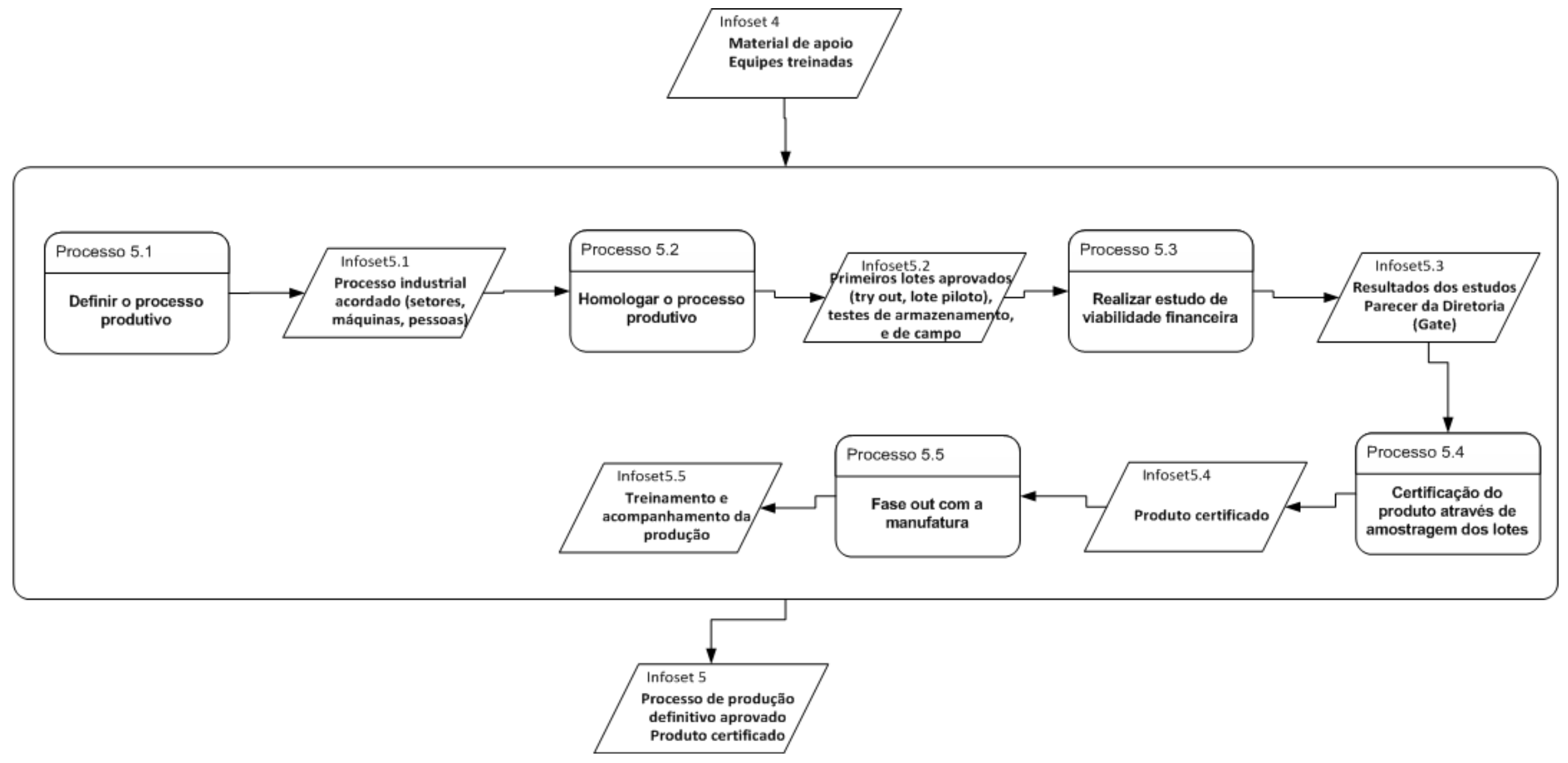

Figura 11: Modelo de Processos de Negócios: processo 5- desenvolver e homologar o processo e certificar o produto (as-is). 


\subsubsection{Modelo de Conceitos}

O Modelo de Conceitos apresenta os principais constructos que servem como base para a estruturação dos demais modelos. A inovação (Conceito 1) é o conceito chave que permeia todos os modelos desse estudo de caso, e que está vinculado à expectativa de liderança no mercado (Conceito 9). A complexidade envolvida no desafio de inovar requer o apoio de um Patrocinador (Conceito 10) hierarquicamente investido de poder. A inovação requer ainda a internalização de novos conhecimentos (Conceito 2), e dada a diversidade desses conhecimentos faz-se necessário o estabelecimento de parcerias (Conceito 3). Vários conceitos são relevantes para a formação dessas parcerias como histórico de colaboração (Conceito 4), certificação de parceiros (Conceito 5), e estabelecimento de contratos (Conceito 6) que garantam a confidencialidade (Conceito 7). Graças aos mecanismos de confidencialidade evita-se a evasão do conhecimento gerado e pode-se assegurar a proteção da propriedade intelectual (Conceito 8).

O conceito de plano estratégico (Conceito 11) e de PDP estruturado (Conceito 17) são partes que compõem o conceito de inovação. O plano, por sua vez, é composto pela idéia de vigilância tecnológica (Conceito 12), a fim de explorar as inovações tecnológicas; pelos conceitos de Design for Excellence (Conceito 13) e Design for Environment (Conceito 14), a fim de equilibrar desempenho técnico e eficácia ambiental; pelo conceito de multifuncionalidade da equipe de projeto (Conceito 15); e pela definição de originalidade (Conceito 16) como diferencial competitivo.

Para as unidades empresariais estudadas, um dos pilares de apoio da inovação é o conceito de PDP estruturado (Conceito 17). Ele é composto por vários outros conceitos: certificação do produto (Conceito 18) e homologação do processo (Conceito 19); benchmarking e clínicas (Conceito 20); gates de aprovação (Conceito 21); métricas (Conceito 22); engenharia simultânea (Conceito 23); ciclo de vida do produto (Conceito 24); e treinamentos (Conceito 25).

A Figura 12 apresenta o modelo de conceitos (as-is). 


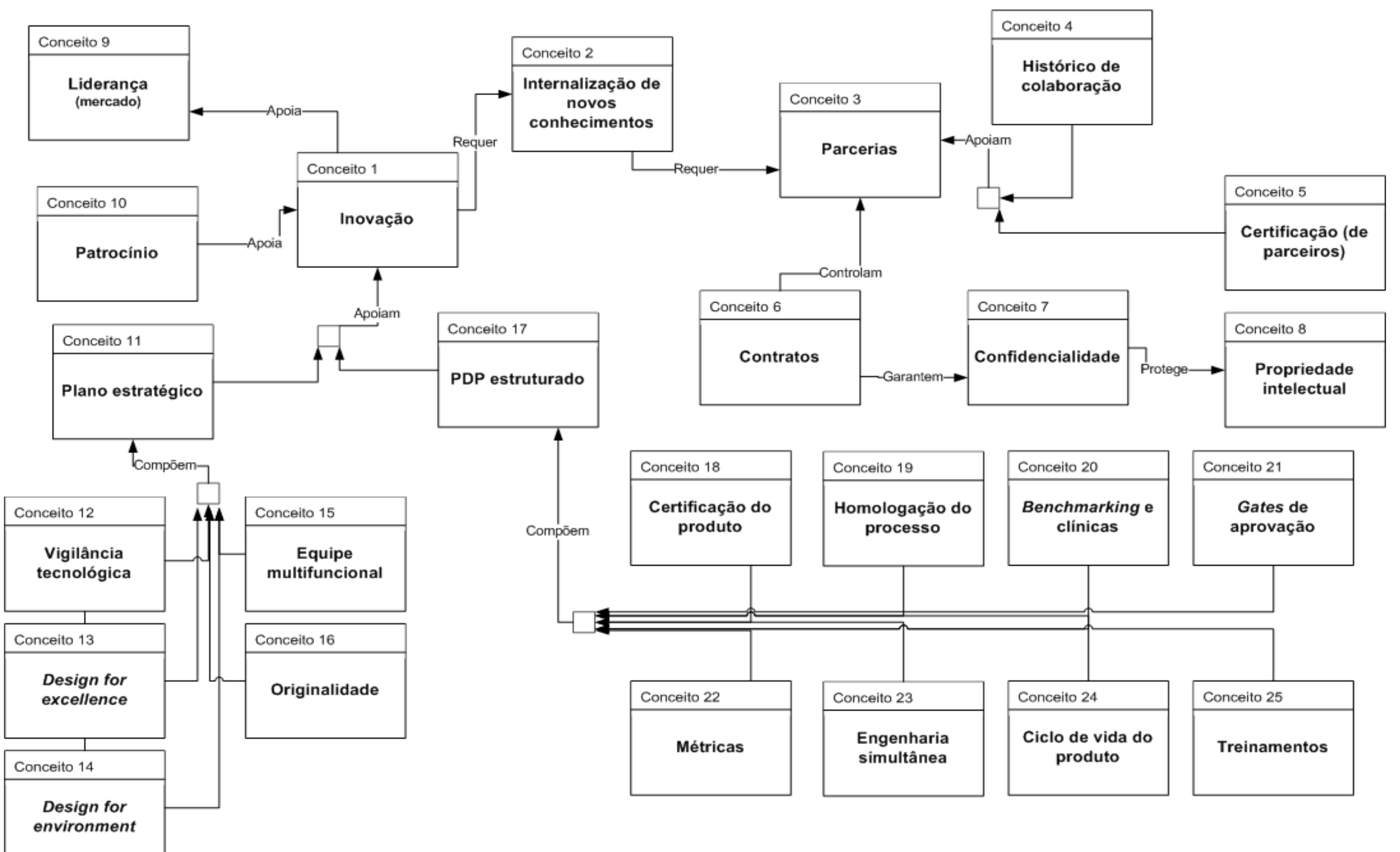

Figura 12: Modelo de Conceitos (as-is). 


\subsection{DISCUSSÃO DO MODELO "AS-IS"}

O resultado do questionário aplicado no estudo de caso (seção 3.1.1) sugere que as unidades empresariais mostraram comportamentos e/ou características associados, pela literatura, aos sistemas complexos como a presença de mudança constante no ambiente, saída e/ou comportamento não proporcional, evolução não linear da topologia, e propriedade de não redutibilidade. No entanto, ficou evidenciado que não ocorreram comportamentos coletivos espontâneos, nem mudança espontânea na estrutura das parcerias, o que permite sustentar que não ocorreu o evento da auto-organização. Os principais elementos identificados pelo questionário como responsáveis pela ausência da auto-organização são: controle centralizado e direto, relacionamento fraco entre as partes, ausência de incentivo para iniciativas próprias, falta de alinhamento no esforço coletivo, e deficiências na aprendizagem. Como as questões utilizadas em campo foram estruturadas utilizando-se conceitos da literatura de redes de inovação e de sistemas complexos, pode-se sugerir que esses elementos indicados pelo questionário possuem fundamento teórico.

A modelagem do cenário de parcerias estabelecidas nas unidades empresariais do estudo de caso (seção 3.2) ajuda na compreensão das informações levantadas pelo questionário. Podese perceber que os relacionamentos estudados não caracterizam elos colaborativos, ao contrário, mostram uma relação de fornecimento regida por contrato a partir de um projeto definido pela empresa focal.

Com relação à centralização do controle tem-se que no Modelo de Objetivos os elementos definidos (objetivos e oportunidades) estão mais direcionados para o controle da empresa líder sobre os parceiros (por exemplo, extrair novos conhecimentos, e transferir desafios técnicos para terceiros - Objetivos 1.4 .2 e 1.4.5). E mesmo quando há a intenção de estabelecer parcerias de longo prazo e aumentar a confiança entre as partes (Objetivos 1.4.1 e 1.4.3), são utilizadas regras (Regras 26, 27, 31 e 32) que reforçam ainda mais esse controle e/ou domínio. As regras definem com rigor os papéis, a porção de acesso de cada parceiro no projeto, e a confidencialidade para com os dados da empresa focal. Por essa razão o questionário detectou que o controle é centralizado e direto, porque o que se busca não é o estabelecimento de laços bilaterais de confiança e comprometimento, mas a garantia de que a empresa líder preserve seus interesses.

$\mathrm{O}$ rigor dos contratos e a restrição de acesso às informações ajudam a esclarecer outros problemas detectados como relacionamento fraco entre as partes, ausência de iniciativas próprias e falta de alinhamento do esforço coletivo. A falta de acesso aos macro-objetivos e outras informações restringe o campo de atuação dos parceiros ao estrito cumprimento dos 
contratos, prejudicando a possibilidade do surgimento de ideias e movimentos que contribuam para as inovações. O Modelo de Atores e Recursos (figura 5) mostra que os parceiros, embora façam parte do processo de desenvolvimento, não estão integrados à equipe de desenvolvimento, ao contrário, eles são controlados por ela. Isso justifica o fato da pesquisa ter detectado deficiência na aprendizagem, porque segundo Manson (2001) e Ozman (2009) o processo de aprendizagem passa necessariamente pela colaboração recíproca entre parceiros a fim de acessar novos conhecimentos e produzir novas competências.

O Modelo de Processos de Negócios também contribui para a compreensão desse cenário. Ele mostra que a prospecção de fornecedores ocorre após o macro processo "gerar a concepção do produto". Isso significa que as principais decisões já foram tomadas em relação ao novo produto quando os fornecedores passam a integrar o PDP, o que limita o fluxo de conhecimentos entre as partes. O próprio termo "fornecedores", utilizado com recorrência pelos entrevistados, evidencia a restrição do papel destinado aos terceiros. Isso reduz as trocas, prejudicando o aprendizado, e traz dificuldades para que surjam iniciativas além do estabelecido nas cláusulas contratuais.

A modelagem das unidades empresariais evidencia que a busca pela inovação está mais na empresa focal do que no grupo de parceiros/fornecedores. A empresa focal visualiza esse grupo como uma forma de ganhar informação, conhecimento, e outros recursos a fim de atender suas prioridades. Essa orientação não colabora para o fenômeno da auto-organização e faz com que as empresas parceiras percebam que o relacionamento com a empresa focal não é colaborativo. Por esse motivo a formalização contratual estabelecida entre os parceiros assegura apenas o cumprimento mínimo das obrigações contratuais, algo necessário, porém insuficiente quando se trata de inovar. A empresa focal acaba inibindo iniciativas potencialmente inovadoras (movimentos locais/individuais que se propagam pela rede) ao usar sua posição privilegiada para impor diretrizes e regras para os demais parceiros (Christopher e Clark, 2007; Ting e Chiu, 2009). Na verdade, a empresa focal que centraliza cada unidade empresarial deveria concentrar esforços na reunião das fontes dispersas de conhecimentos, na gestão da mobilidade desse ativo, na apropriação dos benefícios da inovação e na estabilidade da rede (Dhanaraj e Parkhe, 2006).

Como a auto-organização é caracterizada por movimentos coletivos espontâneos, será necessário que os elementos de apoio (Quadros 4 e 5) estejam presentes nos objetivos, nas regras, nos processos, e na estrutura de atores e recursos. Os elementos de apoio são confiança e comprometimento mútuos, alinhamento dos agentes entre si e com os objetivos globais, compartilhamento de práticas e de conhecimento, descentralização do controle, controle não invasivo (descentralizado, indireto e catalítico), uso da aprendizagem, e condições para a 
propagação de movimentos do tipo bottom-up. Na próxima seção serão discutidas as lacunas e os elementos acima sugeridos.

\subsection{ANÁLISE DA NECESSIDADE DE MUDANÇA (NEED FOR CHANGE)}

Conforme discutido na seção anterior, apesar das unidades empresariais evidenciarem características de sistemas complexos, elas não apresentaram o fenômeno da auto-organização. A seguir cada subseção apresenta dois quadros, o primeiro deles mostra os elementos presentes em cada modelo "as-is" apresentados na Seção 3.1 que apresentam conexão e relevância para a formação e operação das parcerias operadas pelas unidades estudadas. Nesse mesmo quadro são indicadas suas referências na literatura e as unidades que os identificaram. $\mathrm{O}$ segundo quadro resume os elementos da literatura que podem preencher as lacunas de cada modelo "as-is" responsáveis pela ausência do fenômeno da auto-organização.

\subsubsection{Need for Change para o Modelo de Objetivos}

Dentre os objetivos presentes no Modelo de Objetivos desenvolvido através do estudo de caso, apenas 6 deles fazem referência às parcerias entre empresas. O Quadro 6 mostra esses objetivos, as referências literárias que os mencionam e as unidades empresariais que os identificam.

Quadro 6: elementos atuais do Modelo de Objetivos relacionados às parcerias

\begin{tabular}{|c|c|c|c|c|c|c|c|c|c|}
\hline \multirow[t]{2}{*}{ Elementos } & \multirow[t]{2}{*}{ Literatura } & \multicolumn{8}{|c|}{ Empresas } \\
\hline & & 1 & 2 & 3 & 4 & 5 & 6 & 7 & 8 \\
\hline $\begin{array}{l}\text { Reforçar os laços de } \\
\text { parcerias com } \\
\text { terceiros }\end{array}$ & $\begin{array}{l}\text { Sari et al.(2007), Gilbert et } \\
\text { al.(2007), Emden et al.(2006), } \\
\text { Schoonmaker e Carayannis (2010), } \\
\text { Molina-Morales e Mertínez- } \\
\text { Fernández (2010), Ozman (2009) }\end{array}$ & & & & & & & & \\
\hline $\begin{array}{l}\text { Aumentar o nível de } \\
\text { confiança entre os } \\
\text { parceiros }\end{array}$ & $\begin{array}{l}\text { Ritter e Gemünden, 2003; Ojasalo, } \\
\text { 2008; Kotilla et al., 2008; Ollus et } \\
\text { al., 2011; Westergren e Holmström, } \\
2012\end{array}$ & & & & & & & & \\
\hline $\begin{array}{l}\text { Extrair novos conhe- } \\
\text { cimentos dos parceiros }\end{array}$ & & & & & & & & & \\
\hline $\begin{array}{l}\text { Estabelecer parcerias } \\
\text { de longo prazo }\end{array}$ & $\begin{array}{l}\text { Ojasalo (2008), Fukugawa (2006), } \\
\text { Cowan et al. (2005) }\end{array}$ & & & & & & & & \\
\hline $\begin{array}{l}\text { Integrar os parceiros } \\
\text { chaves ao PDP }\end{array}$ & $\begin{array}{l}\text { Ollus et al. (2011) e Alin et al. } \\
\text { (2013), Christopherson e Clark } \\
\text { (2007) }\end{array}$ & & & & & & & & \\
\hline $\begin{array}{l}\text { Transferir desafios } \\
\text { técnicos } \mathrm{p} / \text { parceiros } \\
\text { especializados }\end{array}$ & & & & & & & & & \\
\hline
\end{tabular}


Os elementos presentes no Quadro 6 evidenciam que existe uma preocupação com a formação e a operação das parcerias formadas entre a empresa focal e seus parceiros de desenvolvimento. No entanto, ao mesmo tempo em que há a intenção de reforçar os laços de parcerias com terceiros (Objetivo 1.4), a abordagem adotada é mais do tipo cliente-fornecedor do que colaborativa. Os objetivos "extrair novos conhecimentos dos parceiros" e "transferir desafios técnicos para parceiros especializados" revelam um conceito de benefício unilateral que não encontra apoio na literatura. Dhanaraj e Parkhe (2006), Kash e Rycroft (2002), Tharumarajah (2003), Rycroft e Kash (2004) defendem que deve ocorrer uma troca recíproca de conhecimentos entre os parceiros.

Os Quadros 4 e 5 (Seções 2.3.1e 2.3.2) sugerem alguns elementos retirados da literatura para preencher as lacunas do Modelo de Objetivos responsáveis pela ausência da propriedade de auto-organização. Eles podem ajudar a compor um novo modelo de objetivos que apoie a propriedade de auto-organização.

O Quadro 4 sugere que os relacionamentos são influenciados pelo comprometimento das partes, pela confiança recíproca, pela participação voluntária, pelo alinhamento dos parceiros, pelo compartilhamento de práticas e conhecimentos, e pelo controle distribuído.

O Quadro 5 também indica a importância dos relacionamentos para o fenômeno da autoorganização. A espontaneidade dos comportamentos coletivos e das mudanças na estrutura do sistema nasce da aprendizagem e da interdependência entre os agentes, assim como dos movimentos bottom up isolados que se propagam através dos relacionamentos.

Não há referência a esses elementos no Quadro 6. Por essa razão, no Quadro 7 são apontados os elementos considerados pela literatura como relevantes para apoiar a autoorganização. Eles representam as necessidades de mudança ("need for change") no Modelo de Objetivos "as-is". A ausência deles permite identificar os motivos pelos quais a pesquisa detectou que as unidades empresariais estudadas mostraram características de sistemas complexos (mudança constante, comportamento/saída não proporcional, evolução não linear da topologia, não redutibilidade), mas não apresentaram o fenômeno da auto-organização.

Quadro 7: elementos need for change para o Modelo de Objetivos.

\begin{tabular}{|l|l|}
\hline Elementos p/ Modelo de Objetivos & Literatura \\
\hline $\begin{array}{l}\text { Usar um controle distribuído } \\
\text { (descentralizado e indireto) }\end{array}$ & $\begin{array}{l}\text { Lowe et al. (2012), Pathak et al.(2007), Surana et al. } \\
(2005), \text { Schneider e Somers (2006), Uhl-Bien et al. } \\
(2007)\end{array}$ \\
\hline $\begin{array}{l}\text { Direcionar foco para os relaciona- } \\
\text { mentos }\end{array}$ & $\begin{array}{l}\text { Eschenbacher et al. (2011), Schneider e Somers } \\
(2006), \text { Manson (2001), McCarthy et al.(2000) }\end{array}$ \\
\hline $\begin{array}{l}\text { Incentivar o comprometimento das } \\
\text { partes }\end{array}$ & $\begin{array}{l}\text { Gnyawali e Srivastava (2013), Camarinha-Matos et al. } \\
(2009), \text { Ojasalo (2008) }\end{array}$ \\
\hline
\end{tabular}




\begin{tabular}{|l|l|}
\hline $\begin{array}{l}\text { Apoiar a interdependência entre os } \\
\text { agentes }\end{array}$ & Uhl-Bien et al. (2007), Schneider e Somers (2006), \\
\hline Motivar a participação voluntária & Lowe et al. (2012) \\
\hline Apoiar movimentos bottom up & $\begin{array}{l}\text { Uhl-Bien et al. (2007), Marion e Uhl-Bien, 2001; } \\
\text { Ollus et al. (2011) }\end{array}$ \\
\hline $\begin{array}{l}\text { Promover o alinhamento dos } \\
\text { parceiros }\end{array}$ & $\begin{array}{l}\text { Ollus et al. (2011), Alin et al. (2013), Bititci et al. } \\
\text { (2007) e Corsaro et al. (2012) }\end{array}$ \\
\hline $\begin{array}{l}\text { Incentivar o aprendizado enquanto } \\
\text { geração e uso do conhecimento }\end{array}$ & $\begin{array}{l}\text { Vasileiadou e Safarzynska (2010), Manson (2001), } \\
\text { Cohen e Levinthal (1990), Hoecht e Trott (2006), } \\
\text { Halikkas et al. (2009); Knell e Srholec (2008), Manson } \\
\text { (2001) }\end{array}$ \\
\hline $\begin{array}{l}\text { Fomentar o compartilhamento de } \\
\text { práticas e conhecimentos }\end{array}$ & $\begin{array}{l}\text { Kash e Rycroft (2002; 2004), Sari et al., 2007; Gilbert } \\
\text { et al. 2007; Emden et al., 2006; Schoonmaker e } \\
\text { Carayannis, 2010; Molina-Morales e Mertínez- } \\
\text { Fernández, 2010 }\end{array}$ \\
\hline
\end{tabular}

Um controle distribuído permite o compartilhamento das responsabilidades diante do desafio de inovar, motivando a pró-atividade e a participação voluntaria dos agentes na rede. Os relacionamentos formam os elos por intermédio dos quais fluem os conhecimentos dos seus agentes e as ações colaborativas. O comprometimento entre as partes permite que os agentes ultrapassem os limites das obrigações contratuais. A percepção da interdependência entre os agentes motiva a colaboração entre as partes, assim como o alinhamento dos parceiros permite a canalização, em prol de objetivos em comum, dos esforços gerados a partir de movimentos bottom up. E o aprendizado, enquanto geração e uso do conhecimento, impulsiona a movimentação espontânea porque requer o compartilhamento de práticas e de conhecimentos.

\subsubsection{Need for Change para o Modelo de Regras de Negócios}

O Modelo de Regras de Negócios (Figura 2) apresenta 39 regras que foram estabelecidas pela empresa focal para apoiar seu conjunto de objetivos (Modelo de Objetivos). Catorze dessas regras estão diretamente associadas às parcerias com terceiros. Várias células do Quadro 8 não apresentam referências bibliográficas na literatura de redes e de sistemas complexos.

Quadro 8: elementos atuais do Modelo de Regras de Negócios

\begin{tabular}{|l|l|l|l|l|l|l|l|l|l|}
\hline Elementos & Literatura & \multicolumn{6}{|c|}{ Empresas } \\
\hline $\begin{array}{l}\text { Priorizar o desenvolvi- } \\
\text { mento com terceiros }\end{array}$ & & & & & & & & & \\
\hline $\begin{array}{l}\text { Exigir qualificação } \\
\text { comprovada }\end{array}$ & $\begin{array}{l}\text { Andersson et al. (2008), Bititci } \\
\text { et al. (2007) e Corsaro et al. } \\
\text { (2012) }\end{array}$ & & & & & & & & \\
\hline $\begin{array}{l}\text { Avaliar vínculos de par- } \\
\text { ceiros com concorrentes }\end{array}$ & & & & & & & & & \\
\hline
\end{tabular}




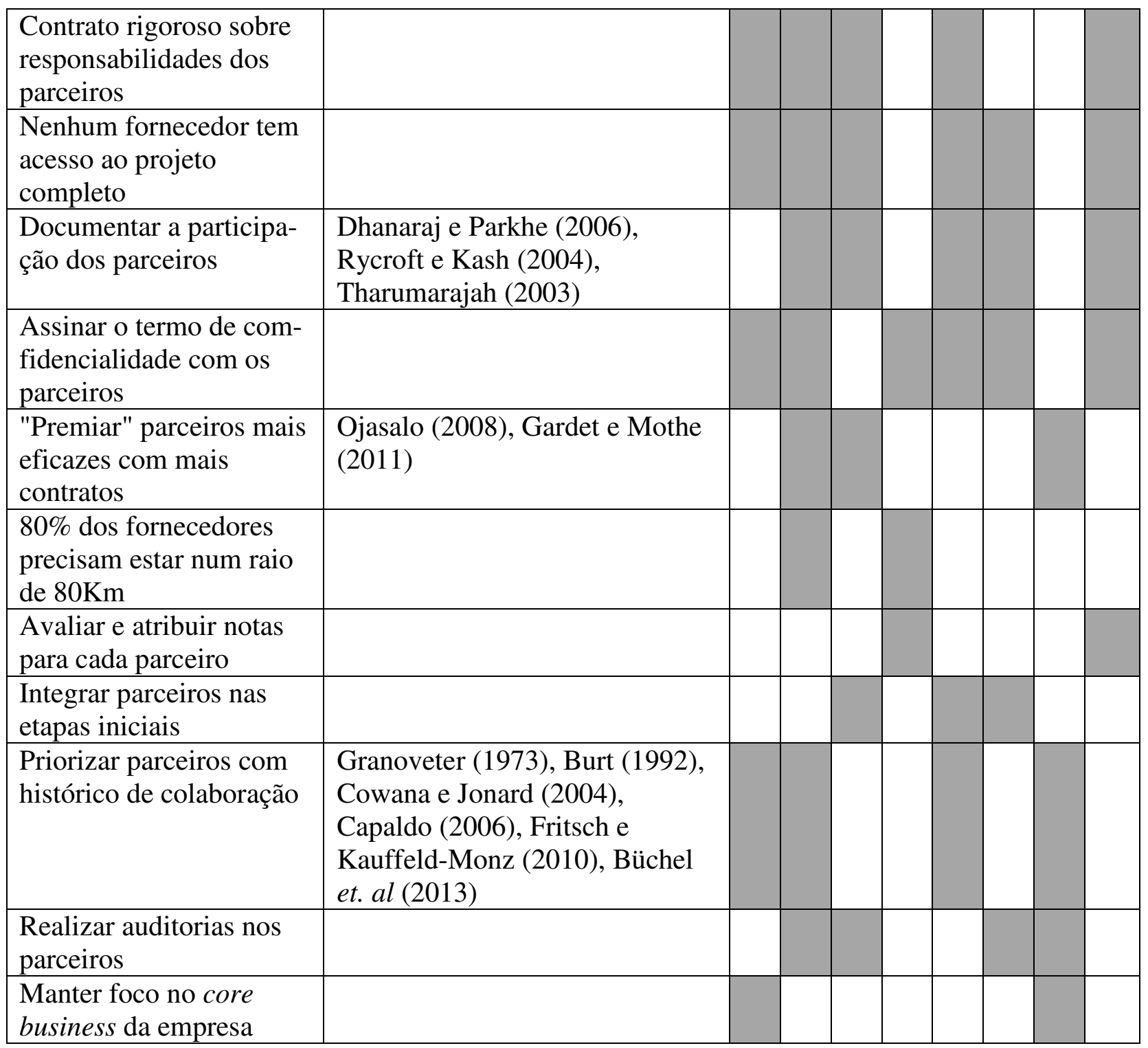

A maioria das regras coletadas no estudo de caso não apresenta fundamento teórico claro e embora haja alguns elementos do Quadro 8 mencionados na literatura há uma significativa divergência de enfoque. Por exemplo, a regra "documentar a participação dos parceiros" tem na literatura um significado mais amplo que é o de aprendizagem e não apenas o de registrar as interações entre as partes. Também no caso da regra "premiar parceiros mais eficazes com mais contratos", na literatura o foco está no estabelecimento de um sistema de recompensas que vai além de aumentar o número de contratos, privilegiando o compartilhamento das informações, do planejamento e das recompensas. E para a regra "priorizar parceiros com histórico de colaboração", o que a literatura de redes de inovação defende é o estabelecimento de um núcleo coeso de agentes caracterizado por um número limitado de ligações fortes e de confiança, vinculado a uma ampla periferia de ligações fracas, responsável por informações novas e não redundantes. 
De modo geral, as regras de negócio identificadas pelo estudo de caso mostram a tendência para restringir as ações dos parceiros (falta de acesso ao projeto completo, contratos rigorosos sobre responsabilidades, auditorias, termo de confidencialidade, avaliação de possíveis vínculos de parceiros com concorrentes). De acordo com Dhanaraj e Parkhe (2006), o papel da empresa focal deveria passar justamente pela gestão da mobilidade do conhecimento e pela gestão da apropriação da inovação. De acordo com Uhl-Bien et al. (2007), o controle do tipo top-down em sistemas com características complexas pode prejudicar o seu funcionamento. A imposição de diretrizes pode inibir comportamentos com potencial para gerar inovações, portanto é preciso criar condições para que os comportamentos espontâneos e internos à rede possam produzir soluções inovadoras (Marion e Uhl-Bien, 2001; Ollus et al. (2011). Um controle descentralizado e de ação mais indireta pode influenciar a auto-organização e apoiar a adaptação do sistema através da inserção de novos agentes, incentivando o aumento do interrelacionamento dentro do sistema e o inter-relacionamento entre sistemas (Uhl-Bien et al., 2007; McCarthy et al., 2000; Pathak et al., 2007).

De acordo com a metodologia EKD, cada objetivo sugerido no Quadro 7 necessita de ao menos uma regra para apoiá-lo (Bubenko et al., 2001). Na primeira coluna do Quadro 9 são apresentados os objetivos presentes no Quadro 8 que estão diretamente associados ao fenômeno da auto-organização. Na segunda coluna aparecem as regras sugeridas como possíveis fontes de apoio e que foram retiradas do modelo conceitual da revisão bibliográfica (Quadros 4 e 5).

Quadro 9: elementos need for change para o Modelo de Regras de Negócios.

\begin{tabular}{|l|l|l|}
\hline $\begin{array}{l}\text { Elementos Modelo } \\
\text { de Objetivos }\end{array}$ & $\begin{array}{l}\text { Elementos Modelo } \\
\text { de Regras }\end{array}$ & Literatura \\
\hline $\begin{array}{l}\text { Usar um controle descen- } \\
\text { tralizado e indireto }\end{array}$ & $\begin{array}{l}\text { Compartilhar o planejamento dos } \\
\text { projetos e a resolução de conflitos }\end{array}$ & $\begin{array}{l}\text { Bititci et al. (2007) e Corsaro } \\
\text { et al. (2012), Ojasalo (2008) }\end{array}$ \\
\hline $\begin{array}{l}\text { Direcionar foco para os } \\
\text { relacionamentos }\end{array}$ & $\begin{array}{l}\text { Avaliar o tipo e a intensidade de } \\
\text { cada relacionamento (definir } \\
\text { escala de prioridades) }\end{array}$ & $\begin{array}{l}\text { Eschenbacher et al. (2011), } \\
\text { Fukugawa (2006), } \\
\text { Camarinha-Matos et } \\
\text { al.(2009), Manson (2001) }\end{array}$ \\
\hline $\begin{array}{l}\text { Incentivar o comprometi- } \\
\text { mento das partes }\end{array}$ & $\begin{array}{l}\text { Trabalhar com uma política de } \\
\text { governança clara, distribuir } \\
\text { benefícios de forma justa }\end{array}$ & $\begin{array}{l}\text { Soriano (2009); Bititci et } \\
\text { al.(2007); Ulbrich et al. } \\
\text { (2011); Camarinha-Matos et } \\
\text { al. (2009) }\end{array}$ \\
\hline $\begin{array}{l}\text { Apoiar a interdependência } \\
\text { entre os agentes }\end{array}$ & $\begin{array}{l}\text { Selecionar empresas com capaci- } \\
\text { dades centrais e ativos comple- } \\
\text { mentares }\end{array}$ & $\begin{array}{l}\text { Kash e Rycroft (2002), } \\
\text { Bititci et al. (2007) e Corsaro } \\
\text { et al. (2012) }\end{array}$ \\
\hline $\begin{array}{l}\text { Motivar a participação } \\
\text { voluntária }\end{array}$ & $\begin{array}{l}\text { Manter uma comunicação aberta, } \\
\text { compartilhar o conhecimento } \\
\text { individual }\end{array}$ & $\begin{array}{l}\text { Ritter e Gemünden, 2003; } \\
\text { Ojasalo, 2008; Kotilla et al., } \\
\text { 2008; Ollus et al., 2011; Alin } \\
\text { et al., 2013; Westergren e } \\
\text { Holmström, 2012 }\end{array}$ \\
\hline
\end{tabular}




\begin{tabular}{|l|l|l|}
\hline $\begin{array}{l}\text { Apoiar movimentos bottom } \\
\text { up }\end{array}$ & $\begin{array}{l}\text { O sistema de recompensas precisa } \\
\text { atrelar os dividendos ao sucesso } \\
\text { do projeto }\end{array}$ & Dhanaraj e Parkhe (2006), \\
\hline $\begin{array}{l}\text { Promover o alinhamento } \\
\text { dos parceiros }\end{array}$ & $\begin{array}{l}\text { Manter sempre os parceiros atuali- } \\
\text { zados (objetivos, metas, benefí- } \\
\text { cios, tarefas) }\end{array}$ & $\begin{array}{l}\text { Bititci et al. (2007) e Corsaro } \\
\text { et al. (2012), Dhanaraj e } \\
\text { Parkhe (2006) }\end{array}$ \\
\hline $\begin{array}{l}\text { Incentivar o aprendizado } \\
\text { enquanto geração e uso do } \\
\text { conhecimento }\end{array}$ & $\begin{array}{l}\text { Alimentar o banco de conheci- } \\
\text { mentos da rede }\end{array}$ & $\begin{array}{l}\text { Cohen e Levinthal (1990), } \\
\text { Nonaka (1994) }\end{array}$ \\
\hline $\begin{array}{l}\text { Fomentar o } \\
\text { compartilhamento de } \\
\text { práticas e conhecimentos }\end{array}$ & $\begin{array}{l}\text { Usar uma plataforma de colabora- } \\
\text { ção que facilite as trocas }\end{array}$ & $\begin{array}{l}\text { Andersson et al. (2008),Wu } \\
\text { et al. (2006), Chung et al. } \\
\text { (2009) }\end{array}$ \\
\hline
\end{tabular}

Não seria possível "estabelecer um controle descentralizado e indireto" sem que fosse compartilhado o planejamento do projeto e a resolução de conflitos. Nesse sentido, as regras definidas para alinhar os parceiros e motivar a participação voluntária também apoiam e motivam que o controle seja compartilhado entre as partes e que ele possa ser usado como instrumento de incentivo indireto e não de coersão.

O objetivo de "direcionar foco para os relacionamentos" pode ser apoiado por uma regra que determine que seja avaliado o tipo e a intensidade de cada relacionamento; isso permite que sejam estabelecidas prioridades dentro da teia de relacionamentos, conduzindo à consolidação de um núcleo coeso de parcerias (estratégia defendida por Büchel et. al, 2013; Capaldo 2006; Cowana e Jonard, 2004; Fritsch e Kauffeld-Monz, 2010).

A fim de "incentivar o comprometimento das partes" é necessário trabalhar com uma política de governança clara e distribuir benefícios de forma justa. A transparência em relação às diretrizes e metas estabelecidas, à condução dos trabalhos, e à distribuição justa dos resultados obtidos incentiva o engajamento das partes diante de uma perspectiva de vantagem mútua.

A "interdependência entre os agentes" é outro ponto destacado pela literatura de redes de inovação para a integração e gestão bem sucedida dos parceiros. Pode-se apoiar esse objetivo selecionando empresas com capacidades centrais e ativos que complementem as competências da empresa focal, mas que estas também possam ser beneficiadas por essa complementaridade. A integração de um novo parceiro à equipe de projeto precisa permitir que haja uma interdependência recíproca entre as partes, isso também promove o comprometimento.

Para "motivar a participação voluntária" pode-se manter canais disponíveis e acessíveis que promovam uma comunicação aberta a fim de que os agentes percebam que terão suas ideias, contribuições e até mesmo insatisfações compartilhadas com os demais. Outro ponto de incentivo para a participação voluntária é o compartilhamento de conhecimento individual, ou 
seja, a possibilidade de todos contribuírem e se beneficiarem com o aprendizado coletivo a partir das trocas entre os parceiros.

O objetivo "Apoiar movimentos bottom up" requer que o sistema de recompensas esteja atrelando os dividendos ao sucesso do projeto. Isso acrescenta um certo desafio permanente aos parceiros, que estarão cientes de precisam tomar iniciativa própria diante de desafios e situações inusitadas a fim de tornar o projeto bem sucedido. A regra que determina a manutenção de canais disponíveis e acessíveis que promovam a comunicação aberta entre os agentes para o compartilhamento de ideias, contribuições e insatisfações também apóia a propagação de movimentos bottom up.

Para "promover o alinhamento dos parceiros" é necessário a atualização constante dos objetivos, metas, tarefas, riscos, ônus e benefícios. O compartilhamento das informações permite que todos tenham uma visão completa da situação e possam contribuir com ideias e ações que, ainda que diferentes, tenham um alvo em comum.

A fim de "incentivar o aprendizado enquanto geração e uso do conhecimento" pode-se desenvolver e alimentar um banco de conhecimentos a partir da externalização proporcionada pela aliança entre os parceiros.

O objetivo "fomentar o compartilhamento de práticas e conhecimentos” pode ser apoiado através do uso de uma plataforma de colaboração que facilite as trocas entre os parceiros. A integração entre os softwares de gerenciamento de projetos ou mesmo entre os bancos de dados permitiria a troca padronizada e rápida de dados e informações sobre questões técnicas, práticas e procedimentos de trabalho, além do próprio status e condições de andamento do projeto.

\subsubsection{Need for Change para o Modelo de Processos}

As Figuras 7 e 8 do Modelo de Processos de Negócios (desenvolver fornecedores, desenvolver protótipos) apresentam 5 processos que foram estabelecidos pela empresa focal e que estão diretamente associados com a formação das parcerias. O Quadro 10 apresenta esses elementos.

Quadro 10: elementos atuais do Modelo de Processos de Negócios

\begin{tabular}{|l|l|l|l|l|l|l|l|l|l|}
\hline Elementos & Literatura & \multicolumn{6}{|c|}{ Empresas } \\
\cline { 3 - 9 } & & $\mathbf{1}$ & $\mathbf{2}$ & $\mathbf{3}$ & $\mathbf{4}$ & $\mathbf{5}$ & $\mathbf{6}$ & $\mathbf{7}$ & $\mathbf{8}$ \\
\hline $\begin{array}{l}\text { Prospectar os parceiros } \\
\text { mais adequados para } \\
\text { cada caso }\end{array}$ & $\begin{array}{l}\text { Bititci et al. (2007), Corsaro et } \\
\text { al. (2012) }\end{array}$ & & & & & & & & \\
\hline $\begin{array}{l}\text { Definir objetivos e metas } \\
\text { a serem alcançados }\end{array}$ & $\begin{array}{l}\text { Bititci et al. (2007), Corsaro et } \\
\text { al. (2012) }\end{array}$ & & & & & & & & \\
\hline
\end{tabular}




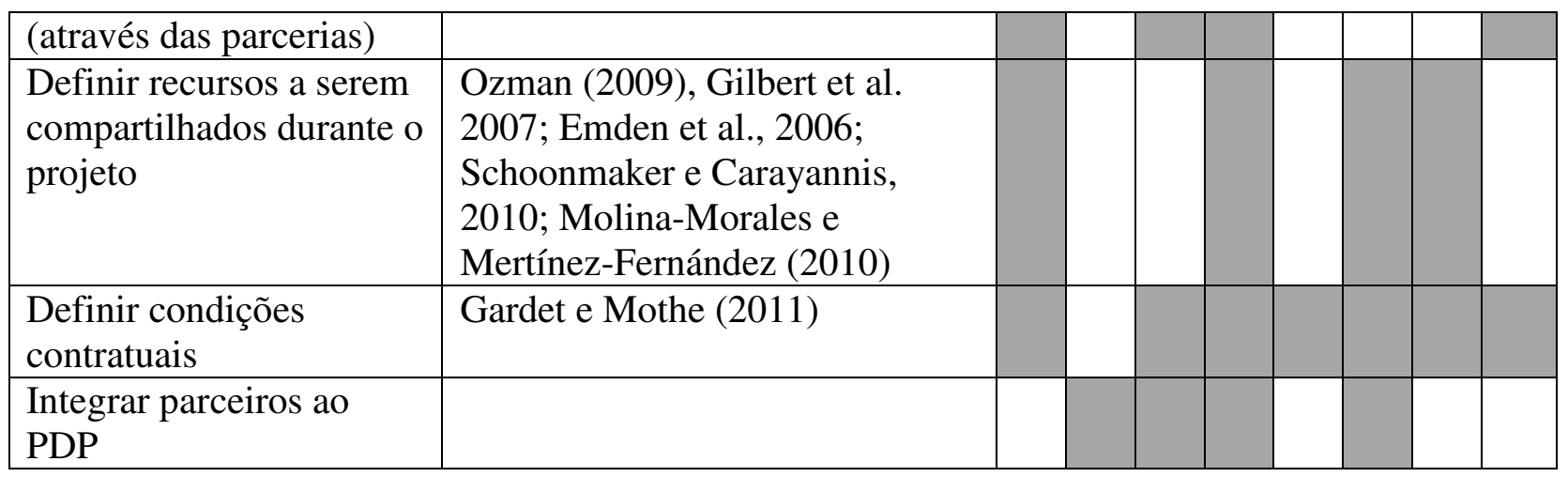

De acordo com os profissionais entrevistados nas unidades empresariais, todos esses processos são definidos, executados e controlados pela empresa focal. Embora haja negociações com os parceiros envolvendo cláusulas contratuais e metas a serem alcançadas, as relações entre as partes permanecem sendo do tipo cliente contratando fornecedor. O processo "integrar parceiros ao PDP” é o único no qual o parceiro tem uma participação mais efetiva.

Como pode ser observado não são mencionadas as atividades relacionadas à fase em que os parceiros estão trabalhando no projeto. Não há atividades específicas para reger os relacionamentos entre as partes após a integração dos parceiros nos projetos.

O Quadro 11 mostra os elementos identificados na literatura que auxiliam a compor o Modelo de Processos de Negócios de uma rede auto-organizada.

Quadro 11: elementos need for change para o Modelo de Processos de Negócios.

\begin{tabular}{|l|l|l|}
\hline $\begin{array}{l}\text { Elementos para o Modelo } \\
\text { de Processos de Negócios }\end{array}$ & Saídas & Literatura \\
\hline $\begin{array}{l}\text { Integrar os parceiros à } \\
\text { equipe de projetos }\end{array}$ & $\begin{array}{l}\text { Alinhamento das expectativas } \\
\text { Gerenciamento da mobilidade do } \\
\text { conhecimento } \\
\text { Geração de novos conhecimentos }\end{array}$ & $\begin{array}{l}\text { Wu et al. (2006), Chung et al. } \\
\text { (2009), Andersson et al. } \\
\text { (2008), Dhanaraj e Parkhe } \\
\text { (2006) }\end{array}$ \\
\hline $\begin{array}{l}\text { Definir claramente a } \\
\text { política de governança }\end{array}$ & $\begin{array}{l}\text { Definição clara sobre regras, ônus } \\
\text { e bônus, propriedade intelectual }\end{array}$ & $\begin{array}{l}\text { Soriano (2009); Bititci et } \\
\text { al.(2007); Ulbrich et al. } \\
\text { (2011); Camarinha-Matos et } \\
\text { al. (2009); Pathak et al. } \\
\text { (2007), Surana et al. (2005) }\end{array}$ \\
\hline $\begin{array}{l}\text { Definir colaborativamente } \\
\text { objetivos e metas a serem } \\
\text { alcançados }\end{array}$ & $\begin{array}{l}\text { Definição realista de objetivos, } \\
\text { metas e papéis } \\
\text { Descentralização do controle } \\
\text { Aumento do comprometimento } \\
\text { et al. (2012), Ojasalo (2008), } \\
\text { Lowe et al. (2012), } \\
\text { Vasileiadou e Safarzynska, } \\
\text { 2010; Pathak et al. (2007), } \\
\text { Marion e Uhl-Bien (2001) }\end{array}$ \\
\hline $\begin{array}{l}\text { Rever as soluções alternati- } \\
\text { vas e a arquitetura do } \\
\text { produto }\end{array}$ & $\begin{array}{l}\text { Geração de novos conhecimentos } \\
\text { - aprendizagem } \\
\text { Promoção de interdependência } \\
\text { Surgimento de novas ideias }\end{array}$ & $\begin{array}{l}\text { Kash e Rycroft (2002), } \\
\text { Ozman (2009), Tharumarajah } \\
\text { (2003), Vasileiadou e } \\
\text { Safarzynska (2010), } \\
\text { Schneider e Somers (2006) }\end{array}$ \\
\hline
\end{tabular}




\begin{tabular}{|l|l|l|}
\hline $\begin{array}{l}\text { Verificar e avaliar o } \\
\text { cumprimento das metas } \\
\text { especificadas }\end{array}$ & $\begin{array}{l}\text { Aumento do comprometimento } \\
\text { Promoção de movimentos bottom } \\
\text { up }\end{array}$ & $\begin{array}{l}\text { Ojasalo (2008), Choi et al. } \\
\text { (2001) e Surana et al. (2005), }\end{array}$ \\
\hline $\begin{array}{l}\text { Gerenciar a apropriação da } \\
\text { inovação }\end{array}$ & $\begin{array}{l}\text { Registro de marcas e patentes } \\
\text { Documentar as lições aprendidas - } \\
\text { aprendizagem }\end{array}$ & $\begin{array}{l}\text { Dhanaraj e Parkhe (2006), } \\
\text { Cohen e Levinthal (1990), } \\
\text { Nonaka (1994) }\end{array}$ \\
\hline
\end{tabular}

Esses processos têm relação direta com a capacidade de auto-organização. O processo "integrar os parceiros à equipe de projetos" precisa substituir o processo "integrar parceiros ao PDP". No processo atual a integração é parcial, ou seja, os parceiros acessam apenas parte das informações que são relacionadas especificamente às suas atribuições técnicas. O Modelo de Atores e Recursos mostra claramente que os parceiros ficam segregados da equipe de projeto e têm pouco acesso às informações do projeto. A saída desse novo processo resulta no alinhamento das expectativas dos envolvidos, no gerenciamento da mobilidade do conhecimento e na geração de novos conhecimentos por intermédio da intensificação dos relacionamentos.

Um forte incentivo à confiança e ao comprometimento entre os parceiros é o estabelecimento de um processo para "definir claramente a política de governança" que irá reger os relacionamentos. A saída desse processo resulta na definição das regras, dos direitos e obrigações, da propriedade intelectual e regras em geral que possam ser aplicadas na resolução de eventuais situações de disputas ou conflitos.

O processo "definir colaborativamente objetivos e metas a serem alcançados" está diretamente associado com a descentralização do controle, e permite uma definição mais realista de objetivos, metas e papéis. O fato das partes serem co-responsáveis por essas definições também contribui para aumentar o nível de comprometimento entre elas.

Um processo que permite à equipe de projetos rever, acompanhada dos parceiros chaves, as alternativas de soluções e a arquitetura do produto contribui para o surgimento de novas ideias, para a geração de novos conhecimentos (aprendizagem) e para a promoção da interdependência entre os parceiros. Essa interdependência ocorre porque cada parceiro pode contribuir apresentando sugestões técnicas dentro de sua área de competência.

O trabalho realizado em parceria precisa ser aferido, e isso implica "verificar e avaliar o cumprimento das metas especificadas". Esse processo impõe que haja comprometimento com os objetivos e como decorrência acaba promovendo movimentos voluntários do tipo bottom up entre os parceiros. As partes sentir-se-ão motivadas para atuar diante da necessidade de atender as metas definidas por eles mesmos.

Por fim, o resultado do trabalho realizado em parceria precisa ser compartilhado proporcionalmente ao esforço individual de cada parceiro. Nesse sentido, o processo "gerenciar 
a apropriação da inovação" produz o registro das marcas e patentes, e documenta as lições aprendidas.

\subsubsection{Need for Change para o Modelo de Atores e Recursos}

O Modelo de Atores e Recursos (Figura 5) apresenta 40 elementos (entre unidades organizacionais, unidades individuais, papéis e recursos). Entretanto, apenas 04 desses elementos têm relação direta com o estabelecimento de parcerias de negócio. O Quadro 12 mostra esses elementos.

Quadro 12: elementos atuais do Modelo de Atores e Recursos

\begin{tabular}{|c|c|c|c|c|c|c|c|c|c|}
\hline \multirow[t]{2}{*}{ Elementos } & \multirow[t]{2}{*}{ Literatura } & \multicolumn{8}{|c|}{ Empresas } \\
\hline & & 1 & 2 & 3 & 4 & 5 & 6 & 7 & 8 \\
\hline Contratos & $\begin{array}{l}\text { Ojasalo (2008), Gardet e Mothe } \\
\text { (2011) }\end{array}$ & & & & & & & & \\
\hline $\begin{array}{l}\text { Parceiro de desenvolvi- } \\
\text { mento (de inovação) }\end{array}$ & $\begin{array}{l}\text { Freel e Harrison (2006), Sammarra } \\
\text { e Biggiero (2008) e Camarinha- } \\
\text { Matos (2009); Kotilla et al., 2008; } \\
\text { Ollus et al., 2011; Alin et al., 2013; } \\
\text { Westergren e Holmström, 2012; } \\
\text { Ollus et al. (2011) e Alin et al. } \\
\text { (2013) }\end{array}$ & & & & & & & & \\
\hline Lista Técnica & & & & & & & & & \\
\hline $\begin{array}{l}\text { Broker (parceiro } \\
\text { especializado em } \\
\text { marketing de mercado) }\end{array}$ & $\begin{array}{l}\text { Mesma literatura que discute a } \\
\text { importância dos parceiros }\end{array}$ & & & & & & & & \\
\hline
\end{tabular}

Vários elementos considerados importantes para a formação e operação de redes de inovação auto-organizadas não aparecem no quadro acima. Os elementos "contratos" e "parceiro" são mencionados explicitamente pela literatura, e embora o termo broker não apareça, seu significado enquanto parceiro de oportunidades está contemplado. No estudo de caso, o termo contrato tem o significado de garantia legal para controlar o trabalho do contratado, e o termo parceiro tem mais o sentido de fornecedor. A literatura reconhece essa situação ao sugerir que a empresa focal presente em várias redes de inovação, com o propósito de proteger-se, usa uma combinação de garantias contratuais para controlar os demais parceiros de sua rede (GARDET e MOTHE, 2011; LIU e MADHAVAN, 2005; VALK e CHAPPIN, 2011). Nesse contexto, o esforço da empresa focal está na apropriação unilateral do conhecimento e dos benefícios produzidos pelas inovações, não havendo uma preocupação clara em compartilhar os resultados obtidos a partir do esforço coletivo.

O Quadro 13 mostra os elementos retirados da literatura que podem ajudar a compor o Modelo de Atores e Recursos de uma rede auto-organizada. 
Quadro 13: elementos need for change para o Modelo de Atores e Recursos.

\begin{tabular}{|l|l|l|}
\hline Ator/Ação/Recurso & $\begin{array}{l}\text { Elementos p/ Modelo de } \\
\text { Atores e Recursos }\end{array}$ & Literatura \\
\hline 1. Ator & Gestor de relacionamentos & $\begin{array}{l}\text { Eschenbacher et al. (2011), Fukugawa } \\
\text { (2006), Camarinha-Matos et al.(2009), } \\
\text { Manson (2001) }\end{array}$ \\
\hline 2. Ator & $\begin{array}{l}\text { Gestor da mobilidade do } \\
\text { conhecimento }\end{array}$ & Dhanaraj e Parkhe (2006) \\
\hline 3. Ator & $\begin{array}{l}\text { Gestor da apropriação da } \\
\text { inovação }\end{array}$ & Dhanaraj e Parkhe (2006) \\
\hline 4. Ator & $\begin{array}{l}\text { Selecionador de empresas } \\
\text { parceiras }\end{array}$ & $\begin{array}{l}\text { Eschenbacher et al. (2011), Ojasalo } \\
\text { (2008), Bititci et al. (2007) e Corsaro et } \\
\text { al. (2012) }\end{array}$ \\
\hline $\begin{array}{l}\text { 5. Alteração na posição } \\
\text { de um ator }\end{array}$ & $\begin{array}{l}\text { Modificação da ligação do } \\
\text { parceiro com a equipe do } \\
\text { projeto }\end{array}$ & $\begin{array}{l}\text { (Tongming (2010), Lichtenstein (2000) } \\
\text { 6. Recurso }\end{array}$ \\
Benefícios (relação) & $\begin{array}{l}\text { Dhanaraj e Parkhe (2006), Ojasalo } \\
\text { (2008), Bititci et al. (2007) e Corsaro et } \\
\text { al. (2012) }\end{array}$ \\
\hline 7. Recurso & Plataforma de colaboração & $\begin{array}{l}\text { Andersson et al. (2008),Wu et al. } \\
\text { (2006), Chung et al. (2009) }\end{array}$ \\
\hline 8. Recurso & $\begin{array}{l}\text { Capacidades centrais e } \\
\text { ativos complementares }\end{array}$ & $\begin{array}{l}\text { Kash e Rycroft (2002), Bititci et al. } \\
\text { (2007) e Corsaro et al. (2012) }\end{array}$ \\
\hline 9. Recurso & Metas estabelecidas & $\begin{array}{l}\text { Bititci et al. (2007) e Corsaro et al. } \\
\text { (2012) }\end{array}$ \\
\hline
\end{tabular}

Tanto a literatura que trata do recorte analítico de redes quanto a de sistemas complexos atribuem papel de destaque para os relacionamentos enquanto indutor para o comportamento auto-organizado (Quadros 4 e 5). Isso justifica a presença de um gestor que possa avaliar, para cada projeto, os tipos e intensidades mais adequados de relacionamentos entre os parceiros.

A aprendizagem é outro elemento de apoio para a auto-organização. Por sua vez, a gestão da mobilidade do conhecimento e a apropriação da inovação constituem fontes de apoio para a aprendizagem. A mobilidade do conhecimento pode ser compreendida como a facilidade com que o conhecimento é compartilhado, adquirido e desenvolvido dentro da rede. A gestão da apropriação da inovação é a habilidade de capturar os benefícios produzidos a partir de uma inovação como know-how, patentes e marcas registradas. Dois papéis podem contribuir nesse sentido, o de gestor da mobilidade do conhecimento (elo entre as fontes dispersas de conhecimento e de facilitador de acesso a essas fontes) e o de gestor da apropriação da inovação (responsável por identificar todos os benefícios, os parceiros responsáveis, e a parcela desses benefícios a que cada um tem direito).

De acordo com Eschenbacher et al. (2011) é importante avaliar o tipo e a intensidade dos relacionamentos entre os parceiros, bem como o compartilhamento de valores e de elementos 
culturais. Essa tarefa pode ser atribuída a um ou mais atores especialmente designados para atuar como selecionadores de empresas parceiras.

Tongming (2010) sugere que as redes de inovação comportam-se como sistemas complexos como decorrência das interações (relacionamentos formais e informais) entre os elos colaborativos da rede. Essas interações geram uma dependência mútua entre os parceiros (Lichtenstein, 2000) e formam o conjunto de relacionamentos que, de acordo com a literatura de redes e de sistemas complexos, constituem a chave para a auto-organização. No atual Modelo de Atores e Recursos o parceiro é um elemento externo à equipe de projeto, e dada a importância dos relacionamentos para a auto-organização sugere-se que esse mesmo parceiro seja integrado à equipe de projeto. Essa mudança de posição facilitará as trocas de informações entre as partes e fomentará novas ideias e procedimentos.

Outro elemento importante para a auto-organização é a definição clara do conjunto dos benefícios que será gerado pela colaboração entre os agentes numa rede de inovação. Por esse motivo torna-se importante que haja no Modelo de Atores e Recursos um elemento denominado benefícios, e que seja especificado quais atores serão responsáveis e quais terão acesso a ele.

A plataforma para colaboração entre os parceiros é mais um recurso sugerido a partir da literatura. Como as empresas constituem entidades formalmente independentes e na maioria dos casos dispersas geograficamente, há a necessidade de se utilizar um recurso que facilite o registro e a troca de informações de maneira remota. Para Dhanaraj e Parkhe (2006), Kash e Rycroft (2002), Tharumarajah (2003), Rycroft e Kash (2004) é imprescindível que haja uma troca de conhecimentos entre os parceiros. Ao longo do tempo essa plataforma pode acumular informações e apoiar a aprendizagem dos envolvidos, sendo que isso se justifica porque a aprendizagem é uma das molas para a auto-organização.

Outro recurso mencionado na literatura e que precisa estar presente no Modelo de Atores e Recursos é a capacidade central e os ativos complementares. Esse recurso, que é formado por um conjunto de elementos, constitui fonte de análise para a seleção de parceiros que serão integrados à equipe de projetos, e também precisam aparecer no Modelo de Atores e Recursos.

As metas e objetivos estipulados também constituem um recurso muito importante para a auto-organização das redes. Eles permitem aferir o desempenho geral da rede e individual de cada parceiro, impulsionando comportamentos isolados e coletivos em prol dos resultados esperados. 


\subsubsection{Need for Change para o Modelo de Conceitos}

No Modelo de Conceitos (Figura 12) aparecem 25 elementos conceituais. Nove desses elementos têm relação direta com o estabelecimento de parcerias de negócio. O Quadro 14 mostra esses elementos.

Quadro 14: elementos atuais do Modelo de Conceitos

\begin{tabular}{|c|c|c|c|c|c|c|c|c|c|}
\hline \multirow[t]{2}{*}{ Elementos } & \multirow[t]{2}{*}{ Literatura } & \multicolumn{8}{|c|}{ Empresas } \\
\hline & & 1 & 2 & 3 & 4 & 5 & 6 & 7 & 8 \\
\hline Inovação & $\begin{array}{l}\text { Christopherson e Kitson (2008); } \\
\text { OECD (2010), Garcia e } \\
\text { Calantone (2002), Chen e Tsou } \\
\text { (2007), Patrakosol (2007), } \\
\text { Prajogo e Ahmed (2006) }\end{array}$ & & & & & & & & \\
\hline $\begin{array}{l}\text { Internalização de novos } \\
\text { conhecimentos }\end{array}$ & $\begin{array}{l}\text { Fukugawa (2006), Cowan et } \\
\text { al.(2005), Rycroft e Kash } \\
\text { (2004), Tharumarajah (2003), } \\
\text { Nonaka (1994), Vasileiadou e } \\
\text { Safarzynska (2010) }\end{array}$ & & & & & & & & \\
\hline $\begin{array}{l}\text { Parcerias (na literatura: } \\
\text { redes de parceiros) }\end{array}$ & $\begin{array}{l}\text { Freel e Harrison (2006), } \\
\text { Sammarra e Biggiero (2008) e } \\
\text { Camarinha-Matos (2009), } \\
\text { Eschenbacher et al. (2011), Kash } \\
\text { e Rycroft (2002) }\end{array}$ & & & & & & & & \\
\hline Histórico de colaboração & $\begin{array}{l}\text { Granoveter (1973), Burt (1992), } \\
\text { Cowana e Jonard (2004), } \\
\text { Capaldo (2006), Fritsch e } \\
\text { Kauffeld-Monz (2010), Büchel } \\
\text { et. al (2013) }\end{array}$ & & & & & & & & \\
\hline Confiança & $\begin{array}{l}\text { Ritter e Gemünden (2003), } \\
\text { Ojasalo (2008), Kotilla et } \\
\text { al.(2008), Ollus et al.(2011); } \\
\text { Alin et al.(2013), Westergren e } \\
\text { Holmström (2012), Gardet e } \\
\text { Mothe (2011) }\end{array}$ & & & & & & & & \\
\hline $\begin{array}{l}\text { Certificação (parceiros } \\
\text { certificados) }\end{array}$ & $\begin{array}{l}\text { Bititci et al. (2007) e Corsaro et } \\
\text { al. (2012) }\end{array}$ & & & & & & & & \\
\hline Vínculo contratual & Gardet e Mothe (2011) & & & & & & & & \\
\hline Propriedade intelectual & Dhanaraj e Parkhe (2006) & & & & & & & & \\
\hline Lições aprendidas & $\begin{array}{l}\text { Cohen e Levinthal (1990), } \\
\text { Hoecht e Trott (2006), Halikkas } \\
\text { et al.(2009), Knell e Srholec } \\
(2008)\end{array}$ & & & & & & & & \\
\hline
\end{tabular}

Tanto na literatura quanto no estudo de caso, o conceito de inovação (elemento 1 do Quadro 14) apresenta o mesmo significado: viabilização comercial bem sucedida de novas 
idéias. Com relação aos elementos 2, 3, 5 e 7 do Quadro 14, o significado mostra-se divergente. $\mathrm{Na}$ literatura, a internalização de novos conhecimentos (elemento 2) deve beneficiar os envolvidos, mas no estudo de caso apresentado as empresas focais buscam apropriar-se do conhecimento dos parceiros, ao mesmo tempo em que se esforçam para se proteger da evasão dos seus conhecimentos por intermédio de contratos. O elemento parcerias (elemento 3) no estudo de caso se contrapõe à literatura, pois as empresas focais tratam os parceiros como fornecedores e, nesse sentido, procuram controlá-los. E o termo confiança (elemento 5), que na literatura está relacionado a competência e comprometimento comprovados, no estudo de caso relaciona-se às garantias proporcionadas pela força dos contratos. Para Gardet e Mothe (2011), a confiança vai além do uso de garantias contratuais (elemento 7) para evitar comportamento oportunista, fortalecendo-se através do compartilhamento das recompensas, e da resolução conjunta de conflitos.

O histórico de colaboração (elemento 4) é um elemento importante para a formação e operação da rede de inovação auto-organizada, pois ele contribui para reforçar a confiança entre os parceiros. Da mesma forma, a propriedade intelectual e as lições aprendidas (elementos 8 e 9) também têm relação com o aumento da confiança e do comprometimento.

A análise do Quadro 14 permite sugerir que apenas alguns conceitos têm relação direta com a propriedade de auto-organização, ou seja, há lacunas que precisam ser preenchidas. Os Quadros 4 e 5 sugerem novos elementos retirados da literatura para apoiar a propriedade de auto-organização de uma rede de inovação. O Quadro 15 relaciona vários elementos que podem ser utilizados ajudar a explicar os quadros anteriores.

Quadro 15: elementos need for change para o Modelo de Conceitos.

\begin{tabular}{|l|}
\hline Elementos p/ Modelo de Conceitos \\
\hline Relacionamentos \\
\hline Comprometimento \\
\hline Participação voluntária \\
\hline Alinhamento \\
\hline Compartilhamento (práticas e conhecimentos) \\
\hline Controle distribuído \\
\hline Movimento bottom-up \\
\hline Interdependência (entre agentes) \\
\hline Aprendizagem \\
\hline Política de governança \\
\hline Colaboração (plataforma) \\
\hline Recompensas \\
\hline Capacidades centrais \\
\hline Ativos complementares \\
\hline
\end{tabular}

Origem: Todos os modelos 


\subsection{CONTRIBUIÇÕES DO NEED FOR CHANGE}

Segundo Bubenko et al. (2001), o need for change corresponde à etapa intermediária entre o mapeamento da situação atual (as-is) e o planejamento da situação futura (to-be). Essa etapa permite a compreensão dos motivos pelos quais as mudanças são necessárias e das alternativas que podem ser adotadas.

De maneira geral, o questionário aplicado em campo revela várias barreiras para a autoorganização. Essas barreiras aparecem na forma de lacunas presentes nos modelos "as-is" desenvolvidos no trabalho de campo (seção 3.1.2), modelos que foram validados pelos entrevistados. A discussão feita compila essas lacunas e acrescenta outras: os elementos com potencial para apoiar a auto-organização, mas que são empregados em campo com sentido divergente da literatura.

As seções anteriores identificam, para cada modelo "as-is" desenvolvido no estudo de caso, os elementos que apresentam potencial para contribuir com o fenômeno da autoorganização. Pode-se observar que apesar desses elementos estarem presentes nas unidades empresariais e na literatura, vários deles são empregados com sentido divergente. Poucos desses elementos presentes nos modelos têm relação direta com a propriedade de auto-organização. Logo, a primeira contribuição das seções anteriores dedicadas ao need for change foi revelar que apesar de haver elementos relacionados com a auto-organização nas unidades empresariais, eles são insuficientes e, em alguns casos, empregados com sentido divergente da literatura.

A segunda contribuição das seções que abordam o "need for change" é a apresentação, a partir dos construtos discutidos na revisão da literatura, dos elementos que podem preencher as lacunas presentes nos modelos "as-is" e, dessa forma, contribuir para a propriedade da autoorganização. Para cada modelo são apontados elementos que podem ajudar a compor uma nova versão desses modelos que se caracterize por fomentar o fenômeno da auto-organização.

A pesquisa verificou que nas parcerias estabelecidas na área de utilidades domésticas, visando a inovação em produtos, há a presença de uma empresa focal centralizadora. Essa empresa focal tende a proteger-se através de uma combinação de garantias contratuais diretas e indiretas a fim de estabelecer controle sobre seus parceiros. A questão sugerida pela literatura é que a empresa focal sozinha não tem todas as respostas para os desafios impostos pelo processo de inovação. Inovar requer a produção de novos conhecimentos (aprendizagem), o que, por sua vez, exige um nível de comprometimento e de trocas que ultrapassa as obrigações contratuais impostas por uma empresa centralizadora. 
Diante desse cenário, este capítulo apresenta um estudo da propriedade de autoorganização nas relações de colaboração entre empresas envolvidas nos processos de inovação de produtos na área de utilidades domésticas no Brasil.

Segundo a literatura, as redes de inovação podem apresentar comportamento complexo como decorrência dos diferentes níveis e intensidades de relacionamento dos seus elos colaborativos, e destes com o ambiente externo. A literatura de sistemas complexos sustenta que a auto-organização é uma importante propriedade desse tipo de sistema. Ela caracteriza-se pela presença de movimentos espontâneos do tipo bottom up estabelecidos pelos próprios agentes internos, o que acaba gerando novos comportamentos coletivos sem a necessidade de imposições externas. Essa capacidade de mobilização coletiva tem relação direta com a capacidade de adaptação desses sistemas.

As mesmas questões discutidas sob o viés teórico foram abordadas no trabalho de campo. Foi detectado que as unidades empresariais estudadas apresentam características típicas de sistemas complexos como mudança constante, comportamento não proporcional, evolução não linear da topologia, e irredutibilidade. A pesquisa não detectou movimentos autoorganizados nas unidades estudadas, porque não foram observadas as condições necessárias para o surgimento de movimentos auto-organizados. Observou-se que os relacionamentos são fracos e como conseqüência não são capazes de produzir trocas e gerar novos conhecimentos. Também se verificou a falta de incentivo para as iniciativas individuais, assim como para um relacionamento pautado pela interdependência entre os parceiros. Outro ponto de destaque foi a centralização do controle pela empresa focal, atuando de maneira direta na condução dos projetos. A descentralização do controle não ocorre porque a empresa focal usa sua posição na rede para controlar os parceiros. Esses dados ajudam a compreender o motivo de não haver auto-organização nas unidades empresariais e, como não foram identificados movimentos autoorganizados, também não foi possível identificar os possíveis benefícios.

Ao explorar as questões de pesquisa por intermédio do estudo de caso, revelaram-se três situações: as relações entre empresas representadas pelas unidades investigadas constituem sistemas complexos; os sistemas estão sendo gerenciados através dos métodos tradicionais de gestão; os sistemas não apresentam comportamento auto-organizado. Como conseqüência, as unidades empresariais não se beneficiam dos possíveis efeitos provocados pela autoorganização.

Os quadros 7 (elementos need for change para o modelo de objetivos), 9 (elementos need for change para o modelo de regras de negócios), 11 (elementos need for change para o modelo de processos de negócios), 13 (elementos need for change para o modelo de atores e recursos) e 
15 (elementos need for change para o modelo de conceitos) apresentam, de acordo com a metodologia EKD, as necessidades de mudança para as unidades abordadas no estudo de caso (seção 3.3). As necessidades de mudança sugeridas para o modelo de objetivos (quadro 7) guiam as necessidades de mudança para os demais modelos (quadros 7, 9, 13 e 15). Logo, há uma relação de apoio entre os elementos sugeridos em cada quadro, e isso oferece as principais diretrizes para apoiar a propriedade de auto-organização nesses agrupamentos de empresas. Temos:

(a) O objetivo "usar controle distribuído" está apoiado na regra "compartilhar o planejamento do projeto e a resolução de conflitos"; nos processos "integrar os parceiros à equipe de projetos", e "definir colaborativamente os objetivos e metas a serem alcançados"; e nos papéis de "gestor dos relacionamentos", "gestor da mobilidade do conhecimento", e "gestor da apropriação da inovação".

(b) O objetivo "direcionar foco para os relacionamentos" está apoiado na regra "avaliar o tipo e a intensidade de cada relacionamento"; no processo "definir claramente a política de governança"; no papel de "selecionador de empresas parceiras" e na alteração da ligação dos parceiros (passar do acesso restrito a alguns recursos para integrar a equipe de projetos).

(c) O objetivo "incentivar o comprometimento entre as partes" está apoiado nas regras "trabalhar com uma política de governança clara e distribuir os benefícios de forma justa"; nos processos "definir colaborativamente objetivos e metas a serem alcançados", "verificar e avaliar o cumprimento das metas especificadas", e "gerenciar a apropriação da inovação"; nos papéis de "gestor dos relacionamentos" e "gestor da apropriação da inovação", e nos recursos "benefícios (lista)" e "metas estabelecidas (lista)".

(d) O objetivo "apoiar a interdependência entre os agentes" está apoiado na regra "selecionar empresas parceiras com capacidades centrais e ativos que se complementem"; no processo "integrar os parceiros à equipe de projetos"; e nos seguintes recursos: "capacidades centrais", "ativos complementares", e "plataforma de colaboração".

(e) O objetivo "motivar a participação voluntária" está apoiado nas regras "manter uma comunicação aberta e compartilhar o conhecimento individual"; no processo "rever as soluções alternativas e a arquitetura do produto"; no papel de "gestor da mobilidade do conhecimento", e no recurso "plataforma de colaboração".

(f) O objetivo "apoiar movimentos bottom up" está apoiado na regra que define que "o sistema de recompensas precisa atrelar os dividendos ao sucesso do projeto"; nos processos "rever soluções alternativas e a arquitetura do produto", e "verificar e avaliar o 
cumprimento das metas"; e nos recursos "plataforma de colaboração", "metas estabelecidas (lista)", e "benefícios (lista)".

(g) O objetivo "promover o alinhamento dos parceiros" está apoiado na regra "manter sempre os parceiros atualizados (metas, objetivos, benefícios, tarefas)"; nos processos "integrar parceiros à equipe de projetos”, "definir claramente a política de governança”, e "definir colaborativamente objetivos e metas a serem alcançados"; e no papel de "gestor da mobilidade do conhecimento", e nos recursos "metas" e "benefícios".

(h) O objetivo "incentivar o aprendizado enquanto geração e uso do conhecimento" está apoiado na regra "alimentar o banco de conhecimentos da rede"; nos processos "rever as soluções alternativas e a arquitetura do produto", e "gerenciar a apropriação da inovação"; no papel de "gestor da mobilidade do conhecimento" e no recurso "plataforma de colaboração".

(i) O objetivo "fomentar o compartilhamento de práticas e conhecimentos" está apoiado na regra "usar uma plataforma de colaboração que facilite as trocas"; no processo "integrar os parceiros à equipe de projetos"; no papel de "gestor da mobilidade do conhecimento" e nos recursos "plataforma de colaboração", "metas" e "benefícios". 


\section{4 - MODELO DE REFERÊNCIA PARA A FORMAÇÃO E OPERAÇÃO DE REDES DE INOVAÇÃO AUTO- ORGANIZADAS NA ÁREA DE UTILIZADADES DOMÉSTICAS NO BRASIL}

Uma das propriedades que os sistemas complexos apresentam é a capacidade de autoorganização, ou seja, a capacidade de obter flexibilidade a partir de uma estrutura de relacionamentos interdependentes, moderadamente acoplados, unida através de uma dinâmica colaborativa que visa atender objetivos em comum, necessidades compartilhadas, e pontos de vista compatíveis (Uhl-Bien et al., 2007). De acordo com Marion (1999), Regine e Lewin (2000), e Mccarthy et al. (2000), a propriedade de auto-organização acrescenta aos sistemas complexos a habilidade de se adaptar diante das eventuais mudanças no ambiente.

A pesquisa de campo apresentou os elementos que podem apoiar a manifestação da propriedade de auto-organização nas redes de inovação na área de utilidades domésticas no Brasil. Nesta etapa do trabalho será apresentado, a partir dos dados discutidos no capítulo anterior, um modelo de referência para a formação e operação de redes de inovação autoorganizadas. O modelo de referência está representado segundo as diretrizes da metodologia EKD. Os seis submodelos mantêm uma lógica de conexão entre si, permitindo a compreensão do domínio modelado a partir de várias perspectivas de análise.

Pode-se considerar que o modelo apresentado constitui um modelo de referência porque permite visualizar o estado atual e futuro do domínio modelado (Bubenko et al. 2001), foi desenvolvido a partir do confronto de duas correntes teóricas e situações práticas (Vernadat, 1996), e captou informações (objetivos, regras, processos, atores e recursos) em comum às unidades empresariais do estudo de caso (Matook e Indulska, 2009; Reinhartz-Berger et al. 2010).

\subsection{O MODELO DE REFERÊNCIA}

A partir dos modelos ("as-is") e das necessidades de mudança apresentados no capítulo 3 será desenvolvido o modelo de referência para a formação e operação de redes de inovação 
auto-organizadas na área de utilidades domésticas no Brasil. Nas caixas destacadas em cinza em cada modelo apresentado estão os elementos sugeridos pela pequisa como relevantes para apoiar a auto-organizaçao.

\subsubsection{Modelo de Objetivos}

O modelo de objetivos apresentado para o estado "to-be" consiste do modelo "as-is" acrescentado dos elementos identificados em campo para esse modelo, são eles: usar controle descentralizado e indireto, direcionar foco para os relacionamentos, incentivar o comprometimento entre as partes, motivar a participação voluntária, incentivar o aprendizado enquanto geração e uso do conhecimento, apoiar a interdependência, apoiar movimentos bottom up, promover o alinhamento dos parceiros, fomentar o compartilhamento de práticas.

A adequação do modelo "to-be" consistiu na inclusão de novos elementos, nos demais modelos outras modificações foram realizadas. $\mathrm{O}$ principal objetivo estabelecido pelas empresas focais que centralizam as unidades estudadas é a ampliação da liderança no segmento de eletrodomésticos (Objetivo 1). Seis objetivos secundários apóiam o Objetivo 1: melhorar a capacidade de inovação (Objetivo 1.1), entregar benefícios para consumidores, acionistas e comunidade (Objetivo 1.2), diminuir o impacto ambiental do negócio (Objetivo 1.3), reforçar os laços de parcerias com terceiros (Objetivo 1.4), selecionar profissionais capacitados para integrar o PDP (Objetivo 1.5), e usar um controle descentralizado e indireto, ou seja, distribuído (Objetivo 1.6).

Os objetivos 1.4 e 1.6 apresentam relação direta com o estabelecimento das parcerias. No entanto, apesar do Objetivo 1.4 esboçar uma preocupação com a formação e a operação das parcerias formadas entre a empresa focal e seus parceiros de desenvolvimento, a abordagem adotada é mais do tipo cliente-fornecedor do que colaborativa.

O Objetivo 1.6 estabelece o uso de um controle descentralizado e indireto, em outras palavras, ele propõe a distribuição do controle entre os parceiros. Para ampliar a liderança no segmento de eletrodoméstico (Objetivo 1) é necessário dividir o peso das responsabilidades, pois a empresa focal sozinha não tem como produzir sempre todo o conhecimento e todas as respostas necessárias ao processo de inovação. Essa descentralização do controle é essencial para o fenômeno da auto-organização e requer uma boa gestão dos relacionamentos (Objetivo 1.6.1), pois são eles que conduzem, dentro de uma rede de inovação, o fluxo de ativos tangíveis e intangíveis entre as partes. Não seria possível compartilhar o controle de maneira eficaz diante de um cenário caracterizado por relacionamentos rígidos e/ou problemáticos. De acordo com Gnyawali e Srivastava (2013), a gestão dos relacionamentos pode aumentar o nível de confiança 
entre os parceiros. Os relacionamentos podem ser reforçados mediante o estabelecimento de três objetivos de apoio: incentivar o comprometimento entre as partes (Objetivo 1.6.1.1), motivar a participação voluntária (Objetivo 1.6.1.2) e incentivar o aprendizado enquanto uso e geração do conhecimento (Objetivo 1.6.1.3). A percepção do aumento do nível de comprometimento entre os parceiros solidifica os laços, da mesma forma que uma postura voluntária diante dos desafios e imprevistos. A geração e o uso de conhecimentos trocados e produzidos entre as partes também reforça os relacionamentos. Uma das formas de incentivar esse comprometimento é através do apoio à interdependência entre os agentes da rede (Objetivo 1.6.1.1.1), pois a percepção de que o sucesso coletivo depende individualmente de cada agente promove o alinhamento dos esforços rumo aos objetivos em comum. O objetivo de incentivar a participação voluntária (Objetivo 1.6.1.2) pode ser fomentado apoiando-se movimentos bottom up (Objetivo 1.6.1.2.1), ou seja, aqueles movimentos espontâneos que surgem sem a imposição de uma diretriz central. A participação voluntária também recebe motivação quando ocorre o alinhamento contínuo dos parceiros em relação aos objetivos gerais (Objetivo 1.6.1.2.2). E para incentivar o aprendizado como meio de geração e uso de conhecimento (Objetivo 1.6.1.3) é necessário fomentar o compartilhamento de práticas e conhecimentos entre os agentes da rede (Objetivo 1.6.1.3.1).

A Figura 13 apresenta o Modelo de Objetivos (to-be). 


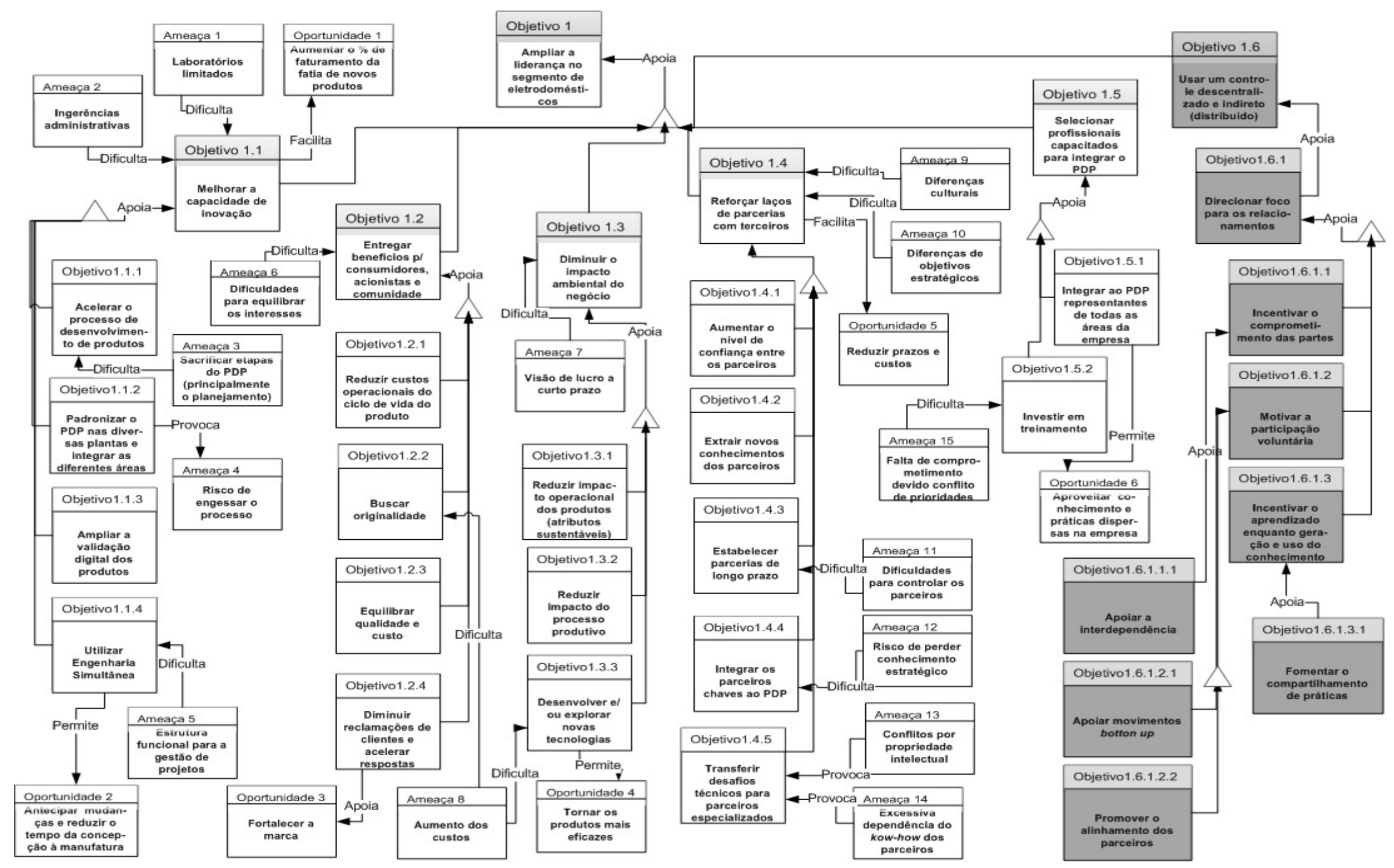

Figura 13: Modelo de Objetivos (to-be) 


\subsubsection{Modelo de Regras de Negócio}

No EKD todas as regras de negócio são vinculadas necessariamente a pelo menos um objetivo no Modelo de Objetivos. Conforme discutido na seção 3.4.2 (Need for Change para o Modelo de Regras de Negócios), no modelo "as-is" há algumas regras definidas para apoiar o estabelecimento das parcerias, no entanto elas estão mais direcionadas para o controle da empresa focal sobre as demais empresas parceiras. Por essa razão, no modelo "to-be" (figura 14 parte A) foi retirada a regra "nenhum fornecedor tem acesso ao projeto completo". Essa regra diminui o acesso dos parceiros às informações, dificultando o objetivo incentivar o aprendizado enquanto geração e uso do conhecimento (Objetivo 1.6.1.3). Essa regra também contraria a mudança sugerida no posicionamento dos parceiros no novo Modelo de Atores e Recursos (figura 15). As regras que definem o estabelecimento de contratos (Regra 26) e de auditorias (Regra 35) foram mantidas por serem necessárias para a formalização comercial das parcerias, e por não representarem oposição à auto-organização.

No modelo "to-be" são apresentadas novas regras de negócio (figura 14 parte B) para apoiar os novos objetivos sugeridos para o Modelo de Objetivos (figura 13). A fim de descentralizar o controle e tornar sua atuação mais indireta (Objetivo 1.6) é necessário aumentar a participação dos parceiros nos principais eventos da rede, logo é necessário compartilhar o planejamento do projeto e a resolução conjunta de conflitos (Regra 38). O direcionamento de foco para os relacionamentos (Objetivo 1.6.1) requer a avaliação do tipo e da intensidade dos relacionamentos (Regra 39) a fim de que sejam estabelecidas estratégias de viabilização para as trocas entre as partes. $\mathrm{O}$ comprometimento (Objetivo 1.6.1.1.), outro elemento importante para a auto-organização, tem relação direta com a capacidade dos parceiros perceberem os benefícios advindos das parcerias. Daí a necessidade de se estabelecer uma política de governança bem clara (Regra 40), na qual estejam contemplados os direitos e obrigações de cada um. A participação voluntária (Objetivo 1.6.1.2) também tem relação direta com a auto-organização, e ela pode ser estimulada a partir da abertura de canais de comunicação (Regra 41). Por fim, outro objetivo importante para a auto-organização é incentivar a aprendizagem enquanto geração e uso do conhecimento (Objetivo 1.6.1.3), o que depende da existência de canais abertos para comunicação (Regra 41) e da existência e abastecimento do banco de conhecimentos da rede (Regra 42). A interdependência entre os agentes (Objetivo 1.6.1.1.1) pode ser reforçada por intermédio da escolha de parceiros com capacidades centrais e ativos que possam ser utilizados de maneira complementar (Regra 43). Os movimentos de base (Objetivo 1.6.1.2.1), também chamados de bottom up, podem ser estimulados criando-se um sistema de recompensas que associe os dividendos a serem distribuídos para os parceiros ao sucesso de cada projeto e à 
importância da contribuição individual (Regra 44). A promoção do alinhamento dos parceiros (Objetivo 1.6.1.2.2) depende essencialmente da obrigatoriedade de fazer a informação circular na rede de forma a mantê-los sempre atualizados (Regra 45). E, por fim, o incentivo ao compartilhamento de práticas (Objetivo 1.6.1.3.1) pode ser facilitado através de uma plataforma de colaboração que funcione como mecanismo para as trocas dentro da rede (Regra 46).

As Figuras 14 partes A e B apresentam o Modelo de Regras de Negócios (to-be). 


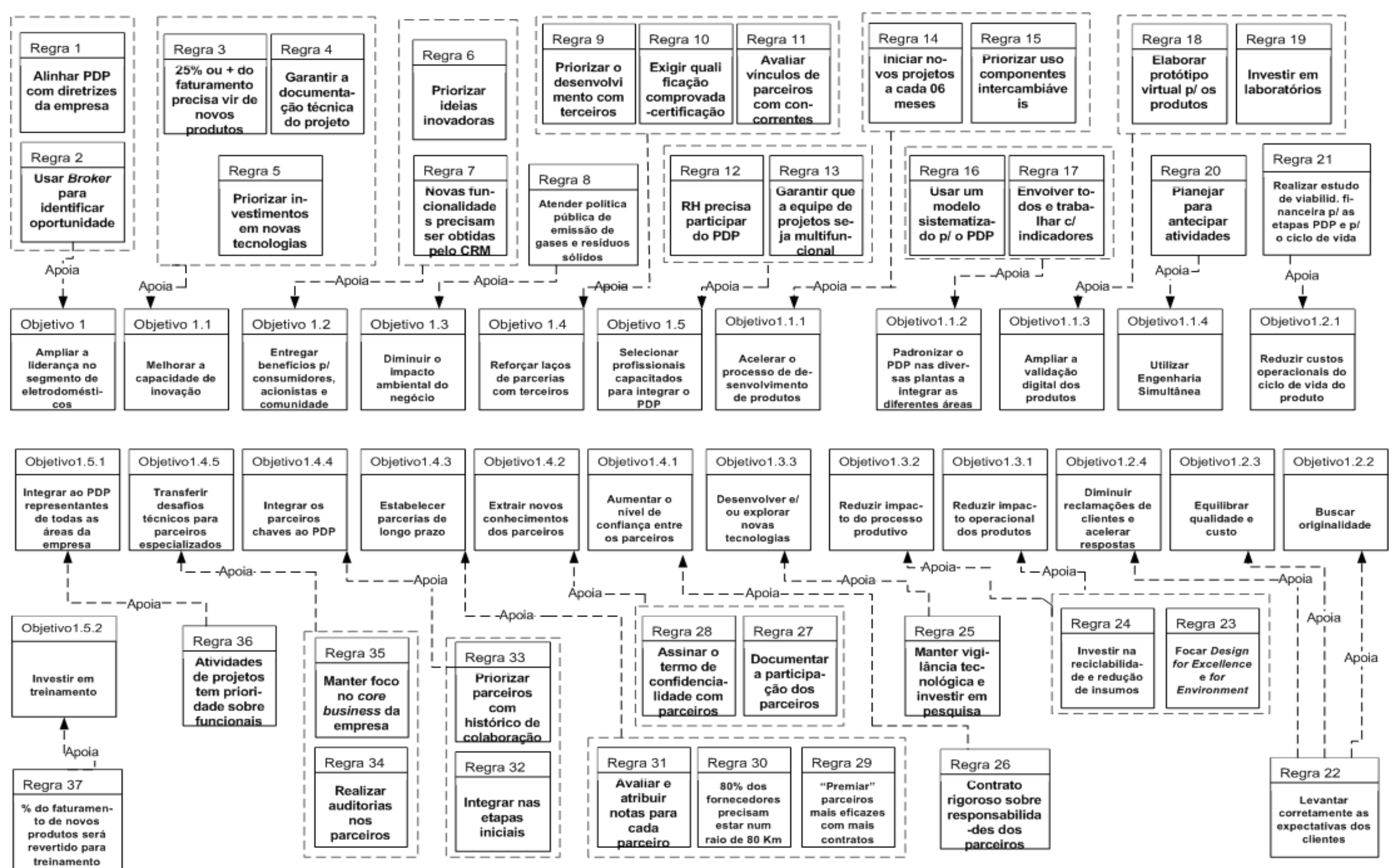

Figura 14: Modelo de regras de Negócios (to-be) - parte A. 


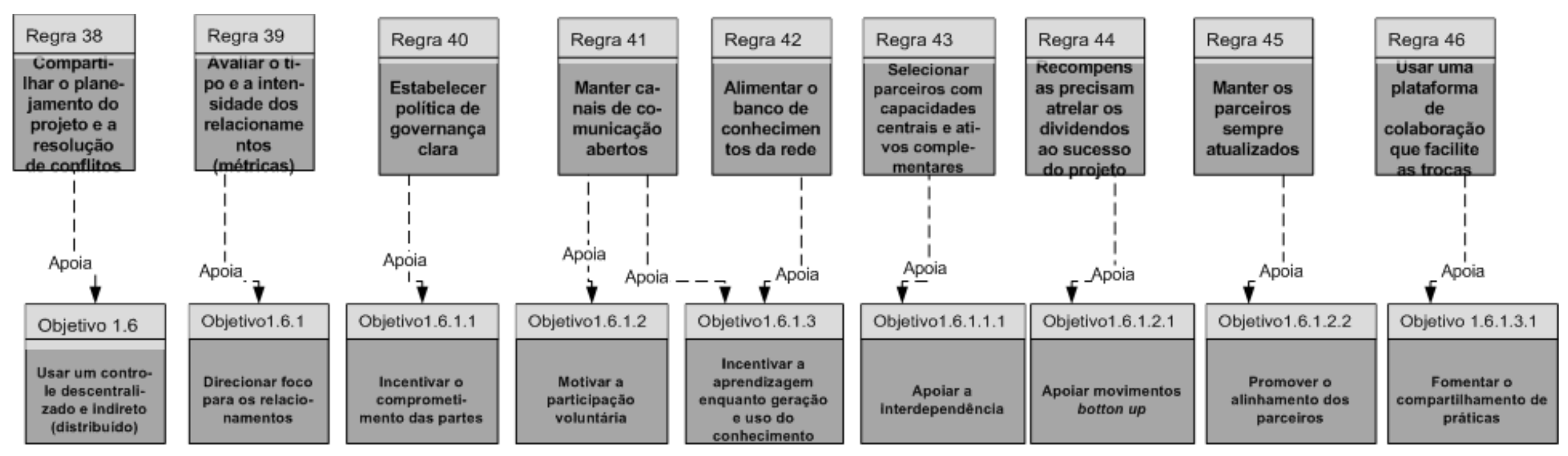

Figura 14: Modelo de regras de Negócios (to-be) - parte B 


\subsubsection{Modelo de Atores e Recursos}

Conforme discussão apresentada na seção 3.4.4 (Need for Change para o Modelo de Atores e Recursos), os elementos presentes nesse modelo "as-is" revelam que a empresa focal presente em cada unidade abordada organiza uma estrutura de forma a concentrar a apropriação unilateral do conhecimento e dos benefícios gerados pelas inovações produzidas em parceria. Para apoiar o objetivo "usar um controle descentralizado e indireto" (Objetivo 1.6) a primeira modificação foi a integração do parceiro de desenvolvimento (Unidade Organizacional 6) à equipe de projeto (Unidade Organizacional 5). Essa integração permite que os parceiros tenham acesso a mais informações do projeto tanto em termos técnicos como em relação aos principais objetivos e metas, o que intensifica a colaboração entre as partes, agregando novas ideias. Essa modificação na integração dos parceiros determinou a retirada, no novo modelo de Regras de Negócio (figura 12 parte A), da regra "nenhum fornecedor tem acesso ao projeto completo".

Novos papéis foram criados nesse modelo. Para atender a Regra 39 (atualizar o tipo e a intensidade dos relacionamentos), o gestor de relacionamentos (Papel 4) fica encarregado de analisar o tipo e a intensidade de conexão adequados diante dos requisitos de cada projeto. $\mathrm{O}$ gestor da mobilidade do conhecimento (Papel 5) trabalha para disponibilizar a plataforma de colaboração (Regra 46), para garantir que os parceiros estejam sempre atualizados (Regra 45), e para alimentar o banco de conhecimentos da rede (Regra 42). O gestor da apropriação da inovação (Papel 6) tem a responsabilidade de gerenciar as discussões sobre a política de governança (Regra 41), assegurando que as regras sobre a apropriação dos dividendos (marcas, patentes, etc.) sejam claras para todos. E, por fim, o papel de selecionador de empresas (Papel 7) ajuda na identificação da complementariedade das capacidades e ativos dos integrantes da rede.

Novos recursos também foram acrescentados ao modelo de atores e recursos. A plataforma de colaboração (Recurso 6) é um elemento essencial para que os parceiros possam integrar-se ao esforço coletivo do projeto. Através dela todos terão acesso aos dados já registrados, bem como será possível fazer a documentação de cada etapa e cada evento relevante do projeto. Esse input coletivo de dados torna o banco de dados mais completo, possibilitando sua utilização em novas oportunidades. A política de governança (Regra 40) precisa gerar uma relação dos benefícios (Recurso 7) para os integrantes da rede de inovação. Da mesma forma, a Regra 43 implica gerar uma descrição das capacidades centrais e dos ativos complementares de cada membro da rede (Recurso 8); tais informações serão utilizadas na formação da rede de inovação. E, por fim, como decorrência da regra 45 (manter os parceiros sempre atualizados) é preciso divulgar continuamente as metas coletivas e individuais estabelecidas pela equipe de projeto (Recurso 9). A Figura 15 apresenta o Modelo de Atores e Recursos (to-be). 


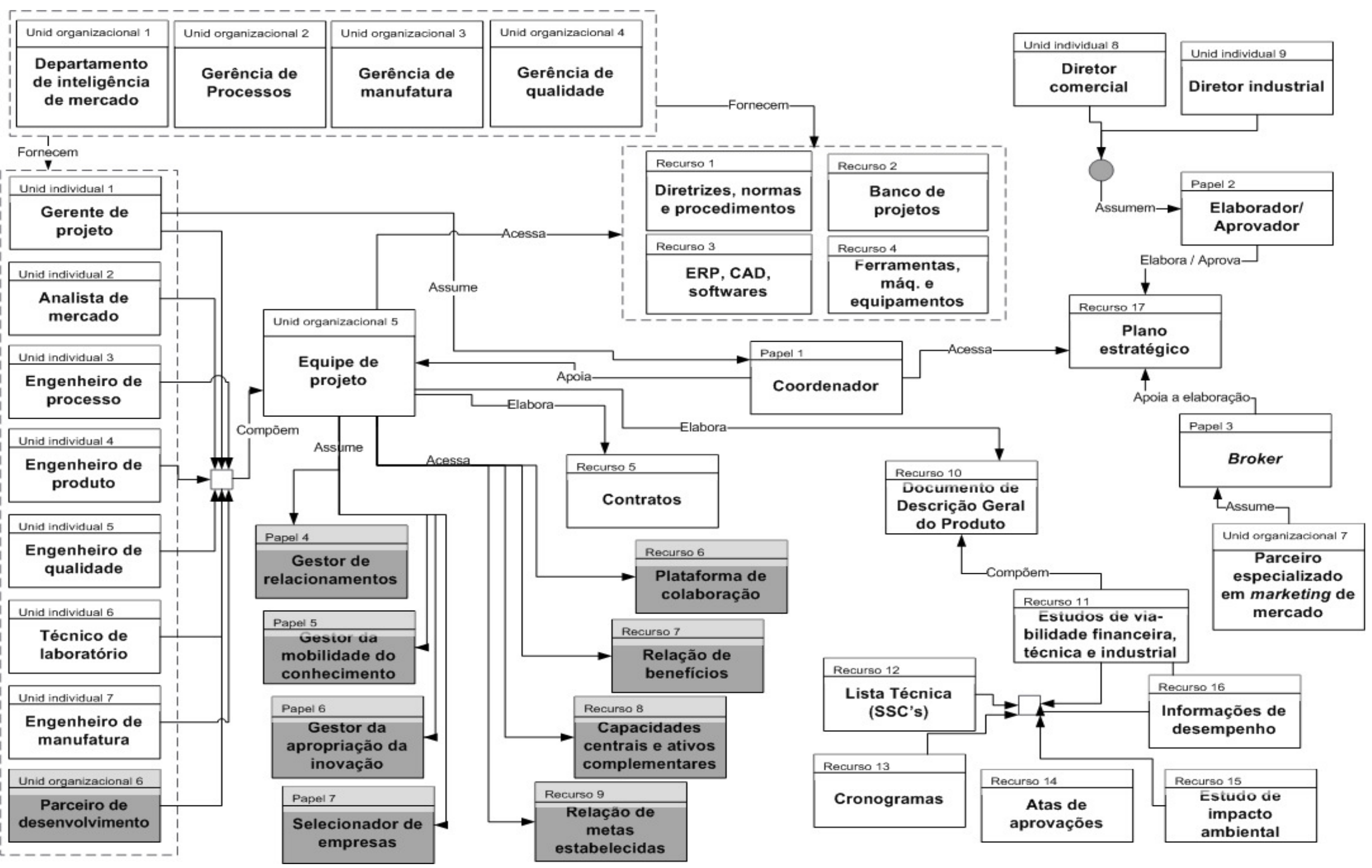

Figura 15: Modelo de Atores e Recursos (to-be) 


\subsubsection{Modelo de Processos de Negócios}

No Modelo de Processos de Negócios "as-is" há dois processos distintos (gerar a concepção do produto e desenvolver fornecedores) que, no modelo "to-be", foram integrados em um processo único com o objetivo de permitir que os parceiros participem das etapas iniciais de concepção do produto: "gerar colaborativamente a concepção do produto (figura 17).

Como os parceiros passam a integrar a equipe de projetos (figura 15 - Modelo de Atores e Recursos), eles podem ajudar a definir colaborativamente os objetivos e metas a serem alcançados no projeto (Processo 1.7) e, a partir dessas metas e métricas de desempenho estipuladas, define-se colaborativamente os recursos a serem compartilhados durante o projeto (Processo 1.8), assim como uma política de governança clara para todos os envolvidos (Processo 1.9). Essa integração dos parceiros à equipe de projetos tem relação com os Modelos de Objetivos e de Regras de Negócios (figuras 13 e 14) por apoiar o uso de um controle descentralizado e indireto (Objetivo 1.6) assim como o compartilhamento do planejamento do projeto e a resolução de conflitos (Regra 38 da figura 14-B). O objetivo "incentivar o comprometimento das partes" (Objetivo 1.6.1.1) e a regra "estabelecer política de governança clara" (Regra 40) também se beneficiam dessa integração e da abordagem colaborativa dos Processos 1.9, 1.12 e 1.13 .

O processo de negociação contratual (Processo 1.10) sofre influência dessa integração dos parceiros (etapas anteriores) porque as partes envolvidas possuem mais informações sobre o projeto. Após a realização de um estudo de viabilidade técnica, financeira e industrial (Processo 1.11) do projeto até aquele ponto, procede-se ao desenvolvimento colaborativo das soluções alternativas (Processo 1.12). É essa lista de soluções para cada função do novo produto que será utilizada para definir colaborativamente a arquitetura do novo produto (Processo 1.13). Após esse processo executa-se um novo estudo de viabilidade técnica, financeira, industial e ambiental (Proceso 1.14).

As Figuras 16 e 17 apresentam as modificações acima comentadas para o Modelo de Processos de Negócios (to-be). 


\begin{tabular}{|c|c|c|c|}
\hline ProcExt 1 & t Ext & Processo 1 & 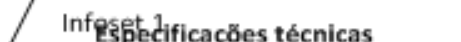 \\
\hline $\begin{array}{c}\text { Planejamento } \\
\text { estratégico mais } \\
\text { portfólio de produtos } \\
\text { para o mercado }\end{array}$ & $\begin{array}{l}\text { Definiçāo do posicionamentc } \\
\text { produto na carteira e no mer }\end{array}$ & $\begin{array}{c}\text { Gerar } \\
\text { colaborativamente a } \\
\text { concepçăo do produto }\end{array}$ & $\begin{array}{c}\text { Arquitetura do produto } \\
\text { Estudo de viabilidade técnica, } \\
\text { financeira, industrial e ambient } \\
\text { Contratos com parceiros }\end{array}$ \\
\hline
\end{tabular}

\begin{tabular}{|c|c|c|c|c|}
\hline Processo 4 & Infoset 3 & Processo 3 & & Processo 2 \\
\hline $\begin{array}{c}\text { Desenvolver e } \\
\text { homologar processo, } \\
\text { e certificar produto }\end{array}$ & $\begin{array}{c}\text { do usuário, arte e faca } \\
\text { embalagem, documenta- } \\
\text { ção do projeto }\end{array}$ & $\begin{array}{l}\text { Desenvolver material } \\
\text { de apoio }\end{array}$ & & $\begin{array}{c}\text { Desenvolver } \\
\text { protótipos (fisico e/ou } \\
\text { virtual) }\end{array}$ \\
\hline
\end{tabular}

Figura 16: Modelo de Processos de Negócios - Macro Processos (to-be) 


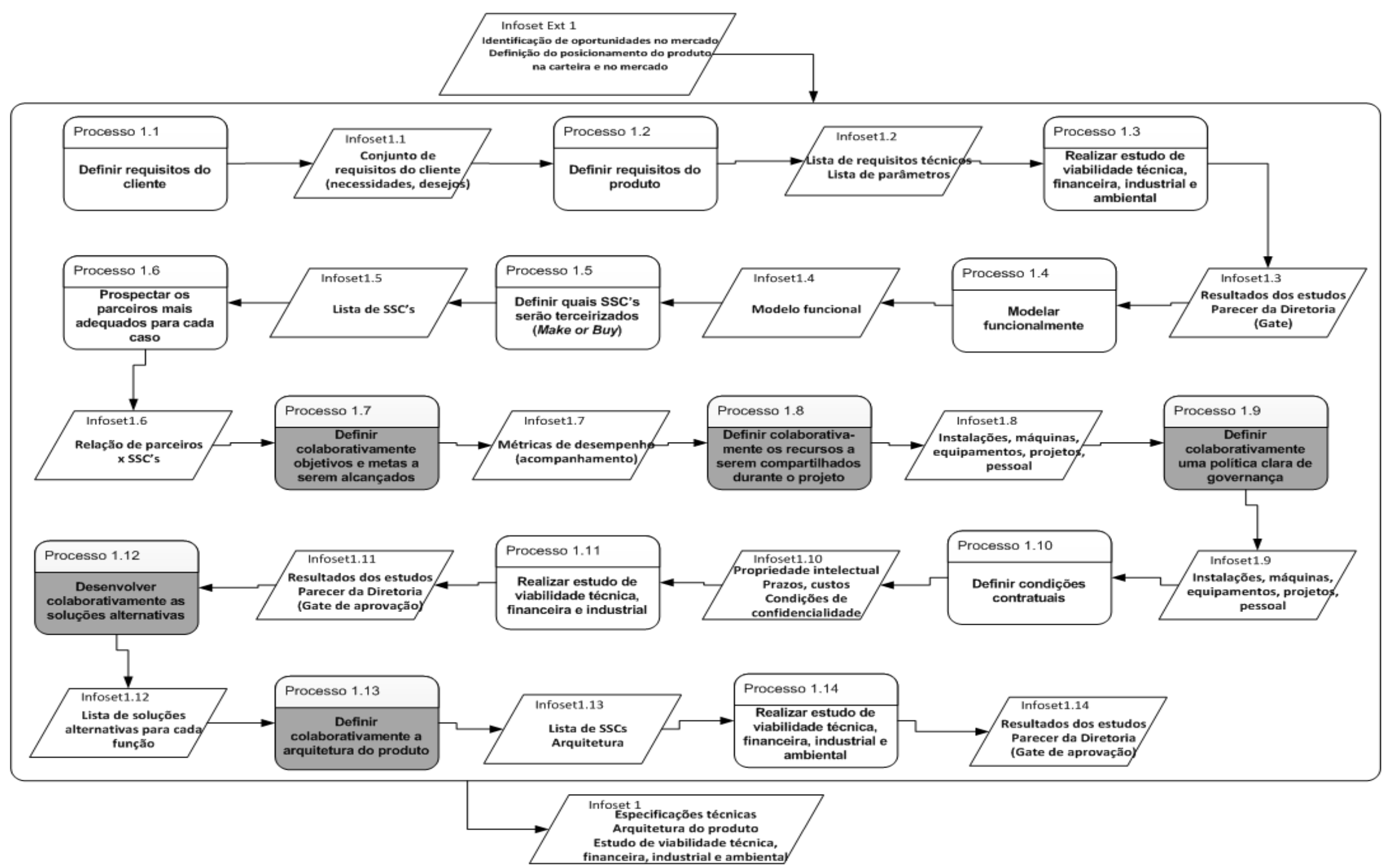

Figura 17: Modelo de Processos de Negócios - Gerar colaborativamente a concepção do produto (to-be) 
Embora não haja alteração direta no processo "Desenvolver protótipos físico e/ou virtuais" (figura 18), como o Modelo de Objetivos "to-be" destaca o relacionamento entre os parceiros (Objetivo 1.6.1 figura 13), o comprometimento (Objetivo 1.6.1.1) e o posicionamento voluntário (Objetivo 1.6.1.2), espera-se que o novo processo "gerar colaborativamente a concepção do produto" (Processo 1 da figura 16) motive uma postura mais pró-ativa dos parceiros e contribua para gerar novas ideias que possam beneficiar o desenvolvimento dos protótipos. A expectativa é que a integração antecipada dos parceiros e o consequente compartilhamento mais efetivo de informações possam beneficiar o desenvolvimento dos modelos virtuais (Processo 3.2), a realização e aferição dos testes de desempenho (Processo 3.3), assim como o desenvolvimento do modelo físico (Processo 3.4) e dos testes de operação e desempenho (Processo 3.5). 


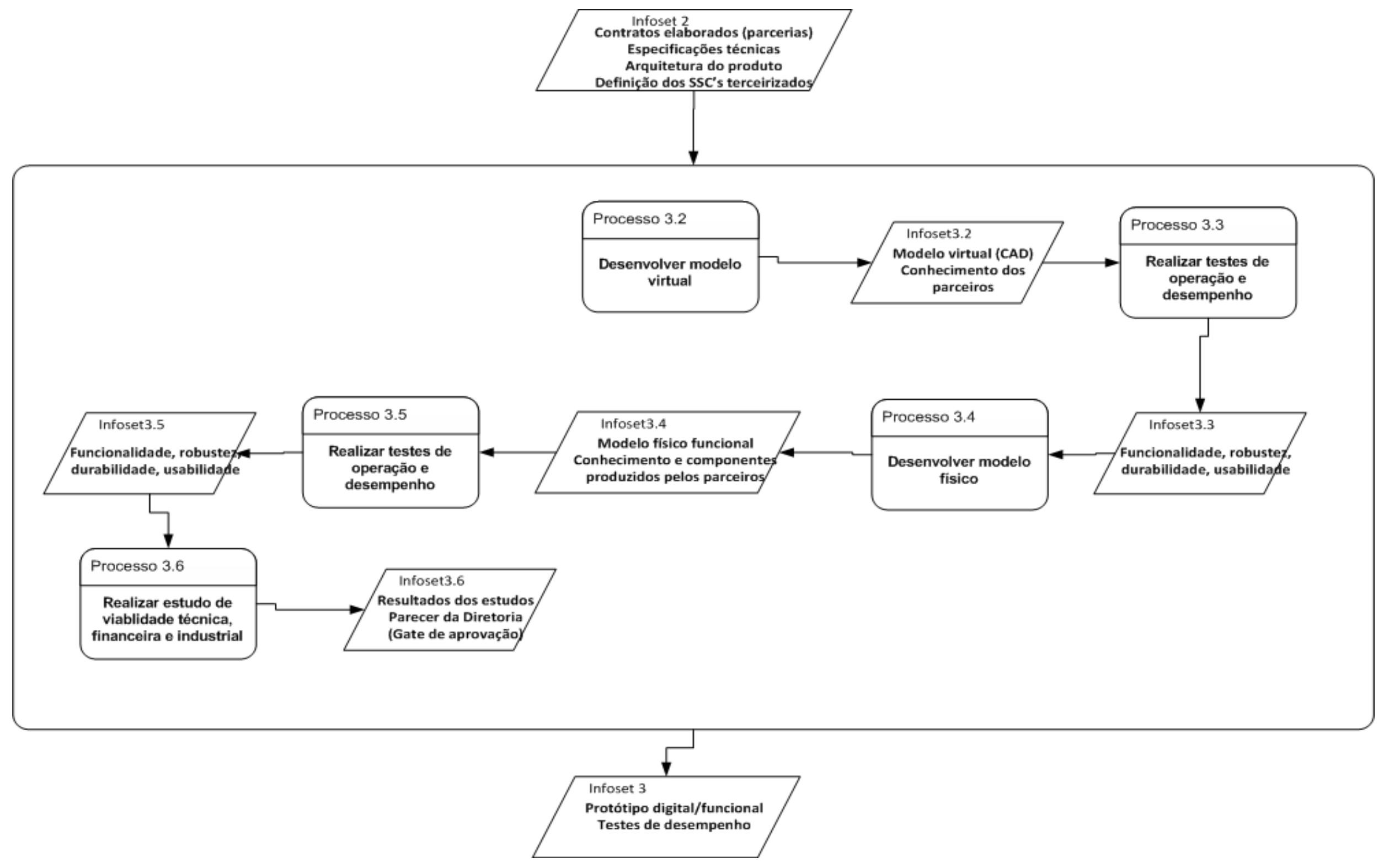

Figura 18: Modelo de Processos de Negócios - Desenvolver protótipos físico e/ou virtuais (to-be) 
Os processos "Desenvolver material de apoio" (figura 19) e "Desenvolver e homologar processo e certificar produto" (figura 20) também mantiveram seu fluxo de atividades. O que mudou é que a proposta de integrar os parceiros na equipe de projetos nas etapas iniciais do projeto de inovação (Processo 1 da figura 17) permite que os parceiros estejam munidos de mais informações quando o projeto chegar nessa etapa. Outra mudança está na possibilidade de que a abertura de canais de comunicação (Regra 41 da figura 14), o uso de uma plataforma de colaboração (Regra 46) e a noção de que os dividendos do projeto estão diretamente associados ao seu sucesso (Regra 44) estimulem uma abordagem mais colaborativa dos agentes durante esses dois processos. 


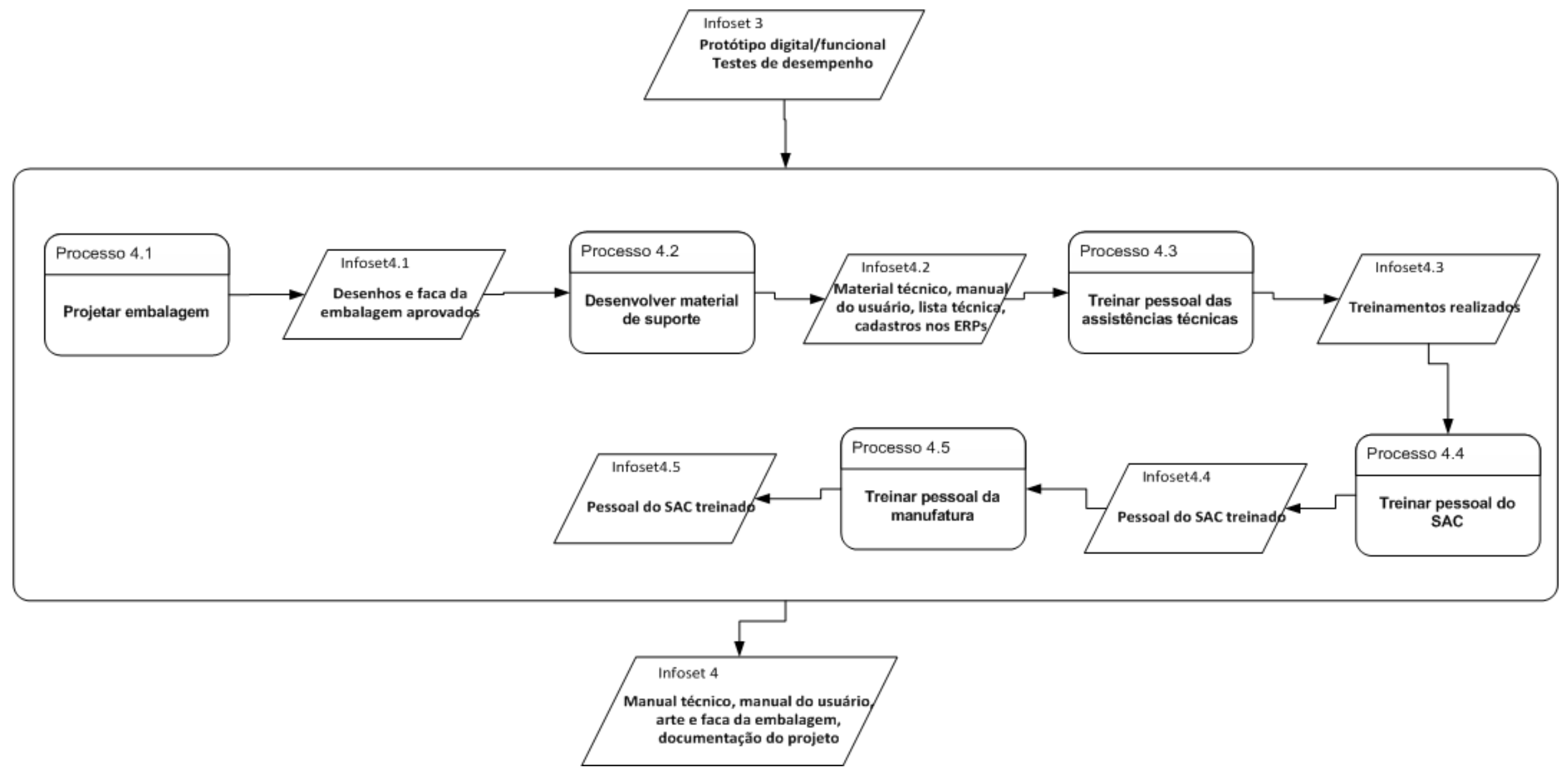

Figura 19: Modelo de Processos de Negócios - Desenvolver material de apoio (to-be) 


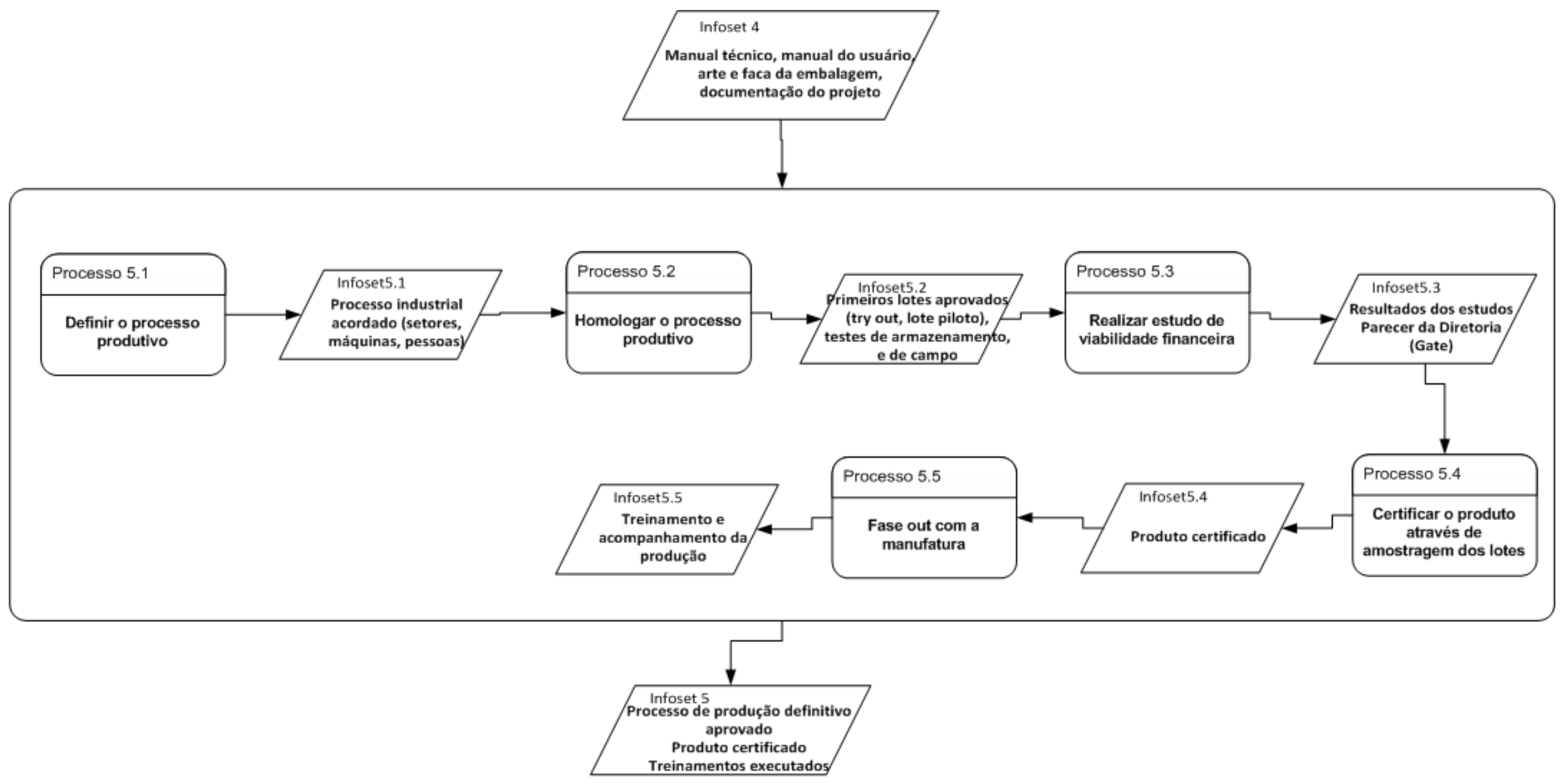

Figura 20: Modelo de Processos de Negócios - Desenvolver e homologar processo e certificar produto (to-be) 


\subsubsection{Modelo de Componentes e Requisitos Técnicos}

A seguir é apresentado o Modelo de Componentes e Requisitos Técnicos para ser utilizado no desenvolvimento de uma plataforma de colaboração para apoiar a operação de redes de inovação auto-organizadas. Os objetivos da plataforma, enquanto sistema de informação, estão alinhados com a propriedade de auto-organização, e esta utiliza recursos da tecnologia da informação.

O Modelo de Componentes e Requisitos Ténicos é elaborado a partir das necessidades e características impostas pelos demais modelos. A figura 21 mostra uma referência simplificada aos modelos de Objetivos, Regras de Negócios, Processos de Negócios, e Atores e Recursos. O primeiro objetivo é apoiar a descentralização do controle dentro das redes (Objetivo SI 1), para isso é estabelecido um requisito não funcional ao sistema para apoiar o compartilhamento do planejamento do projeto. Esse objetivo também recebe apoio do objetivo gerenciar a colaboração entre as partes (Objetivo SI 2), o qual recebe apoio de dois requisitos funcionais de sistema: permitir a colaboração pela internet (Req. Funcional 1), e permitir múltiplos usuários (Req. Funcional 2). Ambos são apoiados pela obrigatoriedade de se garantir a segurança dos dados (Req. N. Funcional 5), que pode ser obtida pelo controle de restrição de acesso no sistema (Req. N. Funcional 6).

Para gerenciar a colaboração entre as partes (Objetivo SI 2) foram estabelecidos três objetivos de apoio. O primeiro deles é gerenciar a mobilidade do conhecimento (Objetivo SI 2.1), que está apoiado por dois requisitos de sistema: permitir o registro de novas ideias nos foruns de discussão (Req. Funcional 3), e armazenar registros dos acessos (Req. Funcional 4). A gestão da mobilidade do conhecimento também está apoiada por dois objetivos: (a) manter canais de comunicação abertos (Objetivo SI 2.1.1), que recebe apoio do requisito disponibilizar ferramentas para comunicação dentro da equipe (Req. Funcional 5), o qual está associado com a necessidade de facilitar a comunicação dentro da equipe de projetos (Req. N. Funcional 2), e do requisito apresentar interface amigável (Req. Funcional 6) o qual está associado com a necessidade de que o sistema permita rápida aprendizagem (Req. N. Funcional 3); (b) e permitir registrar e compartilhar práticas (Objetivo SI 2.1.2), que está apoiado no requisito transacionar diferentes tipos de documentos (Req. Funcional 7).

O segundo objetivo de apoio à gestão da colaboração entre as partes é gerenciar a apropriação da inovação (Objetivo SI 2.2). Esse objetivo está apoiado no requisito documentar resultados do projeto como patentes e fórmulas (Req. Funcional 8); e no requisito monitorar o desempenho dos parceiros (Objetivo SI 2.2.1), o qual recebe apoio dos requisitos manter 
registro dos papéis e responsabilidades dos parceiros (Req. Funcional 9) e monitorar prazos, custos e indicadores (Req. Funcional 10).

O terceiro objetivo de apoio à gestão da colaboração entre as partes é promover o alinhamento dos parceiros (Objetivo SI 2.3). Esse objetivo recebe apoio dos requisitos monitorar prazos, custos e indicadores (Req. Funcional 10), permitir a realização de consultas (Req. Funcional 11), e disparar alertas automaticamente (Req. Funcional 12). Para permitir a realização de consultas é necessário assegurar a confiabilidade das informações (Req. N. Funcional 4).

A Figura 21 apresenta o Modelo de Componentes e Requisitos Técnicos. 


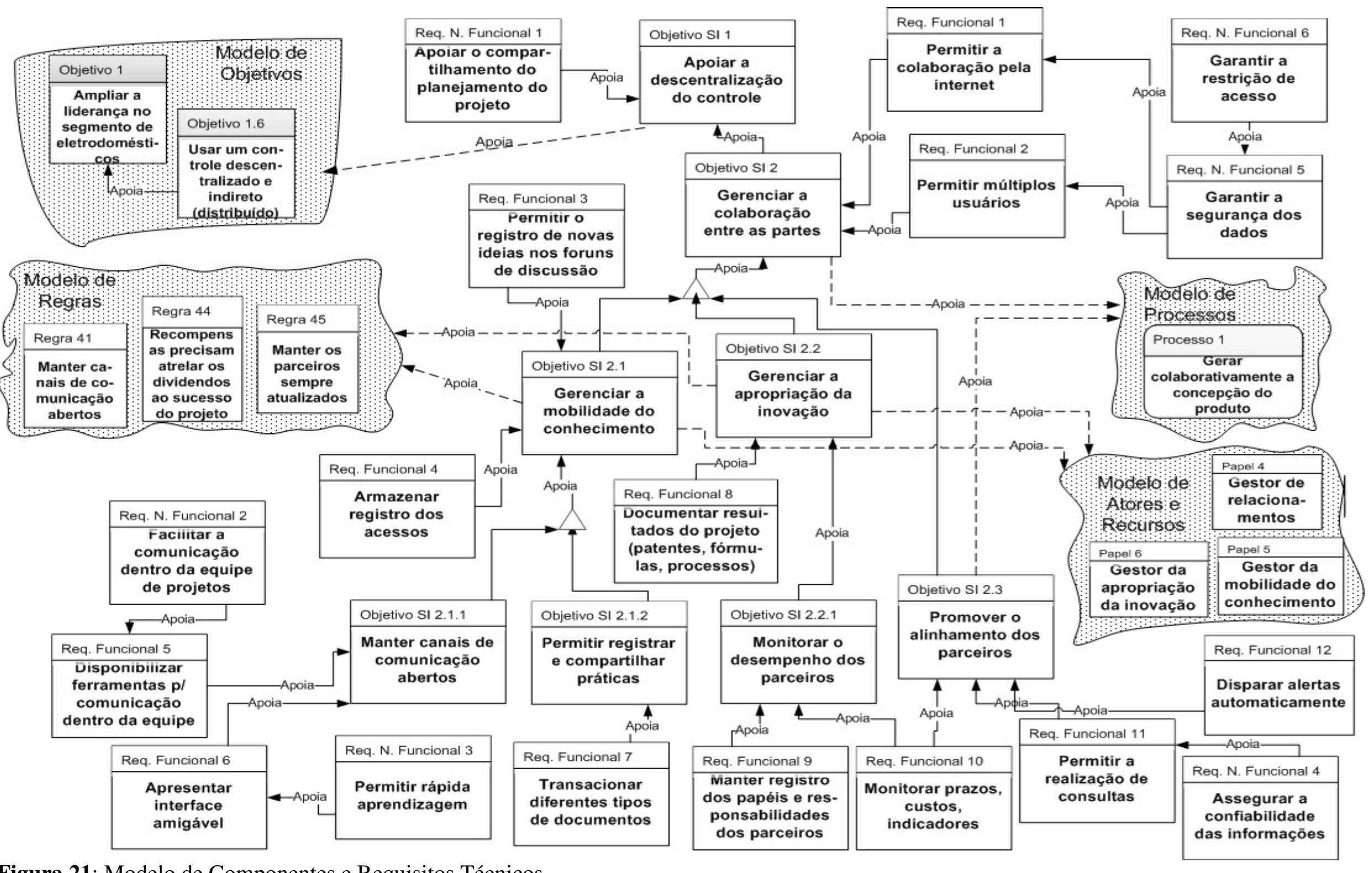

Figura 21: Modelo de Componentes e Requisitos Técnicos 


\subsubsection{Modelo de Conceitos}

Apoiando-se no recorte analítico de redes de inovação e na teoria de sistemas complexos pode-se sugerir que um importante conceito que não está contemplado no modelo de conceitos (as-is) do estudo de caso é a auto-organização (Conceito 21). Sua importância está no fato dele ter potencial para superar a fronteira da contribuição celebrada em contrato e gerar novos conhecimentos (Conceito 20) que serão internalizados pelos parceiros (Conceito 19) e utilizados na concepção de novas ideias e na conseqüente geração de inovações (Conceito 1).

A auto-organização é marcada pelo surgimento de movimentos bottom up (Conceito 22), ou seja, por movimentos iniciados pelos próprios agentes sem a necessária imposição de uma diretriz centralizadora. Esses movimentos são promovidos pela força dos relacionamentos (Conceito 23) que liga os agentes na rede.

Os relacionamentos são formados pelas parcerias (Conceito 36), cuja celebração observa o histórico de colaboração (Conceito 37), a certificação dos parceiros (Conceito 38), e a formalização de contratos (Conceito 39). Os contratos não são mais vistos como garantia exclusiva para a confidencialidade (Conceito 40), mas sim como elementos de apoio com vistas à proteção da propriedade intelectual (Conceito 41). O fortalecimento dos relacionamentos motiva o comprometimento entre as partes (Conceito 30), e isso funciona como suporte aos contratos no apoio à confidencialidade para a proteção dos ativos intelectuais. Esse comprometimento está assentado em três pilares: um sistema de recompensas (Conceito 31) claramente negociado entre as partes; um nível de interdepedência entre os agentes (Conceito 32) que permita a percepção de que o bom desempenho coletivo passa pelo bom desempenho individual, e isso pode ser estimulado pela complementariedade em termos de competências e ativos (Conceitos 34 e 35); e uma política de governança que defina claramente as regras de colaboração (Conceito 33). Alguns elementos integram o conceito de relacionamento nesse contexto: controle descentralizado (Conceito 24), controle indireto (Conceito 25), participação voluntária (Conceito 26), alinhamento entre as partes (Conceito 27), compartilhamento de práticas (Conceito 28), e plataforma de colaboraçao (Conceito 29).

A Figura 22 apresenta o Modelo de Conceitos (to-be). 


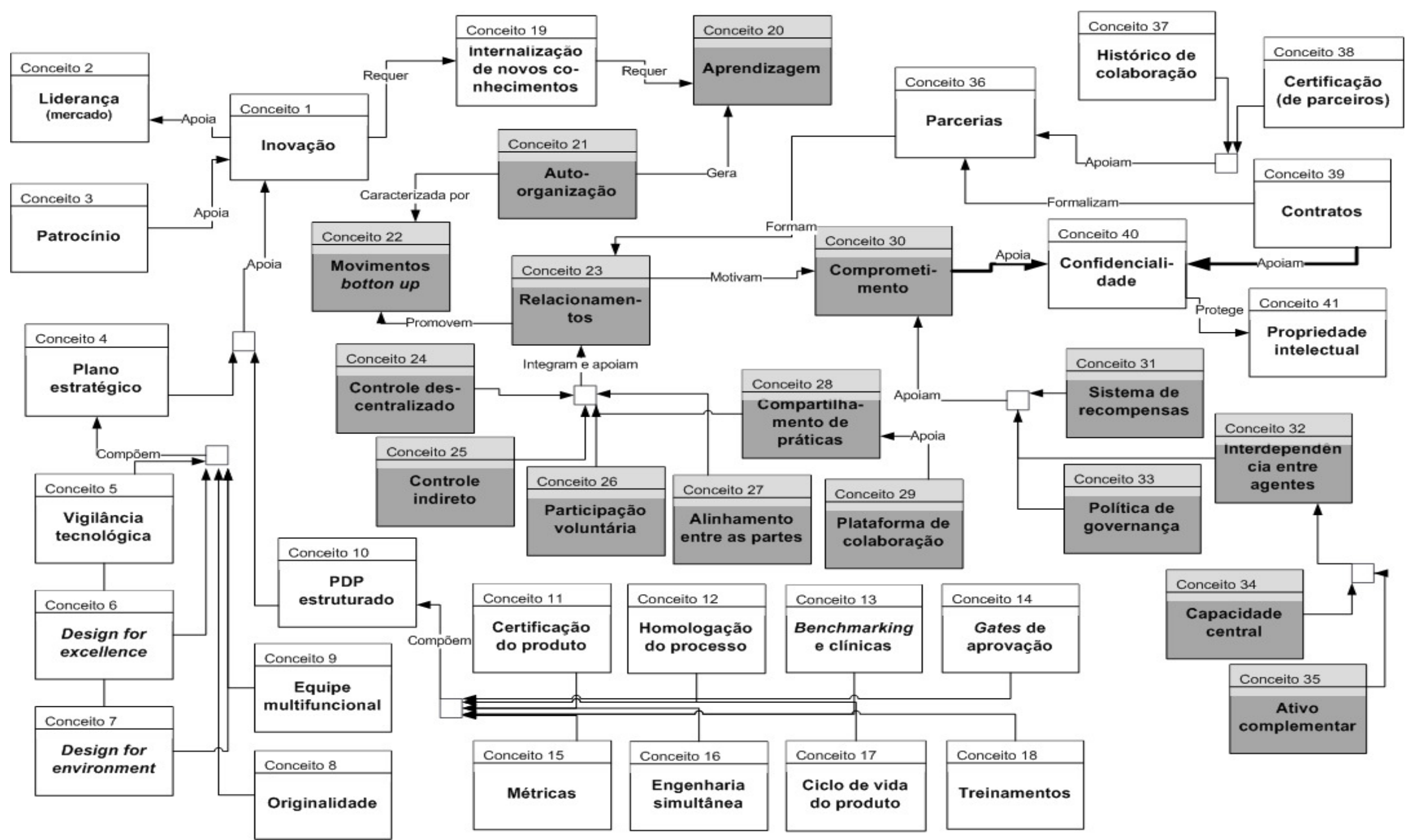

Figura 22: Modelo de Conceitos (to-be) 


\subsection{DISCUSSÃO DOS RESULTADOS}

Cada modelo "to-be" gerado a partir dos elementos discutidos na seção 3.3 ("need for change") apresenta contribuições para a formação e operação de uma rede de inovação caracterizada pelo fenômeno da auto-organização. O principal conceito novo que permeia todos os modelos "to-be" é a auto-organização, registrado no Modelo de Conceitos como Conceito 21. Os vários conceitos associados com auto-organização ajudam a identificar sua origem e contribuem para provocar sua manifestação.

A principal modificação registrada no Modelo de Objetivos "to be" é o estabelecimento de dois elementos diretamente associados ao fenômeno da auto-organização: controle descentralizado e controle indireto (Objetivo 1.6 da Figura 11). O compartilhamento do controle carrega consigo o compartilhamento das responsabilidades, e isso impulsiona/fortalece a movimentação e o comprometimento individual dos agentes na rede. Por sua vez, a aplicação de um controle indireto também faz contraponto à imposição unilateral de diretrizes; o controle passa a apresentar caráter de suporte/apoio. Tanto o recorte analítico de redes de inovação quanto a teoria de sistemas complexos sugerem que os relacionamentos estão no centro da autoorganização e, por sua vez, a descentralização do controle somente pode ser perpetrada mediante o fortalecimento dos relacionamentos (Objetivo 1.6.1). Os demais objetivos sob o Objetivo 1.6.1 funcionam como suporte para o fortalecimento dos relacionamentos.

O Modelo de Regras de Negócios "to-be" tem relação direta com o fenômeno da autoorganização por estabelecer e especificar as condições essenciais (o como) para a viabilização dos objetivos associados com a auto-organização no Modelo de Objetivos. Descentralizar o controle e tornar sua ação mais indireta (Objetivo 1.6) passa necessariamente pelo compartilhamento do planejamento e pela resolução conjunta de conflitos (Regra 39). A avaliação do tipo e da intensidade dos relacionamentos (Regra 40) colabora para definir o nível de integração dos agentes na rede (determinando o núcleo de ligações fortes e a periferia de ligações fracas). A política de governança (Regra 41), os canais de comunicação (Regra 42), os bancos de dados (Regra 43), a complementariedade entre as partes (Regra 44), o sistema de recompensas (Regra 45), a atualização contínua dos parceiros (Regra 46), e a plataforma de colaboração (Regra 47) são elementos que motivam e possibilitam a movimentação expontânea (individual e coletiva) dos parceiros na rede em prol dos objetivos coletivos (auto-organização).

O Modelo de Processos de Negócios "to-be" contribui para fomentar movimentos autoorganizados na rede ao introduzir o processo de geração colaborativa da concepção de produto (Processo 1). Com isso, a integração dos parceiros ocorre nas etapas iniciais de cada projeto, o 
que permite que novas ideias e contribuições possam ser apresentadas desde o início, além de economizar tempo e dinheiro ao evitar mudanças em etapas mais adiantadas do projeto.

A contribuição do Modelo de Atores e Recursos "to-be" ao fenômeno da autoorganização está no acréscimo de novos elementos com potencial para motivar iniciativas do tipo bottom up. Há uma preocupação específica na identificação dos diferentes tipos de relacionamentos na rede (Papel 4), o que permite distribuir os recursos, canais de comunicação e esforços de maneira mais equilibrada. O gerenciamento da distribuição do conhecimento (Papel 5) é outro ponto importante porque no modelo " $a s$-is" as trocas eram bastante limitadas dado o receio de vazamento de ativos intelectuais. Esse papel contribui para que os agentes na rede tenham confiança para tomar iniciativas de compartilhar conhecimento, o que gera aprendizagem e impulsiona a auto-organização. Outro elemento importante nesse modelo é o gerenciamento da apropriação da inovação (Papel 6); a consciência de que as inovações desenvolvidas em rede produzirão benefícios que serão apropriados de forma justa e proporcional motivarão os agentes a mostrar iniciativas. O Broker (Papel 7), ou selecionador de empresas, tem a tarefa de analisar histórico, competênciais e ativos atuais para ajudar a compor uma rede com capacidades e interesse complementares, o que promove a interdependência e a colaboração entre as partes. Todos os recursos apontados no modelo "to-be" (Recursos 6 a 9) oferecem os incentivos e os meios para que a auto-organização possa se manifestar. A plataforma de colaboração é meio (Recurso 6); as relações de benefícios, de capacidades centrais e de metas (Recursos 7 a 9) funcionam como elementos motivacionais.

O Modelo de Componentes e Requisitos Técnicos apresenta os principais requisitos funcionais e não funcionais para o desenvolvimento de uma plataforma tecnológica que facilite o processo de colaboração entre os agentes na rede.

\subsection{VALIDAÇÃO DO MODELO TO-BE EM CAMPO}

O modelo "to-be" apresentado mostra, com base na revisão literária feita no capítulo 2, um conjunto de elementos diretamente associados com o fenômeno da auto-organização. O próximo passo dessa pesquisa é a apresentação de um procedimento de validação desse modelo em campo. Para isso, foram contactados individualmente todos os especialistas entrevistados nas unidades empresariais durante o desenvolvimento do modelo " $a s$-is". A primeira etapa consistiu em discutir novamente o conceito de auto-organização e sua importância para o desenvolvimento de inovações. A segunda etapa foi apresentar o modelo "to-be" desenvolvido na pesquisa, e discutir a relevância de cada elemento como apoio ao fenômeno da autoorganização. A terceira etapa foi apresentar uma tabela para que cada entrevistado pudesse 
emitir, com base na experiência profissional, seu parecer sobre a relevância da auto-organização, do modelo de referência desenvolvido e da adequação de cada conceito dentro desse modelo.

A coleta do parecer de cada especialista ocorreu através do uso de uma escala Likert (Likert, 1932). Essa escala tem sido bastante utilizada como instrumento de pesquisa para a avaliação de conceitos subjetivos. Ela solicita do entrevistado duas dimensões de compreensão para cada conceito: conteúdo e intensidade. Primeiro é preciso avaliar o conteúdo da proposição para depois emitir um nível de parecer, discordando ou concordando. (HODGE \& GILLESPIE, 2003).

De acordo com Wiswanathan et al. (2004) e Dawes (2008), uma escala Likert com cinco posições apresenta algumas características básicas como confiabilidade, validade e sensibilidade. Uma escala com número ímpar de pontos facilita a resposta devido à presença de um ponto intermediário, que representa um nível neutro entre concordância e discordância.

Apenas os novos elementos inseridos no modelo "to-be" foram submetidos à avaliação dos especialistas. Os demais elementos já haviam sido avaliados durante a etapa de modelagem da situação corrente (modelo "as-is"). Os entrevistados puderam atribuir a cada elemento apresentado seu nível de concordância de acordo com a seguinte escala: discordo totalmente (1); discordo (2); não concordo nem discordo (3); concordo (4); concordo totalmente (5). Segue abaixo tabela consolidada com os dados coletados.

A tabela 2 mostra o resumo da avaliação realizada pelos especialistas entrevistados nas oito unidades empresariais que participaram da pesquisa. $\mathrm{O}$ formulário aplicado em campo encontra-se no apêndice E.

Tabela 2: resumo dos dados da validação das questões gerais.

\begin{tabular}{|c|c|c|c|c|c|c|c|c|}
\hline UA 1 & UA 2 & UA 3 & UA 4 & UA 5 & UA 6 & UA 7 & UA 8 & Resposta Consolidada \\
\hline $\begin{array}{l}\text { 1. A auto-organização é uma propriedade que pode contribuir para o alcance das metas nos projetos } \\
\text { de inovação. }\end{array}$ \\
\hline 4 & 5 & 4 & 3 & 4 & 4 & 5 & 4 & Concordo \\
\hline \begin{tabular}{c} 
2. O modelo de referência apresentado pode contribuir para apoiar o processo de auto-organização. \\
\hline 5
\end{tabular} 5 & 4 & 4 & 4 & 4 & 5 & 4 & Concordo \\
\hline 3. O modelo de referência pode ser instanciado na sua unidade empresarial. \\
\hline 4 & 4 & 3 & 2 & 5 & 4 & 5 & 4 & Concordo \\
\hline
\end{tabular}

A tabela acima mostra que, de maneira geral, os especialistas entrevistados em cada unidade empresarial consideram a auto-organização uma propriedade relevante dentro dos projetos de inovação. Os especialistas também consideram que o modelo de referência 
apresentado neste trabalho tem potencial para apoiar a auto-organização, e que o mesmo pode ser utilizado por eles. $\mathrm{O}$ especialista da unidade 4 justificou sua indecisão sobre a relevância da auto-organização mencionando a dificuldade para controlar os parceiros. Os especialistas das unidades 3 e 4 justificaram o posicionamento sobre a instanciação do modelo de referência alegando a necessidade de muito comprometimento entre as partes envolvidas, inclusive de mudança cultural. Esses posicionamentos revelam a percepção das dificuldades inerentes à proposta de mudança apresentada, mas de maneira geral, as respostas permitem inferir que os especialistas consideram relevantes e viáveis os resultados desta pesquisa.

As tabelas 3 a 7 mostram a avaliação da importância de cada elemento que foi inserido no modelo de referência, assim com das demais modificações propostas. Cada submodelo foi separado numa tabela a fim de facilitar a avaliação pelos entrevistados. Não há uma tabela específica para o Modelo de Conceitos porque seus elementos foram retirados dos demais modelos.

De maneira geral não foram registradas objeções a nenhum dos elementos apresentados no Modelo de Objetivos (tabela 3). No entanto, os especialistas das unidades 4 e 5 não concordaram com o elemento participação voluntária, justificando que embora julguem importante esse tipo de comportamento, por outro lado eles acham difícil conseguir fazer com que o parceiro atue dessa forma. Os especialistas das unidades 2 e 4 discordaram sobre o elemento interdependência, devido aos eventuais riscos provocados pela excessiva dependência dos parceiros (interdependência). E o especialista da unidade 2 ficou indeciso sobre o elemento apoiar os movimentos bottom up, isso devido à dificuldade para controlar os parceiros. Essas manifestações são relevantes, mas não comprometem os resultados obtidos.

Tabela 3: resumo dos dados relativos à validação do Modelo de Objetivos.

\begin{tabular}{|c|c|c|c|c|c|c|c|c|}
\hline UA 1 & UA 2 & UA 3 & UA 4 & UA 5 & UA 6 & UA 7 & UA 8 & Resposta Consolidada \\
\hline \multicolumn{9}{|c|}{ 1. Usar um controle descentralizado e indireto. } \\
\hline 5 & 5 & 5 & 4 & 4 & 5 & 5 & 5 & Concordo totalmente \\
\hline \multicolumn{9}{|c|}{ 2. Direcionar foco para os relacionamentos. } \\
\hline 5 & 5 & 5 & 5 & 5 & 5 & 5 & 5 & Concordo totalmente \\
\hline \multicolumn{9}{|c|}{ 3. Incentivar o comprometimento das partes. } \\
\hline 5 & 5 & 5 & 5 & 5 & 5 & 5 & 5 & Concordo totalmente \\
\hline \multicolumn{9}{|c|}{ 4. Motivar a participação voluntária. } \\
\hline 4 & 4 & 5 & 2 & 3 & 4 & 4 & 5 & Concordo \\
\hline \multicolumn{9}{|c|}{ 5. Incentivar o aprendizado enquanto geração e uso do conhecimento. } \\
\hline 5 & 5 & 5 & 5 & 5 & 5 & 5 & 5 & Concordo totalmente \\
\hline
\end{tabular}




\begin{tabular}{|c|c|c|c|c|c|c|c|c|}
\hline \multicolumn{9}{|c|}{ 6. Apoiar a interdependência. } \\
\hline 4 & 3 & 4 & 2 & 5 & 5 & 4 & 4 & Concordo \\
\hline \multicolumn{9}{|c|}{ 7. Apoiar movimentos bottom up. } \\
\hline 4 & 3 & 4 & 4 & 4 & 5 & 4 & 5 & Concordo \\
\hline \multicolumn{9}{|c|}{ 8. Promover o alinhamento dos parceiros. } \\
\hline 4 & 4 & 4 & 4 & 4 & 4 & 4 & 4 & Concordo \\
\hline \multicolumn{9}{|c|}{ 9. Fomentar o compartilhamento. } \\
\hline 5 & 4 & 4 & 4 & 5 & 5 & 5 & 5 & Concordo totalmente \\
\hline
\end{tabular}

Houve uma boa aceitação dos elementos sugeridos para o Modelo de Regras de Negócios. Os especialistas das unidades 3, 4 e 6 ficaram em dúvida sobre a idéia de compartilhar o planejamento do projeto, porque de acordo com eles há estratégias que não podem ser reveladas. Por razões de dificuldade para implantar, os especialistas das unidades 4,5 e 8 discordaram sobre como atrelar as recompensas ao sucesso do projeto. Para eles há uma série de dificuldades como quem assumiria o ônus do em caso de fracasso, e como estabelecer os critérios adequados para a partilha dos dividendos.

Tabela 4: resumo dos dados relativos à validação do Modelo de Regras de Negócios.

\begin{tabular}{|l|c|c|c|c|c|c|c|c|c|}
\hline UA 1 & UA 2 & UA 3 & UA 4 & UA 5 & UA 6 & UA 7 & UA 8 & Resposta Consolidada \\
\hline 1. Compartilhar o planejamento do projeto e a resolução de conflitos. & Concordo \\
\hline 5 & 4 & 3 & 2 & 5 & 3 & 4 & 4 & Concordo \\
\hline 2. Avaliar o tipo e a intensidade dos relacionamentos. \\
\hline 4 & 4 & 4 & 4 & 4 & 4 & 4 & 4 & Concordo totalmente \\
\hline 3. Estabelecer política de governança clara. \\
\hline 5 & 5 & 5 & 4 & 5 & 5 & 4 & 5 & Concordo totalmente \\
\hline 4. Manter canais de comunicação sempre abertos. \\
\hline 5 & 5 & 5 & 5 & 5 & 5 & 5 & 5 & Concordo totalmente \\
\hline 5. Alimentar o banco de conhecimentos da rede. \\
\hline 4 & 4 & 5 & 4 & 4 & 5 & 5 & 5 & Concordo totalmente \\
\hline 6. Selecionar parceiros com capacidades centrais e ativos complementares. \\
\hline 5
\end{tabular}


O Modelo de Atores e Recursos faz referência direta à estrutura que rege os relacionamentos dentro das unidades empresariais. Também nesse caso houve concondância dos entrevistados para com os elementos apresentados. O especialista da unidade 4 manifestou preocupação com a segurança das informações e conhecimentos a partir da integração de terceiros à equipe de projetos, que na verdade é uma preocupação comum nessa área. Os especialistas das unidades 2 e 5 ficaram em dúvida sobre o papel de gestor da apropriação da inovação porque segundo eles esse papel já tem sido conduzido. O mesmo se aplica aos elementos: selecionador de empresas, relação de benefícios e relação de metas. Os entrevistados não questionaram a importância desses elementos, mas a originalidade deles. Isso não altera o propósito da pesquisa nesse ponto que é o de torná-los mais explícitos e funcionais.

Tabela 5: resumo dos dados relativos à validação do Modelo de Atores e Recursos.

\begin{tabular}{|l|c|c|c|c|c|c|c|c|c|}
\hline UA 1 & UA 2 & UA 3 & UA 4 & UA 5 & UA 6 & UA 7 & UA 8 & Resposta Consolidada \\
\hline 1. Integração do parceiro à equipe de projeto. \\
\hline 4 & 4 & 4 & 3 & 4 & 4 & 4 & 4 & Concordo \\
\hline 2. Gestor de relacionamentos. \\
\hline 4 & 5 & 5 & 4 & 4 & 5 & 5 & 5 & Concordo totalmente \\
\hline 3. Gestor da mobilidade do conhecimento. \\
\hline 5 & 5 & 5 & 5 & 5 & 5 & 5 & 5 & Concordo totalmente \\
\hline 4. Gestor da apropriação da inovação. \\
\hline 5 & 3 & 4 & 4 & 3 & 4 & 4 & 4 & Concordo \\
\hline 5. Selecionador de empresas. \\
\hline 3 & 2 & 4 & 2 & 4 & 4 & 3 & 4 & Concordo \\
\hline 6. Plataforma de colaboração \\
\hline 5 & 5 & 5 & 5 & 5 & 5 & 5 & 5 & Concordo totalmente \\
\hline 7. Relação de benefícios \\
\hline 3
\end{tabular}

De maneira geral, os elementos presentes no Modelo de Processos de Negócios foram validados pelos especialistas. Os especialistas das unidades 1 e 4 ficaram indecisos sobre o desenvolvimento colaborativo de soluções alternativas e da arquitetura do produto. Para eles, algumas decisões nesse nível podem ser estratégicas e, portanto, a participação de terceiros precisa ser bem avaliada. 
Tabela 6: resumo dos dados relativos à validação do Modelo de Processos de Negócios.

\begin{tabular}{|c|c|c|c|c|c|c|c|c|}
\hline UA 1 & UA 2 & UA 3 & UA 4 & UA 5 & UA 6 & UA 7 & UA 8 & Resposta Consolidada \\
\hline \multicolumn{9}{|c|}{ 1. Gerar colaborativamente a concepção do produto (antecipar a participação dos parceiros). } \\
\hline 5 & 5 & 4 & 5 & 5 & 5 & 4 & 4 & Concordo totalmente \\
\hline \multicolumn{9}{|c|}{ 2. Definir colaborativamente objetivos e metas a serem alcançados. } \\
\hline 4 & 4 & 5 & 5 & 4 & 5 & 5 & 5 & Concordo totalmente \\
\hline \multicolumn{9}{|c|}{ 3. Definir colaborativamente os recursos a serem compartilhados durante o projeto. } \\
\hline 4 & 4 & 4 & 4 & 4 & 4 & 4 & 5 & Concordo \\
\hline \multicolumn{9}{|c|}{ 4. Definir colaborativamente uma política de governança clara } \\
\hline 5 & 4 & 5 & 5 & 4 & 5 & 4 & 5 & Concordo totalmente \\
\hline \multicolumn{9}{|c|}{ 5. Desenvolver colaborativamente as soluções alternativas. } \\
\hline 3 & 4 & 4 & 3 & 5 & 5 & 5 & 5 & Concordo totalmente \\
\hline \multicolumn{9}{|c|}{ 6. Definir colaborativamente a arquitetura do produto } \\
\hline 3 & 4 & 4 & 3 & 5 & 5 & 4 & 4 & Concordo \\
\hline
\end{tabular}

Os elementos presentes no Modelo de Componentes e Requisitos Técnicos foram aprovados sem qualquer observação por partes dos especialistas.

Tabela 7: resumo dos dados relativos à validação do Modelo de Componentes e Requisitos Técnicos.

\begin{tabular}{|c|c|c|c|c|c|c|c|c|}
\hline UA 1 & UA 2 & UA 3 & UA 4 & UA 5 & UA 6 & UA 7 & UA 8 & Resposta Consolidada \\
\hline \multicolumn{9}{|c|}{ 1. O sistema precisa permitir a descentralização do controle. } \\
\hline 5 & 5 & 5 & 4 & 4 & 5 & 5 & 5 & Concordo totalmente \\
\hline \multicolumn{9}{|c|}{ 2. O sistema precisa gerenciar a colaboração entre as partes. } \\
\hline 5 & 5 & 5 & 5 & 5 & 5 & 5 & 5 & Concordo totalmente \\
\hline \multicolumn{9}{|c|}{ 3. O sistema precisa gerenciar a mobilidade do conhecimento. } \\
\hline 5 & 5 & 5 & 5 & 5 & 5 & 5 & 5 & Concordo totalmente \\
\hline \multicolumn{9}{|c|}{ 4. O sistema precisa gerenciar a apropriação da inovação. } \\
\hline 5 & 4 & 4 & 4 & 4 & 5 & 4 & 5 & Concordo \\
\hline \multicolumn{9}{|c|}{ 5. O sistema precisa promover o alinhamento dos parceiros. } \\
\hline 5 & 5 & 5 & 5 & 5 & 5 & 5 & 5 & Concordo totalmente \\
\hline \multicolumn{9}{|c|}{ 6. O sistema precisa permitir o registro e o compartilhamento das práticas. } \\
\hline 5 & 5 & 5 & 5 & 5 & 5 & 5 & 5 & Concordo totalmente \\
\hline \multicolumn{9}{|c|}{ 7. O sistema precisa monitorar o desempenho dos parceiros. } \\
\hline 5 & 5 & 5 & 5 & 5 & 5 & 5 & 5 & Concordo totalmente \\
\hline
\end{tabular}




\subsubsection{ETAPAS DA VALIDAÇÃO DO MODELO}

O desenvolvimento do modelo de referência seguiu as fases recomendas por Ahlemann e Gastl (2007): planejamento, construção, validação, teste e documentação.

A etapa de planejamento foi realizada com apoio do levantamento teórico sobre o tema de pesquisa, sendo identificados os principais constructos a serem investigados em campo (primeira parte do trabalho). Esses elementos foram utilizados para a elaboração do questionário aplicado e para a análise dos dados coletados na pesquisa de campo.

A etapa de construção envolveu a análise e a modelagem do objeto de pesquisa. Essas atividades foram executadas com o apoio dos especialistas entrevistados na pesquisa de campo. Nessa etapa ocorreu a consolidação num único modelo dos dados coletados nas unidades abordadas, e a discussão das necessidades de mudança e da contribuição dos elementos identificados na literatura (segunda parte do trabalho). Também nessa etapa ocorreu o desenvolvimento de um novo modelo melhorado a partir das informações obtidas nos passos anteriores (terceira parte do trabalho).

A etapa de validação foi realizada através da apresentação aos especialistas do modelo novo melhorado e registrado seus pareceres por intermédio da aplicação de um questionário (terceira parte do trabalho).

A etapa de documentação foi realizada com apoio da metodologia EKD e da descrição detalhada de cada modelo. Todas as unidades foram modeladas com o apoio o EKD, e os modelos individuais foram integrados num modelo consolidado. 


\section{$\underline{5}$ - CONSIDERAÇÕES FINAIS}

Há uma relação positiva entre a diversidade de parceiros envolvidos no processo de inovação e a obtenção de resultados satisfatórios. Os elos colaborativos são fatores de transferência de conhecimentos, recursos e motivação, os quais constituem elementos essenciais para a inovação.

As redes de inovação são formadas por um conjunto de instituições independentes ligadas por vínculos de caráter colaborativo que tem como propósito superar em parceria as incertezas do processo de inovação, envolvendo-se na geração e comercialização de novos produtos, processos e serviços. De acordo com a literatura, as redes de inovação constituem sistemas complexos e a auto-organização é uma importante propriedade desse tipo de sistema, diretamente associada com sua capacidade de adaptação. Ela se caracteriza pelo comportamento coletivo espontâneo do sistema a partir de movimentos bottom up dos agentes.

A proposta de explorar essa propriedade nas redes de inovação está baseada no fato de que o desafio de inovar envolve um cenário competitivo e dinâmico, que exige uma ampla e profunda variedade de conhecimentos. Individualmente, uma empresa líder de uma rede não tem todas as respostas para os desafios de um processo de inovação e, por esse motivo, o nível de trocas e de comprometimento dos parceiros precisa ir além daquele estabelecido pelas obrigações contratuais. A relevância da auto-organização está no fato dela impor um alto nível de comprometimento que permite à empresa líder compartilhar os desafios e oportunidades de um processo de inovação, e dessa forma motivar as trocas de conhecimentos e recursos necessários.

A fim de se estudar a propriedade de auto-organização nos agrupamentos de empresas que buscam a inovação de produtos na área de utilidades domésticas, dividiu-se o trabalho em três partes.Na primeira parte do trabalho, revisão da literatura no capítulo 2, foram identificados os elementos de apoio para a auto-organização: controle descentralizado e indireto, foco nos relacionamentos, comprometimento, interdependência, alinhamento entre as partes, participação voluntária, movimentos bottom up, compartilhamento de práticas e aprendizado. 
Na primeira e segunda partes do trabalho, capítulos 2 e 3, foram exploradas quatro questões de pesquisa. O Quadro 16 resume os resultados obtidos.

Quadro 16: Comparativo da revisão bibliográfica com o estudo de caso

\begin{tabular}{|l|l|l|}
\hline $\begin{array}{l}\text { Questão de pesquisa 1: as } \\
\text { redes de inovação são siste- } \\
\text { mas complexos? }\end{array}$ & $\begin{array}{l}\text { Sim. As redes de inovação } \\
\text { apresentam comportamento } \\
\text { complexo. }\end{array}$ & $\begin{array}{l}\text { Sim. As unidades apresentam } \\
\text { comportamento complexo. }\end{array}$ \\
\hline $\begin{array}{l}\text { Questão de pesquisa 2: como } \\
\text { surge a auto-organização } \\
\text { (como ela se manifesta)? }\end{array}$ & $\begin{array}{l}\text { Como um comportamento } \\
\text { coletivo espontâneo impulsio- } \\
\text { nado por movimentos bottom } \\
\text { up sem a necessidade de }\end{array}$ & $\begin{array}{l}\text { As unidades não apresentaram } \\
\text { movimento coletivo espontâ- } \\
\text { neo (auto-organização). }\end{array}$ \\
\hline $\begin{array}{l}\text { Questão de pesquisa 3: como } \\
\text { criar condiçãos para que a ação de um controle } \\
\text { auto-organização ocorra? }\end{array}$ & $\begin{array}{l}\text { Controle descentralizado e } \\
\text { indireto, comprometimento, } \\
\text { participação voluntária, inter- } \\
\text { dependência, alinhamento, } \\
\text { política justa de benefícios. }\end{array}$ & $\begin{array}{l}\text { Controle centralizado e direto, } \\
\text { contratos formais, restrição de } \\
\text { cionamento do tipo cliente / } \\
\text { fornecedor. }\end{array}$ \\
\hline $\begin{array}{l}\text { Questão de pesquisa 4: como } \\
\text { garantir que a auto-organiza- } \\
\text { ção traga benefícios para a a } \\
\text { rede? }\end{array}$ & $\begin{array}{l}\text { Aprendizado como pivô para } \\
\text { a condução dos relaciona- } \\
\text { mentos, alinhamento dos par- } \\
\text { ceiros com os objetivos em } \\
\text { comum. }\end{array}$ & Não houve benefícios. \\
\hline
\end{tabular}

A segunda coluna do quadro acima mostra que as unidades abordadas apresentam características de sistemas complexos, o que confirma o pressuposto teórico registrado na primeira coluna. No entanto, de acordo com os entrevistados essas unidades não apresentaram a propriedade de auto-organização (dados da segunda linha). A ausência dessa propriedade tem relação com algumas características como controle centralizado e direto, foco na formalização contratual das relações, restrição de acesso para os parceiros às informações, relação do tipo cliente fornecedor com os parceiros. De maneira geral os relacionamentos são fracos, restringindo-se às obrigações estabelecidas em contratos, o que impede trocas efetivas de informações e conhecimentos que ultrapassem os limites contratuais de uma simples relação de 
fornecimento. A auto-organização está diretamente associada com a capacidade de aprendizado e esta depende da geração e uso do conhecimento produzido.

Ainda no capítulo 3, segunda parte do trabalho, foi realizada a modelagem do cenário atual das relações dentro de cada unidade empresarial para a inovação em produtos. As características impeditivas ao fenômeno da auto-organização foram confrontadas com alguns elementos identificados na literatura. Para cada lacuna foram apontados os elementos de apoio para a auto-organização identificados no capítulo 2 (revisão bibliográfica), e que passaram a ser rotuladas como necessidades de mudança (need for change).

$\mathrm{Na}$ terceira parte do trabalho, capítulo 4, foram acrescentados ao modelo gerado no capítulo 3 os elementos considerados essenciais para o surgimento de movimentos autoorganizados. Nesse novo modelo "to-be" foram feitas outras modificações como a exclusão de elementos, a combinação de processos, a criação de novos papeis e recursos, e o reposicionamento dos parceiros. O modelo de referência proposto é composto por seis submodelos individuais e cada um deles contribui para sistematizar as condições necessárias para a formação e operação das redes de inovação auto-organizadas na área de utilidades domésticas no Brasil.

O novo Modelo de Objetivos ("to-be") apresenta as principais diretrizes de apoio para a propriedade de auto-organização. Ele sistematiza o uso de um controle descentralizado como meio de fomentar movimentos auto-organizados, e assim apoiar o principal objetivo das unidades empresariais da área em estudo, a liderança no segmento de eletrodomésticos. O modelo atribui um papel de destaque para os relacionamentos como apoio para a descentralização do controle. O fortalecimento das relações estabelece o nível de confiança necessário para que o controle seja compartilhado. Os relacionamentos, por sua vez, são apoiados pelo comprometimento recíproco, participação voluntária, aprendizado, interdependência, movimentos bottom up, alinhamento dos parceiros e compartilhamento de práticas.

O novo Modelo de Regras de Negócios apresenta as condições básicas para a viabilização dos objetivos presentes no Modelo de Objetivos. Para cada novo objetivo há uma ou mais regras de apoio. A descentralização do controle requer o compartilhamento do planejamento dos projetos e da resolução dos conflitos. $\mathrm{O}$ foco nos relacionamentos requer a avaliação do tipo e da intensidade dos relacionamentos com cada parceiro, evitando-se assim o investimento desnecessário de recursos (tempo e dinheiro). O incentivo ao comprometimento requer o estabelecimento de uma política de governança clara; e a participação voluntária depende da abertura de canais de comunicação entre as partes. $\mathrm{O}$ aprendizado da rede requer a 
atualização permanente do banco de conhecimentos; a interdependência na rede passa pela seleção de parceiros com capacidades centrais e ativos complementares; o incentivo aos movimentos bottom up requer a associação dos dividendos ao sucesso de cada projeto; o alinhamento dos parceiros requer a atualização constante das partes; e o compartilhamento de conhecimentos e práticas pode ser incentivado por intermédio de uma plataforma de colaboração.

O novo Modelo de Atores e Recursos apresentam os papéis e recursos diretamente associados com a auto-organização e que também são necessários para a viabilização do Modelo de Objetivos. São eles: gestor de relacionamentos, gestor da mobilidade do conhecimento, gestor da apropriação da inovação, Broker (selecionador de empresas com capacidades centrais e ativos complementares), plataforma de colaboração, relação de metas e de benefícios. Esse modelo também apresenta uma mudança no posicionamento dos parceiros, os quais passam a integrar a equipe de projetos. Essa modificação apóia os objetivos de descentralizar o controle e fortalecer os relacionamentos, tornando mais efetivas as trocas entre as partes.

O novo modelo de Processos de Negócios apresenta a combinação de dois processos originais, resultando no processo "gerar colaborativamente a concepção do produto". A primeira consequiência é a antecipação da participação dos parceiros nos projetos, o que pode promover uma contribuição já nas etapas iniciais de cada projeto (promovendo idéias inovadoras e reduzindo custos com mudanças em etapas mais avançadas). A segunda consequiência é a abordagem mais colaborativa entre as partes, que decorre da possibilidade de participar e contribuir mais efetivamente para o sucesso dos projetos.

O Modelo de Componentes e Requisitos Técnicos identifica, a partir dos submodelos gerados ("to be"), um conjunto de objetivos visando o desenvolvimento de uma plataforma de colaboração para os agentes na rede (sistema de informação). Para cada objetivo presente nesse modelo são identificados os respectivos objetivos funcionais e não funcionais. A plataforma a ser desenvolvida a partir desse modelo é um recurso que pode apoiar a comunicação entre as partes, ajudar no compartilhamento de informações e no registro do conhecimento produzido, facilitar o alinhamento dos agentes, e como consequiência fortalecer os relacionamentos.

A contribuição acadêmica da intersecção entre o recorte analítico de redes de inovação e a teoria de sistemas complexos está na possibilidade de se analisar as redes como sistemas complexos e, como conseqüência, atribuir a elas a propriedade de auto-organização. Outro benefício é a indicação dos principais elementos teóricos de apoio para a auto-organização em ambientes de redes de inovação. 
A pesquisa apresenta algumas contribuições para o mercado. A primeira contribuição da pesquisa está no apoio ao principal objetivo identificado nas unidades empresariais: ampliar a liderança no segmento de eletrodomésticos. A criação de condições para o surgimento e a propagação de movimentos bottom up espontâneos dentro de uma rede de inovação (conceito de auto-organização) promove o aprendizado através da troca de conhecimentos e da geração de novas ideias, elementos essenciais para superar a complexidade imposta pelo desafo da inovação.

A segunda contribuição da pesquisa está na proposta de uma nova forma de gerenciamento interorganizacional para os agentes que integram uma rede de inovação através da descentralização do controle apoiada pelo fortalecimento dos relacionamentos. O modelo de referência apresentado propõe o compartilhamento do controle e das responsabilidades dentro do processo de gerar inovações, elementos chaves para o surgimento de movimentos autoorganizados. Isso reduz a carga sobre a empresa focal, aumenta o comprometimento e possibilita mais trocas dentro do esforço de inovar.

A terceira contribuição da pesquisa está na proposição de um modelo de referência (genérico e flexível) para ser instanciado nos casos de formação e operação de redes de inovação auto-organizadas na área de utilidades domésticas no Brasil.

Como limitações da pesquisa pode-se citar: (a) a perspectiva considerada em cada unidade empresarial ficou restrita a da empresa focal, principal responsável pelos projetos de inovação; (b) alguns elementos de apoio para a auto-organização não foram detalhados: não foram sugeridos critérios para a distribuição justa dos benefícios entre os parceiros; não foram sugeridos elementos para compor uma política de governança clara que atenda às expectativas das partes envolvidas; (c) não foi discutida a interação dos novos papéis, sugeridos para apoiar as interações dentro de um ambiente auto-organizado, com a hierarquia tradicional presente nas unidades empresariais.

Para futuros trabalhos podemos sugerir que novas investigações sejam conduzidas envolvendo os principais parceiros da empresa focal. Essa abordagem pode apresentar novos elementos de apoio ao processo de auto-organização. Também podemos sugerir que novos trabalhos sejam conduzidos na composição de uma política de governança e na identificação de critérios para a distribuição dos benefícios entre os parceiros. Outras oportunidades de pesquisa são: instanciar o modelo de referência proposto para futuros projetos de formação e operação de redes de inovação na área de utilidades domésticas, e analisar outros agrupamentos de empresas no setor de eletrônicos sob a perspectiva do modelo de referência proposto. 


\section{REFERÊNCIAS}

ABINEE, Comportamento da indústria elétrica e eletrônica: ano 2013 projeção para 2014, http://www.abinee.org.br/informac/arquivos/dados13.pdf, 2013.

AHLEMANN, F. Towards a conceptual reference model for project management information systems, International Journal of Project Management, 27, 19-30, 2009.

AHLEMANN, F.; GASTL, H. Process model for an empirically grounded reference model construction, In: FETTKE, P.; LOSS, P. (Eds.). Reference modeling for business systems analysis. Hershey: Idea Group Publishing, 2007.

ALIN, P.; MAUNULA, A.O.; TAYLOR, J.E.; SMEDS, R. Aligning Misaligned Systemic Innovations: Probing Inter-Firm Effects Development in Project Networks, Project Management Journal, Vol. 44, No. 1, 77-93, 2013.

AMARA, N.; LANDRY, R. Sources of information as determinants of novelty of innovation in manufacturing firms: evidence from the 1999 statistics Canada innovation survey, Technovation, 25, 245-259, 2005.

ANDERSSON, M.; LINDGREN, R.; HENFRIDSSON, O. Architectural knowledge in interorganizational IT innovation, Journal of Strategic Information Systems, 17, 19-38, 2008.

ARMOUTIS, N.; MAROPOULOS, P. G.; MATTHEWS, P.; LOMAS, C. Establishing agile supply networks through competence profiling, International Journal of Computer Integrated Manufacturing, v.21, n.2, 166-173, 2008.

BATTY, M.; TORRENS, P.M. Modelling and prediction in a complex world, Futures, 37, 745-766, 2005.

BECKER, W.; DIETZ, J. R\&D cooperation and innovation activities of firms - evidence for the German manufacturing industry, Research Policy, 33, 209-223, 2004.

BECHEIKH, N.; LANDRY, R.; AMARA, N. Lessons from Innovation Empirical Studies in the Manufacturing Sector: A Systematic Review of the Literature from 1993-2003, Technovation, Vol. 26, Issue 5, p.644-664, 2006. 
BELL, J.; DEN OLDEN, B.; ZIGGER, G. W. Dynamics of cooperation: at the brick of irrelevance. Journal of management studies, 43:7, 2006.

BITITCI, U.; TURNER, T.; MACKAY, D.; KEARNEY, D.; PARUNG, J.; WALTERS, D. Managing synergy in collaborative enterprises, Production Planning \& Control, v.18, n.6, 454- 465, 2007.

BRITTO, J. Cooperação interindustrial e redes de empresas, In. KUPFER, D; HASENCLEVER, L., Economia Industrial, UFRJ, Rio de Janeiro, 2002.

BUBENKO, J.; PERSSON, A.; STIRNA, J. EKD User Guide ELEKTRA Project, Research Report, 2001.

BÜCHEL, B.; NIEMINEN, L.; ARMBRUSTER-DOMEYER, H.; DENISON, D. Managing stakeholders in team-based innovation: The dynamics of knowledge and trust networks, European Journal of Innovation Management, Vol. 16 No. 1, pp. 22-49, 2013.

BURT, R. (1992). Structural holes versus network closure as social capital. In Lin, N., Cook, K., \& Burt, R. (Ed.) (2001). Social Capital: Theory and Research. NY: Aldine DE Gruyter.

CALIA, R.C.; GUERRINI, F.M., MOURA, G.L. Innovation networks: From technological development to business model reconfiguration, Technovation, 27, 426-432, 2007.

CAMARINHA-MATOS, L.M. Collaborative networked organizations: Status and trends in manufacturing, Annual Reviews in Control, 33, 199-208, 2009.

CAMARINHA-MATOS, L.M.; AFSARMANESH, H.; GALEANO, N.; MOLINA, A. Collaborative networked organizations: concepts and practice in enterprise manufacturing, Computers \& Industrial Engineering, 57, 46-60, 2009.

CAMARINHA-MATOS, L.; AFSARMANESH, H. On reference models for collaborative network organizations, Journal of Production Research, v. 46, 7, 2453- 2569, 2008.

CAMARINHA-MATOS, L.; ABREU, A. Performance of indicators for collaborative networks based on collaboration benefits, Production Planning and Control, v.18, 7, 592-609, 2007.

CAMARINHA-MATOS, L.; AFSARMANESH, H. Collaborative networks: a new science discipline, Journal of Intelligent Manufacturing, v. 16, 439-452, 2005.

CAPALDO A. Network structure and innovation: the leveraging of a dual network as a distinctive relational capability, Strategic Management Journal, 28, 585-608, 2007.

CHEN, J.S.J.; TSOU, H.T. Information technology adoption for service innovation practices and competitive advantage: the case of financial firms, Information Research, ISSN 1368-1613, Vol. 12, $\mathrm{N}^{\circ} .3,2007$.

CHESBROUGH, H; PRENCIPE, A; Networks of innovation and modularity - a dynamic perspective, International Journal of Technology Management, Vol. 42, No. 4, 2008.

CHOI, T.Y.; DOOLEY, K.J.; RUNGTUSANATHAM, M. Supply networks and complex adaptive systems: control versus emergence, Journal of Operations Management, 19, 351-366, 2001.

CHRISTOPHERSON, S.; CLARK, J. Power in Firm Networks: What it Means for Regional Innovation Systems, Regional Studies, 41:9, 1223-1236, 2007. 
CHRISTOPHERSON, S.; KITSON, M. Innovation, networks and knowledge exchange, Cambridge Journal of Regions, Economy and Society, 1, 165-173, 2008.

CHUNG, J.K.H; KUMARASWAMY, M.M.; PALANEESWARAN, E. Improving megaproject briefing through enhanced collaboration with ICT, Automation in Construction 18, 966-974, 2009.

COHEN W. M.; LEVINTHAL D. A. Absorptive Capacity: A New Perspective on Learning and Innovation, Administrative Science Quarterly, Vol. 35, pp.128-152, 1990.

COLLIER, T. C.; TAYLOR, C. E. Self-organization in sensor networks. Journal of Parallel and Distributed Computing, 64(7):866-873, 2004.

CONNER, K.; PRAHALAD, C. K. A resource-based theory of the firm: knowledge vs. opportunism, Organization Science, 7, 477-501, 1996.

CORSARO, D.; CANTÙ, C.; TUNISINI, A. Actors' Heterogeneity in Innovation Networks, Industrial Marketing Management, 41, 780-789, 2012.

COWANA, R.; JONARD, N. Network structure and the diffusion of knowledge, Journal of Economic Dynamics \& Control, 28, 1557 - 1575, 2004.

DAHLANDER, L.; GANN, D.M. How open is innovation? Research Policy, 39, 699-709, 2010.

DE VANY, A. Information, chance, and evolution: alchian and the economics of self-organization. Economic Inquiry (July), 427-443, 1996.

DHANARAJ, C.; PARKHE, A. Orchestrating innovation networks. Academy of Management Review, 31(3), 659-669, 2006.

DOOLEY, K.J.; VAN DE VEN, A.H. Explaining Complex, Organizational Dynamics, Organization Science/Vol. 10, No. 3, pp. 358-372, 1999.

DAWES, J. Do data characteristics change according to the number of scale points used? An experiment using 5-point, 7-point and 10-point scales. International Journal of Market Research, 50 (1), p. 61-77, 2008.

EMDEN, Z.; CALANTONE R.; DROGE C. Collaborating for New Product Development: Selecting the Partner with Maximum Potential to Create Value, The Journal of Product Innovation Management, 23:330-341, 2006.

ERMILOVA, E.; AFSARMANESH, H. Competency modeling targeted on boosting configuration of virtual organizations, Production Planning \& Control: The Management of Operations, 21:2, 103-118, 2010.

ESCHENBÄCHER, J.; SEIFER, M.; THOBEN, K.D. Improving distributed innovation processes in virtual organizations through the evaluation of collaboration intensities, Production Planning \& Control: The Management of Operations, 22:5-6, 473-487, 2011.

FAEMS, D.; LOOY, B.V.; DEBACKERE, K; Interorganizational Collaboration and Innovation: Toward a Portfolio Approach, The Journal of Innovation Management, 22, 238-250, 2005. 
FAGERBERG, J.; VERSPAGEN, B. Innovation studies -The emerging structure of a new scientific field, Research Policy, 38, 218-233, 2009.

FETTKE, P.; LOSS, P. Classification of reference models: a methodology and its application. Information Systems and e-Business Management, v. 1, n. 1, p. 35-53, 2003.

FREEL, M.S.; HARRISON, R.T. Innovation and cooperation in the small firm sector: Evidence from 'Northern Britain', Regional Studies, 40: 4, 289 - 305, 2006.

FRENKEN, K. A complexity approach to innovation networks. The case of the aircraft industry (19091997), Research Policy, 29, 257-272, 2000.

FRENKEN, K. Technological innovation and complexity theory, Economics of Innovation and New Technology , Vol. 15(2), March, pp. 137-155, 2006.

FRITSCH, M.; KAUFFELD-MONZ, M. The impact of network structure on knowledge transfer: an application of social network analysis in the context of regional innovation networks, The Annals of Regional Science, 44, 21-38, 2010.

FUKUGAWA, N., Determining Factors in Innovation of Small Firm Networks: A case of Cross Industry Groups in Japan, Small Business Economics, 27: 181-193, 2006.

GARCIA, R.; CALANTONE, R. A critical look at technological innovation typology and innovativeness terminology: a literature review, The Journal of Product Innovation Management, 19, 110 - 132, 2002.

GARDET, E.; MOTHE, C. The Dynamics of Coordination in Innovation Networks, European Management Review, Vol. 8, 213-229, 2011.

GILBERT, N.; AHRWEILER, P.; PYKA, A. Learning in innovation networks: Some simulation experiments, Physica, A, 378, 100-109, 2007.

GOEPP,V.; ROSE, B.; CAILLAUD, E. Coupling reference modeling and performance evaluation for the effective integration of eco-design tools into the design process, International Journal of Computer Integrated Manufacturing, 27:3, 242-265, 2014.

GOODERHAM, P.S.; ULSET, S. Beyond the M-form: towards a critical test of the new form. International Journal of the Economics of Business, 9, 117-38, 2002.

GNYAWALI, D.R.; SRIVASTAVA, M.K. Complementary effects of clusters and networks on firm innovation: A conceptual model, Journal of Engineering and Technology Management, 30, 1-20, 2013.

GRANOVETTER, M.S. The strength of weak ties, American Journal of Sociology, 78:1360-1380, 1973.

HADDAR, N.Z.; MAKNI, L.; ABDALLAH, H.B. Literature review of reuse in business process modeling, Software System Model, 13:975-989, 2014 
HALLIKAS, J.; KARKKAINEN, H.; LAMPELA, H, Learning in networks: an exploration from innovation perspective, International Journal of Technology Management, Vol. 45, Nos. 3/4, 2009.

HARRYSON, S.J.; DUDKOWSKI, R.; STERN, A. Transformation Networks in Innovation Alliances The Development of Volvo C70, Journal of Management Studies, 45, 2008.

HAUSMAN, A. Innovativeness among small businesses: Theory and propositions for future research, Industrial Marketing Management, 34, 773- 782, 2005.

HELD M., BLOCHINGER W., Structured collaborative workflow design, Future Generation Computer Systems, 25, 638-653, 2009.

HODGE, D. R.; GILLESPIE, D. F. Phrase completion: an alternative to Likert scales. Social Work Research, 27 (1), p. 45-55, 2003.

HOECHT, A.; TROTT, P. Outsourcing, information leakage and the risk of losing technology-based competencies, European Business Review, Vol. 18 Iss: 5, pp.395 - 412, 2006.

INDULSKA, M.; MATOOK, S. Improving the quality of process reference models: A quality function deployment-based approach, Decision Support Systems, 47, 60-71, 2009

INKPEN, A. C.; TSANG, E. W. K. Social capital, networks, and knowledge transfer, Academy of Management Review, 30, 146-66, 2005.

IYER, G.R.; LAPLACA, P.J.; SHARMA, A. Innovation and new product introductions in emerging markets - Strategic recommendations for the Indian market, Industrial Marketing Management, 35, 373-382, 2006.

JACOBIDES, M. G.; KNUDSEN, T.; AUGIER, M. Benefiting from innovation: value creation, value appropriation and the role of industry architectures, Research Policy, 35, 1200-21. 2006.

KASH, D.; RYCROFT, R. Emerging patterns of complex technological innovation, Technological Forecasting \& Social Change, 69, 581-606, 2002.

KAPLAN, B.; DUCHON, D. Combining qualitative and quantitative methods in information systems research: a case study, MIS Quarterly, (12:4), pp. 571-586, 1988.

KATZY, B.R.; CROWSTON, K. Competency rallying for technical innovation-The case of the Virtuelle Fabrik, Technovation, 28, 679-692, 2008.

KOTILLA, M.R.; RONI, P. Collaboration and trust in two organic food chains, British Food Journal, Vol. 110, N.4/5, 376-394, 2008.

KOSANKE, K. CIMOSA - Overview and status, Computers in Industry, Volume 27, Issue 2, Pages 101-109, 1995.

KNELL, M., SRHOLEC, M. Technological collaboration and foreign ownership across firms in Europe.

Report, Innovation Watch-Systematic, 2008. 
KRUGMAN, P. How the Economy Organizes Itself in Space: A Survey of the New Economic Geography, Working Papers 96-04-021, Santa Fe Institute, 1996.

LEE, S.; YONG, H. Distributed agile: project management in a global environment, Empirical Software Engineering, 15:204-217, 2010.

LESOURNE, J. Self-organization as a process in evolution of economic systems. In: Day, R.H., Chen, P. (Eds.), Nonlinear Dynamics and Evolutionary Economics. Oxford University Press, New York, pp. 150-166, 1993.

LICHTENSTEIN, B.M.B. Emergence as a process of self-organizing, Journal of Organizational Change Management, Vol. 13 No. 6, pp. 526-544, 2000.

LIKERT, R. A technique for the measurement of attitudes. Archives in Psychology, 140, p. 1-55, 1932.

LIU B.S.; MADHAVAN, R.; SUDHARSHAN, D. DiffuNET: The impact of network structure on diffusion of innovation, European Journal of Innovation Management, Vol. 8 No. 2, pp. 240-262, 2005.

LOUCOPOULOS, P.; KAVAKLI, V. Enterprise Knowledge Management and Conceptual Modelling, Conceptual Modeling, Volume 1565 of the series Lecture Notes in Computer Science pp 123-143, 1999.

LOWE, M.S.; WILLIAMS, A.M.; SHAW, G.; CUDWORTH, K. Self-organizing innovation networks, mobile knowledge carriers and diasporas: insights from a pioneering boutique hotel chain, Journal of Economic Geography 12, pp. 1113-1138, 2012.

LYONS, M. Knowledge and the modelling of complex systems, Futures, 37, 711-719, 2005.

MANN, S. Self-assembly and transformation of hybrid nano-objects and nanostructures under equilibrium and non-equilibrium conditions, Nature Materials, Vol.8, October 2009.

MANSON, S. Simplifying complexity: a review of complexity theory, Geoforum, 32, 405-414, 2001.

MARION, R. The Edge of Organization. Thousand Oaks, CA, Sage Publications, 1999.

MARION, R.; UHL-BIEN, M. Leadership in complex organizations, The Leadership Quarterly, 12, 389-418, 2001.

MARTIN, X.; SALOMON, R. Tacitness, learning and international expansion: a study of foreign direct investment in a knowledge-intensive industry. Organizational Science, 14, 297-351, 2003.

MCCARTHY, I.P.; RAKOTOBE-JOEL, T.; FRIZELLE, G. Complex systems theory: implications and promises for manufacturing organizations, International Journal of Manufacturing Technology and Management, Vol. 2, Nos. 1-7, 2000.

MCEVILY, B.; Marcus, A. Embedded ties and the acquisition of competitive capabilities, Strategic Management Journal, 26, 1033-55, 2005.

MOLINA-MORALES, F.X.; MERTÍNEZ-FERNÁNDEZ, M.T. Social Networks: Effects of Social Capital on Firm Innovation, Journal of Small Business Management, 48(2), pp. 258-279, 2010.

NIETO, M.J.; SANTAMARIA, L. The importance of diverse collaborative networks for the novelty of product innovation, Technovation, 27, 367-377, 2007. 
NONAKA, I. A dynamic theory of organizational knowledge creation, Organizational Science, Vol.5, N. 1, 1994.

OECD, The measurement of scientific and technological activities - Proposed Guidelines for collecting and interpreting technological innovation data, Organization for Economic Co-operation and Development, OECD Publishing, 2010.

OJASALO, J. Management of innovation networks: a case study of different approaches, European Journal of Innovation Management, Vol. 11 No. 1, pp. 51-86, 2008.

OLLUS, M.; JANSSON, K.; KARVONEN, I.; UOTI, M.; RIIKONEN, H. Supporting collaborative project management, Production Planning \& Control, Vol. 22, Nos. 5-6, July-September, 538-553, 2011.

OZMAN, M. Inter-firm networks and innovation: a survey of literature, Economics of Innovation and New Technology, Vol. 18, No. 1, 39-67, 2009.

PÁDUA, S.I.D.; CAZARINI, E.W.; INAMASU R.Y. Modelagem organizacional - captura dos requisitos organizacionais, Gestão \& Produção, v.11, n.2, p.197-209, 2004.

PALMBERG, C. The sources and success of innovations - Determinants of commercialisation and break-even times, Technovation, 26, 1253-1267, 2006.

PATHAK, S.D.; DAY, J.M.; NAIR, A.; SAWAYA, W.J.; KRISTAL, M.M. Complexity and Adaptivity in Supply Networks: Building Supply Network Theory Using a Complex Adaptive Systems Perspective, Journal compilation Decision Sciences Institute, Volume 38 Number 4, 2007.

PATRAKOSOL, B.; OLSON, D.L. How interfirm collaboration benefits IT innovation, Information \& Management, 44, 53-62, 2007.

PHELAN, S. A Note on the Correspondence Between Complexity and Systems Theory, Systemic Practice and Action Research, Vol. 12, No. 3, 1999.

POLACEK, G.A., GIANETTO, D.A., KHASHANAH, K., VERMA, D. On Principles and Rules in Complex Adaptive Systems: A Financial System Case Study, Systems Engineering Vol. 15, No. 4, 2012.

PRAJOGO, D.I.; AHMED, P.K. Relationships between innovation stimulus, innovation capacity, and innovation performance, R\&D Management, vol.36, no.5, pp.499-515, 2006.

PREHOFER, C.; BETTSTETTER, C. Self-organization in communication networks: Principles and design paradigms. IEEE Communications Magazine, 43(7):78-85, July 2005.

PROVAN, K.G.; FISH A.; SYDOW J. Interorganizational networks at the network level: A Review of the Empirical Literature on Whole Networks, Journal of Management, vol. 33 n.3, 479-516, 2007.

REGINE, B., LEWIN, R. Leading at the edge: How leaders influence complex systems. Emergence, 2(2), 5-23, 2000. 
REINHARTZ-BERGER, I.; SOFFER, P.; STURM, A. Extending the Adaptability of Reference Models, IEEE transactions on Systems, Man, and Cybernetics - Part A: Systems and Human, Edmonton, v. 40, n. 5, p. 1045-146, 2010

RITTER, T.; GEMÜNDEN, H.G. Network competence: Its impact on innovation success and its antecedents, Journal of Business Research, 56, 745- 755, 2003.

ROMERO, D.; MOLINA, A. Virtual organization breeding environments toolkit: reference model, management framework and instantiation methodology, Production Planning \& Control: The Management of Operations, v.21, n.2, 181-217, 2010

ROSE-ANDERSSEN, C.; ALLEN, P.M.; TSINOPOULOS, C.; MCCARTHY, I. Innovation in manufacturing as an evolutionary complex system, Technovation, 25, 1093-1105, 2005.

ROXENHALL, T. Network structure and innovation in strategic innovation networks, International Journal of Innovation Management, Vol. 17, No. 2, 2013.

RYCROFT, R.W.; KASH, D.E. Self-organizing innovation networks - implications for globalization, Technovation, 24, 187-197, 2004.

SAMMARRA, A.; BIGGIERO, L. Heterogeneity and Specificity of Inter-Firm Knowledge Flows in Innovation Networks, Journal of Management Studies, 45:4, 2008.

SARI, B.; SEN, T.; KILIC, S.E. Formation of dynamic virtual enterprises and enterprise networks, The International Journal of Advanced Manufacturing Technology, 34, 1246-1262, 2007.

SCHNEIDER, M.; SOMERS, M. Organizations as complex adaptive systems: Implications of Complexity Theory for leadership research, The Leadership Quarterly, 17, 351-365, 2006.

SCHOONMAKER, M.G.; CARAYANNIS, E.G. Assessing the Value of Regional Innovation Networks, Journal of the Knowledge Economy, 1:48-66, 2010.

SCHUH, G.; ROZENFELD, H.; ASSMUS, D.; ZANCUL, E. Process oriented framework to support PLM implementation, Computers in Industry, v.59, n.2/3, p.210-218, 2008.

SINGH, U.N. On the Origin of a Self-organizing System: Structural Versus Functional Organization, Journal of Theoretical Biology, 99, 15-20, 1982.

SMITH, A.C.T. Complexity theory for organisational futures studies, VOL. 7 NO. 3 ,pp. 22-30, Emerald Group Publishing Limited, ISSN 1463-6689, 2005.

SORIANO D.R., URBANO D., Overview of collaborative entrepreneurship: an integrated approach between business decisions and negotiations, Group Decision Negotiation, pp.419-430, 2009.

STOCK, G.N.; GREIS, N.P.; FISCHER, W.A. Firm size and dynamic technological innovation, Technovation, 22, 537-549, 2002.

STOJKOVIC, M.; SIMIC, V.; MILOSEVIC, D. Visualization of fish community distribution patterns using the self-organizing map: A case study of the Great Morava River system (Serbia), Ecological Modelling, Volume: 248 Pages: 20-29, 2013. 
SURANA, A.; KUMARA, S.; GREAVES, M.; RAGHAVAN, U.N. Supply-chain networks: a complex adaptive systems perspective, International Journal of Production Research, 43:20, 4235-4265, 2005. SWENSON, R. Emergent attractor and the law of maximum entropy production: foundations to a theory of general evolution, Systems Research, Vol. 6 No. 3, pp. 187-97, 1989.

THARUMARAJAH, A. A self-organising view of manufacturing enterprises, Computers in Industry, 51, 185-196, 2003.

THEOLEYRE, F.; VALOIS, F. A self-organization structure for hybrid networks, Ad Hoc Networks, 6, 393-407, 2008.

THORGREN S., WINCENT J., ORTQVIST D., Designing interorganizational networks for innovation: an empirical examination of network configuration, formation and governance, Journal of Engineering and Technology Management, pp.148-166, 2009.

TING, Y.; CHIU, H. How network competence and network location influence innovation performance, Journal of Business \& Industrial Marketing, 24/1, 46-55, 2009.

TONGMING, J. Study on the evolution of the innovation network in view of self-organizing theory, IEEE, International Conference on Computer Application and System Modeling, 2010.

TSAI, K.H., Collaborative networks and product innovation performance, Research Policy, 38, pp.765778, 2009.

TZENG, C. A review of contemporary innovation literature: A Schumpeterian perspective. Innovation: management, Policy \& Practice, v.11, 373-394, 2009.

UHL-BIEN, M.; MARION, R.; MCKELVEY, B. Complexity Leadership Theory: Shifting leadership from the industrial age to the knowledge era, The Leadership Quarterly, 18, 298-318, 2007.

ULBRICH, S.; TROITZSCH, H.; VAN DEN ANKER, F.; PLÜSS, A.; HUBER, C. How teams in networked organizations develop collaborative capability: processes, critical incidents and success factors, Production Planning \& Control, Vol. 22, Nos. 5-6, 488-500, 2011.

VALK, T.; CHAPPIN, M.M.H. Evaluating innovation networks in emerging technologies, Technological Forecasting \& Social Change, 78, 25-39, 2011.

VASILEIADOU, E.; SAFARZYNSKA, K. Transitions: Taking complexity seriously, Futures 42, 11761186, 2010.

VERNADAT, F. B. Enterprise Modeling and Integration: principles and applications, Chapman \& Hall, London, p. 1-27, 1996.

VERNADAT, F.B. Enterprise modeling and integration (EMI): current status and research perspectives, Annual Reviews in Control, 26, 15-25, 2002.

WADHAWAN, V.K. Complex Systems: An Introduction - Information Theory, Chaos Theory and Computational Complexity, Resonance, 14, 8, 2009.

WALKER, C.C.; DOOLEY, K.J The Stability of Self-Organized Rule-Following Work Teams, Computational \& Mathematical Organization Theory, 5:1, 5-30, 1999. 
WANG, F.; WANG, F.; HUANG, B; YANG, L.T. SONR: A reliable reputation system of self-organized network, Journal of Network and Computer Applications, 35, 914-926, 2012.

WANKE, P.F.; CORREA, H.L.; HIJJAR, M.F. Establishing the relationship between logistics complexity and supply chain objectives and decision areas in large companies operating in Brazil, Journal of Operations and Supply Chain Management, 3 (1), pp 34 - 54, 2010.

WESTERGREN, U.H.; HOLMSTRÖM, J. Exploring preconditions for open innovation: Value networks in industrial firms, Information and Organization, 22, 209-226, 2012.

WISWANATHAN, M.; SUDMAN, S. e JOHSON, M. Maximum versus meaningful discrimination in scale response: implications for validity of measurement of consumer perception about products. Journal of Business Research. n. 57, p. 08-24, 2004.

WU, F.; YENIYURT, S.; KIM, D.; CAVUSGIL, T. The impact of information technology on supply chain capabilities and firm performance: A resource-based view, Industrial Marketing Management, 35, 493-504, 2006.

YIN, R.K. Estudo de Caso - Planejamento e Métodos. Porto Alegre, Bookman, 2005.

ZENG, S.X.; XIE, X.M.; TAMC, C.M. Relationship between cooperation networks and innovation performance of SMEs, Technovation, 30, 181-194, 2010. 


\section{ANEXO A - EKD (Enterprise Knowledge Development) como metodologia de modelagem para a gestão do conhecimento}

Segundo o Manual de Oslo (OECD, 2006) o conhecimento desempenha um papel crucial no progresso da "economia baseada no conhecimento".

Conforme Bubenko et al. (2001), um modelo é uma maneira estruturada de representar o conhecimento de uma empresa a fim de melhorar a compreensão do seu contexto interno e externo, e facilitar a comunicação entre os agentes envolvidos. Para Kirikova (2000) um modelo precisa aliar a propriedade de representar o conhecimento em sua estrutura com a capacidade de transmitir este conhecimento às pessoas.

Kirikova (2000) enfatiza ainda que a compreensão adequada da organização envolve a noção de quais elementos constituem a empresa e como estes estão relacionados, como eles trabalham juntos, assim como o papel da empresa dentro do seu ambiente de atuação e os possíveis motivos para a mudança no comportamento do sistema como um todo.

Nurcan e Rolland (2003) afirmam que a metodologia EKD fornece um método para desenvolver e documentar o conhecimento organizacional e ajudar as empresas a desenvolverem modelos para a implantação de mudanças. O EKD mostra como a empresa está funcionando num determinado momento, quais os requisitos para a mudança e as razões para isso, quais alternativas podem ser visualizadas a fim de atingir estes requisitos, quais os critérios e argumentos para avaliar estas alternativas, ao mesmo tempo em que mapeia o conhecimento acumulado pela empresa.

A metodologia EKD normalmente requer o envolvimento de estrategistas, gerentes, equipes operacionais e especialistas em modelagem organizacional, os quais trabalharão na compreensão, no diagnóstico e no design de um novo modelo (BUBENKO et al., 2001).

\section{Submodelo do EKD}


Conforme Bubenko et al. (2001), a saída do EKD é um conjunto de modelos conceituais e inter-relacionados que fornecem uma visão multifacetada de uma empresa. Estes modelos serão um ponto de referência entre as diferentes áreas da organização, facilitando a comunicação, compreensão e comprometimento entre as partes envolvidas. Outro ponto de destaque é a independência tecnológica que a abstração retratada nos modelos proporciona, ou seja, o mesmo modelo pode ser implementado sobre diferentes plataformas tecnológicas, e mesmo assim eles permanecerão válidos.

O Modelo de Objetivos descreve os objetivos essenciais da empresa, ao mesmo tempo em que define a razão para os componentes dos demais modelos. Neste modelo os objetivos, problemas, ameaças e oportunidades são inter-relacionados para representar a visão e a estratégia da empresa, procurando mostrar o que a organização quer alcançar ou evitar.

O Modelo de Regras de Negócios é concebido em consonância com o modelo de objetivos e é usado para definir e manter explícitas as regras e políticas que norteiam o comportamento da empresa dentro do contexto de negócios. Neste modelo o foco está na política e nas regras, buscando mostrar como elas apóiam o Modelo de Objetivos (BUBENKO et al., 2001).

O Modelo de Processos de Negócios mapeia os fluxos físico (material) e lógico (informação). O relacionamento deste modelo com os demais justifica a presença de cada processo de negócio mapeado (BUBENKO et al., 2001).

No Modelo de Atores e Recursos o foco está na estrutura da organização, ou seja, nos agentes/pessoas, nas unidades, nos papéis e nos recursos, buscando-se identificar quais indivíduos são responsáveis pelos processos, objetivos e como eles se relacionam (BUBENKO et al., 2001).

O Modelo de Conceitos é usado para definir os termos e conceitos mencionados nos demais modelos, tornando mais clara a compreensão do conhecimento registrado em cada submodelo do EKD (BUBENKO et al., 2001).

O Modelo de Requisitos e Componentes técnicos torna-se relevante quando existe o objetivo de levantar requisitos para o desenvolvimento de um sistema computacional. Ele reúne a especificação dos requisitos técnicos tanto para o desenvolvimento quanto para a implantação de um sistema. Neste modelo aparecem quais são os requisitos técnicos que o sistema deve atender e como eles estão relacionados com os demais sub-modelos do EKD (BUBENKO et al., 2001).

A figura 23 mostra a estrutura da metodologia EKD. 


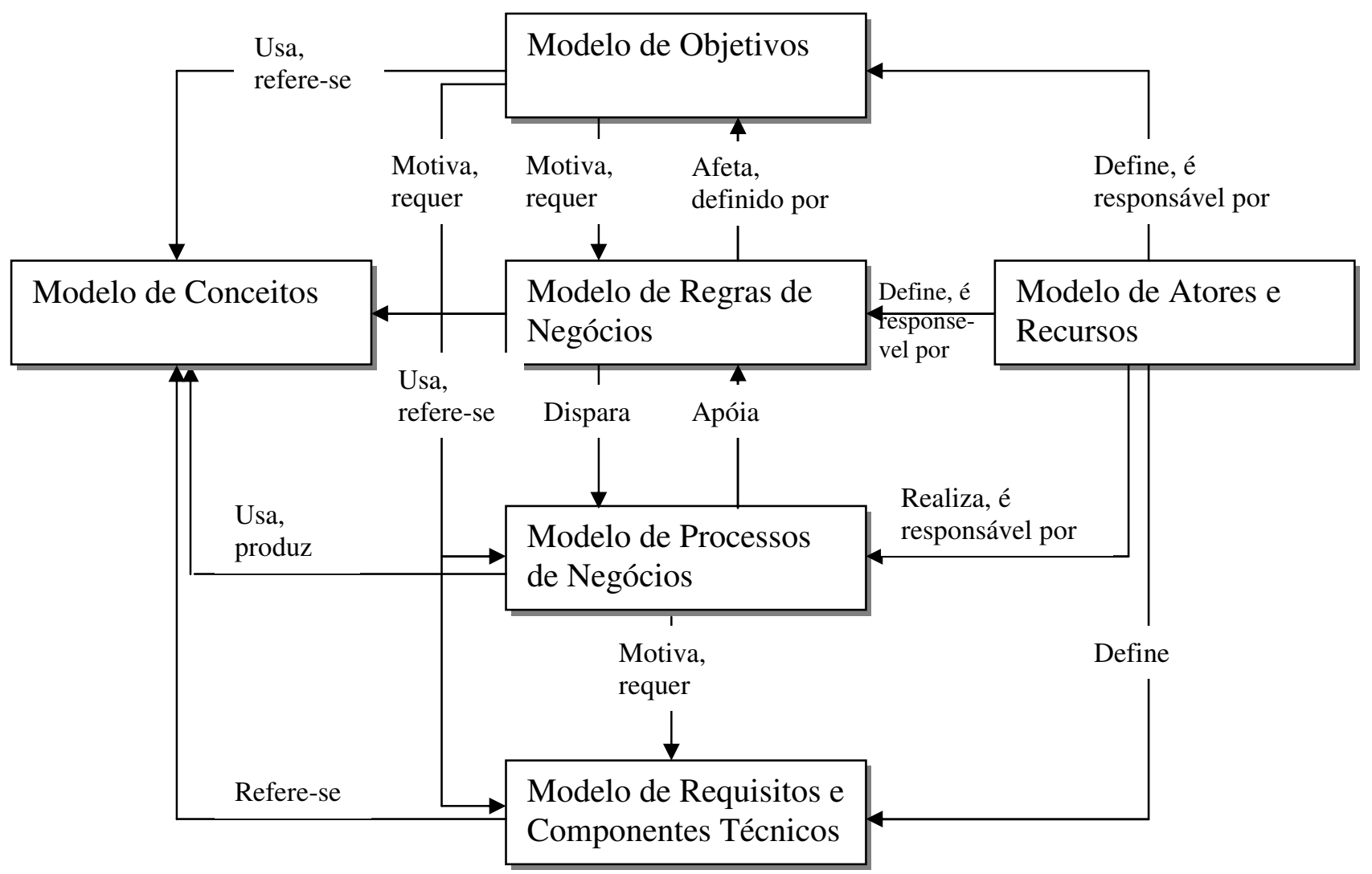

Figura 23: Os sub-modelos da metodologia EKD.

Importante destacar que, de acordo com Nurcan e Rolland (2003), a combinação desses sub-modelos produz uma saída capaz de descrever o novo sistema a ser construído e a organização na qual ele (sistema) irá operar. O EKD vai um pouco além dos modelos orientados a decisão e fornece um processo guia capaz de indicar quais atividades são adequadas sob determinadas situações e como realizá-las visando a mudança organizacional.

O EKD pode ajudar a criar o ambiente que Prajogo e Ahmed (2005) sugerem como favorável e necessário à inovação. Isso através do mapeamento, acúmulo e compartilhamento de conhecimento, possibilidade de simulação de cenários, vínculo claro entre processos e objetivos organizacionais, assim como entre as regras, processos e objetivos.

Para Saad et al. (2005) as empresas precisam investir na identificação e preservação do conhecimento crucial, mais precisamente aquele que contribui com os objetivos estratégicos, que tem sido efetivamente utilizado e que, se perdido, pode ser de difícil recuperação devido a restrições de prazo, custo e complexidade. Saaty (2008) considera que não é o volume de informações que contribui para melhorar a compreensão de um problema, mas a qualidade das informações envolvidas. 


\section{Relacionamento entre os submodelos}

As ligações entre os sub-modelos mapeiam a dinâmica do conhecimento organizacional. Enquanto os sub-modelos abordam o domínio do problema a partir de diferentes perspectivas, as ligações entre os modelos garantem a integração destas perspectivas e fornecem uma visão completa e consolidada do domínio modelado.

Conforme Bubenko et al. (2001), as ligações entre os sub-modelos tornam o modelo principal rastreável como um todo. A declaração de um objetivo no Modelo de Objetivos pode ser definida mais claramente dentro do Modelo de Conceitos, estabelecendo-se desta forma uma ligação entre um componente no Modelo de Objetivos e o correspondente no Modelo de Conceitos. Da mesma forma as ligações entre o Modelo de Objetivos e o Modelo de Processos justificam a presença de cada processo em apoio aos objetivos a serem perseguidos pela organização.

Os relacionamentos sugeridos por Bubenko et al. (2001) entre os diversos sub-modelos da metodologia EKD facilitam a compreensão do porquê da presença de certos processos, regras ou requisitos. A seguir algumas considerações feitas sobre estes relacionamentos a partir de Bubenko et al. (2001):

- Ligações entre o Modelo de Objetivos e o Modelo de Regras do Negócio mostram quais e como as principais regras do negócio afetam os objetivos declarados pela organização.

- Ligações entre o Modelo de Objetivos e o Modelo de Atores e Recursos esclarecem a presença de cada ator e seus respectivos papéis dentro do contexto organizacional.

- Ligações entre o Modelo de Objetivos e o Modelo de Conceitos têm a função de descrever os componentes do Modelo de Objetivos, facilitando a compreensão conceitual destes últimos dentro do contexto de negócios.

- Ligações entre o Modelo de Objetivos e o Modelo de Processos de Negócio mostram quais processos são requeridos para o alcance dos objetivos estabelecidos no Modelo de Objetivos.

- Ligações entre o Modelo de Atores e Recursos e o Modelo de Regras do Negócio descrevem como componentes do Modelo de Atores e Recursos estão relacionados com o Modelo de Processos de Negócio através das regras estabelecidas dentro do Modelo de Regras do Negócio.

- Ligações entre o Modelo de Regras do Negócio e o Modelo de Processos de Negócio descrevem como as regras expressam as condições para que os processos sejam disparados.

- Ligações entre o Modelo de Processos de Negócio e o Modelo de Conceitos esclarecem o contexto em que determinadas atividades ocorrem dentro dos processos. 
- Ligações entre o Modelo de Requisitos e Componentes Técnicos e os componentes de outros sub-modelos podem ser mais complexas do que os relacionamentos binários normais. O Modelo de Processos de Negócio motiva os objetivos e requisitos de um sistema de informação, assim como o Modelo de Regras de Negócios relaciona restrições impostas pelo negócio que precisam ser contempladas dentro deste sistema.

\section{Avaliação da metodologia EKD}

De acordo com Nurcan e Rolland (2003) o EKD é uma metodologia para o gerenciamento da mudança organizacional. Ele fornece um método para desenvolver e documentar o conhecimento organizacional, ajudando as empresas a desenvolver modelos para definir e implementar as mudanças desejadas a partir da perspectiva do próprio conhecimento organizacional.

Nurcan e Rolland (2003) sugerem que para dominar o processo de mudança é preciso 04 grandes passos:

- Análise reversa: abstrair um modelo a partir da realidade atual ( $A S-I S)$.

- Definição da mudança: definir a realidade futura $(T O-B E)$ a partir do modelo atual.

- Implementação da Mudança: implementação da nova organização a partir do modelo TO$B E$.

- Integração legada: levar em conta o contexto atual durante a implementação da mudança.

Pádua et al. (2004) sustenta que o EKD apresenta um framework para a empresa organizar o seu conhecimento a fim de formar a base necessária para operacionalizar estes quatro passos. O conjunto de modelos da metodologia permite que seja registrada uma imagem do estado atual, que sejam construídos cenários futuros, e que haja fácil compreensão e justificativa das decisões tomadas rumo à implementação das mudanças desejadas.

Nurcan e Rolland (2003) sugerem como diferentes estratégias podem ser montadas a partir da combinação de diferentes caminhos percorridos pelo grafo produzido pelo EKD. De acordo com os autores, uma estratégia pode ser compreendida como um método para se alcançar um objetivo e a maneira como este objetivo pode ser alcançado pode ser capturada percorrendose o grafo formado pelo modelo de objetivos em interface com os demais modelos.

Bubenko et al. (2001) sugere que a participação dos stakeholders durante a fase de modelagem é muito importante. Pádua et al. (2004) comenta que a abrangência com que a metodologia integra as diversas perspectivas do ambiente modelado resulta numa melhor compreensão por parte dos stakeholders, ao mesmo tempo em que estimula a participação deles. 
Conforme sugerido por Pádua et al. (2004), pode-se utilizar técnicas com rigor matemático para analisar os modelos produzidos pelo Modelo de Processos de Negócios do EKD. As redes de Petri (Zisman, 1977) podem ser usadas para responder à questão da falta de uma sintaxe e uma semântica bem definidas, responsável por dificultar análises mais complexas de consistência e completude de cada modelo Pádua et al. (2004).

Algumas razões para utilizar redes de Petri na validação de modelos de processos de negócios:

- Possibilidade de verificar se o processo termina num estado aceitável e se há alguma relação de dependência inconsistente entre as tarefas (Adam, 1998).

- Apresentação de uma semântica formal clássica que permite a definição não-ambígua de um processo de negócio (Aalst, 1998).

- Os estados podem ser representados explicitamente, o que permite que as escolhas sejam explícitas na modelagem de processos. Somando-se a isso, todas as construções de rotas existentes nos sistemas de gerenciamento de processos podem ser modeladas (PÁDUA et al., 2004).

Outra questão relacionada com a utilização da metodologia EKD é a definição do papel do facilitador. Como sugerido por Bubenko e Stirna (1998), o facilitador responsável pelo processo de modelagem precisa garantir que o esforço investido não se dilua em refinamentos supérfluos. A liberdade proporcionada pela abertura que o método oferece precisa ser continuamente acompanhada para evitar um nível de detalhamento que não agregue valor ao modelo produzido.

Para minimizar os problemas de uso da metodologia EKD, Bubenko et al. (2001) sugere alguns procedimentos que, na verdade, extrapolam a esfera técnica de uma simples modelagem organizacional:

- Introdução da metodologia à empresa: evidenciar para os gestores e para todos os envolvidos os possíveis benefícios agregados pelo método, mostrando exemplos de cases de sucesso.

- Definição precisa do escopo e do foco do projeto: todos os envolvidos precisam estar cientes do propósito e dos resultados esperados do projeto.

- Preparação e atribuição de papéis: o grupo precisa cobrir a maior área possível do domínio de conhecimento requisitado pelo projeto.

- Apoio da alta administração da empresa e disponibilidade de tempo e recursos. 


\section{APÊNDICE A - Questionário}

A seguir está listado o questionário utilizado nas entrevistas para auxiliar a responder as questões de pesquisa propostas neste trabalho. Todas as questões foram elaboradas a partir dos principais conceitos discutidos na revisão da literatura sobre inovação, redes de inovação e sistemas complexos. O questionário procura verificar se as unidades empresariais estudadas apresentam características de sistemas complexos, como a auto-organização surge e/ou se manifesta, quais os elementos de apoio para ela acontecer, e quais os principais benefícios obtidos por seu intermédio.

\section{Seção Número 1: As redes de inovação apresentam características de sistemas complexos.}

1.1 (mudança constante) A operação da rede de inovação foi influenciada por eventos provocados por estímulos internos e externos à rede? (Conceito 14)

(a) Os parceiros eram entidades independentes no mercado, possuíam seus próprios clientes, fornecedores, produtos. (estavam sujeitos às forças externas)

(b) O ambiente que cercava a rede apresentava disputa por clientes, competição para o lançamento de novos produtos.

(c) $\mathrm{O}$ ambiente que cercava a rede caracteriza-se por uso intensivo de tecnologia

(d) O ciclo de vida dos produtos desenvolvidos pela rede tem encurtado ao longo do tempo

(e) $\mathrm{O}$ conhecimento necessário para operar neste segmento de mercado tem-se mostrado cada vez mais heterogêneo e disperso no próprio ambiente

1.2 (comportamento não proporcional) A saída da rede (resultados) foi não proporcional aos estímulos de entrada? (Conceito 13)

(a) Algum pequeno evento imprevisto disparou grandes mudanças no resultado esperado 
(b) Eventos relativamente simples e inicialmente não previstos tiveram seus efeitos maximizados à medida que se propagaram pela rede

(c) A rede lidou bem com os problemas até certo ponto, depois qualquer nova dificuldade gerava grande estresse

(d) O uso de um processo de trabalho não equalizou a entrada e a saída do projeto

(e) Apesar do uso pleno de todos os recursos, os resultados ficaram aquém das expectativas

1.3 (evolução não linear da topologia) A estrutura da rede sofreu variações/mudanças não lineares durante a fase de operação? (Conceito 12)

(a) Algum evento não planejado mudou a estrutura de poder da rede

(b) Ocorreu a inserção não prevista de novos agentes na rede no decorrer do projeto

(c) Ocorreu a saída não prevista de novos agentes na rede no decorrer do projeto

(d) A força do vínculo entre os parceiros mudou no decorrer do projeto de forma não prevista

(e) A densidade (número de relacionamentos) da rede mudou no decorrer do projeto de forma não prevista

1.4 (não redutibilidade) A rede apresentou comportamento não compreendido apesar da atenção/controle ao comportamento individual dos agentes? (Conceito 11)

(a) O resultado proporcionado pela rede foi além da soma individual dos esforços

(b) A rede produziu conhecimento próprio/novo (houve inferências a partir do conhecimento individual de cada parceiro)

(c) Os parceiros mostraram-se dependentes uns dos outros para realizar suas atividades

(d) Os parceiros sofreram influências recíprocas ao longo do tempo

(e) O controle da rede foi feito a partir de um senso em comum de gestão (não prevaleceu uma lógica única)

1.5 (Controle descentralizado, indireto, catalítico) A forma de controle apresentada pela rede mostra-se descentralizada, indireta e catalítica? (Conceito 8, 9, 24)

(a) Houve um equilíbrio de poder entre os parceiros da rede

(b) As decisões foram tomadas de forma compartilhada

(c) A gestão da rede busca influenciar e motivar os parceiros no comprometimento com os objetivos da rede.

(d) $\mathrm{O}$ controle reuniu condições para que a comunicação fosse aberta e transparente

(e) $\mathrm{O}$ controle foi determinante na distribuição dos recursos e responsabilidade 


\section{Seção Número 2: Como surge a auto-organização}

2.1 (auto-organização: comportamento coletivo espontâneo) A rede apresentou em determinados momentos comportamento coletivo espontâneo como resultado da propagação de movimentos localizados? (Conceito 30)

(a) Alguma nova idéia e/ou comportamento isolado apresentado no decorrer do projeto foi responsável por mudanças significativas no fluxo de trabalho da rede como um todo

(b) Novas negociações foram estabelecidas entre os parceiros para redefinir a distribuição de benefícios e/ou riscos detectados no decorrer do projeto

(c) Novos movimentos foram provocados devido a mudanças não previstas no ambiente (oportunidades, ameaças)

(d) Novos movimentos foram provocados pela adoção de alguma nova tecnologia ao longo do projeto

(e) Novos comportamentos foram gerados pela adoção de algum novo procedimento de trabalho ao longo do projeto

2.2. (mudança espontânea na estrutura) Percebeu-se na rede mudanças espontâneas na estrutura/morfologia? (Conceito 31)

(a) Novas ligações entre os parceiros foram estabelecidas durante a operação da rede

(b) Ocorreu uma redistribuição dos papéis e/ou responsabilidades durante a operação da rede por iniciativa dos próprios parceiros

(c) Ocorreu a entrada não prevista inicialmente de novos parceiros durante a operação da rede devido a algum movimento local

(d) Ocorreu a saída não prevista inicialmente de novos parceiros durante a operação da rede devido a algum movimento local

(e) Ocorreram mudanças na estrutura de poder da rede devido a iniciativas locais

2.3 (aprendizagem/relacionamentos) Os vínculos entre os parceiros foram fortes o suficiente para permitir o fluxo de conhecimentos e as trocas de experiências? (Conceito 20)

(a) Havia um clima de confiança em termos de ética entre as partes envolvidas

(b) Havia um clima de confiança em termos de competência técnica entre as partes envolvidas

(c) Percebeu-se que havia comprometimento entre as partes 
(d) Ocorreu um compartilhamento espontâneo de conhecimento

(e) Ocorreu o uso do conhecimento compartilhado

2.4. (Condições para movimentos locais espontâneos, bottom up) Houve algum tipo de incentivo para que os parceiros tivessem iniciativas próprias? (Conceito 8)

(a) Ocorreram reuniões periódicas para discussão de novas idéias visando resolver problemas ou aproveitar oportunidades.

(b) As iniciativas individuais, desde que bem alinhadas com os objetivos gerais, foram bem recebidas e apoiadas

(c) Havia vários canais de comunicação disponíveis e de fácil acesso como e-mail, banco de idéias, fórum, telefone, vídeo-conferência

(d) A rede, enquanto entidade/sistema, demonstrou disposição para mudar

(e) A rede reconheceu (recompensou com dinheiro, novos contratos, prestígio) as iniciativas e esforços próprios/individuais

2.5 (influência/interdependência) Os parceiros na rede apresentaram uma relação de influência recíproca e de interdependência? (Conceito 16)

(a) Ficou perceptível que o conhecimento individual isolado era insuficiente para obter o sucesso desejado

(b) As atividades realizadas pelos parceiros estavam ligadas entre si de alguma forma

(c) As ligações entre os parceiros eram fortes, com intensa troca de conhecimentos e recursos

(d) Ocorreram situações nas quais um parceiro precisou aguardar que outro terminasse uma atividade para que ele pudesse iniciar a sua

(e) Os parceiros associavam o sucesso da rede ao seu próprio sucesso individual

\section{Seção Número 3: Como permitir que a auto-organização ocorra}

3.1 (controle descentralizado) Existiu um equilíbrio de poder na rede?

(a) A empresa proprietária do projeto estava aberta a mudanças

(b) O núcleo de parceiros que compunha a rede possuía poderes semelhantes

(c) Para o caso de mudanças imprevistas, negociações abertas foram estabelecidas

(d) Quando necessário procurou-se um equilíbrio entre competição e colaboração

(e) As situações não previstas que poderiam impactar o projeto foram negociadas na rede 
3.2 (controle descentralizado) As decisões foram tomadas de forma compartilhada?

(a) Havia alguma forma/método para apoiar a tomada de decisão

(b) Havia informação suficiente para apoiar a tomada de decisão

(c) As decisões tiveram suas raízes sempre no conhecimento compartilhado

(d) Várias perspectivas e fontes foram analisadas para cada tomada de decisão

(e) Todos os parceiros tiveram oportunidade de manifestação

3.3 (controle indireto) O tipo de controle forneceu motivação para o estreitamento dos relacionamentos?

(a) Definiu claramente os critérios para integrar a rede

(b) Indicou claramente os benefícios da rede

(c) Reconheceu a contribuição dos parceiros

(d) Definiu claramente a política de proteção da propriedade intelectual

(e) Distribuiu de maneira adequada os benefícios

3.4 (controle indireto) O tipo de controle forneceu motivação adicional (além dos contratos) para o cumprimento das metas

(a) As metas estabelecidas refletiam os objetivos principais

(b) As metas estabelecidas refletiam o consenso dos parceiros

(c) As metas estabelecidas estavam dentro de um cronograma exequiível

(d) As metas estabelecidas estavam dentro de um orçamento exeqüível

(e) Havia o comprometimento dos parceiros com as metas (auto-gestão)

3.5 (controle catalítico) O tipo de controle reuniu condições para que a comunicação fosse aberta e transparente?

(a) O controle providenciou canais de comunicação abertos

(b) O controle providenciou canais de comunicação acessíveis

(c) O controle colaborou para que eventuais diferenças nas competências técnicas não prejudicassem a comunicação entre os parceiros

(d) $\mathrm{O}$ controle facilitou a ocorrência de reuniões não previstas frente a novas oportunidades e/ou desafios

(e) O controle incentivou a divulgação clara das decisões tomadas 
3.6 (controle catalítico) O tipo de controle auxiliou na distribuição dos recursos e das responsabilidades?

(a) O controle ajudou na identificação das competências dos parceiros e das responsabilidades a serem distribuídas

(b) O controle ajudou a organizar uma infra-estrutura de recursos para ser utilizada por todos

(c) O controle certificou-se que todos estavam capacitados para usar os recursos disponíveis

(d) O controle auxiliou na liberação dos recursos de acordo com as responsabilidades

(e) O controle interveio no sentido de providenciar recursos sempre que necessário

\section{Seção Número 4: Como fazer para que a auto-organização traga benefícios para a rede}

4.1 (alinhamento) Ocorreu o alinhamento dos agentes em relação aos objetivos globais da rede (dessa forma pôde-se obter uma canalização dos movimentos de auto-organização)?

(a) Todos conheciam os objetivos da rede e canalizaram iniciativas individuais para eles

(b) Todos visualizavam benefícios individuais nos objetivos da rede

(c) Havia um comprometimento de todos os envolvidos

(d) As metas refletiam bem os objetivos globais da rede

(e) Todos estavam de acordo com as metas

4.2 (aprendizagem) A aprendizagem, enquanto geração e uso do conhecimento, funcionou como pivô central para a condução dos relacionamentos?

(a) Ocorreram movimentos de internalização do conhecimento (uso de conhecimento previamente documentado pelos agentes da rede)

(b) Ocorreram movimentos de externalização do conhecimento (documentação do conhecimento individualizado nos agentes)

(c) Ocorreram movimentos de socialização do conhecimento (transferência de conhecimento entre as pessoas)

(d) Ocorreram movimentos de combinação do conhecimento (uso de ferramentas de TI para extrair novas informações a partir de bancos de dados existentes)

(e) Novas ideias e conceitos surgiram a partir do esforço para compartilhar conhecimentos

4.3 (comprometimento) Ocorreram iniciativas espontâneas a partir de problemas e/ou oportunidades isolados ligados aos macro objetivos 
(a) Os parceiros não ficaram presos a um único papel, pelo contrário, trabalharam olhando sempre para os objetivos estabelecidos

(b) Os parceiros, dentro de suas atribuições, procuraram usar todos os recursos necessários para realizar suas atividades

(c) Novos conhecimentos foram compartilhados diante de novas situações

(d) Novas idéias foram defendidas pelos parceiros ao longo do projeto

(e) Novos relacionamentos foram estabelecidos por iniciativa dos próprios parceiros

4.4 (ligações fortes/fracas) A rede possuía um núcleo coeso vinculado a uma periferia de ligações fracas.

(a) Os parceiros da rede já possuíam um histórico de colaboração

(b) Os parceiros do núcleo da rede estavam alinhados

(c) Os parceiros do núcleo estavam comprometidos

(d) Quando preciso, cada parceiro acionou a sua rede particular de contatos

(e) A maior parte do conhecimento transferido foi tácito

4.5 (movimentos bottom up) Havia incentivos para apoiar a propagação de movimentos isolados e com potencial através da rede?

(a) Havia apoio para o surgimento de comportamentos espontâneos dos parceiros

(b) Havia incentivo para o aumento da densidade da rede (estabelecimentos de novos relacionamentos)

(c) Havia um comitê (ou mecanismo) para analisar o comportamento geral da rede

(d) Havia um comitê (ou mecanismo) para analisar comportamentos isolados na rede

(e) Foram estabelecidos critérios (metas, indicadores) para identificar os movimentos com maior potencial

Os dados coletados em campo foram compilados na tabela abaixo. 
Tabela 8: Compilação dos dados levantados no questionário

\begin{tabular}{|c|c|c|c|c|c|c|c|c|c|c|c|}
\hline \multirow{2}{*}{\multicolumn{2}{|c|}{$\begin{array}{r}\text { Total de pontos Teórico } \\
\text { Total de pontos Real }\end{array}$}} & $\begin{array}{l}\text { Unid. } 1 \\
100\end{array}$ & $\begin{array}{l}\text { Unid. } 2 \\
100\end{array}$ & $\begin{array}{c}\text { Unid. } 3 \\
100\end{array}$ & $\begin{array}{c}\text { Unid. } 4 \\
100\end{array}$ & $\begin{array}{l}\text { Unid. } 5 \\
100\end{array}$ & $\begin{array}{l}\text { Unid. } 6 \\
100\end{array}$ & $\begin{array}{c}\text { Unid. } 7 \\
100\end{array}$ & $\begin{array}{l}\text { Unid. } 8 \\
100\end{array}$ & MÉDIA & \\
\hline & & 43,7 & 40,5 & 57,0 & 45,4 & 41,8 & 50,4 & 39,8 & 43,9 & 45,31 & $45 \%$ \\
\hline $\begin{array}{l}\text { SEÇÃO 1-Identificação de } \\
\text { características de sistemas complexos }\end{array}$ & $\begin{array}{l}\text { Vale } 25 \\
\text { pontos }\end{array}$ & 18,0 & 18 & 20 & 15 & 15 & 18 & 17 & 14 & 16,88 & $68 \%$ \\
\hline Q2 - comportamento não proporcional & $\begin{array}{l}\text { Vale } 5 \\
\text { pontos }\end{array}$ & 4 & 5 & 5 & 3 & 2 & 2 & 3 & 3 & 3,38 & $68 \%$ \\
\hline Q3 - evolução não linear da topologia & $\begin{array}{l}\text { Vale } 5 \\
\text { pontos }\end{array}$ & 3 & 4 & 4 & 3 & 2 & 4 & 3 & 2 & 3,13 & $63 \%$ \\
\hline Q4 - não redutibilidade & $\begin{array}{l}\text { Vale } 5 \\
\text { pontos }\end{array}$ & 4 & 3 & 4 & 3 & 3 & 5 & 4 & 3 & 3,63 & $73 \%$ \\
\hline $\begin{array}{l}\text { SEÇÃO 2-Ocorrência da auto- } \\
\text { organização durante os projetos }\end{array}$ & $\begin{array}{l}\text { Vale } 25 \\
\text { pontos }\end{array}$ & & & & & & & & & 8,63 & $35 \%$ \\
\hline $\begin{array}{l}\text { Q1 - comportamento coletivo } \\
\text { espontâneo }\end{array}$ & $\begin{array}{l}\text { Vale } 5 \\
\text { pontos }\end{array}$ & $\mathbf{0}$ & $\mathbf{0}$ & $\mathbf{1}$ & 2 & $\mathbf{0}$ & 1 & $\mathbf{0}$ & $\mathbf{1}$ & 0,63 & $13 \%$ \\
\hline Q2 - mudança espontânea na estrutura & $\begin{array}{l}\text { Vale } 5 \\
\text { pontos }\end{array}$ & 1 & 1 & $\mathbf{1}$ & 1 & 2 & $\mathbf{0}$ & $\mathbf{0}$ & 1 & 0,88 & $18 \%$ \\
\hline
\end{tabular}




\begin{tabular}{|c|c|c|c|c|c|c|c|c|c|c|c|}
\hline Q3 - aprendizagem e/ou relacionamentos & $\begin{array}{l}\text { Vale } 5 \\
\text { pontos }\end{array}$ & 2 & 3 & 2 & 3 & 2 & 3 & 2 & 3 & 2,50 & $50 \%$ \\
\hline $\begin{array}{l}\text { Q4 - condições para movimentos locais } \\
\text { espontâneos, bottom up }\end{array}$ & $\begin{array}{l}\text { Vale } 5 \\
\text { pontos }\end{array}$ & $\mathbf{1}$ & 1 & 2 & 2 & 3 & 3 & $\mathbf{1}$ & 2 & 1,88 & $38 \%$ \\
\hline Q5 - influência e/ou interdependência & $\begin{array}{l}\text { Vale } 5 \\
\text { pontos }\end{array}$ & 4 & 3 & 3 & 2 & 4 & 2 & 2 & 2 & 2,75 & $55 \%$ \\
\hline $\begin{array}{l}\text { SEÇÃO 3-Existência de elementos } \\
\text { para permitir que o fenômeno da } \\
\text { auto-organização ocorra }\end{array}$ & $\begin{array}{l}\text { Vale } 25 \\
\text { pontos }\end{array}$ & 11,69 & 7,51 & 15,02 & 13,35 & 10,84 & 13,36 & 10,85 & 10,86 & 11,68 & $47 \%$ \\
\hline $\begin{array}{l}\text { Q1 - controle descentralizado: equilíbrio } \\
\text { de poder na rede }\end{array}$ & $\begin{array}{l}\text { Vale } 4,17 \\
\text { pontos }\end{array}$ & $\mathbf{0}$ & $\mathbf{0}$ & $\mathbf{0 , 8 4}$ & $\mathbf{0 , 8 4}$ & $\mathbf{0}$ & 1,67 & $\mathbf{0}$ & 1,67 & 0,63 & $13 \%$ \\
\hline $\begin{array}{l}\text { Q2 - controle descentralizado: processo } \\
\text { decisório compartilhado }\end{array}$ & $\begin{array}{l}\text { Vale } 4,17 \\
\text { pontos }\end{array}$ & $\overline{0,84}$ & 0 & 1,67 & 0,84 & 1,67 & 0,84 & 0,84 & 0,84 & 0,94 & $19 \%$ \\
\hline $\begin{array}{l}\text { Q4 - controle indireto: provedor de } \\
\text { motivação para cumprimento das metas }\end{array}$ & $\begin{array}{l}\text { Vale } 4,17 \\
\text { pontos }\end{array}$ & 1,67 & 0,84 & 2,5 & 2,5 & 2,5 & 3,34 & 1,67 & 1,67 & 2,09 & $42 \%$ \\
\hline $\begin{array}{l}\text { Q5 - controle catalítico: fornecedor de } \\
\text { condições para comunicação aberta e } \\
\text { transparente }\end{array}$ & $\begin{array}{l}\text { Vale } 4,17 \\
\text { pontos }\end{array}$ & 3,34 & 4,17 & 3,34 & 2,5 & 2,5 & 3,34 & 2,5 & 1,67 & 2,92 & $58 \%$ \\
\hline $\begin{array}{l}\text { Q6 - controle catalítico: responsável por } \\
\text { distribuir recursos e responsabilidades }\end{array}$ & $\begin{array}{l}\text { Vale } 4,17 \\
\text { pontos }\end{array}$ & 4,17 & 1,67 & 4,17 & 3,34 & 2,5 & 3,34 & 4,17 & 3,34 & 3,34 & $67 \%$ \\
\hline
\end{tabular}




\begin{tabular}{|c|c|c|c|c|c|c|c|c|c|c|c|}
\hline $\begin{array}{l}\text { SEÇÃO 4-Ocorrência de benefícios da } \\
\text { auto-organização para os objetivos da } \\
\text { unidade empresarial }\end{array}$ & $\begin{array}{l}\text { Vale } 25 \\
\text { pontos }\end{array}$ & 6 & 7 & 13 & 7 & 5 & 10 & 7 & 10 & 8,13 & $33 \%$ \\
\hline $\begin{array}{l}\text { Q1 - canalização de esforços: } \\
\text { alinhamento dos agentes com os } \\
\text { objetivos globais da rede }\end{array}$ & $\begin{array}{l}\text { Vale 5 } \\
\text { pontos }\end{array}$ & 1 & 1 & 2 & 1 & 1 & 1 & 2 & 2 & 1,38 & $28 \%$ \\
\hline $\begin{array}{l}\text { Q3 - Movimentos isolados: incentivos } \\
\text { para apoiar a propagação de movimentos }\end{array}$ & $\begin{array}{l}\text { Vale } 5 \\
\text { pontos }\end{array}$ & 1 & 1 & 3 & 1 & 1 & 1 & 2 & 3 & 1,63 & $33 \%$ \\
\hline $\begin{array}{l}\text { Q4 - Estrutura da rede: núcleo coeso } \\
\text { cercado por ligações fracas }\end{array}$ & $\begin{array}{l}\text { Vale } 5 \\
\text { pontos }\end{array}$ & 2 & 4 & 4 & 3 & 2 & 5 & 3 & 3 & 3,25 & $65 \%$ \\
\hline
\end{tabular}




\section{APÊNDICE B - Método de escolha dos elementos presentes nos modelos}

Este Apêndice apresenta o critério utilizado para justificar a escolha dos elementos presentes nos modelos apresentados na Seção 8.2. A seleção de cada elemento que compõe os modelos que representam o estado "as-is" da formação e operação das alianças estudadas baseou-se na frequiência desses elementos dentro do estudo de caso. Apenas elementos que aparecem em três ou mais unidades empresariais foram considerados no modelo AS-IS consolidado. Esse critério foi utilizado porque o questionário aplicado revelou que individualmente nenhuma unidade apresentou características muito distintas uma das outras no que tange às parcerias, por isso os elementos identificados em cada unidade empresarial tem exatamente a mesma relevância para a pesquisa. Além disso, essa reincidência dos elementos nas diversas unidades estudadas remete à idéia de melhores práticas adotadas de maneira ampla no ambiente empresarial.

Os quadros abaixo resumem os dados. O primeiro quadro faz referência aos elementos presentes no Modelo de Objetivos consolidado (Figura 3). Nela está identificado cada elemento, a unidade na qual ele foi identificado, e o número total de ocorrências.

\begin{tabular}{|l|c|c|c|c|c|c|c|c|c|}
\hline Objetivos & U1 & U2 & U3 & U4 & U5 & U6 & U7 & U8 & Total \\
\hline $\begin{array}{l}\text { 1. Ampliar a liderança no segmento de } \\
\text { eletrodomésticos }\end{array}$ & & $\mathrm{x}$ & & & & $\mathrm{x}$ & $\mathrm{x}$ & $\mathrm{x}$ & 4 \\
\hline 2. Melhorar a capacidade de inovação & & & $\mathrm{x}$ & & $\mathrm{x}$ & $\mathrm{x}$ & $\mathrm{x}$ & & 4 \\
\hline 2.1 Acelerar o PDP & & $\mathrm{x}$ & $\mathrm{x}$ & $\mathrm{x}$ & $\mathrm{x}$ & $\mathrm{x}$ & $\mathrm{x}$ & & 6 \\
\hline $\begin{array}{l}\text { 2.2 Padronizar o PDP nas diversas } \\
\text { plantas e integrar as diferentes áreas }\end{array}$ & $\mathrm{x}$ & $\mathrm{x}$ & & & & $\mathrm{x}$ & $\mathrm{x}$ & & 4 \\
\hline $\begin{array}{l}\text { 2.3 Ampliar a validação digital dos } \\
\text { produtos }\end{array}$ & & $\mathrm{x}$ & $\mathrm{x}$ & & & $\mathrm{x}$ & $\mathrm{x}$ & & 4 \\
\hline
\end{tabular}




\begin{tabular}{|c|c|c|c|c|c|c|c|c|c|}
\hline 2.4 Utilizar a Engenharia Simultânea & $\mathrm{x}$ & & $\mathrm{x}$ & & & $\mathrm{x}$ & $\mathrm{X}$ & & 4 \\
\hline $\begin{array}{l}\text { 3. Entregar benefícios } \mathrm{p} / \text { consumidores, } \\
\text { acionistas e comunidade }\end{array}$ & & & $\mathrm{x}$ & $\mathrm{x}$ & $\mathrm{x}$ & & & & 3 \\
\hline $\begin{array}{l}\text { 3.1 Reduzir custos operacionais do } \\
\text { ciclo de vida do produto }\end{array}$ & $\mathrm{x}$ & $\mathrm{x}$ & & $\mathrm{x}$ & & $\mathrm{x}$ & $\mathrm{x}$ & & 5 \\
\hline 3.2 Buscar originalidade & & & & $\mathrm{x}$ & $\mathrm{x}$ & & & $\mathrm{x}$ & 3 \\
\hline 3.3 Equilibrar qualidade e custo & $\mathrm{x}$ & $\mathrm{x}$ & & $\mathrm{x}$ & & & $\mathrm{x}$ & & 4 \\
\hline $\begin{array}{l}\text { 3.4 Diminuir reclamações de clientes e } \\
\text { acelerar respostas }\end{array}$ & & & & $\mathrm{X}$ & & & $\mathrm{x}$ & $\mathrm{x}$ & 3 \\
\hline $\begin{array}{l}\text { 4. Diminuir impacto ambiental do } \\
\text { negócio }\end{array}$ & & & $\mathrm{x}$ & $\mathrm{x}$ & $\mathrm{x}$ & & & $\mathrm{x}$ & 4 \\
\hline $\begin{array}{l}\text { 4.1 Reduzir impacto operacional dos } \\
\text { produtos }\end{array}$ & & & $\mathrm{x}$ & $\mathrm{x}$ & $\mathrm{x}$ & & & $\mathrm{x}$ & 4 \\
\hline 4.2 Reduzir impacto do processo & & & $\mathrm{x}$ & $\mathrm{x}$ & $\mathrm{x}$ & & & $\mathrm{x}$ & 4 \\
\hline $\begin{array}{l}\text { 4.3 Desenvolver e/ou explorar novas } \\
\text { tecnologias }\end{array}$ & $\mathrm{x}$ & $\mathrm{x}$ & $\mathrm{x}$ & & & & & $\mathrm{x}$ & 4 \\
\hline 5. Reforçar laços de parcerias com $3^{\circ} \mathrm{s}$. & $\mathrm{x}$ & $\mathrm{x}$ & $\mathrm{x}$ & $\mathrm{x}$ & $\mathrm{x}$ & & & $\mathrm{x}$ & 6 \\
\hline $\begin{array}{l}\text { 5.1 Aumentar o nível de confiança } \\
\text { entre os parceiros }\end{array}$ & $\mathrm{x}$ & $\mathrm{x}$ & & & $\mathrm{x}$ & & & $\mathrm{x}$ & 4 \\
\hline 5.2 Extrair novos conhecimentos & $\mathrm{x}$ & & $\mathrm{x}$ & & $\mathrm{x}$ & & & $\mathrm{x}$ & 4 \\
\hline $\begin{array}{l}5.3 \text { Estabelecer parcerias de longo } \\
\text { prazo }\end{array}$ & $\mathrm{x}$ & $\mathrm{x}$ & $\mathrm{x}$ & $\mathrm{x}$ & & & & & 4 \\
\hline $\begin{array}{l}\text { 5.4 Integrar os parceiros chaves no } \\
\text { PDP }\end{array}$ & & $\mathrm{x}$ & $\mathrm{x}$ & & $\mathrm{x}$ & $\mathrm{x}$ & & & 4 \\
\hline $\begin{array}{l}\text { 5.5 Transferir desafios técnicos } \\
\text { parceiros especializados }\end{array}$ & $\mathrm{x}$ & $\mathrm{x}$ & & & & & $\mathrm{x}$ & & 3 \\
\hline $\begin{array}{l}\text { 6. Selecionar profissionais capacitados } \\
\text { para integrar o PDP }\end{array}$ & $\mathrm{x}$ & & & $x$ & $\mathrm{x}$ & $\mathrm{x}$ & & & 4 \\
\hline 6.2 Investir em treinamento & $\mathrm{x}$ & $\mathrm{x}$ & & & & $\mathrm{x}$ & & & 3 \\
\hline $\begin{array}{l}\text { 6.3 Integrar ao PDP representantes de } \\
\text { todas as áreas da empresa }\end{array}$ & & $\mathrm{x}$ & & $\mathrm{X}$ & $\mathrm{x}$ & & $\mathrm{x}$ & & 4 \\
\hline
\end{tabular}

O modelo de Regras de Negócio (Figura 4) foi consolidado respeitando-se a regra do EKD que determina que todo objetivo necessita de uma regra que o apóie. Para cada objetivo presente no Modelo de Objetivos consolidado (Figura 3) foram associadas as regras 
correspondentes, encontradas nas unidades abordadas, que apóiam esses objetivos. Por essa razão não há um quadro com freqüências de regras.

A seleção dos elementos que compõe o Modelo de Processos de Negócios (Figuras 6, 7, $8,9,10,11)$ também se baseou na frequiência de aparição desses elementos em cada unidade estudada. Apenas elementos que aparecem em três ou mais unidades empresariais foram considerados no modelo "as-is" consolidado. O quadro abaixo resume os dados.

\begin{tabular}{|c|c|c|c|c|c|c|c|c|c|}
\hline Processos & U1 & U2 & $\mathbf{U 3}$ & U4 & U5 & U6 & U7 & U8 & Total \\
\hline $\begin{array}{l}\text { 1.(Proc Externo) Planejamento } \\
\text { estratégico mais portfólio de produtos } \\
\text { para o mercado }\end{array}$ & $\mathrm{x}$ & $\mathrm{x}$ & $\mathrm{x}$ & $\mathrm{x}$ & & $\mathrm{x}$ & $\mathrm{x}$ & $\mathrm{x}$ & 8 \\
\hline 1. Gerar a concepção do produto & $\mathrm{x}$ & & $\mathrm{x}$ & & & $\mathrm{x}$ & & $\mathrm{x}$ & 4 \\
\hline 1.1 Definir requisitos do cliente & $\mathrm{x}$ & & $\mathrm{x}$ & $\mathrm{x}$ & & & & & 3 \\
\hline 1.2 Definir requisitos do produto & & & $\mathrm{x}$ & $\mathrm{x}$ & $\mathrm{x}$ & & & & 3 \\
\hline $\begin{array}{l}\text { 1.3 Realizar estudo de viabilidade } \\
\text { técnica, financeira e industrial }\end{array}$ & $\mathrm{x}$ & $\mathrm{x}$ & $\mathrm{x}$ & $\mathrm{x}$ & $\mathrm{x}$ & & $\mathrm{x}$ & $\mathrm{x}$ & 7 \\
\hline 1.4 Modelar funcionalmente & & & $\mathrm{x}$ & & & $\mathrm{x}$ & & $\mathrm{x}$ & 3 \\
\hline 1.5 Desenvolver soluções alternativas & & & $\mathrm{x}$ & & & $\mathrm{x}$ & & $\mathrm{x}$ & 3 \\
\hline 1.6 Definir arquitetura & $\mathrm{x}$ & $\mathrm{x}$ & $\mathrm{x}$ & $\mathrm{x}$ & $\mathrm{x}$ & $\mathrm{x}$ & $\mathrm{x}$ & & 7 \\
\hline $\begin{array}{l}\text { 1.7 Realizar estudo de viabilidade } \\
\text { técnica, financeira e industrial }\end{array}$ & & & $\mathrm{x}$ & $\mathrm{x}$ & $\mathrm{x}$ & $\mathrm{x}$ & $\mathrm{x}$ & $\mathrm{x}$ & 6 \\
\hline 2.Desenvolver fornecedores & & $\mathrm{x}$ & $\mathrm{x}$ & $\mathrm{x}$ & $\mathrm{x}$ & $\mathrm{x}$ & $\mathrm{x}$ & $\mathrm{x}$ & 7 \\
\hline $\begin{array}{l}\text { 2.1 Definir quais componentes serão } \\
\text { terceirizados (Make or buy decision) }\end{array}$ & $\mathrm{x}$ & & $\mathrm{x}$ & & $\mathrm{x}$ & & $\mathrm{x}$ & & 4 \\
\hline $\begin{array}{l}\text { 2.2 Prospectar os parceiros mais } \\
\text { adequados para cada caso }\end{array}$ & & $\mathrm{x}$ & $\mathrm{x}$ & $\mathrm{x}$ & & & $\mathrm{x}$ & & 4 \\
\hline $\begin{array}{l}\text { 2.3 Definir objetivos e metas a serem } \\
\text { alcançados }\end{array}$ & $\mathrm{x}$ & $\mathrm{x}$ & $\mathrm{x}$ & & $\mathrm{x}$ & & & $\mathrm{x}$ & 5 \\
\hline $\begin{array}{l}\text { 2.4 Definir recursos a serem } \\
\text { compartilhados durante o projeto }\end{array}$ & $\mathrm{x}$ & & & & & $\mathrm{x}$ & $\mathrm{x}$ & $\mathrm{x}$ & 4 \\
\hline 2.5 Definir condições contratuais & $\mathrm{x}$ & $\mathrm{x}$ & $\mathrm{x}$ & $\mathrm{x}$ & $\mathrm{x}$ & $\mathrm{x}$ & & $\mathrm{x}$ & 7 \\
\hline $\begin{array}{l}\text { 2.6 Realizar estudo de viabilidade } \\
\text { técnica, financeira e industrial }\end{array}$ & & & $\mathrm{x}$ & $\mathrm{x}$ & $\mathrm{x}$ & $\mathrm{x}$ & $\mathrm{x}$ & & 5 \\
\hline $\begin{array}{l}\text { 3.Desenvolver protótipos (físico e/ou } \\
\text { virtual) }\end{array}$ & $\mathrm{x}$ & $\mathrm{x}$ & $\mathrm{x}$ & $\mathrm{x}$ & $\mathrm{x}$ & $\mathrm{x}$ & $\mathrm{x}$ & $\mathrm{x}$ & 8 \\
\hline 3.1 Integrar parceiros ao PDP & $\mathrm{X}$ & & $\mathrm{x}$ & $\mathrm{x}$ & & $\mathrm{x}$ & $\mathrm{x}$ & & 5 \\
\hline
\end{tabular}




\begin{tabular}{|c|c|c|c|c|c|c|c|c|c|}
\hline 3.2 Desenvolver modelo virtual & & & $\mathrm{x}$ & $\mathrm{x}$ & $\mathrm{x}$ & $\mathrm{x}$ & $\mathrm{x}$ & $\mathrm{x}$ & 6 \\
\hline $\begin{array}{l}\text { 3.3 Realizar testes de operação e } \\
\text { desempenho }\end{array}$ & $\mathrm{x}$ & & $\mathrm{x}$ & $\mathrm{x}$ & $\mathrm{x}$ & $\mathrm{x}$ & $\mathrm{x}$ & $\mathrm{x}$ & 7 \\
\hline 3.4 Desenvolver modelo físico & $\mathrm{x}$ & $\mathrm{x}$ & $\mathrm{x}$ & $\mathrm{x}$ & $\mathrm{x}$ & $\mathrm{x}$ & $\mathrm{x}$ & $\mathrm{x}$ & 8 \\
\hline $\begin{array}{l}\text { 3.5 Realizar testes de operação e } \\
\text { desempenho }\end{array}$ & $\mathrm{x}$ & $\mathrm{x}$ & $\mathrm{x}$ & $\mathrm{x}$ & $\mathrm{x}$ & $\mathrm{x}$ & $\mathrm{x}$ & $\mathrm{x}$ & 8 \\
\hline $\begin{array}{l}\text { 3.6 Realizar estudo de viabilidade } \\
\text { técnica, financeira e industrial }\end{array}$ & & & $\mathrm{x}$ & $\mathrm{x}$ & $\mathrm{x}$ & $\mathrm{x}$ & & $\mathrm{x}$ & 5 \\
\hline 4. Desenvolver material de apoio & $\mathrm{x}$ & $\mathrm{x}$ & $\mathrm{x}$ & & $\mathrm{x}$ & $\mathrm{x}$ & $\mathrm{x}$ & & 6 \\
\hline 4.1 Projetar embalagem & $\mathrm{x}$ & $\mathrm{x}$ & $\mathrm{x}$ & & $\mathrm{x}$ & & & $\mathrm{x}$ & 5 \\
\hline 4.2 Desenvolver material de suporte & $\mathrm{x}$ & $\mathrm{x}$ & $\mathrm{x}$ & & $\mathrm{X}$ & $\mathrm{x}$ & $\mathrm{x}$ & & 6 \\
\hline $\begin{array}{l}4.3 \text { Treinar pessoal das assistências } \\
\text { técnicas }\end{array}$ & $\mathrm{x}$ & & & & & $\mathrm{x}$ & $\mathrm{x}$ & & 3 \\
\hline 4.4 Treinar pessoal do SAC & $\mathrm{x}$ & $\mathrm{x}$ & & & & $\mathrm{x}$ & $\mathrm{x}$ & & 4 \\
\hline $\begin{array}{l}\text { 5. Desenvolver e homologar processo e } \\
\text { certificar produto }\end{array}$ & & $\mathrm{x}$ & $\mathrm{x}$ & $\mathrm{x}$ & $\mathrm{x}$ & $\mathrm{x}$ & $\mathrm{x}$ & $\mathrm{x}$ & 7 \\
\hline 5.1 Definir o processo produtivo & $\mathrm{x}$ & $\mathrm{x}$ & $\mathrm{x}$ & $\mathrm{x}$ & $\mathrm{X}$ & $\mathrm{x}$ & $\mathrm{x}$ & $\mathrm{x}$ & 8 \\
\hline 5.2 Homologar o processo produtivo & $\mathrm{x}$ & $\mathrm{x}$ & $\mathrm{x}$ & $\mathrm{x}$ & $\mathrm{x}$ & $\mathrm{x}$ & $\mathrm{x}$ & $\mathrm{x}$ & 8 \\
\hline $\begin{array}{l}\text { 5.3 Realizar estudo de viabilidade } \\
\text { financeira }\end{array}$ & & & $\mathrm{x}$ & $\mathrm{x}$ & $\mathrm{X}$ & $\mathrm{x}$ & & & 4 \\
\hline $\begin{array}{l}\text { 5.4 Certificação do produto através de } \\
\text { amostragem dos lotes }\end{array}$ & & $\mathrm{x}$ & $\mathrm{x}$ & & $\mathrm{X}$ & & $\mathrm{x}$ & & 4 \\
\hline 5.5 Fase out com a manufatura & $\mathrm{x}$ & $\mathrm{x}$ & $\mathrm{x}$ & X & $\mathrm{x}$ & $\mathrm{x}$ & $\mathrm{x}$ & $\mathrm{x}$ & 8 \\
\hline
\end{tabular}

Da mesma forma que nos modelos anteriores, a escolha dos elementos que compõem o Modelo de Atores e Recursos (Figura 5) também seguiu o critério que privilegiou os elementos mais recorrentes nas unidades empresariais.

\begin{tabular}{|l|c|c|c|c|c|c|c|c|c|}
\hline Atores e recursos & U1 & U2 & U3 & U4 & U5 & U6 & U7 & U8 & Total \\
\hline 1. Diretor comercial & $\mathrm{x}$ & $\mathrm{x}$ & $\mathrm{x}$ & $\mathrm{x}$ & $\mathrm{x}$ & $\mathrm{x}$ & $\mathrm{x}$ & $\mathrm{x}$ & 8 \\
\hline 2. Diretor industrial & $\mathrm{x}$ & $\mathrm{x}$ & $\mathrm{x}$ & & $\mathrm{x}$ & $\mathrm{x}$ & $\mathrm{x}$ & $\mathrm{x}$ & 7 \\
\hline $\begin{array}{l}\text { 3. Departamento de inteligência de } \\
\text { mercado }\end{array}$ & $\mathrm{x}$ & $\mathrm{x}$ & $\mathrm{x}$ & $\mathrm{x}$ & & & $\mathrm{x}$ & $\mathrm{x}$ & 6 \\
\hline 4. Gerência de processos & & & $\mathrm{x}$ & & $\mathrm{x}$ & & $\mathrm{x}$ & $\mathrm{x}$ & 4 \\
\hline 5. Gerência de manufatura & $\mathrm{x}$ & $\mathrm{x}$ & $\mathrm{x}$ & $\mathrm{x}$ & $\mathrm{x}$ & & $\mathrm{x}$ & $\mathrm{x}$ & 7 \\
\hline 6. Gerência de qualidade & $\mathrm{x}$ & & $\mathrm{x}$ & $\mathrm{x}$ & $\mathrm{x}$ & $\mathrm{x}$ & $\mathrm{x}$ & $\mathrm{x}$ & 7 \\
\hline 7. Gerente de projeto & $\mathrm{x}$ & & $\mathrm{x}$ & & $\mathrm{x}$ & $\mathrm{x}$ & $\mathrm{x}$ & $\mathrm{x}$ & 6 \\
\hline
\end{tabular}




\begin{tabular}{|c|c|c|c|c|c|c|c|c|c|}
\hline 8. Analista de mercado (marketing) & & $\mathrm{x}$ & $\mathrm{x}$ & $\mathrm{x}$ & & $\mathrm{x}$ & $\mathrm{x}$ & $\mathrm{x}$ & 6 \\
\hline 9. Engenheiro de processo & & $\mathrm{x}$ & $\mathrm{x}$ & $\mathrm{x}$ & $\mathrm{x}$ & $\mathrm{x}$ & $\mathrm{x}$ & & 6 \\
\hline 10. Engenheiro de produto & & $\mathrm{x}$ & $\mathrm{x}$ & $\mathrm{x}$ & $\mathrm{x}$ & & $\mathrm{x}$ & & 5 \\
\hline 11. Engenheiro de qualidade & & & $\mathrm{x}$ & & $\mathrm{x}$ & & $\mathrm{x}$ & $\mathrm{x}$ & 4 \\
\hline 12. Técnico de laboratório & $\mathrm{x}$ & $\mathrm{x}$ & & & & $\mathrm{x}$ & & $\mathrm{x}$ & 4 \\
\hline 13. Engenheiro de manufatura & $\mathrm{x}$ & & & & $\mathrm{x}$ & $\mathrm{x}$ & $\mathrm{x}$ & $\mathrm{x}$ & 5 \\
\hline 14. Diretrizes, normas e procedimentos & $\mathrm{x}$ & $\mathrm{x}$ & $\mathrm{x}$ & $\mathrm{x}$ & & $\mathrm{x}$ & $\mathrm{x}$ & $\mathrm{x}$ & 7 \\
\hline 15. Bancos de projetos & $\mathrm{x}$ & & $\mathrm{x}$ & $\mathrm{x}$ & $\mathrm{x}$ & & & & 4 \\
\hline 16. ERP, CAD, Softwares & $\mathrm{x}$ & & & & $\mathrm{x}$ & $\mathrm{x}$ & $\mathrm{x}$ & $\mathrm{x}$ & 5 \\
\hline 17. Ferramentas, máq. e equipamentos & $\mathrm{X}$ & $\mathrm{x}$ & $\mathrm{x}$ & & & & $\mathrm{x}$ & $\mathrm{x}$ & 5 \\
\hline 18. Equipe de projeto & $\mathrm{x}$ & $\mathrm{x}$ & $\mathrm{x}$ & $\mathrm{X}$ & $\mathrm{X}$ & $\mathrm{x}$ & $\mathrm{x}$ & $\mathrm{x}$ & 8 \\
\hline 19. Coordenador & $\mathrm{x}$ & $\mathrm{x}$ & $\mathrm{x}$ & $\mathrm{x}$ & $\mathrm{x}$ & $\mathrm{x}$ & $\mathrm{x}$ & $\mathrm{x}$ & 8 \\
\hline 20. Contratos & $\mathrm{x}$ & $\mathrm{x}$ & $\mathrm{x}$ & $\mathrm{X}$ & $\mathrm{X}$ & $\mathrm{x}$ & $\mathrm{x}$ & $\mathrm{x}$ & 8 \\
\hline $\begin{array}{l}\text { 21. Documento de descrição geral do } \\
\text { produto }\end{array}$ & $\mathrm{x}$ & $\mathrm{x}$ & $\mathrm{x}$ & $\mathrm{x}$ & $\mathrm{x}$ & $\mathrm{x}$ & $\mathrm{x}$ & $\mathrm{x}$ & 8 \\
\hline 22. Parceiro de desenvolvimento & $\mathrm{x}$ & $\mathrm{x}$ & $\mathrm{x}$ & $\mathrm{x}$ & $\mathrm{x}$ & $\mathrm{x}$ & $\mathrm{x}$ & $\mathrm{x}$ & 8 \\
\hline 23. Lista técnica (SSC's) & & $\mathrm{x}$ & $\mathrm{x}$ & $\mathrm{x}$ & $\mathrm{x}$ & $\mathrm{x}$ & $\mathrm{x}$ & $\mathrm{x}$ & 7 \\
\hline 24. Cronogramas & $\mathrm{x}$ & & $\mathrm{x}$ & $\mathrm{X}$ & $\mathrm{X}$ & & & & 4 \\
\hline 25. Atas e aprovações & $\mathrm{x}$ & $\mathrm{x}$ & $\mathrm{x}$ & $\mathrm{X}$ & $\mathrm{X}$ & $\mathrm{x}$ & $\mathrm{x}$ & $\mathrm{x}$ & 8 \\
\hline 26. Estudo de impacto ambiental & & & $\mathrm{x}$ & $\mathrm{x}$ & $\mathrm{x}$ & & & $\mathrm{x}$ & 4 \\
\hline $\begin{array}{l}\text { 27. Estudos de viabilidade técnica, } \\
\text { financeira e industrial }\end{array}$ & $\mathrm{x}$ & $\mathrm{x}$ & $\mathrm{x}$ & $\mathrm{X}$ & $\mathrm{X}$ & $\mathrm{x}$ & $\mathrm{x}$ & $\mathrm{x}$ & 8 \\
\hline 28. Informações de desempenho & $\mathrm{x}$ & $\mathrm{x}$ & $\mathrm{x}$ & $\mathrm{X}$ & $\mathrm{x}$ & $\mathrm{x}$ & $\mathrm{x}$ & $\mathrm{x}$ & 8 \\
\hline 29. Elaborador/Aprovador & $\mathrm{X}$ & $\mathrm{x}$ & $\mathrm{x}$ & $\mathrm{X}$ & $\mathrm{X}$ & $\mathrm{x}$ & $\mathrm{x}$ & $\mathrm{x}$ & 8 \\
\hline 30. Plano estratégico & $\mathrm{x}$ & $\mathrm{x}$ & $\mathrm{x}$ & $\mathrm{X}$ & $\mathrm{X}$ & $\mathrm{x}$ & $\mathrm{x}$ & $\mathrm{x}$ & 8 \\
\hline 31. Broker & & $\mathrm{x}$ & & $\mathrm{X}$ & & & & $\mathrm{x}$ & 3 \\
\hline $\begin{array}{l}\text { 32. Parceiro especializado em } \\
\text { marketing de mercado }\end{array}$ & & $\mathrm{x}$ & & $\mathrm{x}$ & & & & $\mathrm{x}$ & 3 \\
\hline
\end{tabular}

Os elementos presentes no Modelo de Conceitos (Figura 12) ajudam a explicar o significado dos elementos presentes nos demais modelos. Após a finalização de todos os modelos consolidados do estado As-Is, foram identificados os conceitos que atuam como suporte para compreendê-los. Por esse motivos não há um quadro mostrando a freqüência dos conceitos. 


\section{APÊNDICE C - Os modelos em cada unidade empresarial}

A seguir serão apresentados e comentados todos os modelos individuais do estado "as$i s "$ de cada unidade de análise trabalhada em campo.

\section{Unidade de análise Número 1}

O Modelo de Objetivos apresenta um objetivo principal que é trabalhar integrado o PDP nas diversas plantas da empresa (Objetivo 1). Esse objetivo apresenta a possibilidade de engessar o processo (Ameaça 1), ao mesmo tempo em que permite aproveitar o conhecimento disperso mas plantas (Oportunidade 1). Três objetivos formam uma estrutura de apoio: estabelecer diretrizes para planejar, desenvolver, implantar e avaliar projetos (Objetivo 2); utilizar a Engenharia Simultânea (Objetivo 3), que permite reduzir o tempo da concepção à manufatura (Oportunidade 3) e antecipar ao máximo as mudanças nos projetos (Oportunidade 4); e desenvolver parcerias externas (Objetivo 4), que traz o risco da evasão de conhecimento (Ameaça 3). O Objetivo 2 recebe apoio de três objetivos secundários: padronizar a geração de documentos de projetos (Objetivo 2.1), que permite registrar as lições aprendidas (Oportunidade 2); treinar colaboradores (Objetivo 2.2), que sofre com a falta de comprometimento dos envolvidos (Ameaça 2); e selecionar especialistas para o PDP (Objetivo 2.3). O uso da Engenharia Simultânea (Objetivo 3) está presente porque existe o objetivo de reduzir custo e melhorar o produto (Objetivo 3.1). O Objetivo 4 também apresenta alguns objetivos que atuam como apoio: aumentar o nível de confiança entre as partes (Objetivo 4.1); estabelecer parcerias de longo prazo (Objetivo 4.2); extrair novos conhecimentos (Objetivo 4.3); transferir desafios técnicos para terceiros (Objetivo 4.4); explorar novas tecnologias (Objetivo 4.5).

Cada objetivo possui uma regra de apoio, o Objetivo 1 de integrar o PDP nas diversas plantas tem uma regra que determina o Uso de um único modelo para o desenvolvimento de qualquer produto e em todas as plantas (Regra 2). O objetivo de estabelecer diretrizes (Objetivo 2) tem várias regras que funcionam como diretrizes: Atender prazos legais (Regra 2); Atender 
política ambiental e de qualidade (Regra 3); Validar todo projeto em cada checkpoint (Regra 4); Budgets acima de um valor precisam da aprovação do presidente (Regra 5). O uso da Engenharia simultânea (Objetivo 3) decorre da regra que determina que se planeje para antecipar as atividades de projeto/industriais (Regra 6). O desenvolvimento de parcerias externas (Objetivo 4) requer que se avalie a existência de vínculos entre possíveis parceiros e concorrentes. A padronização da documentação (Objetivo 2.1) começa com a adoção do idioma inglês (Regra 9), e da exigência de se atualizar continuamente o plano principal do projeto (Regra 8). As Regras 10, 11 e 12 forçam o atendimento do Objetivo 2.2 (Treinar colaboradores e gestores): a equipe precisa ser multifuncional, conduzir o projeto e gerar toda a documentação (Regra 10); as atividades de teste de campo precisam atender as instruções de trabalho corporativo (Regra 11); e as especificações de Engenharia de Produto precisam seguir procedimentos da qualidade (Regra 12). A seleção de especialistas para compor a equipe do projeto (Objetivo 2.3) justifica-se porque a unidade de análise procura acompanhar o mercado e a tecnologia (Regras 13 e 14). A fim de reduzir os custo e melhorar o produto (Objetivo 3.1) há uma regra que determina que se analise a documentação de outros projetos similares (Regra 15) a fim de se levantar as lições aprendidas e que podem contribuir com os novos produtos. Para aumentar o nível de confiança entre as partes (Objetivo 4.1) deve-se fazer uma descrição clara das responsabilidades dos terceiros (Regra 15). Como há uma preocupação em obter novos conhecimentos a partir do contato com terceiros (Objetivo 4.2) sem a perda de ativos intelectuais criou-se a regra que exige que se assine um termo de confidencialidade (Regra 16). A intenção de estabelecer parcerias de longo prazo (Objetivo 4.3) tem apoio na avaliação da qualidade e desempenho das parcerias anteriores (Regra 17). transferência de desafios técnicos para terceiros (Objetivo 4.4) encontra apoio na regra que exige que se mantenha o foco no core business da empresa (Regra 18). E para explorar novas tecnologias (objetivo 4.5) busca-se priorizar investimentos em pesquisas (Regra 19).

O Modelo de Processo de Negócios envolve dois sub-processos externos: realizar préestudo e selecionar projetos e gerentes (ProcExt 1); Aprovar o projeto na diretoria (ProcExt 2). Com essas definições temos os dois primeiros sub-processos internos: planejar o projeto e definir os conceitos do produto (Processo 1), e aprovar projeto na diretoria (Processo 2). Devido ao espaço de tempo consumido nas primeiras etapas, novamente avalia-se o mercado, o projeto e o sistema de produção (Processo 3) buscando verificar se os primeiros parâmetros do projeto continuam válidos. Essa avaliação sobre o mercado inclui analisar os fornecedores e os passos seguintes: definir metas e condições contratuais para os parceiros (Processo 5) e definir os recursos a serem compartilhados (Processos 5 e 6). Realiza-se um estudo de viabilidade 
econômica (Processo 7) já considerando os terceiros, aprova-se na diretoria (Processo 8) e integra-se os parceiros ao PDP (Processo 9). Neste ponto inicia-se a engenharia do produto e do processo e o estudo de capacidade industrial (Processo 10), produzindo-se protótipos virtuais e funcionais bem como testes laboratoriais e de análise ambiental (InfoSet 10), procede-se à aprovação na diretoria (Processo 11), realiza-se a análise do produto e do processo (Processo 12), desenvolve-se embalagem (Processo 13) e material de apoio (processo 14). Nesse ponto inicia-se a produção de lotes experimentais (Processo 15), o que permite a coleta de feedback/follow-up inclusive do mercado. Para encerrar, realiza-se o treinamento das equipes envolvidas (Processo 16).

O Modelo de Atores e Recursos evidencia que as principais unidades organizacionais (de Qualidade, de Engenharia, de Manufatura, e de Marketing) fornecem os recursos básicos necessários a cada projeto: base de dados e softwares (Recurso 1); normas e procedimentos (Recurso 2); ferramentas, máquinas e equipamentos (Recurso 3). Além disso, essas unidades fornecem todas as unidades individuais que comporão a Equipe de projeto (Unidade organizacional 5): Gerente de projeto (Unidade individual 1), analista de impacto ambiental (Unidade individual 2), gerente de componentes eletrônicos (Unidade individual 3), Supervisores de laboratório (unidade individual 4), gerente industrial (unidade individual 5), e gerente de logística (unidade individual 6). O número de pessoas que atuam em cada uma dessas funções pode variar de acordo com cada projeto. O corpo diretor assume o Papel 2 de orientar o Coordenador do projeto (Papel 1) e de aprovar o Plano principal do projeto (Recurso 5). A Equipe de projeto recebe apoio do Coordenador em relação as orientações estratégicas da empresa focal para elaborar os Contratos (Recurso 4) assinados com os Parceiros (Unidade Organizacional 6) e para elaborar/controlar o Plano principal do projeto. Embora esse plano contenha todas as informações relacionadas ao produto, ao processo e ao projeto, os Parceiros acessam apenas o projeto técnico do componente específico pelo qual serão responsáveis (Recurso 6). As demais partes do plano principal ficam acessíveis apenas ao pessoal interno da empresa focal: cronograma (Recurso 7), atas de aprovações (Recurso 8), laudo técnico de manufaturabilidade (Recurso 9), resultados dos testes de laboratório e de campo (Recurso 10) e o orçamento (Recurso 11).

Vários conceitos integram os modelos apresentados. A integração do PDP (Conceito 1) é responsabilidade de uma Equipe multifuncional (Conceito 7) apoiada por um Patrocinador (Conceito 8), e atribui-se a ela a capacidade de promover Inovação (Conceito 2). Isso ocorre porque a integração do PDP facilita a Gestão do conhecimento (Conceito 16) e como consequência a Geração de novos conhecimentos (Conceito 17), o que pode ser beneficiado pela 
prática de Benchmarkings e clínicas (Conceito 18). A integração do PDP tem base em vários conceitos: Certificação e Homologação de produto e processo (Conceito 9); Gates, que são as etapas de aprovação (Conceito 10); Padronização de documentos (Conceito 11), Padronização de procedimentos, como inspeções (Conceito 12); Equipe multifuncional (Conceito 13) tanto em termos de visão como de habilidades; Engenharia simultânea (Conceito 14) para antecipar mudanças e atividades; e Política ambiental (Conceito 15) como preocupação em todas as plantas. 


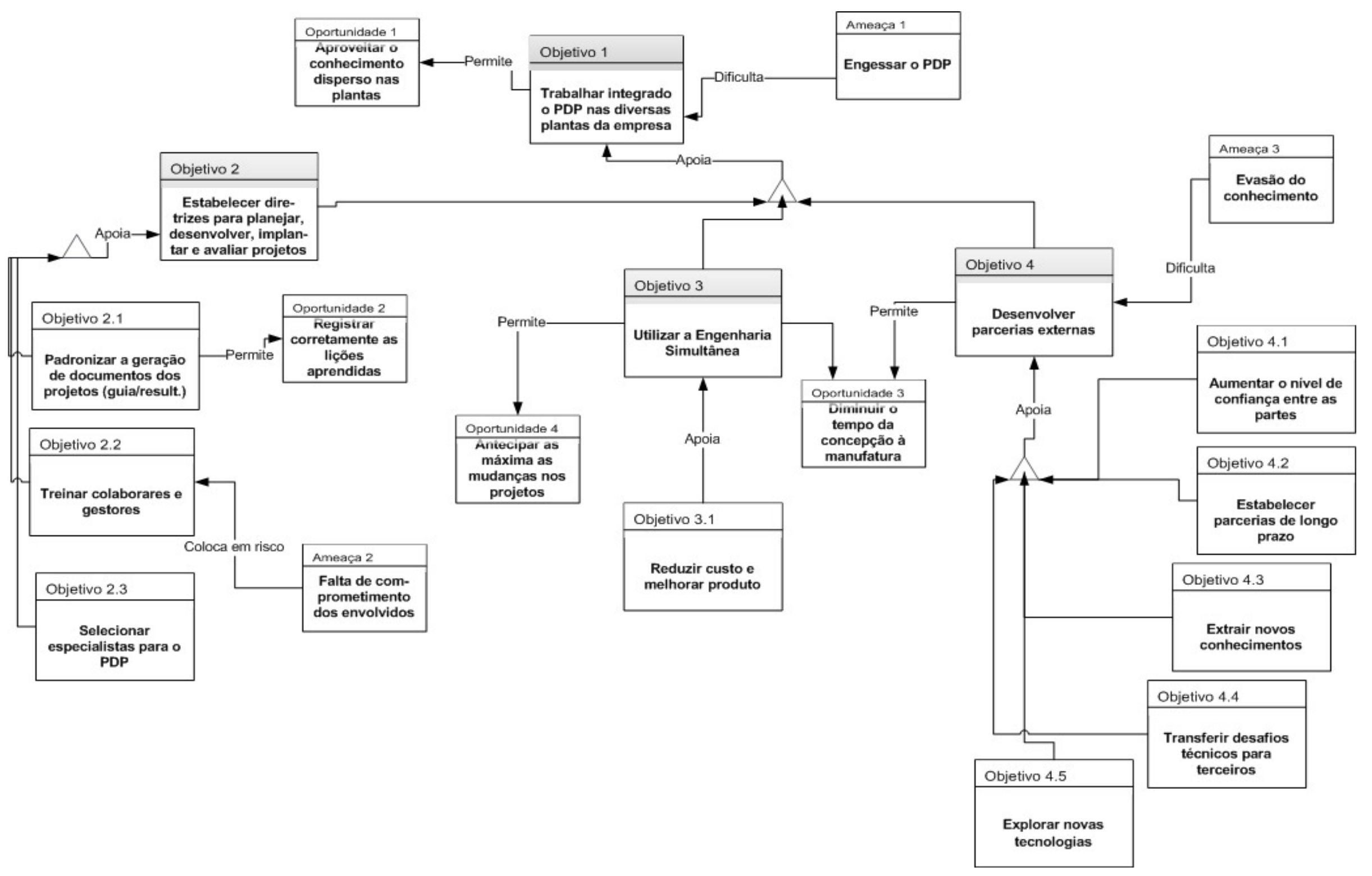

Figura 24: Modelo de Objetivos (as-is) - unidade de análise número 1. 

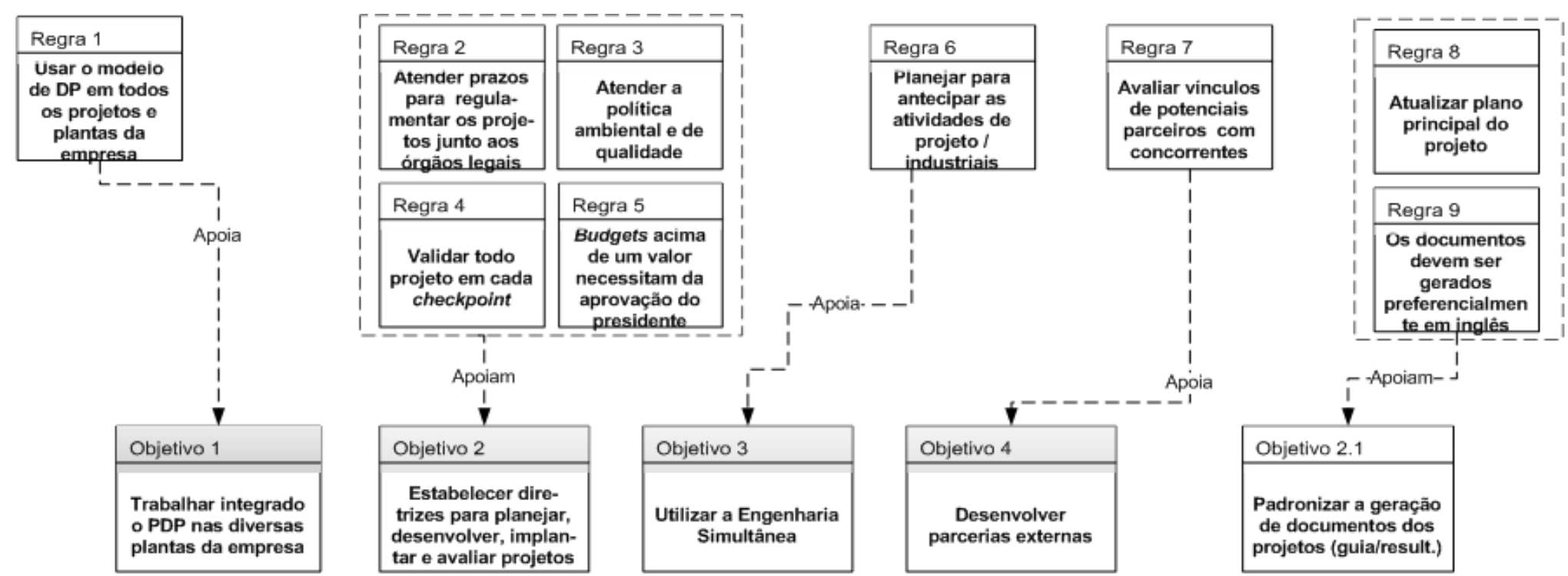

Apoia

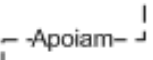

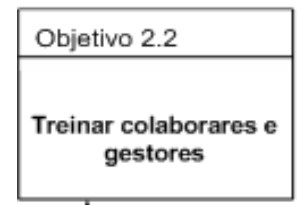

I_- Apoia- - -

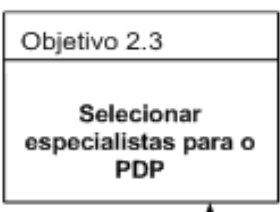

PDP

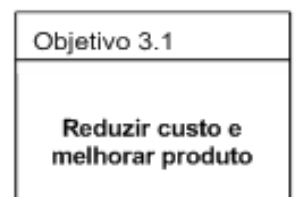

I _-Apoia- - -
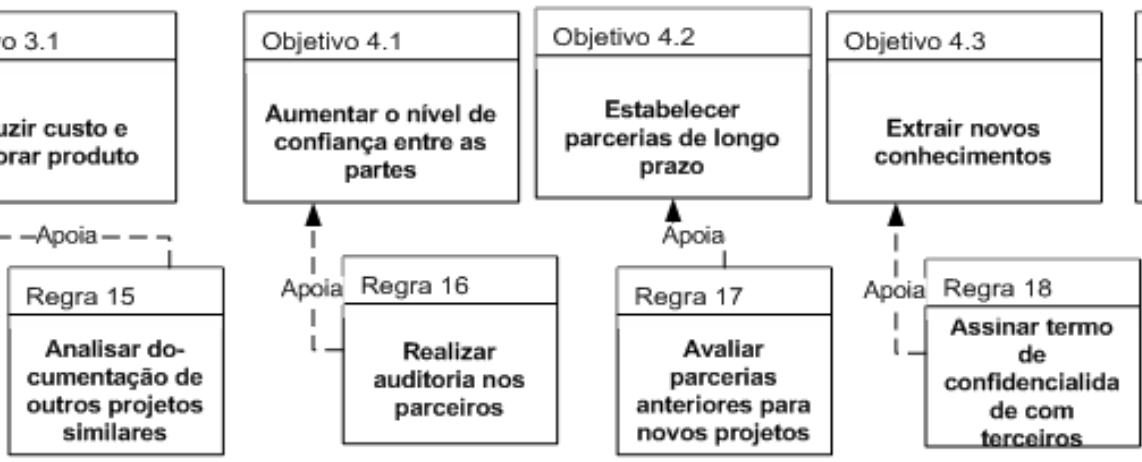

(1) Apos

similares

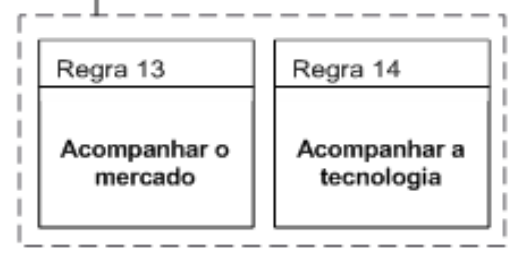

Figura 25: Modelo de Regras de Negócios (as-is) - unidade de análise número 1. 


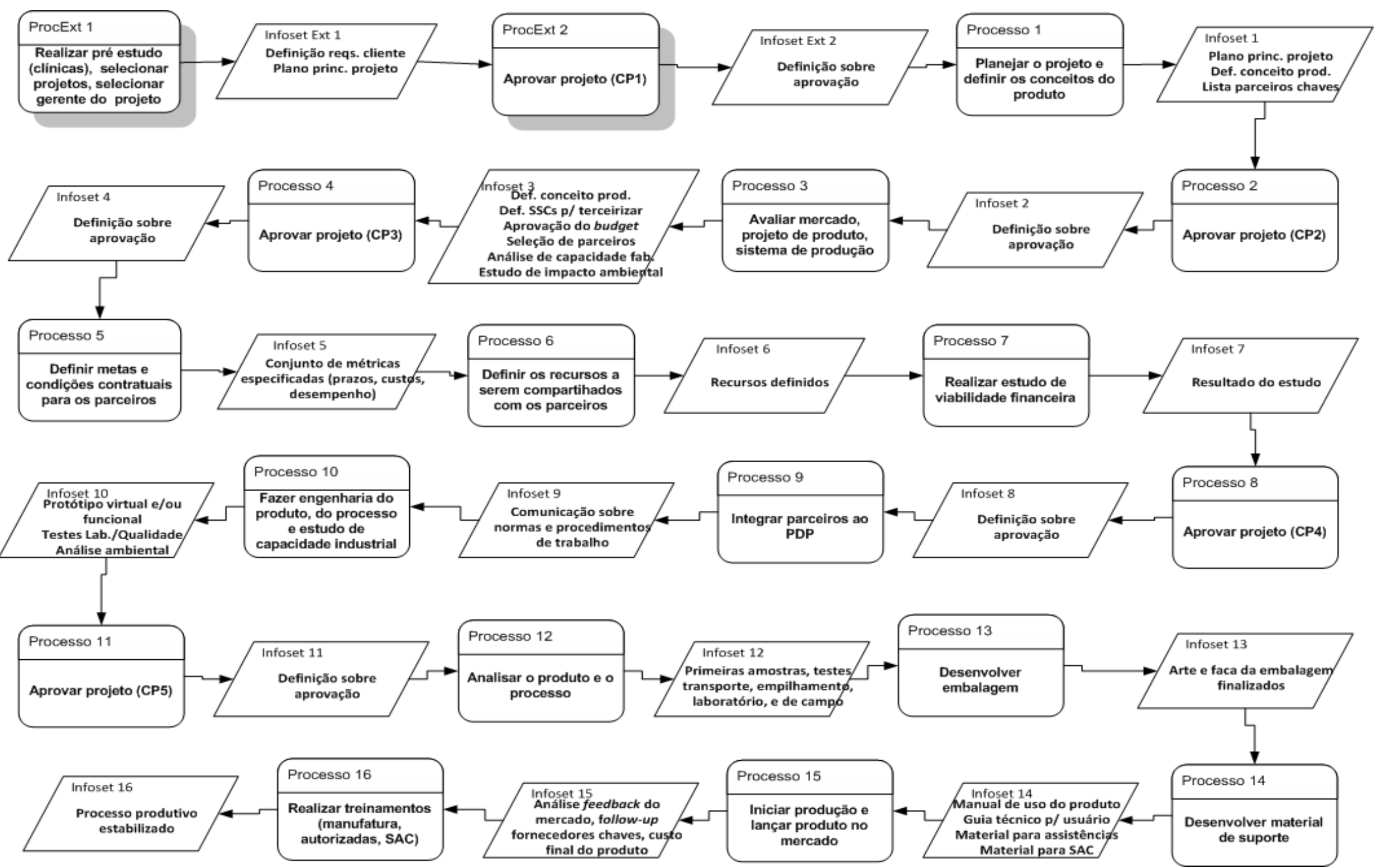

Figura 26: Modelo de Processo de Negócios (as-is) - unidade de análise número 1. 


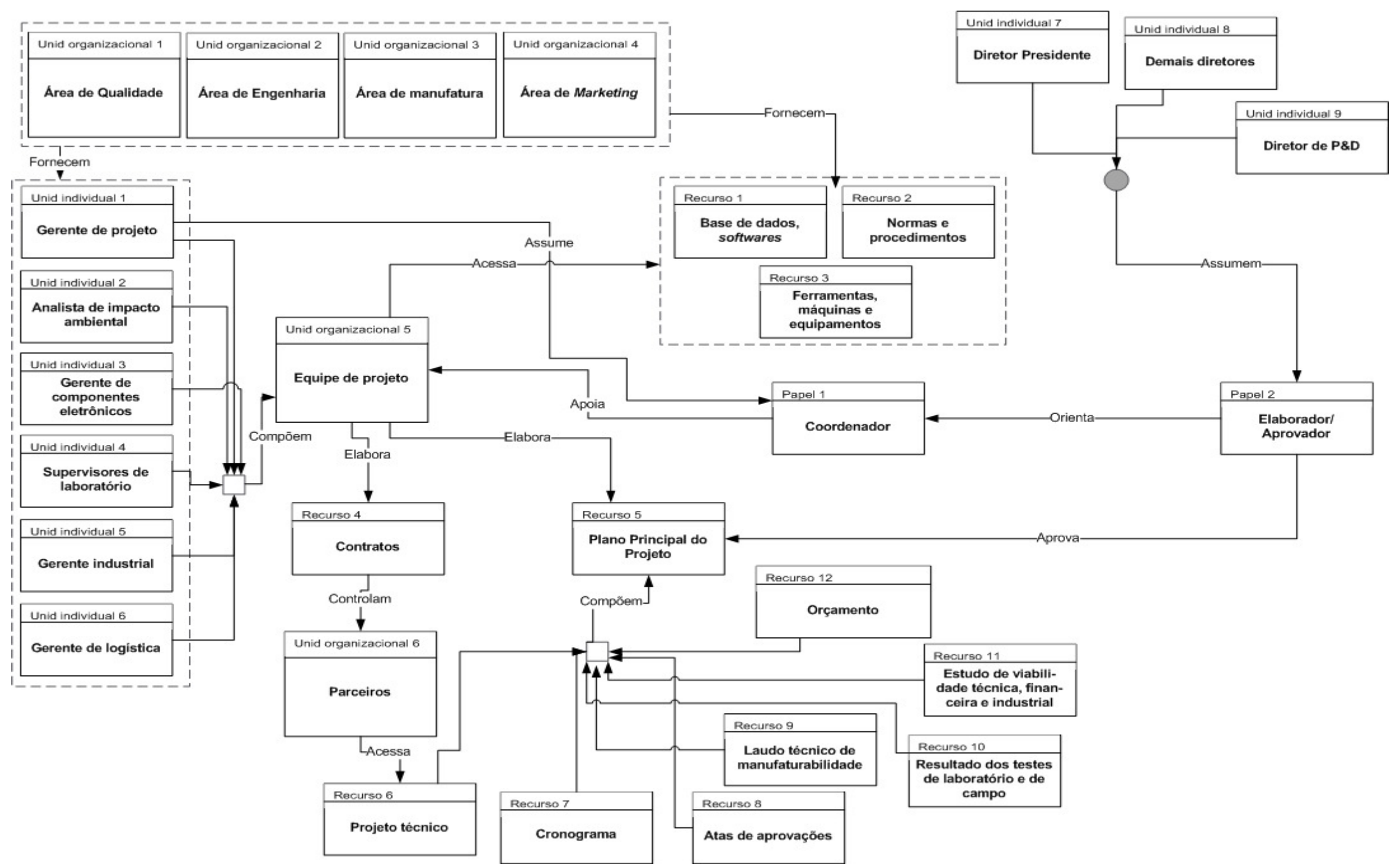

Figura 27: Modelo de Atores e Recursos (as-is) - unidade de análise número 1. 


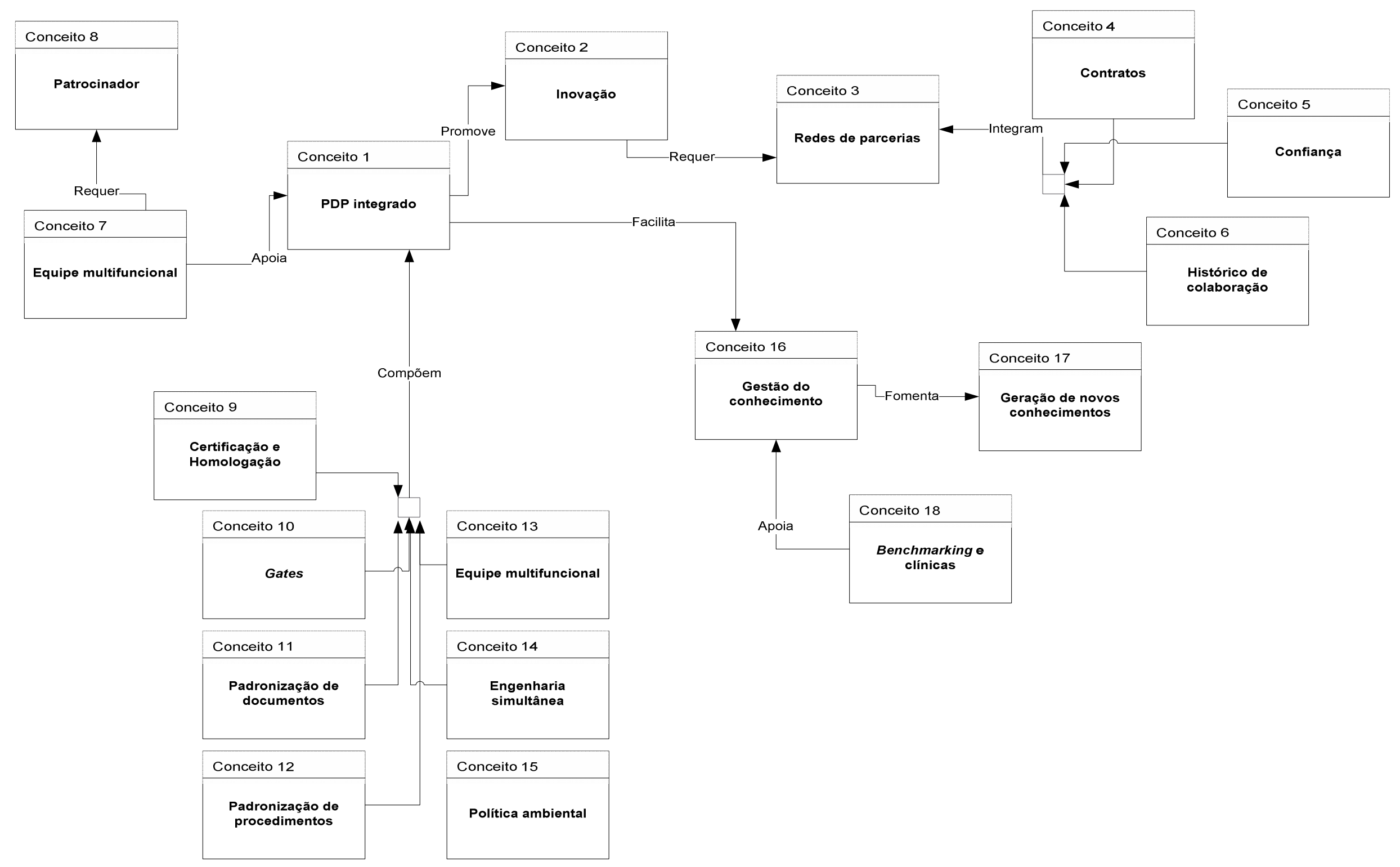

Figura 28: Modelo de Conceitos (as-is) - unidade de análise número 1. 
2. Unidade de análise Número 2

No centro das preocupações dessa unidade de análise está o aumento da vantagem competitiva em relação aos concorrentes (Objetivo 1). Assumindo que a inovação pode funcionar como alavanca para os negócios, define-se um segundo objetivo que também é crítico: acelerar o processo de inovação reduzindo prazos e custos (Objetivo 2); essa antecipação permite antecipar-se aos concorrentes (Oportunidade 1) e reforçar a marca (Oportunidade 2). A saída encontrada para viabilizar o Objetivo 2 é melhorar continuamente o PDP (Objetivo 3), e isso apresenta alguns pontos de alerta, como: a empresa focal possui base familiar (Ameaça 1), o que às vezes distorce a hierarquia; percebe-se que há ingerência da área comercial na engenharia (Ameaça 2); os laboratórios são relativamente limitados (Ameaça 3); não existe uma política de incentivos para novas ideias (Ameaça 4). Cinco objetivos de suporte apóiam o Objetivo 3: tornar mais rápido o PDP (Objetivo 3.1), o que pode pressionar pela supressão de algumas etapas (Ameaça 5), e que encontra apoio na determinação de usar tecnologia para validar digitalmente os novos produtos (Objetivo 3.1.1); garantir o cumprimento das etapas do PDP p/ todos os produtos (Objetivo 3.2); selecionar, treinar e integrar representantes de todas as áreas no PDP (Objetivo 3.3), garantindo que a equipe de projeto seja multifuncional; reduzir os custos mantendo a qualidade do produto (Objetivo 3.4); e integrar o próprio fornecedor ao PDP da empresa (Objetivo 3.5) para que ele traga contribuições valiosas, sem perder de vista algumas dificuldades como baixa qualificação de parte dos fornecedores para trabalhar integrado (Ameaça 6), risco de perder informação estratégica (Ameaça 7), ficar na dependência de terceiros (Ameaça 8), e o risco de conflitos de objetivos entre os parceiros (Ameaça 9). A integração do fornecedor ao PDP (Objetivo 3.5) apoia o aumento da confiança na rede de parceiros (Oportunidade 3) e apresenta quatro objetivos de apoio: fidelizar o fornecedor buscando estabelecer parcerias de longo prazo (Objetivo 3.5.1); desenvolver novos tipos de contratos (Objetivo 3.5.2); transferir parte dos desafios técnicos para terceiros (Objetivo 3.5.3); desenvolver e absorver novas tecnologias (Objetivo 3.5.4).

O Modelo de Regras de Negócio é composto por 21 regras. Para aumentar a vantagem competitiva existe uma regra que destaca a priorização de ideias inovadoras (Regra 1), cujo papel é servir como filtro de projetos. Para acelerar o processo de inovação e reduzir prazos e custos procura-se estreitar laços com universidades e fornecedores (Regra 2) e estar sempre em contato com as melhores práticas industriais (Regra 3). Duas condições empreendidas para melhorar continuamente o PDP (Objetivo 3) são documentar as lições aprendidas (Regra 4) e avaliar anualmente o PDP da empresa (Regra 5). Para acelerar o PDP (Objetivo 3.1) há uma regra que estabelece que projetos de inovações incrementais devam ter ciclo máximo de 06 
meses (Regra 6). A garantia do cumprimento das etapas do PDP (Objetivo 3.2) está apoiada em uma regra direta e duas indiretas: sempre há uma equipe de projeto responsável pelo projeto (Regra 7), a equipe de projeto deve acompanhar o projeto até rodar os primeiros lotes (Regra 8), e a equipe de projetos pode ser acionada mesmo após o fase out (Regra 9). A justificativa para a seleção, treinamento, integração e reconhecimento de pessoas de todas as áreas no PDP (Objetivo 3.3) está na regra que define que a equipe de projetos precisa ser multifuncional (Regra 10). Para reduzir os custos mantendo a qualidade (Objetivo 3.4) é preciso investir em novos processos, materiais e tecnologias (Regra 11). Para integrar o fornecedor ao PDP (Objetivo 3.5) é preciso avaliar o histórico de colaboração em outros projetos (Regra 12). O objetivo de usar tecnologia para validar digitalmente os novos produtos (Objetivo 3.1.1.) está apoiado na regra que determina o investimento de recursos em laboratórios (Regra 13). A ideia de fidelizar o fornecedor (Objetivo 3.5.1) está apoiada em três regras fundamentais: premiar os parceiros mais eficazes com mais contratos (Regra 14); estabelecer claramente papéis e responsabilidades (Regra 15); e $80 \%$ dos fornecedores precisam pertencer a um raio aproximado de $60 \mathrm{~km}$ (Regra 16). O estabelecimento de novos tipos de contratos (Objetivo 3.5.2) envolve restringir o acesso do fornecedor ao projeto (Regra 17), garantir a propriedade intelectual (Regra 18) e assinar um termo de sigilo entre as partes (Regra 19). A transferência de parte dos desafios técnicos para terceiros (Objetivo 3.5.3) carece que se prospecte parceiros com competência comprovada (Regra 20) e atribua-se preferência para fornecedores certificados (Regra 21). E, por fim, para desenvolver e absorver novas tecnologias (Objetivo 3.5.4) é necessário seguir a regra que impõe a manutenção da vigilância tecnológica (Regra 22).

O Modelo de Processos começa através de um processo externo: elaborar estratégia para inovar produto (ProcExt 1). A partir da elaboração dessa visão estratégica inicia-se a geração de novas ideias (Processo 1) e, em seguida, gera-se as especificações técnicas (Processo 2). Partindo-se das ideias e especificações define-se a arquitetura do novo produto (Processo 3). Nesse ponto é necessário realizar um primeiro estudo de viabilidade técnica e financeira do produto (Processo 4). A partir daí gera-se o protótipo digital (Processo 6) obtendo-se alguns resultados de desempenho. O próximo passo (Processo 6) é a geração do memorial descritivo básico (MDB) que conterá, dentro outros, listas explodidas de itens, definiç̧ão de fornecedores, plano de embalagem. Nesse momento, procura-se realizar uma pesquisa de mercado para verificar se as condições levantadas no ProcExter 1 continuam válidas, por esse motivo há um importante gate de aprovação com a diretoria (Processo 8). De posse das informações geradas nos passos anteriores define-se os parceiros mais adequados para integrar o processo de desenvolvimento (Processo 9) e gera-se um protótipo funcional (Processo 10). Com esse 
protótipo, a equipe de desenvolvimento tem dados mais definitivos sobre as variáveis de performance do produto. O próximo passo é a especificação do processo de produção (Processo 11), depois o projeto da embalagem (Processo 12), e o planejamento do treinamento da mão de obra e da distribuição dos turnos de trabalho (Processo 13). Gera-se então o material de suporte que será distribuído tanto internamente quanto externamente para o mercado (Processo 14). O PDP é considerado finalizado quando é gerado o lote piloto (Processo 15) e a partir daí passa-se para a área de manufatura a tarefa de produzir o novo produto em alta escala.

O Modelo de Atores e Recursos apresenta seis unidades organizacionais. As quatro primeiras são: gerência de $\mathrm{P} \& \mathrm{D}$, gerência de marketing, gerência de engenharia, e gerência de manufatura. Elas provém recursos como normas e procedimentos (Recurso 1) e ferramentas, máquinas e equipamentos (Recurso 2), além das unidades individuais que compõem a Equipe de projeto (Unidade Organizacional 5). Seis unidades individuais compõem a equipe de projeto, são elas: gerente de $\mathrm{P} \& \mathrm{D}$, técnico de laboratório, engenheiro de processo, analista de marketing, engenheiro de produto, engenheiro de processo. Percebe-se que não há uma unidade individual assumindo o papel Coordenador (Papel 1), isso fica sob a responsabilidade da própria equipe de projeto. A equipe tem acesso às orientações estratégicas (Recurso 10) elaboradas pelos diretores: diretor comercial (Unidade Individual 7) e diretor industrial (Unidade Individual 8). Essas orientações são elaboradas com apoio de um parceiro especializado em mercado (Unidade Organizacional 7) que assume o a posição de Broker (Papel 3) ou seja, prospectador de oportunidades e/ou tendências. Por fim, a equipe de projetos elabora os contratos (Recurso 3) que irão controlar as relações com os fornecedores de componentes (Unidade Organizacional 6), e também elabora o Memorial Descritivo Básico (Recurso 4). Este documento é composto por várias partes como especificações técnicas (Recurso 5), listas explodidas de componentes, custo do ferramental e componentes, especificações de desempenho, estudos de viabilidade financeira, técnica e industrial.

O Modelo de Conceitos é formado por 11 conceitos e inicia apresentando a orientação estratégica (Conceito 1) apoiada pela inovação competitiva (Conceito 2). As redes de parcerias (Conceito 3) apresentam os requisitos necessários para a prática da inovação em nível competitivo, e são apoiadas pelo conceito de formalização contratual das relações (Conceito 4). Dentre as concepções estratégicas temos a de fidelização do fornecedor (Conceito 5) e a de Broker de oportunidades (Conceito 6), sendo que o conjunto de lições aprendidas ao longo do tempo (conceito 7) apoia essas e outras concepções. O conceito de equipe multifuncional (Conceito 8) está diretamente vinculado ao de orientação estratégica, sendo ela responsável pelo 
acompanhamento solidário (conceito 9) e por gerar a concepção do produto (Conceito 10), que é elaborado pensando-se no ciclo de vida completo do produto (Conceito 11) 


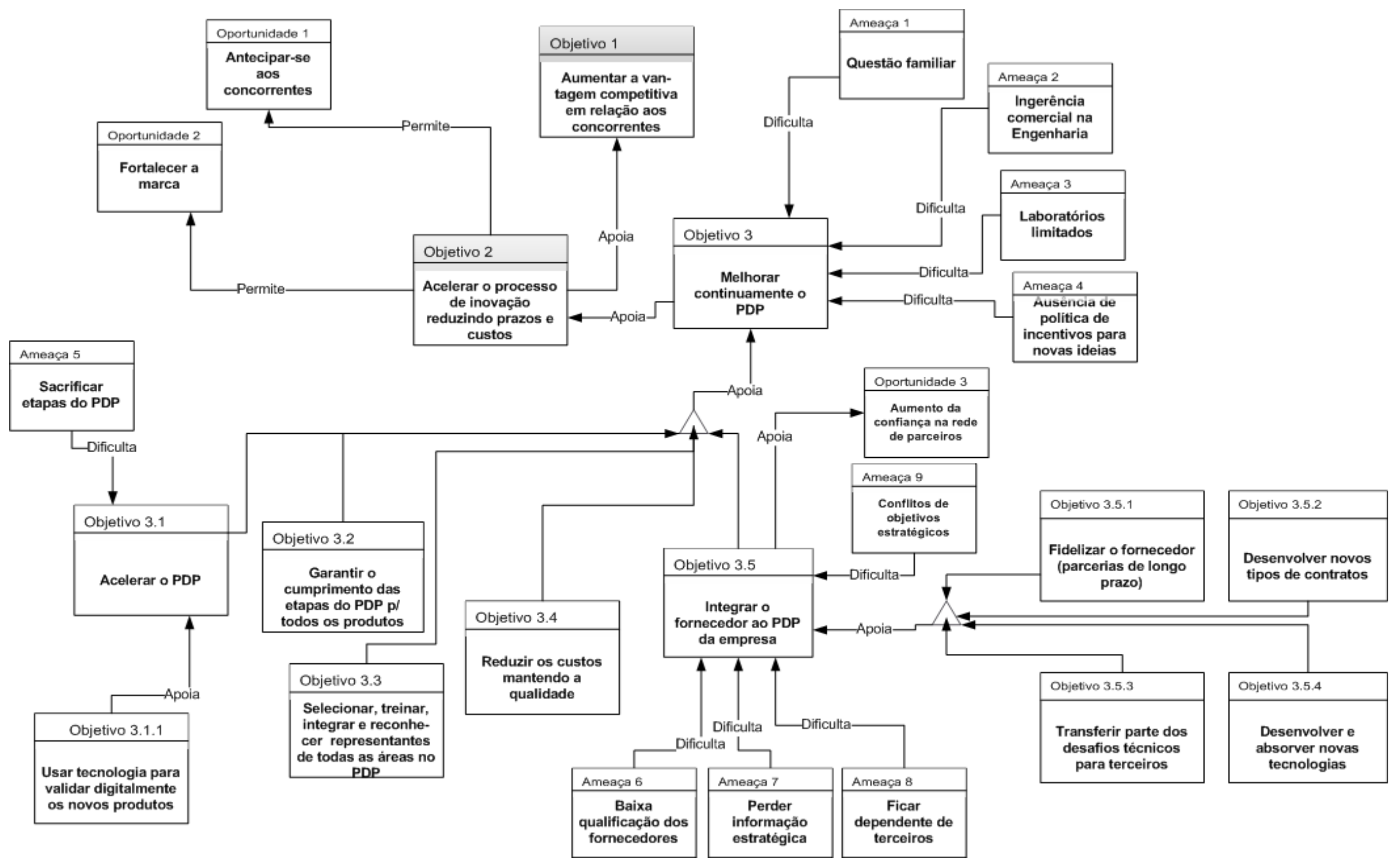

Figura 29: Modelo de Objetivos (as-is) - unidade de análise número 2. 


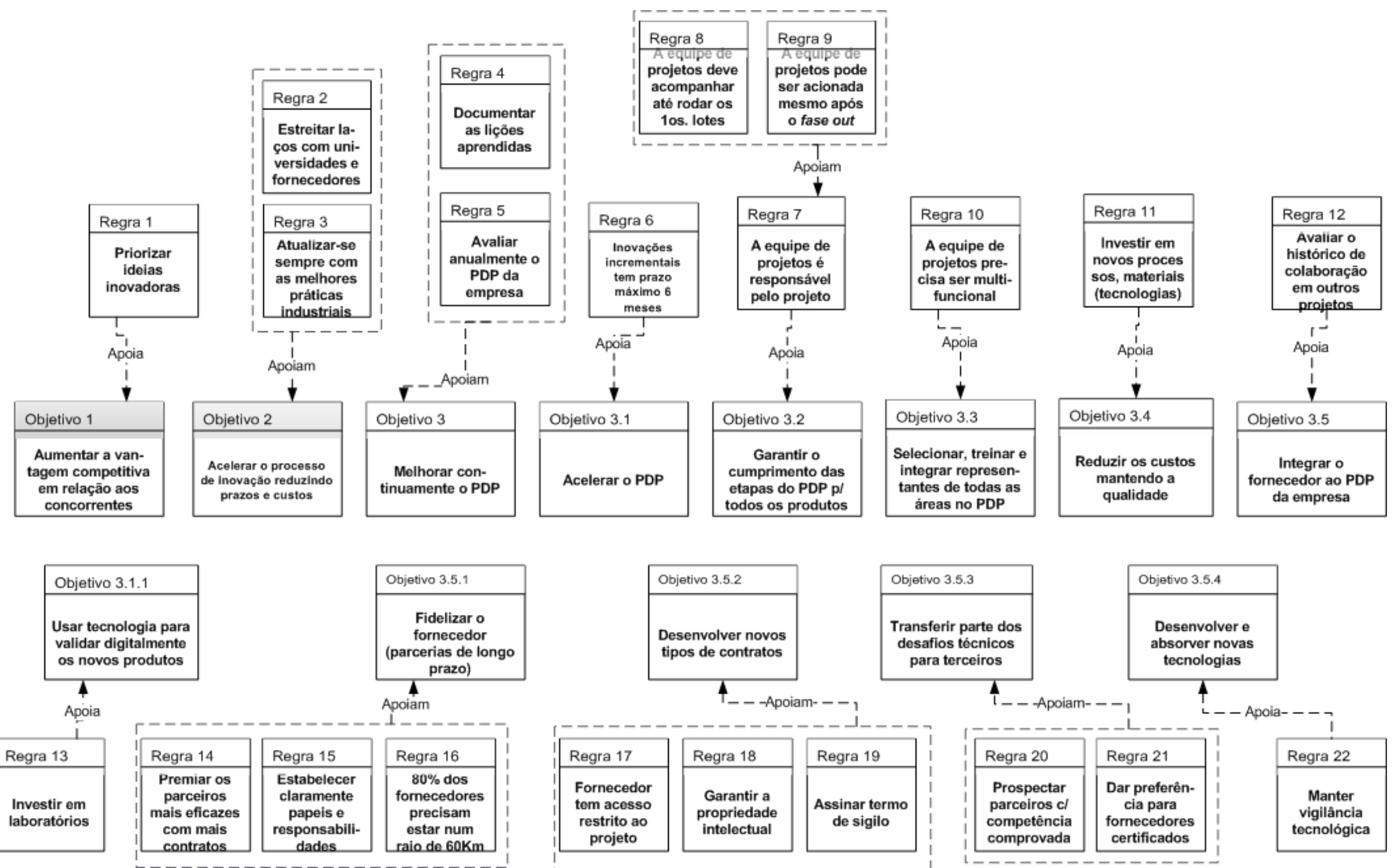

Figura 30: Modelo de Regras de Negócios (as-is) - unidade de análise número 2. 


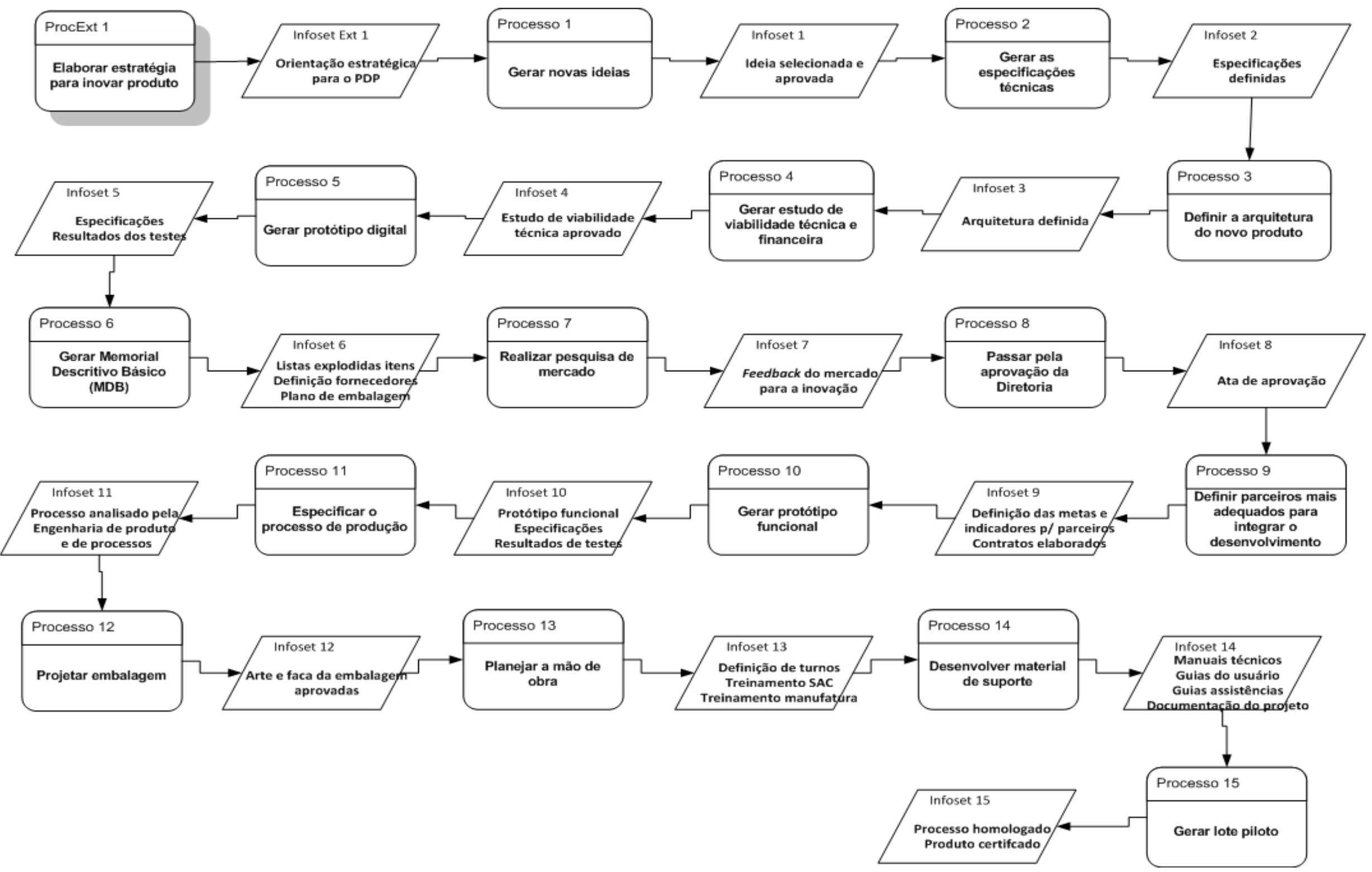

Figura 31: Modelo de Processo de Negócios (as-is) - unidade de análise número 2. 


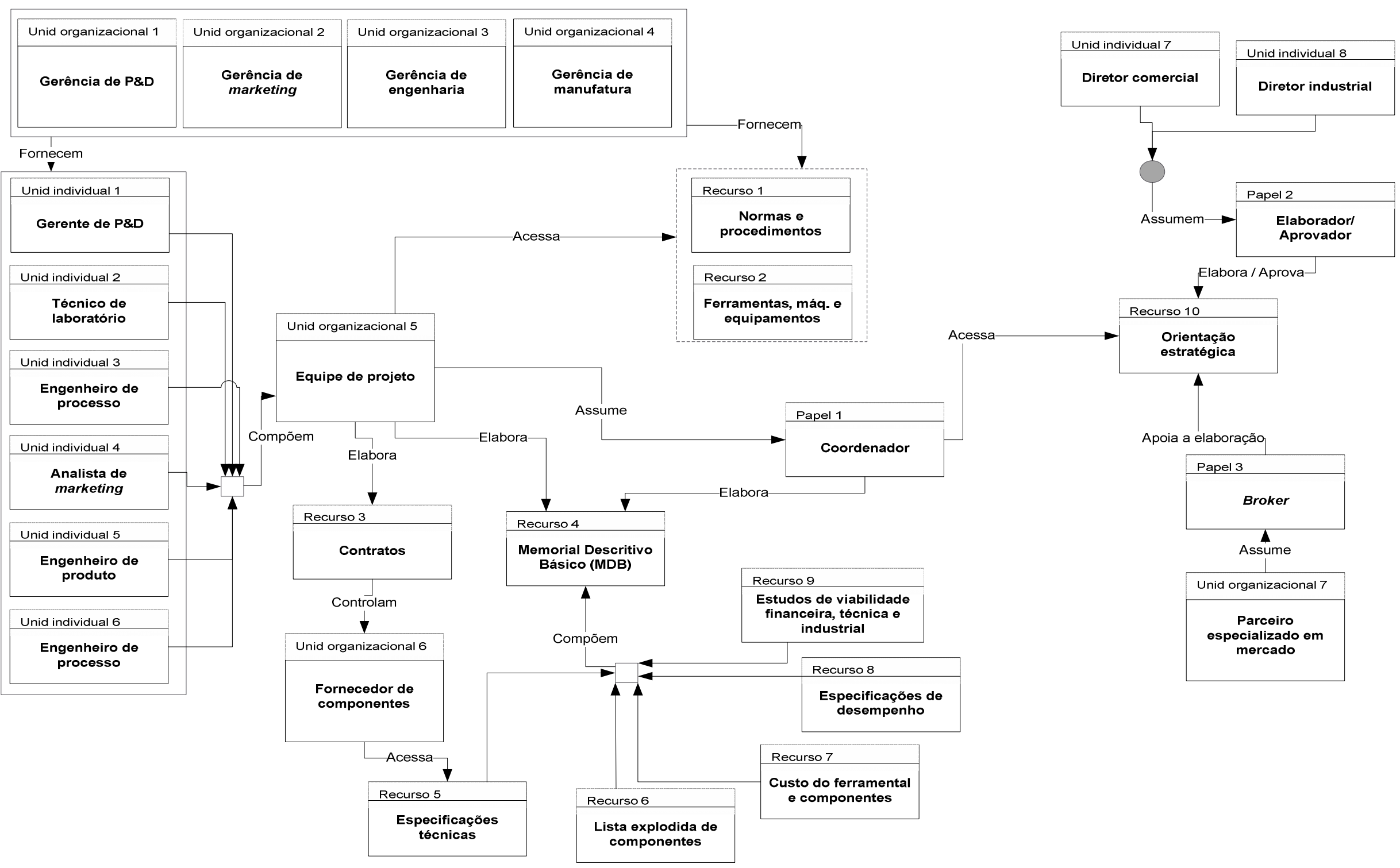

Figura 32: Modelo de Atores e Recursos (as-is) - unidade de análise número 2. 


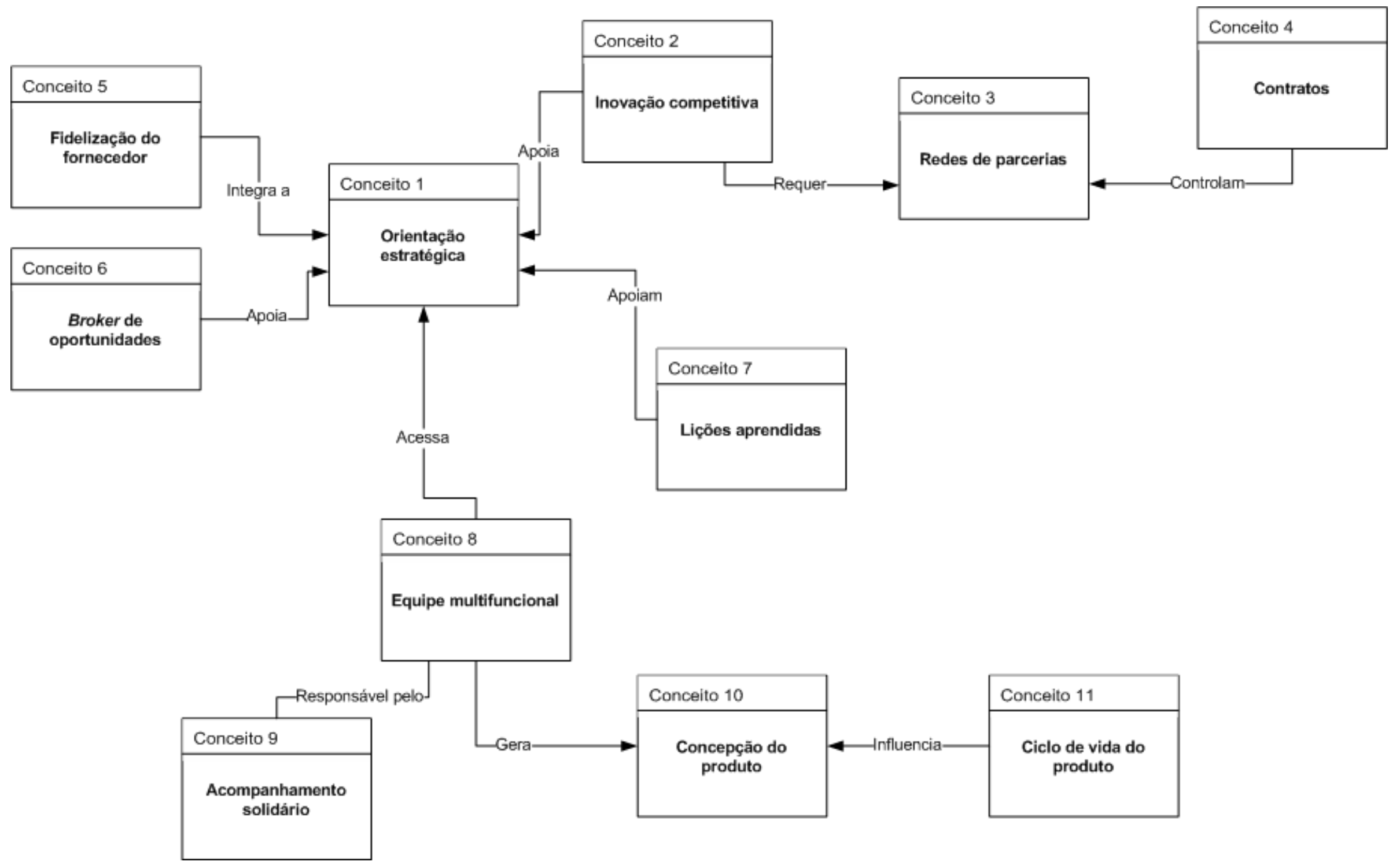

Figura 33: Modelo de Conceitos (as-is) - unidade de análise número 2. 
3. Unidade de análise Número 3

O Modelo de Objetivos da unidade 3 também é encabeçado por uma perspectiva comercial, entregar benefícios para consumidores, sociedade e acionistas (Objetivo 1). Esse alvo sofre com a dificuldade para se equilibrar os interesses entre as partes (Ameaça 1), os quais podem ser conflituosos. O alcance desse alvo requer que se mantenha a inovação como prioridade estratégica (Objetivo 2), o que permite gerar novos conhecimentos (Oportunidade 1). Três objetivos apoiam o direcionamento da unidade para a inovação constante: acelerar o desenvolvimento de pesquisas e o PDP (Objetivo 2.1); diminuir o impacto ambiental do negócio (Objetivo 2.2), que pode esbarrar na visão de lucro a curto prazo (Ameaça 3); reforçar os laços de parcerias com terceiros a longo prazo (Objetivo 2.3), que pode acarretar a perda de conhecimento estratégico (Ameaça 4). Para acelerar as pesquisas busca-se utilizar a Engenharia Simultânea (Objetivo 2.1.1) antecipando e realizando em paralelo as atividades, explorar novas tecnologias (Objetivo 2.1.2) que possam melhorar produto e processo, e validar os produtos com softwares de simulação (Objetivo 2.1.3). Os dois primeiros objetivos apresentam um desafio que é o aumento da complexidade dos projetos (Ameaça 2). Sobre o Objetivo 2.2, trabalha-se com dois objetivos de apoio: desenvolver produtos com atributos sustentáveis (Objetivo 2.2.1) e desenvolver processos e estrutura industrial sustentáveis em termos econômicos e ambientais (Objetivo 2.2.2). Para reforçar os vínculos com os parceiros (Objetivo 2.3), objetivo esse que sofre ameaça das diferenças culturais (Ameaça 4) e da perda de conhecimento estratégico (Ameaça 5), a unidade de análise tem três objetivos de suporte: integrar os parceiros chaves ao PDP (Objetivo 2.3.1); auditar os parceiros mais importantes (Objetivo 2.3.2), e assim acompanhar o relacionamento e as trocas, mas que pode acrescentar mais custo e esforço (Ameaça 5); e extrair novos conhecimentos (Objetivo 2.3.3).

O Modelo de Regras de Negócios apresenta 17 regras básicas que apoiam o Modelo de Objetivos. Para conseguir entregar benefícios aos stakeholders (Objetivo 1) há três regras: para ser aprovado todo novo produto precisa ser rentável (Regra 1), o que gera benefícios para funcionários, diretores e acionistas; todos projetos precisa apresentar novas funções e design (Regra 2), o que traz benefícios para usuários; o CRM precisa ser usado para estreitar o relacionamento com clientes e comunidade (Regra 3). Para manter a inovação como prioridade estratégica (Objetivo 2) há a regra que estabelece que 25\% do faturamento deve provir de novos produtos (Regra 4). Para acelerar o PDP (Objetivo 2.1) deve-se investir em tecnologia (Regra 5). A fim de diminuir o impacto ambiental do negócio (Objetivo 2.2) é preciso focar no Design for Excellence e no Design for Environment (Regra 6) e atender política pública de emissão de gases e resíduos sólidos (Regra 7). Para conseguir reforçar os laços de longo prazo com os 
parceiros (Objetivo 2.3) é preciso estabelecer contratos rigorosos de direitos e deveres (Regra 8) e exigir comprovação de qualificação dos parceiros (Regra 9). O desejo de usar a Engenharia Simultânea (Objetivo 2.1.1) requer que seja realizado um planejamento eficiente do paralelismo e da antecipação de atividades (Regra 10). A regra que apoia o objetivo de explorar novas tecnologias (Objetivo 2.1.2) mostra o para quê dessas tecnologias: elas precisam facilitar a manufatura, o diagnóstico e a manutenção (Regra 11). O objetivo de validar produtos com softwares (Objetivo 2.1.3) tem apoio a regra que define o uso de protótipos virtuais para os novos projetos (Regra 12). Para desenvolver produtos com atributos sustentáveis (Objetivo 2.2.1) a unidade de análise trabalha com produtos plataforma (Regra 13) pensando em sustentabilidade econômica, e reforça a reciclabilidade (Regra 14) pensando em ganhos ambientais. Para manter a sustentabilidade dos processos e da estrutura industrial (Objetivo 2.2.2) busca-se reduzir o consumo de água e energia, bem como a diminuição da liberação de resíduos do processo fabril (Regra 15). A integração dos parceiros chaves no PDP (Objetivo 2.3.1) precisa ocorrer nas etapas iniciais do processo de desenvolvimento (Regra 16) para melhor explorar o conhecimento dos parceiros, e ha que se restringir o acesso do parceiro apenas as informações necessárias ao seu trabalho (Regra 17). Toda parceria precisa ser auditada (Objetivo 2.3.2) para assegurar o bom andamento das tarefas, e alguns pontos avaliados são o cumprimento do código de conduta e o cumprimento das metas estabelecidas (Regra 18). Por fim, o objetivo de extrair/aproveitar o conhecimento dos parceiros requer que a participação de qualquer terceiro seja documentada (Regra 19).

O processo que estrutura o PDP inicia com a realização do planejamento estratégico por parte da Diretoria (ProcExt 1), o que resulta em um plano estratégico que funciona como diretriz para o levantamento de requisitos do cliente (Processo 1). Os próximos passos incluem uma definição dos requisitos do produto (Processo 2) e a realização de estudos de viabilidade financeira, industrial e ambiental (Processo 2). Após as devidas aprovações, as próximas etapas envolvem a modelagem funcional (Processo 4), o desenvolvimento de soluções alternativas (Processo 5), e a definição da arquitetura do produto (Processo 6). Nesse ponto é realizado um novo estudo de viabilidade financeira, industrial e ambiental (Processo 7), cuja aprovação permite o desenvolvimento de um protótipo virtual e/ou físico (Processo 8). Com os dados obtidos a partir do protótipo seleciona-se os SSC's (sistemas, subsistemas e componentes) a serem desenvolvidos interna e externamente (Processo 9) e, com isso, pode-se trabalhar os potenciais parceiros (Processo 10). Novamente um estudo de viabilidade financeira (Processo 11) decidirá a continuação ou não do processo. Na sequência ocorre a integração dos parceiros ao PDP (Processo 12) em relação às normas, procedimentos e metas; o planejamento e 
negociação do processo de manufatura (Processo 13); a criação do material de suporte (Processo 14); e o projeto da embalagem (Processo 15). Os dois próximos processos certificam o produto (Processo 16) e homologam o processo (Processo 17). Um novo estudo de viabilidade financeiro é realizado (Processo 18) e finaliza-se com o fase out com a manufatura (Processo 19).

O Modelo de Atores e Recursos apresenta oito unidades organizacionais, sendo que as cinco primeiras (gerência de design e inovação, departamento de inteligência de mercado, gerência de processos, gerência de manufatura, gerência de qualidade) são responsáveis por prover todas as unidades individuais que integram a Equipe de Projeto (Unidade Organizacional 6) e por fornecer alguns recursos essenciais como código de conduta e contratos (Recurso 1); banco de projetos (Recurso 2); ferramentas, máquinas e equipamentos (Recurso 3). As unidades individuais que integram a equipe de projeto são: gerente de projeto (Unidade Individual 1), analista de mercado (Unidade Individual 2), engenheiro de processo (Unidade Individual 3), engenheiro de produto (Unidade Individual 4), engenheiro de qualidade (Unidade Individual 4), analista de custos (Unidade Individual 6). Há um gerente de projeto que assume como Coordenador (Papel 1) do projeto e que tem acesso direto ao Plano estratégico (Recurso 7) produzido pela diretoria da unidade de análise: diretor de P\&D (Unidade Individual 7), diretor comercial (Unidade Individual 8), e diretor industrial (Unidade Individual 9). Esse plano também é elaborado com o apoio de um parceiro especializado em marketing de mercado (Unidade Organizacional 8) que assume como Broker (Papel 3) de oportunidades. A equipe de projetos elabora os contratos (Recurso 4) com os parceiros de desenvolvimento (Unidade Organizacional 7), cujo papel é acessar apenas os documentos relativos aos componentes e sistemas (Recurso 6) que irão desenvolver. O documento técnico do produto (Recurso 5) é elaborado e gerenciado pela equipe do projeto e é composto por componentes e sistemas (Recurso 6), roteiro de fabricação (Recurso 7), desenhos técnicos (Recurso 8), estudo de impacto ambiental (Recurso 9), cronogramas (Recurso 10), estudos de viabilidade técnica e financeira (Recurso 11).

O plano estratégico (Conceito 1) representa o conceito a partir do qual derivam os demais conceitos. Ele é formado pela engenharia simultânea (Conceito 2), design for excellence (Conceito 3), design for environment (Conceito 4), código de conduta (Conceito 5), parceiros chaves (Conceito 6), integração estratégica de fornecedores (Conceito 7). O conceito de plano estratégico tem forte conexão com o de inovação (Conceito 8) que recebe apoio do modelo de PDP da empresa (Conceito 13), e requer uma rede eficiente de parceiros (Conceito 9). A rede de parceiros tem sua segurança em dois pilares básicos, a certificação dos parceiros (Conceito 10) e os contratos (Conceito 12), sendo que ambos colaboram para aumentar a confiança entre as 
partes. O conceito de modelo de PDP (Conceito 13) existe na empresa por força do próprio conceito de inovação. O modelo de PDP é formado por SSC's (Conceito 14), gates de aprovação (Conceito 15), arquitetura (Conceito 16), protótipos (Conceito 17), certificação (Conceito 18), homologação (Conceito 19). 


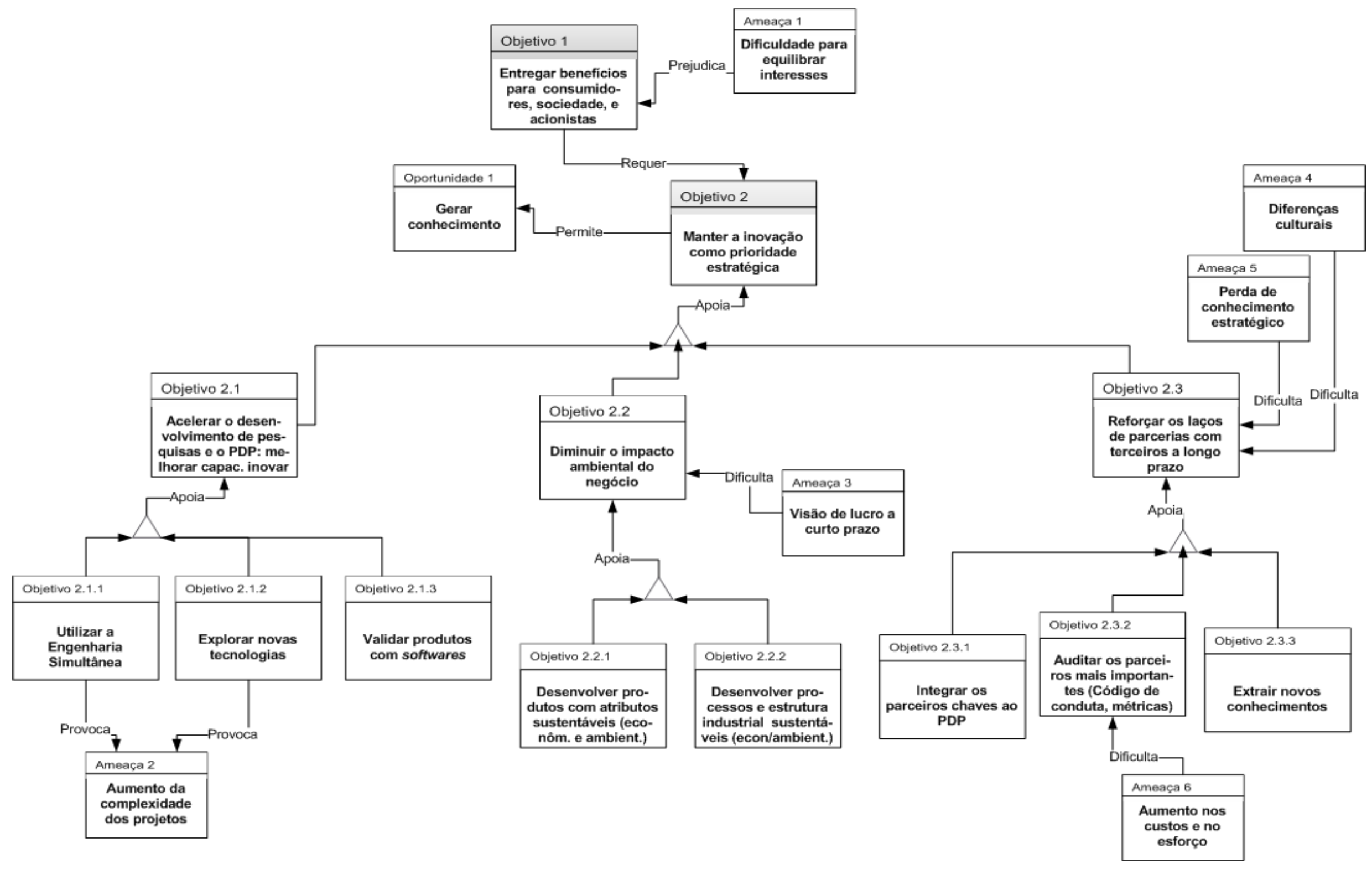

Figura 34: Modelo de Objetivos (as-is) - unidade de análise número 3 


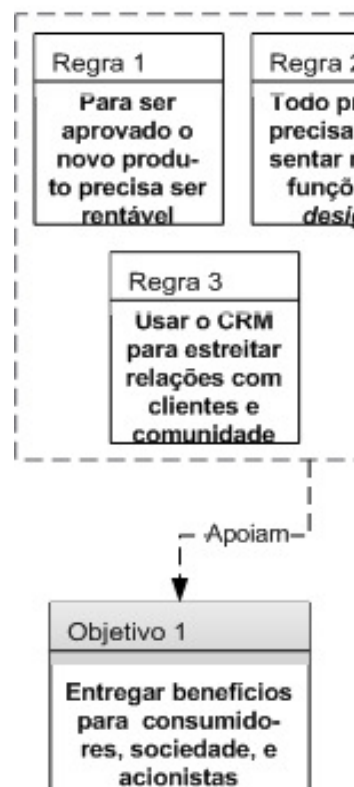

acionistas

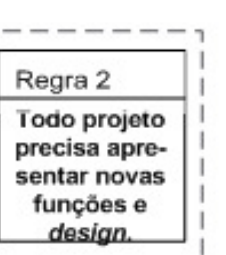

sign.
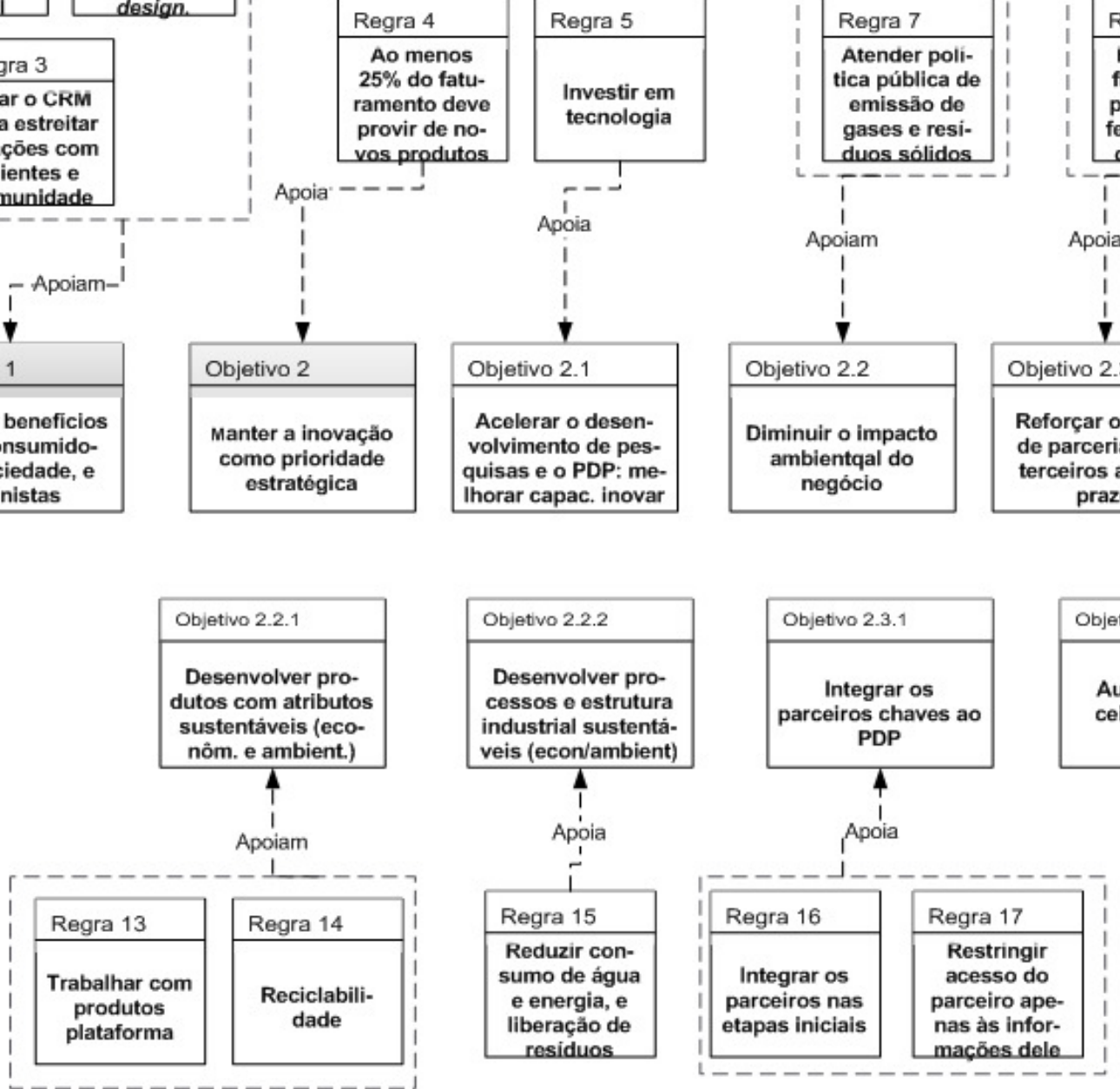

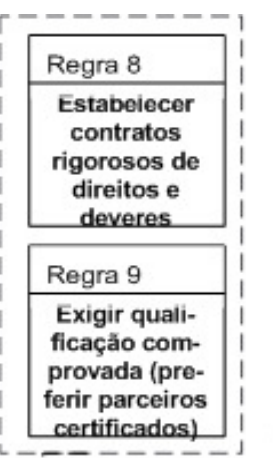

-
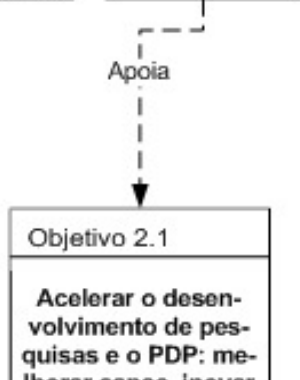

quisas eOPDP. me-

Ihorar capac. inovar
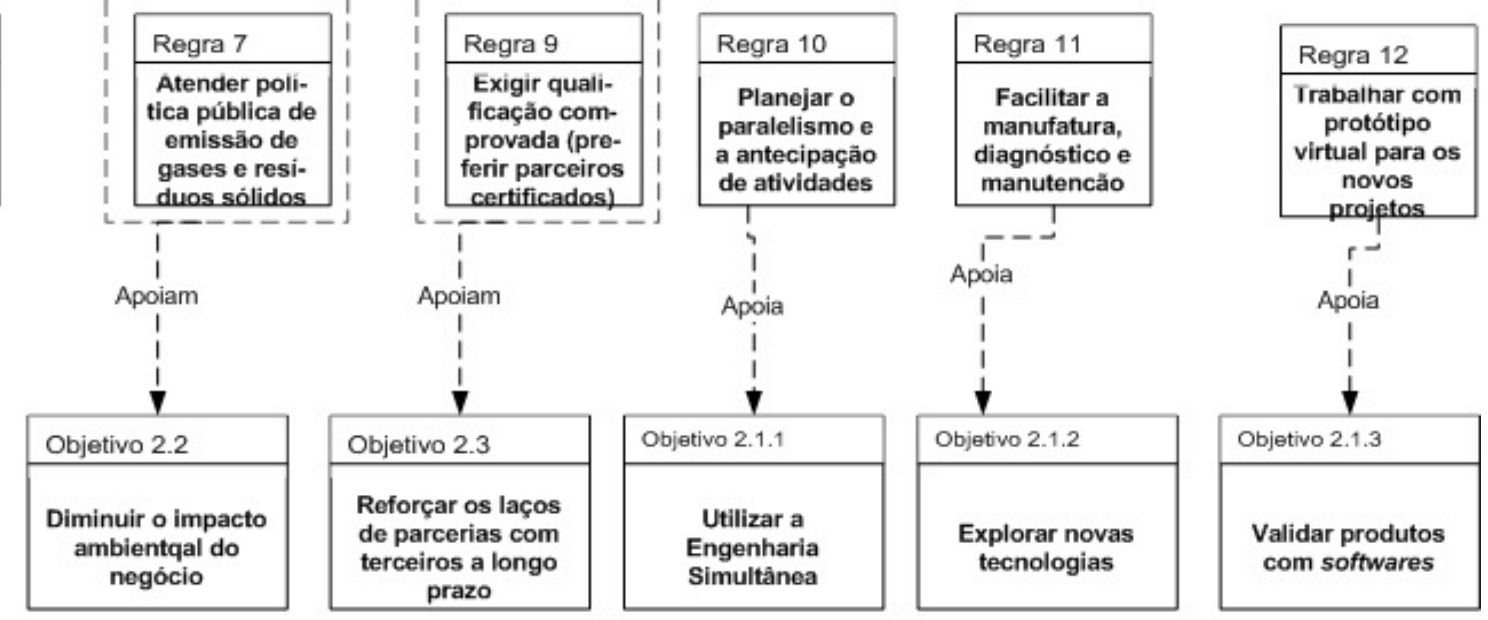

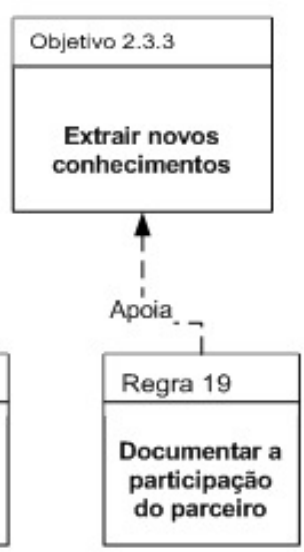

Figura 35: Modelo de Regras de Negócios (as-is) - unidade de análise número 3. 


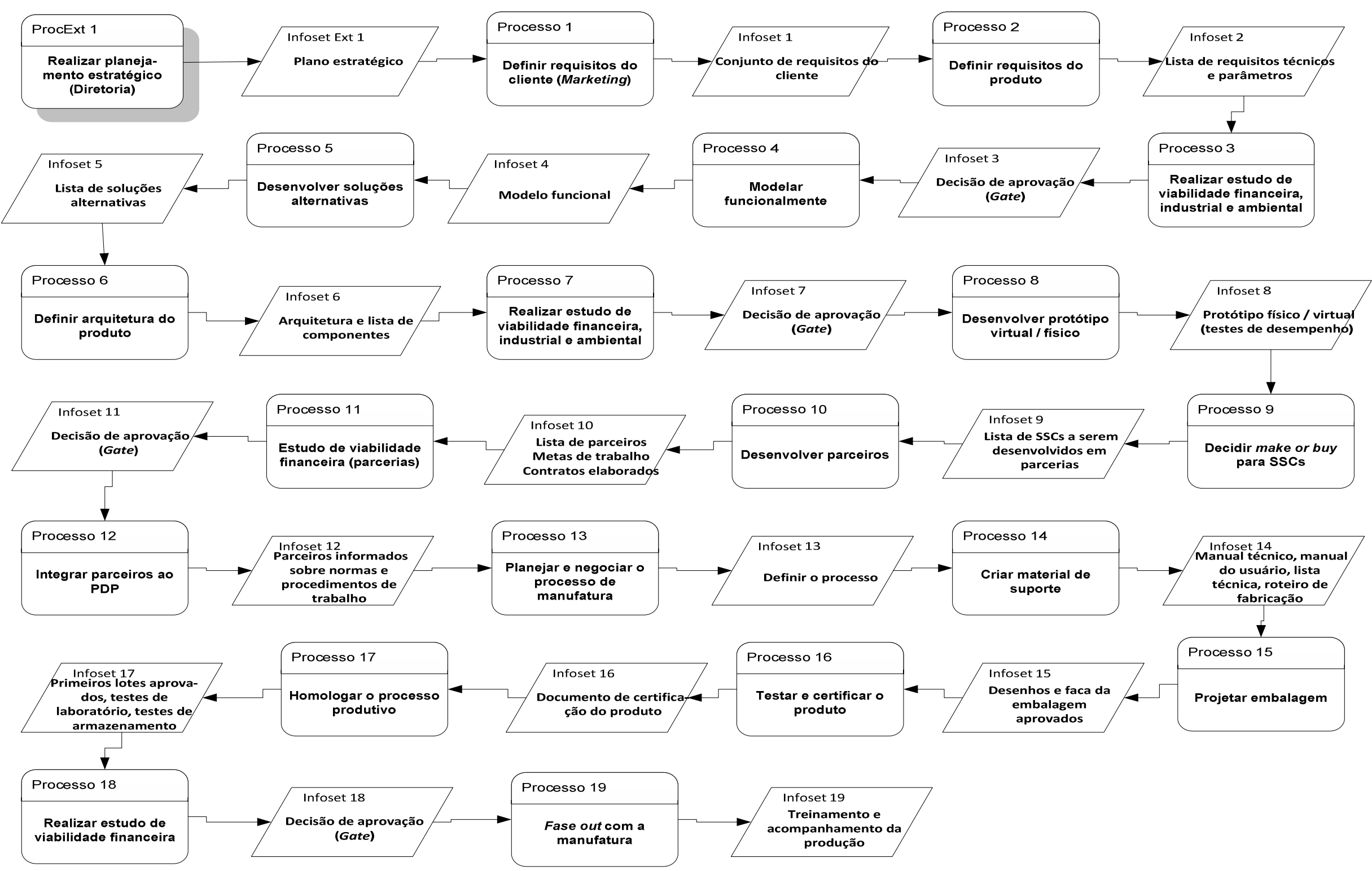

Figura 36: Modelo de Processo de Negócios (as-is) - unidade de análise número 3. 


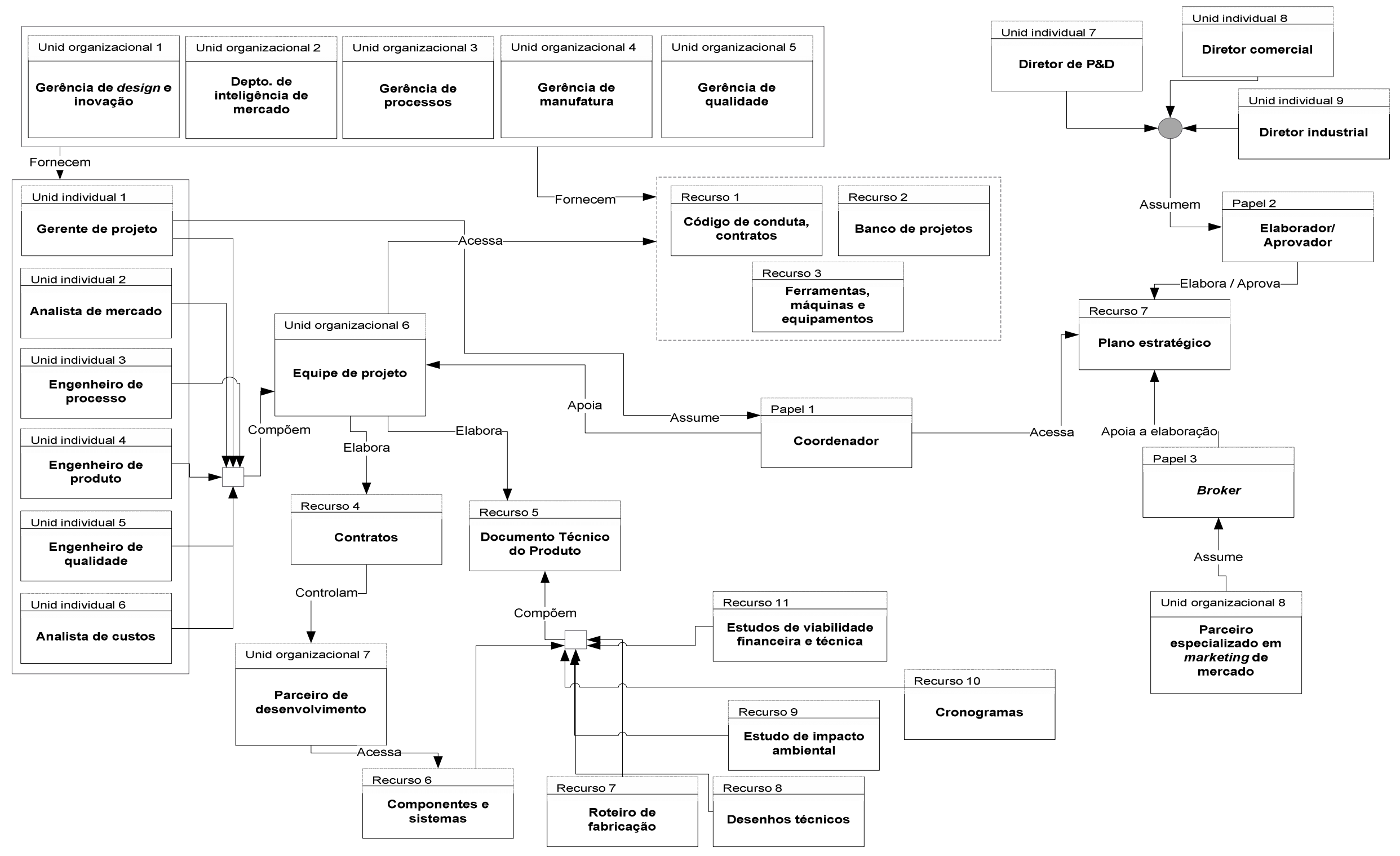

Figura 37: Modelo de Atores e Recursos (as-is) - unidade de análise número 3. 


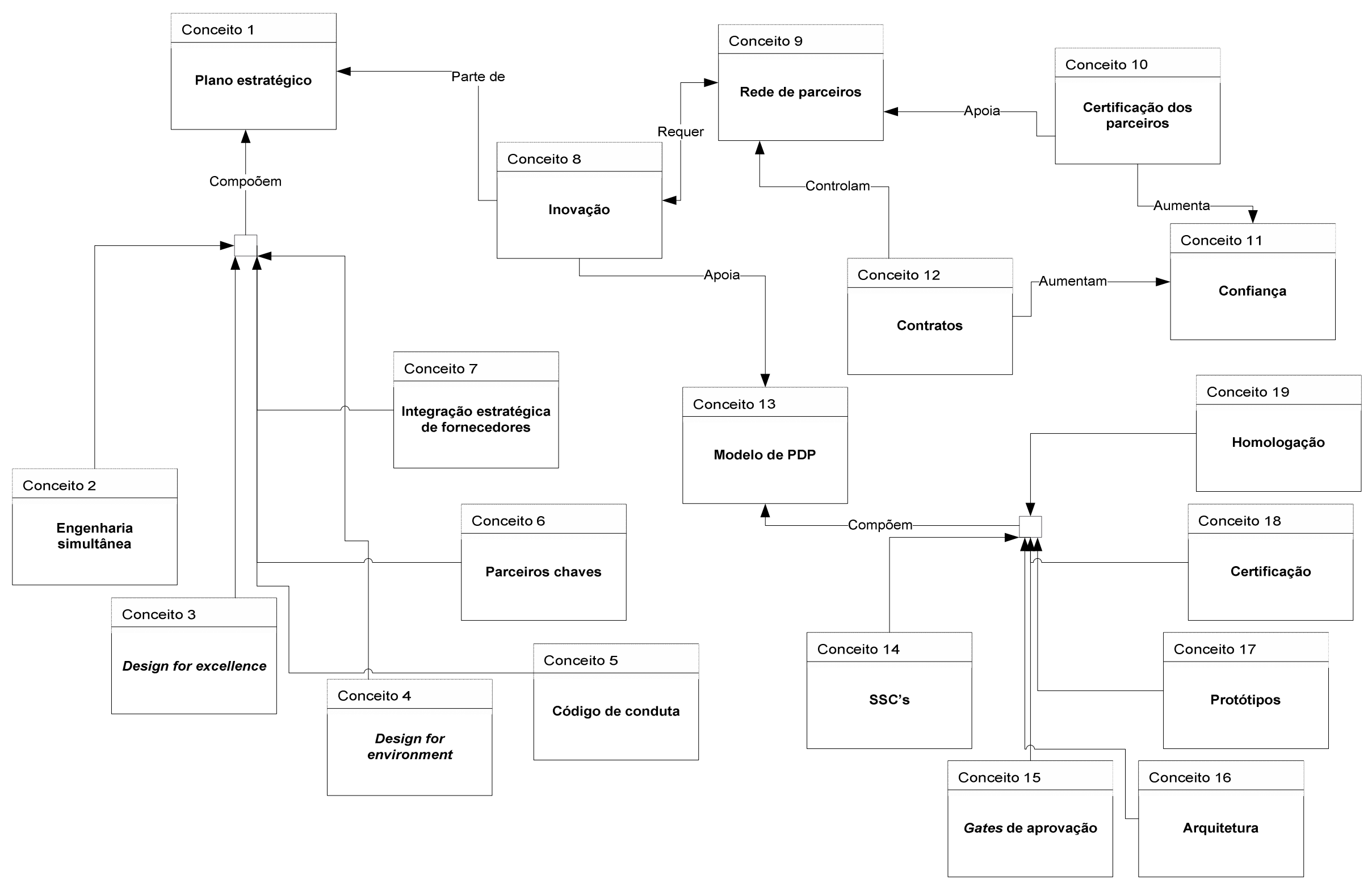

Figura 38: Modelo de Conceitos (as-is) - unidade de análise número 3. 
4. Unidade de análise Número 4

O Modelo de Objetivos dessa unidade de análise apresenta como objetivo primário o aumento da participação no mercado (Objetivo 1) e, para isso, tem-se como foco a entrega de benefícios para os stakeholders (Objetivo 2) que acaba melhorando a imagem no mercado (Oportunidade 1). Esse segundo objetivo é formado por três objetivos de apoio: inovar continua e rapidamente (Objetivo 3), que sofre com as ingerências (Ameaça 1); equilibrar o custo e a qualidade (Objetivo 4), que pode sofrer com o excesso de foco no custo (Ameaça 4); investir pesado em comunicação (Objetivo 5). Para ajudar no desafio de inovar continuamente foram estabelecidos cinco objetivos de apoio: colocar o design for environment como diferencial competitivo (Objetivo 3.1), o que pode aumentar a complexidade tecnológica (Ameaça 2); reduzir custos com o ciclo de vida operacional do produto (Objetivo 3.2); diminuir reclamações de clientes e acelerar respostas (Objetivo 3.3); tornar os produtos mais eficientes e originais (Objetivo 3.4), o que se tornar um desafio ainda maior considerando que os cronogramas são cada vez mais apertados (Ameaça 3); acelerar o processo de desenvolvimento de produtos (Objetivo 3.5). Para viabilizar o objetivo de equilibrar o preço e a qualidade (Objetivo 4) foi definido que é essencial levantar corretamente as expectativas dos clientes (Objetivo 4.1), o que possibilita identificar oportunidades de negócio (Oportunidade 2). O objetivo de investir pesado em comunicação (Objetivo 5) vai além do simples provimento de canais para trocas, por isso foram estabelecidos dois objetivos de apoio: estabelecer parcerias de longo prazo (Objetivo 5.1), que facilita a compreensão mútua entre as partes (Oportunidade 3), mas que sempre traz uma dificuldade para controlar os parceiros (Ameaça 5); e integrar na equipe de projetos especialistas de todas as áreas (Objetivo 5.2), o que contribui para reduzir imprevistos no projeto (Oportunidade 4), mas que não é simples de fazer devido à estrutura organizacional do tipo funcional (Ameaça 6).

No Modelo de Regras de Negócio o aumento da participação no mercado (Objetivo 1) está apoiado na regra que estabelece a necessidade de alinhar o PDP com as diretrizes estratégicas da empresa (Regra 1). A entrega de benefícios para os stakeholders (Objetivo 2) está apoiada em duas regras básicas: estabelecer parceria com Broker para detectar as lacunas e assim prospectar oportunidades (Regra 2); e ideias inovadoras receberão prioridade da direção da empresa (Regra 3), o que facilita a priorização dos projetos. Para manter um processo contínuo e rápido de inovação (Objetivo 3) adota-se o desenvolvimento baseado em componentes intercambiáveis (Regra 4). O desafio de equilibrar custo e qualidade (Objetivo 4) precisa ser continuamente monitorado por intermédio de estudos de viabilidade financeira ao longo das diferentes etapas do PDP (Regra 5). Uma das maneiras de investir pesado em 
comunicação (Objetivo 5) é assegurar que haja canais de comunicação presenciais e remotos disponíveis (Regra 6). Para apoiar a intenção de colocar o Design for Environment como diferencial competitivo procura-se partir da reciclabilidade como conceito base (Regra 7). A redução de custos com o ciclo de vida operacional do produto está apoiada em duas regras de negócio: realizar estudo de viabilidade financeira considerando todo o ciclo de vida do produto (Regra 8) para identificar potenciais gargalos ou ameaças; e desenvolver novos produtos cujos processos de manufatura e de manutenção sejam mais simples (Regra 9). Para diminuir reclamações de clientes e acelerar respostas é importante reforçar o SAC (Regra 10). Devido ao tipo de produto desenvolvido, para torná-lo mais eficiente e original (Objetivo 3.4) é necessário investimento em tecnologia (Regra 11). Para acelerar o PDP (Objetivo 3.5) definiu-se como diretriz básica que serão manufaturados internamente apenas os componentes considerados estratégicos (Regra 12). O levantamento correto das expectativas dos clientes (Objetivo 4.1) é imprescindível adotar o VoC (Voice of Client) nos projetos (Regra 13). O estabelecimento de parcerias de longo prazo (Objetivo 5.1) está apoiado em três regras: atribuir notas para cada parceiro durante o PDP (Regra 14), o que permite avaliar o desempenho dos parceiros ao longo do tempo; privilegiar os fornecedores fisicamente mais próximos (Regra 15), o que facilita a interação entre as partes e ainda acompanhar o trabalho realizado pelo contratado; e estabelecer contratos claros sobre sigilo industrial (Regra 16), o que protege a propriedade intelectual das partes. Por fim, para integrar na equipe de projetos especialistas de todas as áreas (Objetivo 5.2), deve-se garantir que a equipe de projeto precisa ser multifuncional (Regra 17) e que as atividades de projeto tenham prioridade sobre as atividades funcionais (Regra 18).

O Modelo de Processos de Negócios começa com a vigilância ao mercado e suas variáveis como concorrência e governo (ProcExt1). O primeiro processo dentro do PDP é uma pesquisa de mercado feita com os clientes (Processo 1) para levantar necessidades e expectativas deles em relação ao produto. Com isso pode-se definir os requisitos do produto (Processo 2), estruturar as informações técnicas e assim elaborar a sua arquitetura (Processo 3). Em seguida é feita uma análise financeira e técnica (Processo 4), cujo resultado será submetido à avaliação da diretoria (Processo 5 para depois definir-se a lista de parceiros que trabalharão no projeto (Processo 6). Desenvolve-se o protótipo virtual e/ou físico (Processo 7) e com as informações obtidas faz-se o planejamento do processo de manufatura (Processo 8). A próxima etapa é a definição da contratação de mão de obra, realização de treinamento, contratação e integração de fornecedores (Processo 9). Neste ponto do PDP é realizada uma análise financeira e técnica (Processo 10) que será submetida à aprovação da diretoria. Na sequência é produzido o lote piloto (Processo 11) e com as informações produzidas são feitos ajustes no processo de 
manufatura (Processo 12). Novamente é feita uma análise financeira (Processo 13) e por último são executadas as atividades de faseout com a área de manufatura (Processo 14).

O Modelo de Atores e Recursos apresenta oito unidades organizacionais, sendo que cinco delas disponibilizam a estrutura básica para o projeto, tanto em termos de recursos como de unidades individuais. Dos recursos fornecidos temos: normas e procedimentos (Recurso 1), bases de dados de projetos (Recurso 2), estudos de viabilidade financeira (Recurso 3), estudos de viabilidade técnica (Recurso 4), e histórico sobre as parcerias (Recurso 5). Das unidades individuais fornecidas e que formam a equipe de projeto (Unidade Organizacional 6) temos: gerente de P\&D (Unidade Individual 1), designer (Unidade Individual 2), analista de marketing (Unidade Individual 3), engenheiro de produto (Unidade Individual 4), engenheiro de processo (Unidade Individual 5), e engenheiro de segurança do trabalho (Unidade Individual 6). A equipe de projeto acessa os recursos disponibilizados e recebe apoio do coordenador do projeto (Papel 1), que é representado pelo gerente de $\mathrm{P} \& \mathrm{D}$. No exercício desse papel ele acessa as diretrizes estratégicas (Recurso 7) elaboradas pela diretoria administrativo/financeira (Unidade Individual 8) e pela diretoria comercial (Unidade Individual 9). Essas diretrizes são elaboradas com apoio de uma parceiro especializado em mercado (Unidade Organizacional 8) que assume a função de Broker (Papel 3). A equipe de projeto elabora os contratos (Recurso 7) que controlam os parceiros de projeto (Unidade Organizacional 7), e também elabora o documento técnico do produto (Recurso 6) que é composto por especificações técnicas (Recurso 8), estudo de impacto ambiental (Recurso 9), informações financeiras (Recurso 10), cronogramas (Recurso 11), informações de tryout (Recurso 12).

No Modelo de Conceitos a inovação (Conceito 1) é parte integrante da diretriz estratégica da organização (Conceito 2), e isso certamente ajuda nas decisões sobre investimentos. Os desafios impostos pela necessidade de inovar requerem uma equipe de parceiros (Conceito 9) como fonte de apoio, a qual está apoiada no histórico de cooperação (Conceito 10), na confidencialidade (Conceito 11), em equipe multifuncional (Conceito 12), e no conceito de Broker (Conceito 13). A diretriz estratégica é composta por: vigilância ao mercado (Conceito 3), homologações e certificações (Conceito 4), voice of client (Conceito 5), reciclabilidade (Conceito 6), fase out (Conceito 7), e design for environment (Conceito 8). 


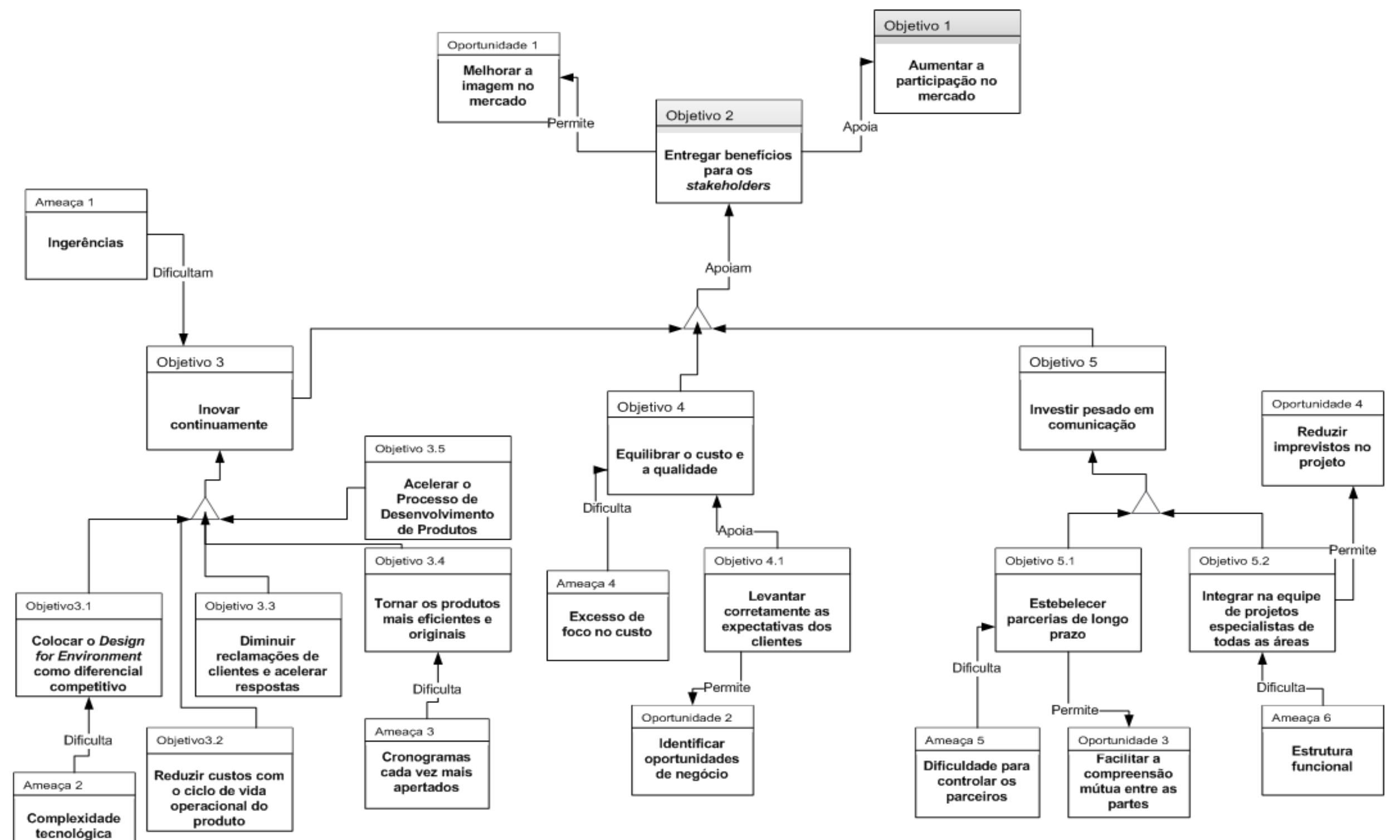

Figura 39: Modelo de Objetivos (as-is) - unidade de análise número 4 


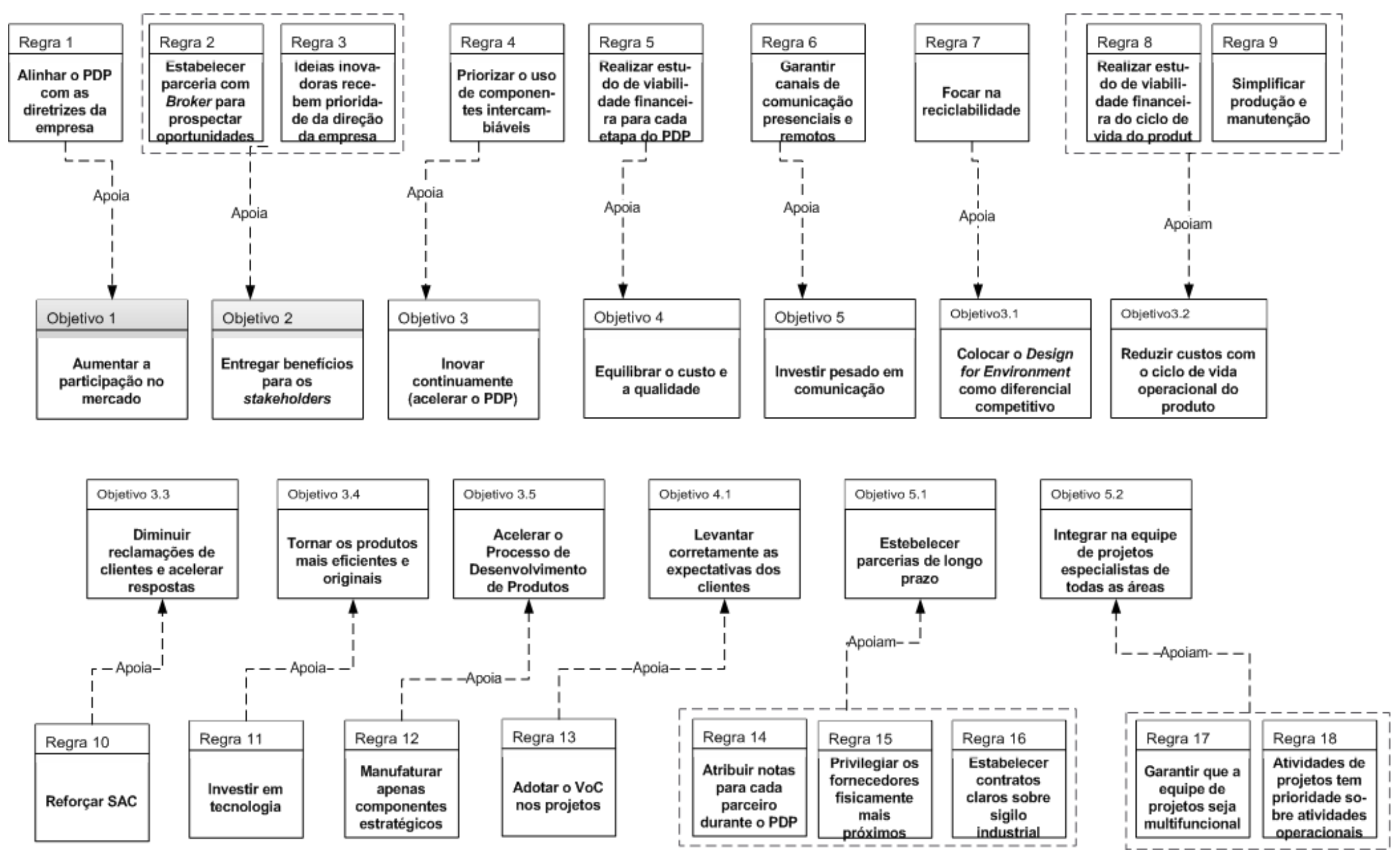

Figura 40: Modelo de Regras de Negócios (as-is) - unidade de análise número 4. 


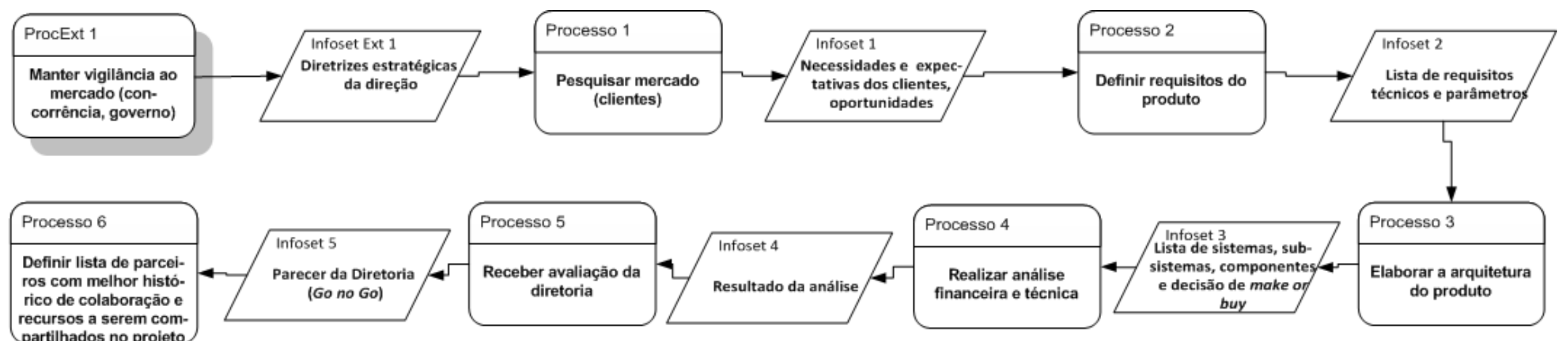

partillhados no projeto
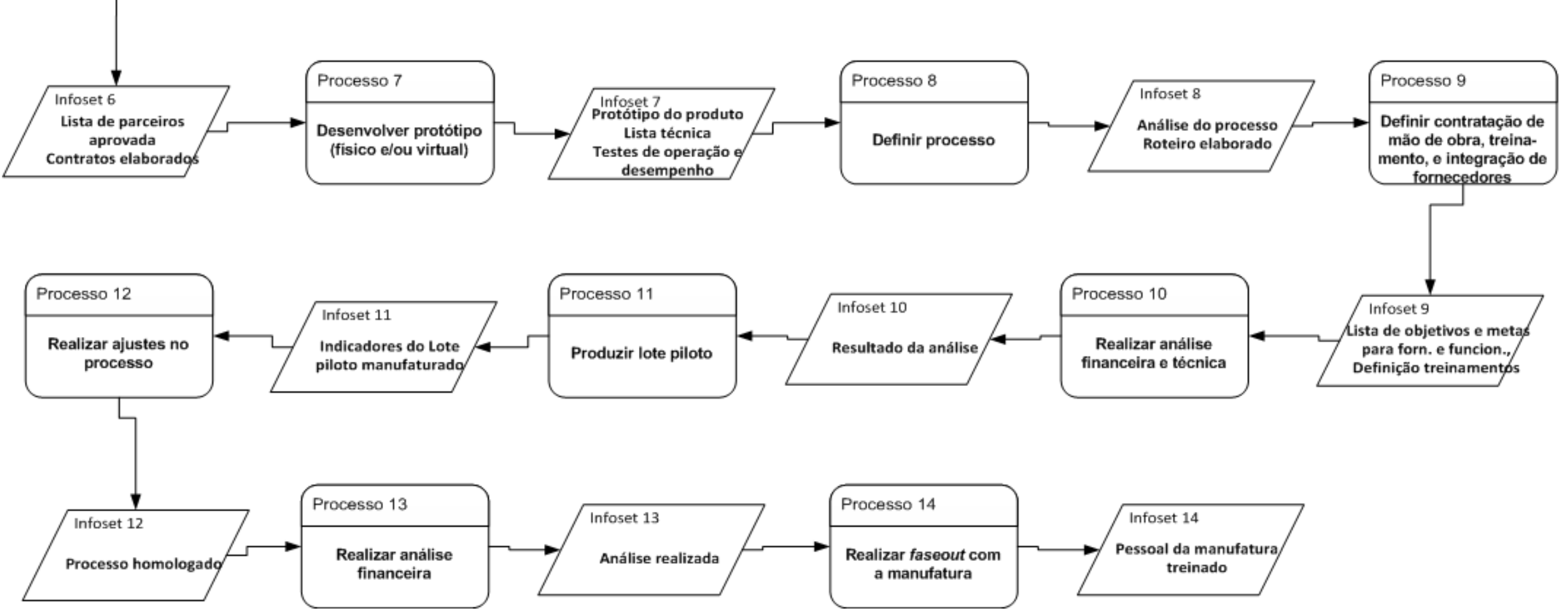

Figura 41: Modelo de Processo de Negócios (as-is) - unidade de análise número 4. 


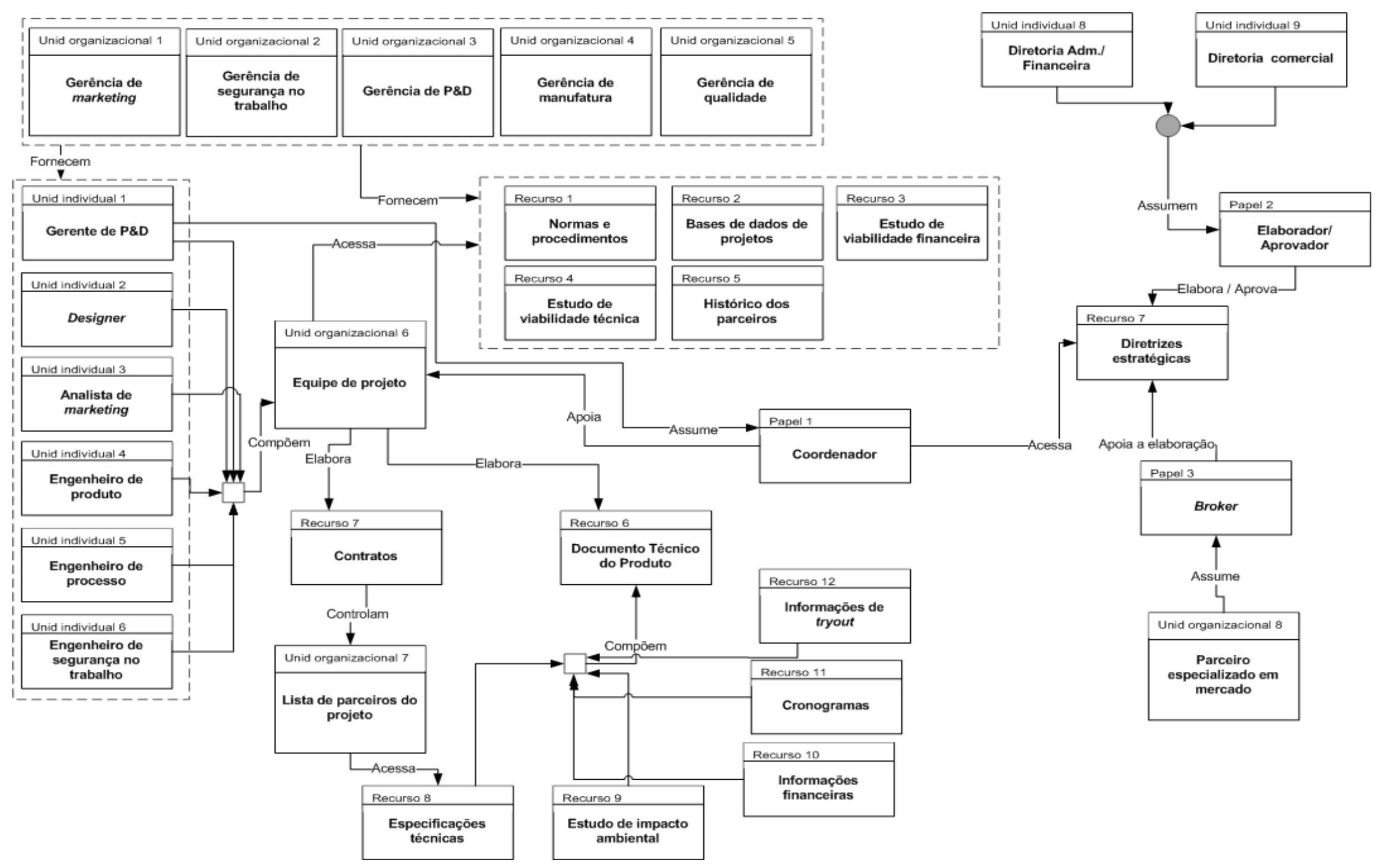

Figura 42: Modelo de Atores e Recursos (as-is) - unidade de análise número 4. 


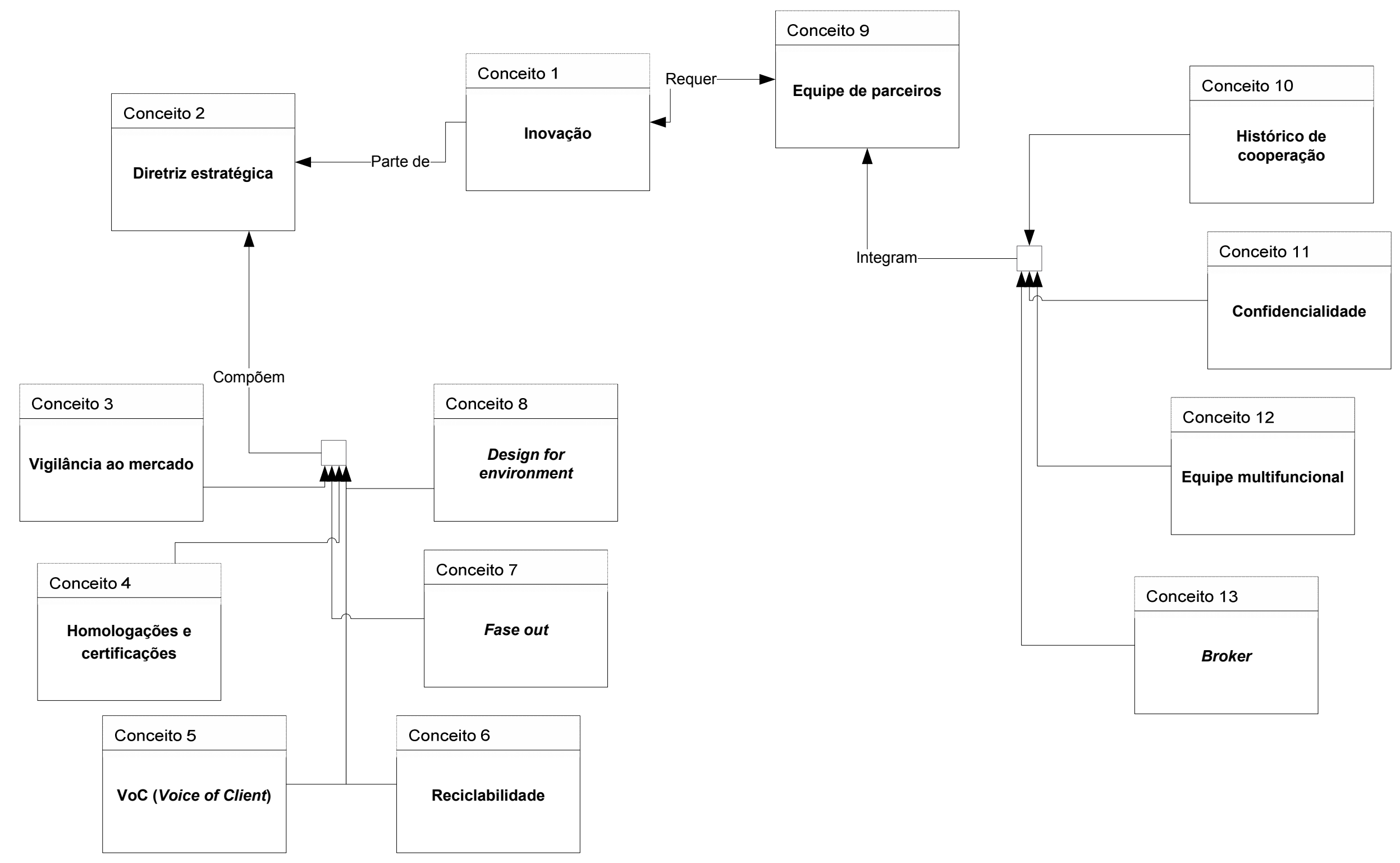

Figura 43: Modelo de Conceitos (as-is) - unidade de análise número 4. 
5. Unidade de análise Número 5

O Modelo de Objetivos dessa unidade de análise destaca que facilitar a vida das pessoas, entregando benefícios para os stakeholders (Objetivo 1), é o alvo principal, inclusive por ajudar a reforçar a marca diante da concorrência (Oportunidade 1). Esse objetivo recebe apoio de quatro objetivos secundários: investir na melhora da capacidade de inovar para alcançar a excelência e a confiabilidade (Objetivo 2), priorizar a responsabilidade ambiental (Objetivo 3), selecionar profissionais dinâmicos e participativos para integrar o projeto (Objetivo 4), intensificar o relacionamento de longo prazo com os fornecedores/parceiros (Objetivo 5). Investir em inovação (Objetivo 2) esbarra no custo (Ameaça 1) e recebe apoio de: buscar originalidade (Objetivo 2.1), que esbarra na necessidade de know how técnico (Ameaça 2); unir design com praticidade, qualidade, segurança e economia (Objetivo 2.1); melhorar a eficiência produtiva (Objetivo 2.3), o que permite explorar melhor o conhecimento interno e otimizar o uso dos recursos (Oportunidade 2); e reduzir o tempo de lançamento de novos produtos (Objetivo 2.4). Para priorizar a responsabilidade ambiental (Objetivo 3) foram postulados dois outros objetivos de apoio: reduzir impacto operacional dos produtos (Objetivo 3.1), e reduzir impacto do processo produtivo (Objetivo 3.2), sendo que ambos contribuem para reduzir o uso de recursos finitos como água e energia (Oportunidade 3). A seleção de profissionais para integrar o projeto (Objetivo 4) encontra resistência nos conflitos gerados pelas atribuições funcionais (Ameaça 3), e recebe apoio de: investir em reconhecimento (Objetivo 4.1), e de investir em treinamento (Objetivo 4.2). O objetivo de intensificar o relacionamento de longo prazo (Objetivo 5) esbarra no risco da perda de conhecimento estratégico (Ameaça 4) e na dificuldade para controlar os parceiros (Ameaça 5), mas ele está apoiado nos seguintes objetivos: aumentar o nível de conformidade dos parceiros com a empresa (Objetivo 5.1), o que muitas vezes esbarra na diferenças culturais (Ameaça 6); extrair novos conhecimentos dos parceiros (Objetivo 5.2); evitar a perda indesejada de conhecimento (Objetivo 5.3); e integrar os parceiros já nos estágios iniciais do PDP (Objetivo 5.4) visando antecipar ideias inovadoras e a resolução de problemas (Oportunidade 4).

No Modelo de Regras de Negócios aparecem 14 regras que apóiam os objetivos declarados no Modelo de Objetivos. Para facilitar a vida das pessoas (Objetivo 1) determina-se que seja criado um ranking para a devida priorização dos investimentos nos projetos considerados mais inovadores (Regra 1). Para impulsionar a ideia de investir em inovação (Objetivo 2) fica estabelecido que $25 \%$ do faturamento da empresa precisa ter origem nos novos produtos (Regra 2). A priorização da responsabilidade ambiental (Objetivo 3) tem um ponto de apoio na regra que determina que seja incluso o conceito de reciclabilidade nos novos projetos 
(Regra 3). A seleção de profissionais para integrar o PDP (Objetivo 4) requer que a área de Recursos Humanos (RH) mantenha o perfil atualizados de todos os profissionais internos (Regra 4). Para intensificar o relacionamento de longo prazo com fornecedores/parceiros (Objetivo 5) é necessário registrar e pontuar a participação dos parceiros (Regra 5). A busca pela originalidade (Objetivo 2.1) está apoiada pela regra que estabelece que sejam realizadas clínicas para levantar as expectativas dos clientes (Regra 6). De maneira semelhante, para conseguir unir design com praticidade e economia (Objetivo 2.2) há uma regra que estabelece que para cada projeto sejam feitos benchmarking no mercado (Regra 7). O objetivo 2.3, melhorar a eficiência produtiva, e o objetivo 2.4, reduzir o tempo de lançamento de novos produtos, são beneficiados pela determinação de que todo PDP deve gerar o estudo de um novo processo de manufatura. A redução do impacto operacional dos produtos (Objetivo 3.1) e do processo produtivo (Objetivo 3.2) tem apoio na determinação de reduzir o consumo de água e energia (Regra 9). Para que seja possível investir em reconhecimento e treinamento (Objetivos 4.1 e 4.2) criou-se uma regra que especifica de onde vem o dinheiro necessário: parte do faturamento dos novos produtos precisa ser revertido para treinamento e para pagar gratificações (Regra 10). Para aumentar o nível de conformidade dos parceiros com a empresa (Objetivo 5.1) deve-se priorizar os parceiros com histórico de colaboração e competências comprovadas (Regra 11). Como existe um receio de evasão de conhecimentos quando da extração de novos conhecimentos dos parceiros (Objetivo 5.2), determina-se que nenhum fornecedor pode ter acesso ao projeto completo (Regra 12). Ainda nessa linha, para evitar a perda indesejada de conhecimento (Objetivo 5.3) é preciso redigir contratos claros sobre sigilo e funções dentro da parcerias (Regra 13). E, por fim, para integrar os parceiros já nos estágios iniciais (Objetivo 5.4) é preciso antecipar as decisões de make or buy (Regra 14).

O Modelo de Processos de Negócios começa com a definição estratégica sobre o portfólio de produtos, estabelecendo-se de que maneira a carteira de produtos vai atender o mercado (ProcExt 1). Como primeiro passo interno do PDP é realizada a análise do produto antecessor e dos principais concorrentes (Processo 1), com isso determina-se novas funcionalidades e características para o novo produto (Infoset 10). Em seguida realiza-se um estudo de viabilidade financeira, técnica, industrial e ambiental (Processo 2), cujo resultado será submetido à aprovação da diretoria (Processo 3). Depois de aprovado, o projeto entra na etapa de definição da arquitetura do produto (Processo 4), sendo que sua saída alimenta a etaspa de construção de protótipos virtuais e/ou físicos (Processo 5), cujo resultado esclarece a necessidade de sistemas, subsistemas e componentes, o que permite decidir sobre a necessidade ou não de se estabelecer parcerias externas (Processo 6). Os protótipos também permitem que 
sejam realizados testes de desempenho (Processo 7), cujos resultados ajudam a compor um novo estudo de viabilidade financeira e industrial (Processo 8) que será submetido à aprovação da diretoria (Processo 9). Em seguida são desenvolvidas embalagens, manuais técnicos, documentos técnicos (Processo 10) e também o processo de manufatura (Processo 11). Esse processo precisa ser homologado e o produto certificado (Processo 12). Novamente é feito um estudo de viabilidade financeira (Processo 13) e na sequência ocorre o fase out em forma de treinamento com a área de manufatura (Processo 14).

No Modelo de Atores e Recursos a equipe de projeto (Unidade Organizacional 6) é composta por: gerente de projeto (Unidade Individual 1), engenheiro de qualidade (Unidade Individual 2), engenheiro de processos (Unidade Individual 3), engenheiro de produto (Unidade Individual 4), engenheiro de produção (Unidade Individual 5), analista de custos (Unidade Individual 6). Esses elementos são oferecidos pelas unidades organizacionais gerência de engenharia de $P \& D$ (Unidade Organizacional 1), gerência de qualidade (Unidade Organizacional 2), gerência de processos (Unidade Organizacional 3), gerência de manufatura (Unidade Organizacional 4), gerência financeira (Unidade Organizacional 5). Essas mesmas unidades fornecem orçamentos e desenhos técnicos (Recurso 1), relatórios de acompanhamento de projetos (Recurso 2), além de softwares e laboratórios (Recurso 3). Esses recursos são utilizados pela equipe de projeto para elaborar a RTP (Registro Técnico do Produto - Recurso 5) assim como os contratos para controlar o relacionamento com os parceiros de desenvolvimento (Unidade Organizacional 7). De toda a RTP apenas os SSC's (Recurso 6) específicos serão acessados pelos parceiros de desenvolvimento, sendo as demais partes de uso privativo da equipe de projeto: estudo de viabilidade financeira (Recurso 7), cronogramas (Recurso 8), atas e aprovações (Recurso 9), estudo de viabilidade técnica (Recurso 10), estudo de impacto ambiental (Recurso 11), desenhos técnicos (Recurso 12), especificações de desempenho (Recurso 13). O coordenador do projeto (Papel 1) recebe apoio da diretoria, ele acessa o documento de posicionamento estratégico (Recurso 14) elaborado pela direção e também recebe orientação direta do diretor comercial (Unidade Individual 7), diretor industrial (Unidade Individual 8) e do diretor financeiro (Unidade Individual 9).

No Modelo de Conceitos o posicionamento estratégico (Conceito 1) patrocina o esforço pela inovação (Conceito 8). A inovação requer uma rede de parceiros (Conceito 12) composta por vários conceitos como certificação (Conceito 13), decisões make or buy (Conceito 14), conformidade (Conceito 15), contratos (Conceito 16) e colaboração (Conceito 17). A inovação também está apoiada nos conceitos de clínicas (Conceito 9), vigilância tecnológica (Conceito 10), e benchmarking (Conceito 11). Integram o posicionamento estratégico: originalidade 
(Conceito 2), eficiência produtiva (Conceito 2), proteção da propriedade intelectual (Conceito 4), reciclabilidade (Conceito 5), reconhecimento (Conceito 6), e responsabilidade ambiental (Conceito 7). 


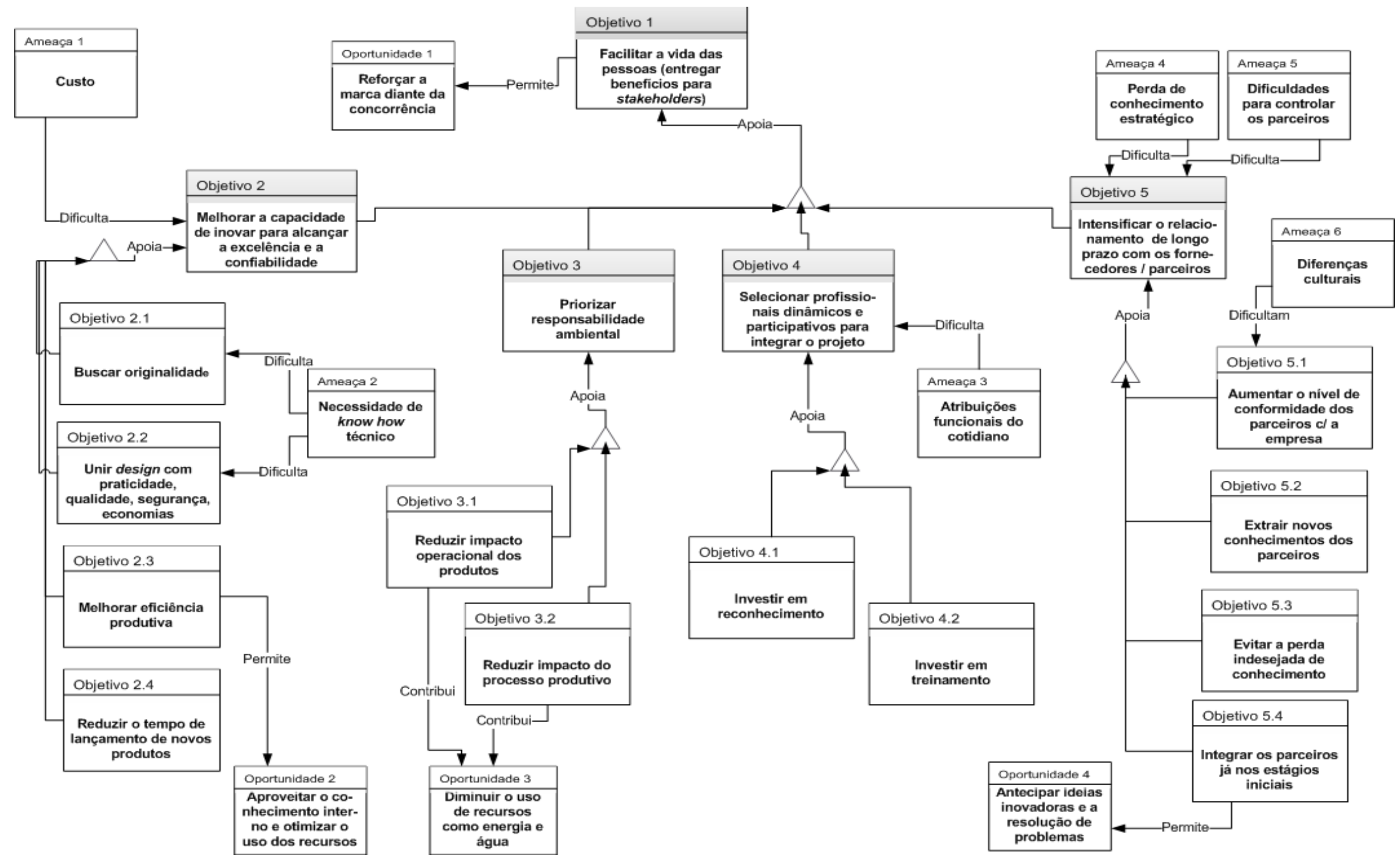

Figura 44: Modelo de Objetivos (as-is) - unidade de análise número 5 


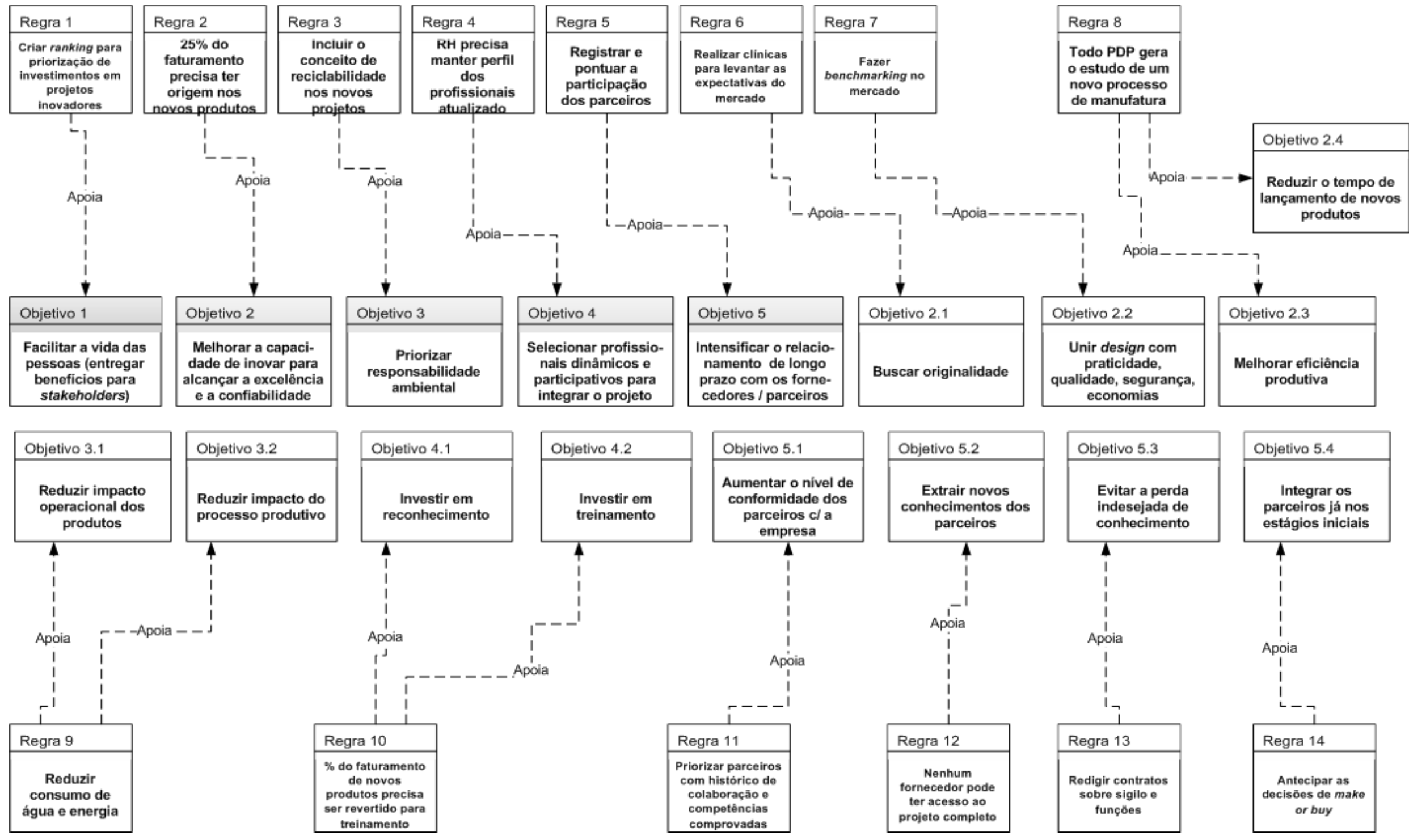

Figura 45: Modelo de Regras de Negócios (as-is) - unidade de análise número 5. 


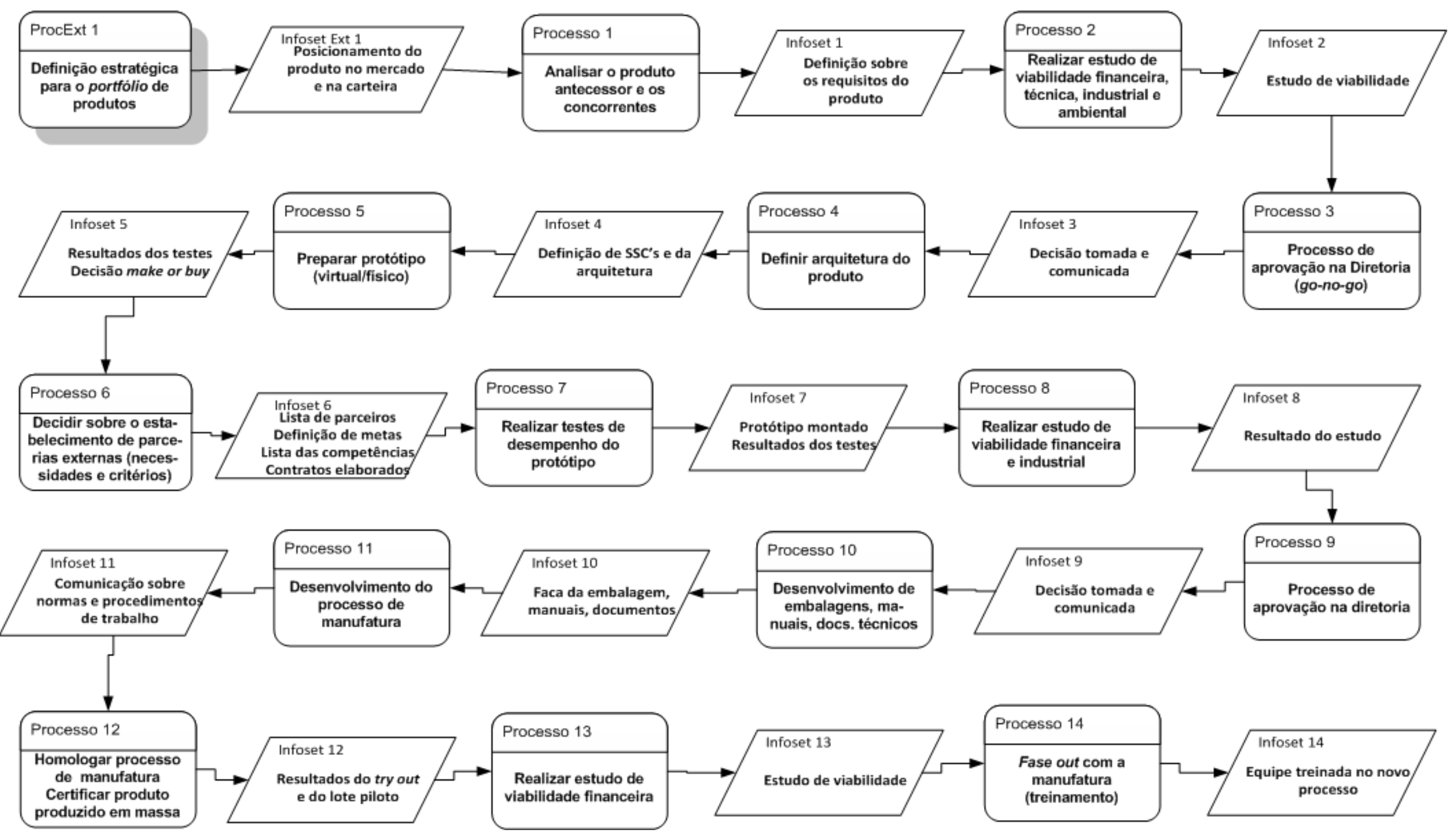

Figura 46: Modelo de Processo de Negócios (as-is) - unidade de análise número 5. 


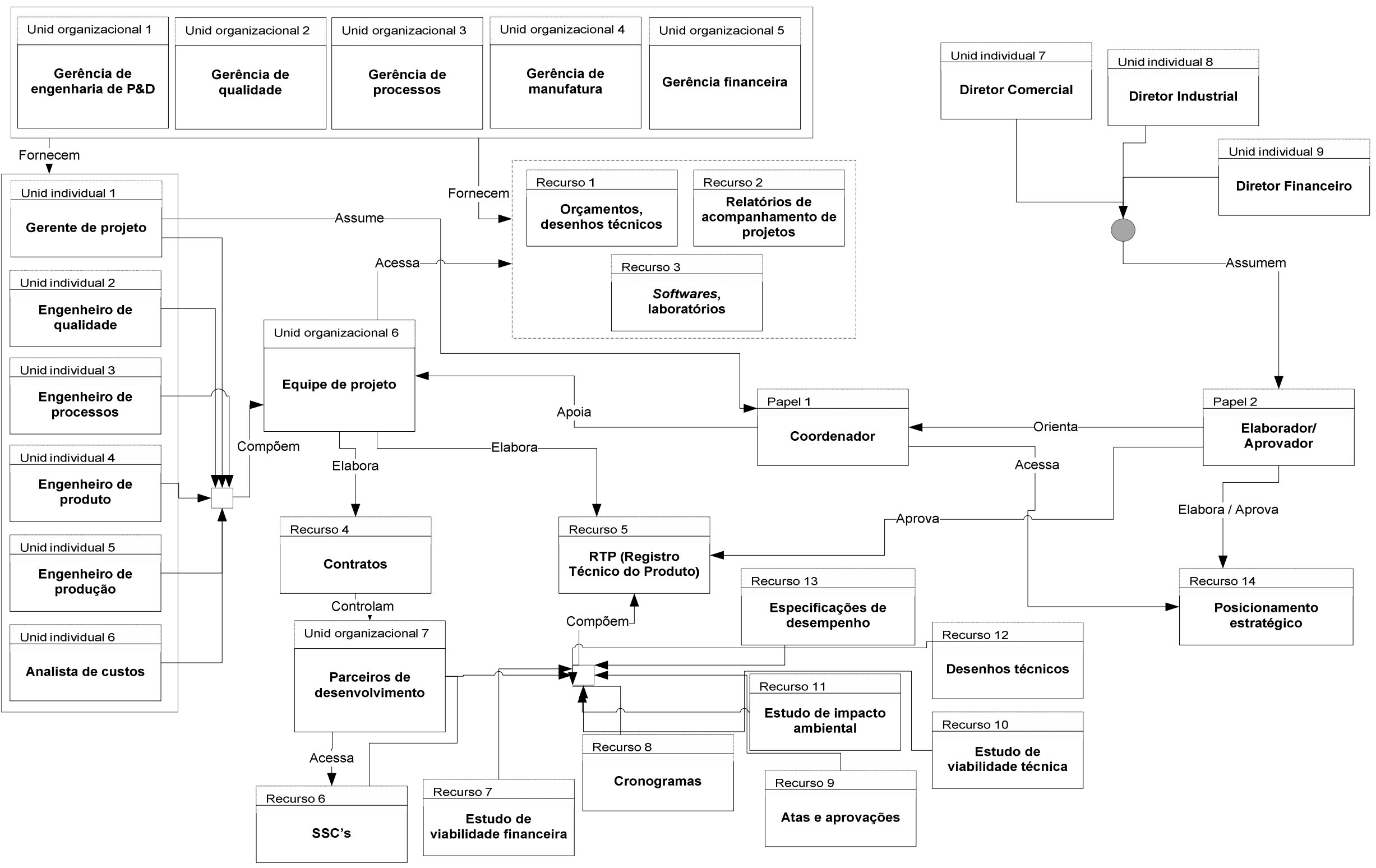

Figura 47: Modelo de Atores e Recursos (as-is) - unidade de análise número 5. 


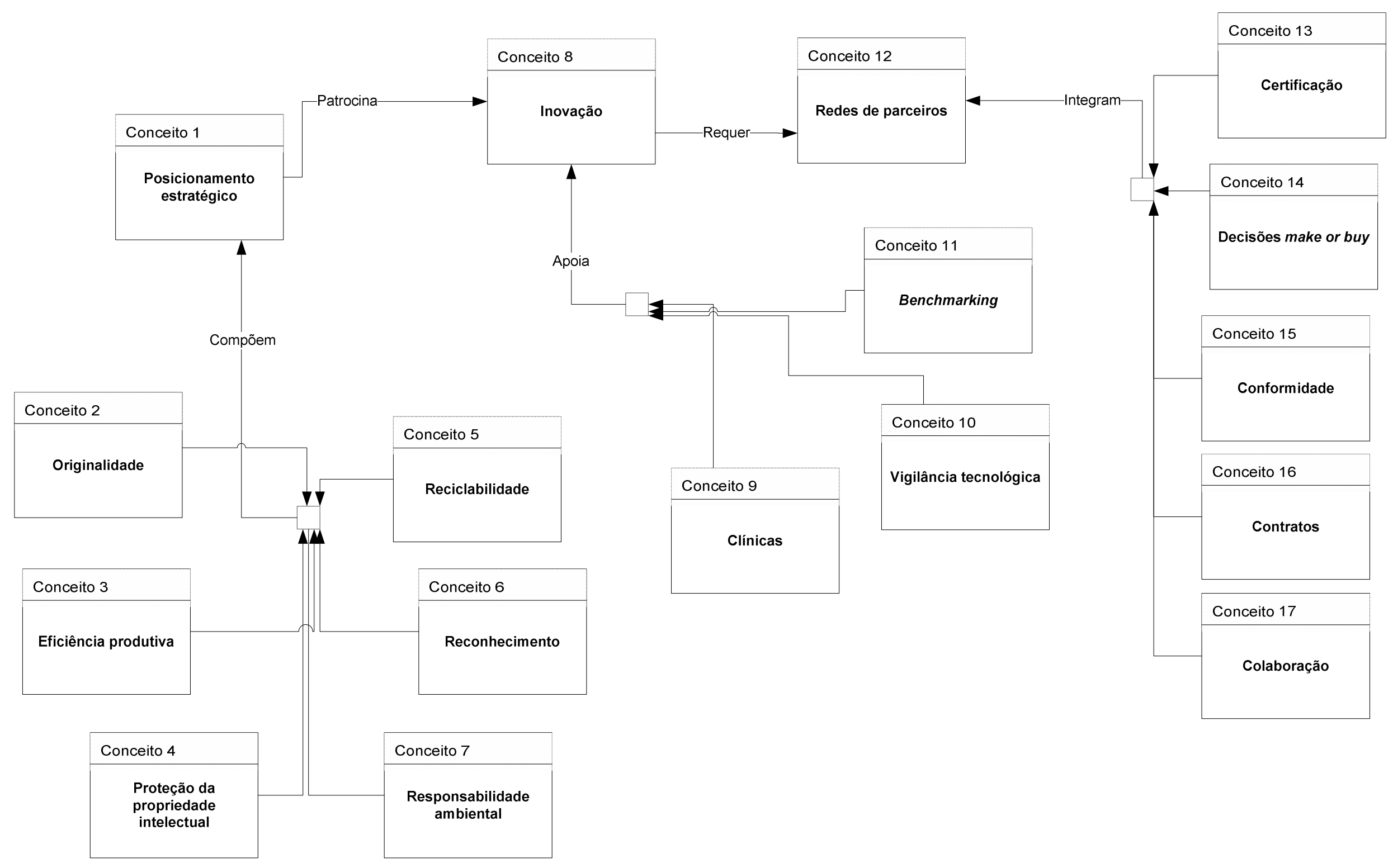

Figura 48: Modelo de Conceitos (as-is) - unidade de análise número 5. 
6. Unidade de análise Número 6

O Modelo de Objetivos mostra que essa unidade de análise procura aumentar sua capacidade de competir no mercado (Objetivo 1) diante da oportunidade de ampliar a liderança nas classes C e D da população (Oportunidade 1). Esse objetivo é apoiado por outros três objetivos: melhorar a capacidade de inovar os produtos (Objetivo 2); reduzir custos no PDP e na manufatura(Objetivo 3), mas que pode inicialmente requerer investimentos (Ameaça 2); e reduzir o intervalo de lançamento de novos produtos (Objetivo 4), que pode em algum momento sacrificar uma das etapas do PDP (Ameaça 3). O objetivo de melhorar a capacidade de inovar os produtos está apoiado em outros cinco objetivos: selecionar especialistas para a equipe de projetos (Objetivo 2.1); treinar e reconhecer os integrantes da equipe de projetos (Objetivo 2.2); usar intensivamente a TI que a empresa possui (Objetivo 2.3); padronizar e integrar as áreas envolvidas no PDP (Objetivo 2.4), o que permite otimizar o uso do conhecimento interno disponível (Oportunidade 2); explorar as tecnologias disponíveis no mercado para desenvolver ou aperfeiçoar a tecnologia de domínio interno (Objetivo 2.5), apesar disso esbarrar em possíveis limitações técnicas internas (Ameaça 1). Para alcançar o objetivo número 3 foram adotados alguns objetivos de apoio: aumentar a validação digital dos produtos (Objetivo 3.1), avaliar o uso de novos materiais (Objetivo 3.2), melhorar os processos de produção (Objetivo 3.3). O objetivo de reduzir o intervalo de lançamento de novos produtos é apoiado por: aumentar a participação de parceiros no PDP (Objetivo 4.1), pois isso contribui para o acesso a novos conhecimentos e recursos (Oportunidade 3); reduzir os desvios não planejados, inconsistências e retrabalhos (Objetivo 4.2); e usar a engenharia simultânea (Objetivo 4.3), o que pode aumentar a complexidade da condução do projeto (Ameaça 4).

O Modelo de Regras de Negócios apresenta 17 regras que apoiam o Modelo de Objetivos. Para aumentar a capacidade de competir no mercado é preciso alinhar o PDP às estratégias da empresa (Regra 1). Há duas regras que apoiam o desejo de melhorar a capacidade de inovar os produtos: garantir a documentação técnica do projeto (Regra 2), que serve preserva o conhecimento gerado em cada projeto; e priorizar investimentos em novas tecnologias (Regra 3), pois a tecnologia traz novas oportunidades de melhorias. Para reduzir custos no PDP e na manufatura é necessário fazer um estudo de viabilidade financeira a cada etapa do PDP (Regra 4). Com o intuito de viabilizar o objetivo de reduzir o intervalo para lançar novos produtos foi estabelecido que novos projetos serão iniciados a cada 06 meses (Regra 5). Para nortear a seleção de especialistas para a equipe de projeto definiu-se que a equipe de projetos precisa ser multifuncional (Regra 6). O treinamento e o reconhecimento dos integrantes da equipe de projeto (Objetivo 2.2) recebe recurso financeiro de parte da renda de novos produtos 
desenvolvidos (Regra 7). Uma das formas de usar intensivamente a TI da empresa (Objetivo 2.3) é minerar os bancos de dados e explorar as demais ferramentas tecnológicas (Regra 8). Para padronizar e integrar as áreas envolvidas no PDP (Objetivo 2.4) é necessário fazer reuniões periódicas com representantes de todas as áreas (Regra 9). Também é importante manter o laboratório de pesquisa (Regra 10) para poder estudar e explorar as tecnologias disponíveis no mercado. Para aumentar a validação digital dos produtos é preciso trabalhar com protótipo virtual para cada novo produto (Regra 11). O objetivo de avaliar o uso de novos materiais passa necessariamente pela ideia de reciclabilidade (Regra 12). A melhora dos processos de produção (Objetivo 3.3) requer que seja realizado um estudo do processo produtivo para cada novo produto (Regra 13). O desafio de aumentar a participação de parceiros no PDP (Objetivo 4.1) requer que nenhum fornecedor tenha acesso ao projeto completo (Regra 14), que os parceiros sejam auditados (Regra 15), que a documentação dos parceiros seja documentada (Regra 16), que os contratos garantam a propriedade intelectual (Regra 17), e que sejam reforçados os laços com os terceiros (Regra 18). Para reduzir os desvios não planejados, inconsistências e retrabalhos do PDP (Objdetivo 4.2) é obrigatório o uso de um método sistematizado para o PDP (Regra 19). E como requisito da engenharia simultânea (Objetivo 4.3) é importante antecipar de forma planejada partes das atividades futuras do PDP (Regra 20).

No Modelo de Processos de Negócios as estratégias da diretoria e os estudos de mercado (ProcExt 1) antecedem as atividades do PDP. O primeiro processo interno ao PDP é a realização de um estudo de viabilidade técnica, financeira e ambiental (Processo 1) a partir das definições estabelecidas no ProcExt 1. Em seguida é desenvolvido o conceito do produto (Processo 2) e depois é desenvolvida a arquitetura do produto (Processo 3). Com a arquitetura definida tem-se informação dos principais componentes e por isso pode-se trabalhar os parceiros que participarão do PDP (Processo 4) e definir os recursos necessários para trabalhar em parceria (Processo 5). A equipe de projeto desenvolve um protótipo virtual (Processo 6) que fornece dados para um estudo de viabilidade financeira e industrial (Processo 7) e, de posse dessas novas informações, a equipe desenvolve um protótipo físico (Processo 8). Os parceiros são integrados nessa etapa para o fornecimento de componentes (Processo 9). A próxima etapa é o desenvolvimento do processo, dos manuais técnicos e a finalização de toda a documentação do projeto (Processo 10). Em seguida é homologado o processo de produção (Processo 11), 'e feito um estudo de viabilidade financeira e industrial (Processo 12), e realizado o treinamento da área industrial, do SAC e das autorizadas (Processo 13).

No Modelo de Atores e Recursos há quatro unidades organizacionais responsáveis por fornecer a infra-estrutura básica para o projeto: área financeira (Unidade Organizacional 1), área 
de vendas (Unidade Organizacional 2), gerência de engenharia de produtos (Unidade Organizacional 3), e área de qualidade (Unidade Organizacional 4). Essas unidades fornecem laboratório de desenvolvimento (Recurso 1), diretrizes e manuais (Recurso 2), ERP e softwares em geral (Recurso 3), e um banco de dados com histórico documental de projetos (Recurso 4). Essas unidades também fornecem as unidades individuais que integram a equipe de projeto (Unidade Organizacional 5): gerente de projeto (Unidade Individual 1), engenheiro de produto (Unidade Individual 2), analista de vendas (Unidade Individual 3), analista financeiro (Unidade Individual 4), técnico de qualidade (Unidade Individual 5), técnico de laboratório (Unidade Individual 6). A equipe de projeto recebe apoio do gerente de projeto que assume o papel de coordenador (Papel 1). Dentro dessa função ele tem acesso ao plano estratégico (Recurso 7) elaborado pelo diretor comercial (Unidade Individual 7) e pelo diretor industrial (Unidade Individual 8). A equipe de projeto acessa todos os recursos disponíveis durante a condução do projeto, ficando responsável pela elaboração do manual de especificação técnica (Recurso 5) e pelos contratos (Recurso 6) que controlam os parceiros de desenvolvimento (Unidade Organizacional 6). Esses parceiros acessam apenas a lista específica de componentes, sistemas ou sub-sistemas (Recurso 7) pelos quais ficarão responsáveis. O manual de especificação técnica é formado ainda pelos documentos de informação geral sobre o projeto (Recurso 8), informações de testes e desempenho (Recurso 9), especificações de papéis e responsabilidades (Recurso 10), dados financeiros (Recurso 11).

No Modelo de Conceitos a inovação (Conceito 1) está atrelada ao conhecimento externo (Conceito 9) e esse provém das parcerias (Conceito 10). Dois conceitos importantes integram o conceito de parcerias: propriedade intelectual (Conceito 11) e competências (Conceito 12). Dois conceitos também integram o conceito de inovação: acompanhamento financeiro (Conceito 7) e uso intensivo da TI (Conceito 8). Há um consenso na unidade de análise estudada de que a inovação acrescenta um componente a mais de complexidade em cada projeto desenvolvido (Conceito 2). Essa complexidade passa pelas inconsistências (Conceito 3) nos projetos, validação digital (Conceito 4), retrabalho (Conceito 5) em vários casos, e uso da engenharia simultânea (Conceito 6). 


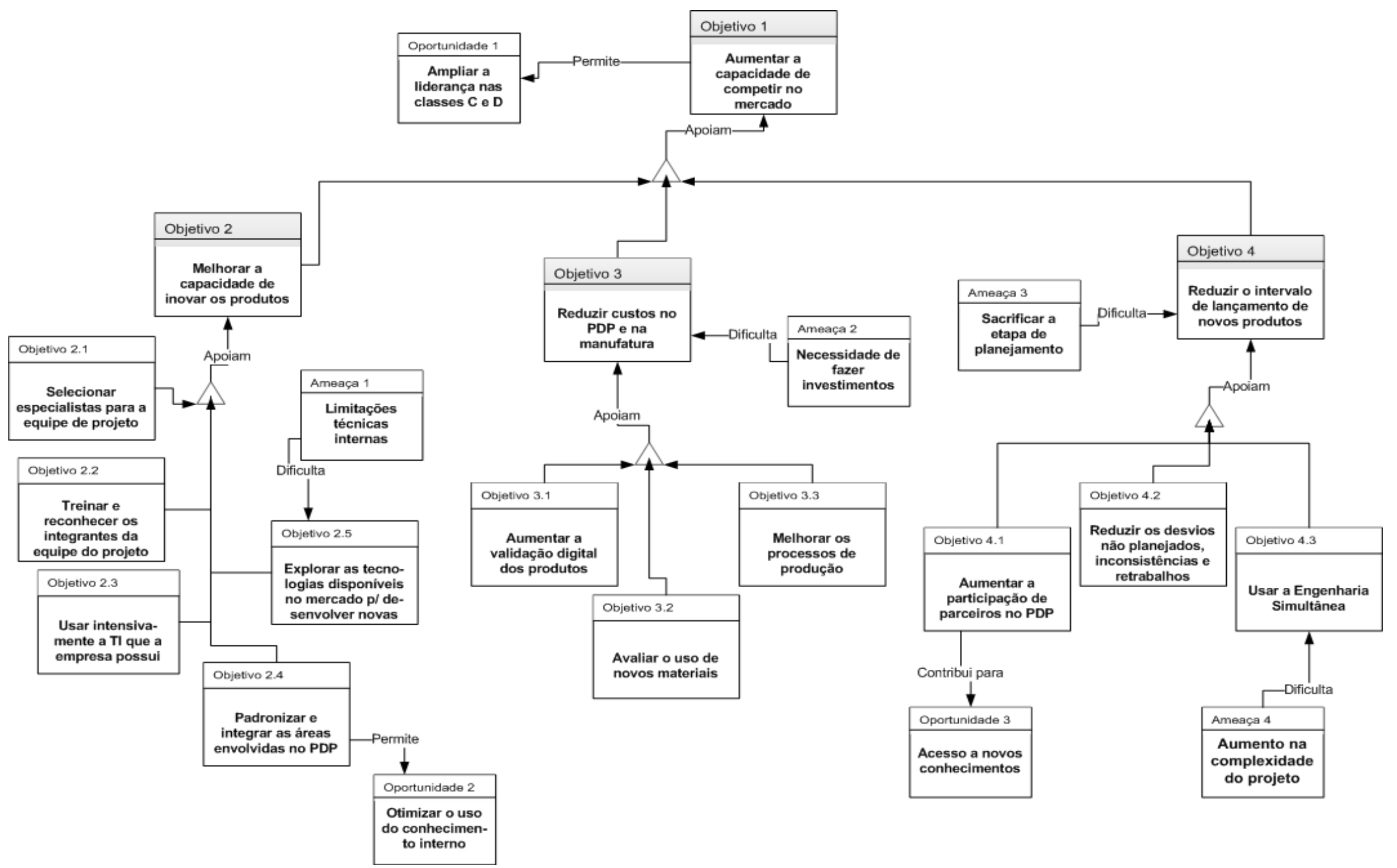

Figura 49: Modelo de Objetivos (as-is) - unidade de análise número 6 

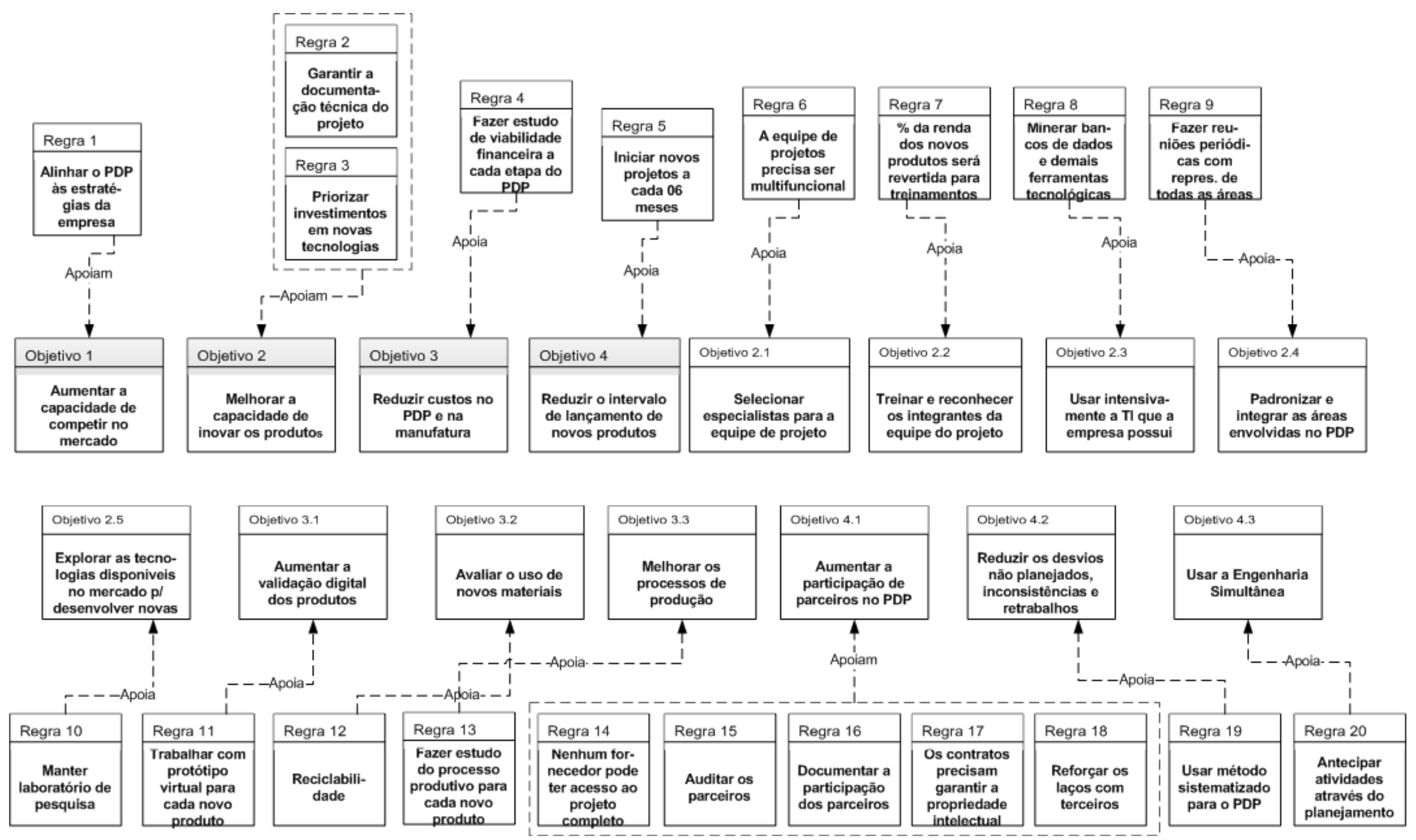

Figura 50: Modelo de Regras de Negócios (as-is) - unidade de análise número 6. 


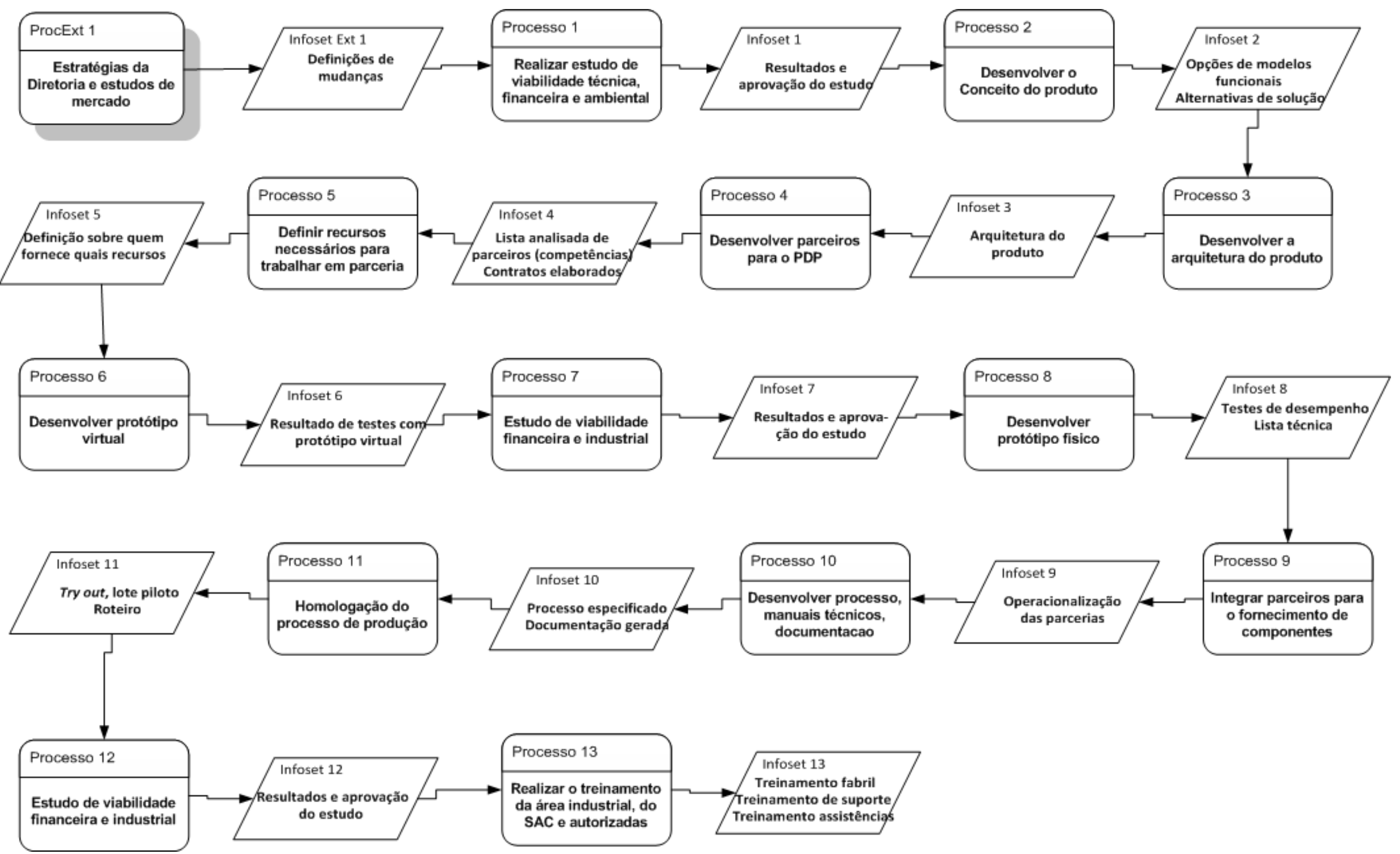

Figura 51: Modelo de Processo de Negócios (as-is) - unidade de análise número 6. 


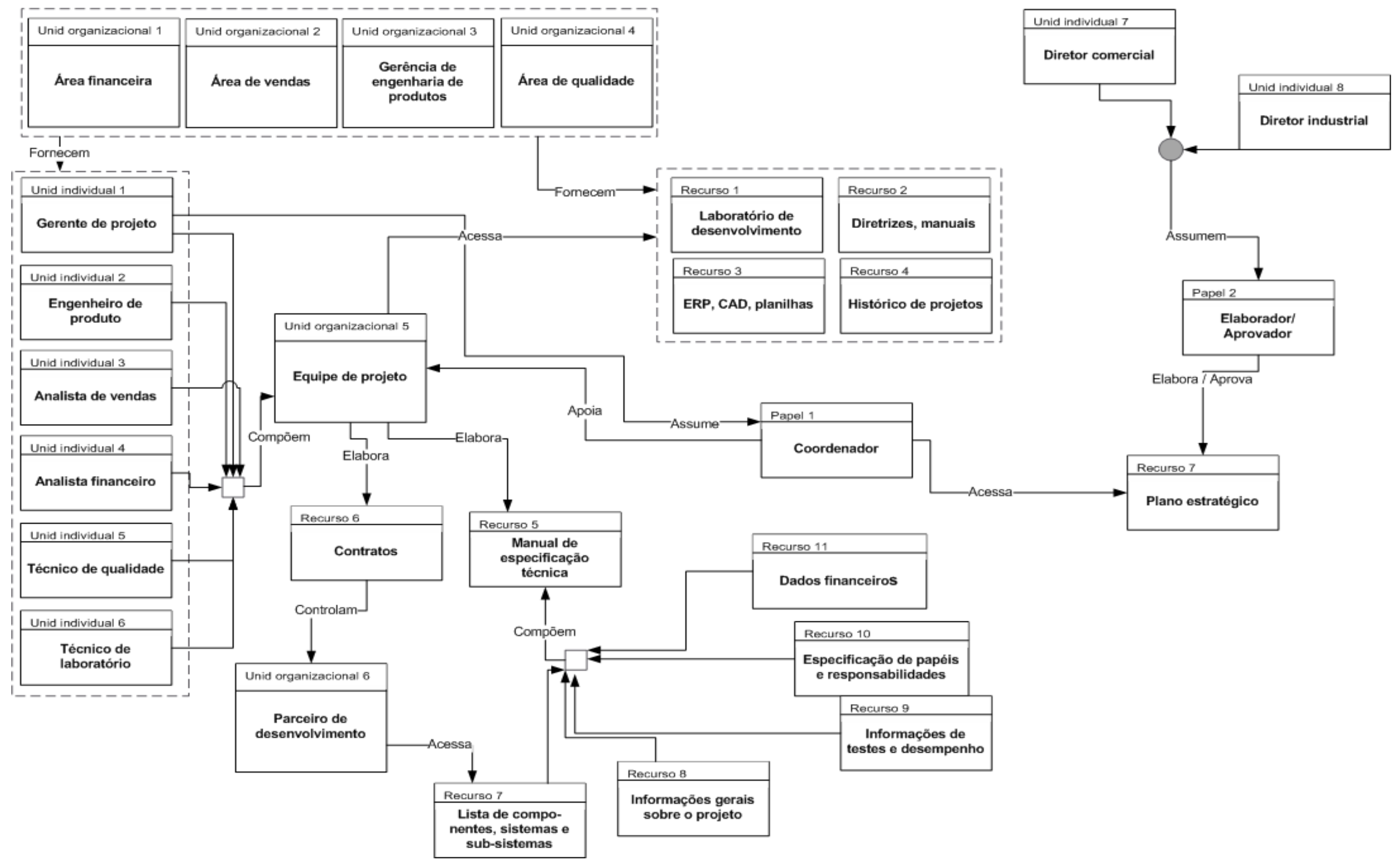

Figura 52: Modelo de Atores e Recursos (as-is) - unidade de análise número 6. 


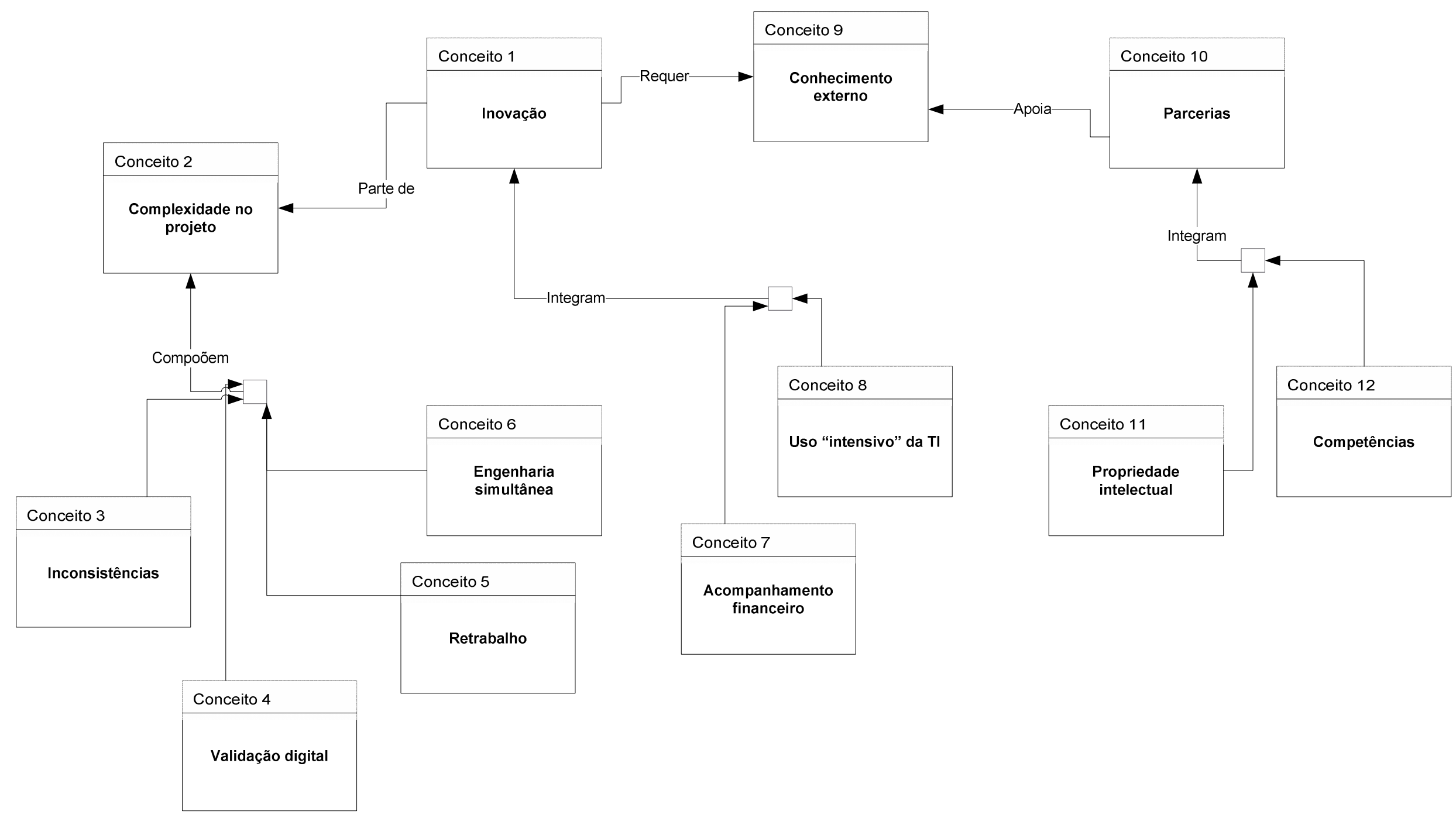

Figura53: Modelo de Conceitos (as-is) - unidade de análise número 6. 
7. Unidade de análise Número 7

No Modelo de Objetivos a mola principal é a determinação de aumentar a participação no mercado (Objetivo 1). Esse objetivo é apoiado pela determinação de aumentar o percentual de faturamento dos novos produtos sobre o volume de vendas (Objetivo 2), mas que é ameaçado pela estrutura funcional da organização a qual influenciar negativamente a gestão dos projetos (Ameaça 1). Esse objetivo 2, por sua vez, é apoiado por outros três objetivos: desenvolver produtos inovadores que beneficiam os stakeholders (Objetivo 2.1), reduzir custos operacionais do PDP e da manufatura (Objetivo 2.2), e acelerar o processo de desenvolvimento de produtos (Objetivo 2.3). Para desenvolver produtos inovadores foram estabelecidos quatro objetivos de apoio: agregar valor aos produtos em termos de design, performance e/ou funcionalidade (Objetivo 2.1.1), o que esbarra na concorrência dos produtos chineses (Ameaça 2); melhorar a qualidade dos produtos para reduzir gastos com garantias (Objetivo 2.1.2); responder mais rápido às chamadas de problemas dos clientes (Objetivo 2.1.3); e aperfeiçoar os mecanismos e/ou recursos de inovação (Objetivo 2.1.4). Para reduzir custos operacionais busca-se padronizar e integrar as áreas envolvidas no PDP (Objetivo 2.2.1), o que permite que se trabalhe por processo (Oportunidade 1), mas que esbarra na comunicação deficiente entre as áreas (Ameaça 3). Para acelerar o PDP foram adotados quatro objetivos de apoio: transferir parte dos desafios técnicos para terceiros (Objetivo 2.3.1), o que permite manter o foco no controle do processo (Oportunidade 2), mas que pode provocar vários problemas como evasão de informação (Ameaça 4), excessiva dependência de know-how de terceiros (Ameaça 5), e conflito por propriedade intelectual (Ameaça 6); "premiar" os parceiros mais eficazes com maior número de contratos (Objetivo 2.3.2); empregar a engenharia simultânea (Objetivo 2.3.3), o que permite antecipar as mudanças e eventuais problemas decorrentes (Oportunidade 3); e ampliar a validação digital dos produtos (Objetivo 2.3.4).

O Modelo de Regras de Negócios mostra que para aumentar a participação no mercado a unidade de análise usa os serviços de um Broker para prospectar novas oportunidades (Regra 1). Também há uma regra que determina que $20 \%$ do faturamento anual precisa vir dos novos produtos e isso foi estabelecido para oferecer um parâmetro para o objetivo de aumentar o percentual do faturamento dos novos produtos (Objetivo 2). O objetivo de desenvolver produtos inovadores que beneficiem os stakeholders tem apoio em duas regras: ficar atento às inovações tecnológicas (Regra 3) e usar contribuições dos clientes, parceiros e funcionários (Regra 4). Duas regras também foram designadas para apoiar o objetivo de reduzir custos operacionais do PDP e da manufatura: respeitar cronogramas e orçamentos (Regra 5) e simplificar o processo de produção (Regra 6). Para acelerar o PDP deve-se priorizar o uso de componentes 
intercambiáveis (Regra 7) e estabelecer escala de prioridades de projetos (Regra 8). Os objetivos de agregar valor aos produtos em termos de design, performance e funcionalidades (Objetivo 2.1.1) e melhorar a qualidade dos produtos para reduzir gastos com garantias (Objetivo 2.1.2) estão apoiados nas seguintes regras: identificar as necessidades e expectativas dos clientes (Regra 9) e buscar desempenho equivalente ou superior aos concorrentes (Regra 10). O objetivo responder mais rápido às chamadas de problemas dos clientes (Objetivo 2.1.3) tem apoio da regra trabalhar com níveis de atendimento e prazos determinados (Regra 11). Para aperfeiçoar os mecanismos e/ou recursos da inovação (Objetivo 2.1.4) procura-se identificar as causas dos piores desempenhos de projetos (Regra 12). Para padronizar e integrar as áreas envolvidas no PDP (Objetivo 2.2.1) é necessário trabalhar com gates de aprovação e comunicação (Regra 13) e estabelecer indicadores de desempenho para as áreas (Regra 14). Para transferir desafios técnicos para terceiros (Objetivo 2.3.1) é preciso selecionar parceiros com competências comprovadas (Regra 15) e auditar os parceiros no decorrer dos projetos (Regra 15). Essa mesma regra 15 apoia o objetivo de "premiar" os parceiros mais eficazes com maior número de contratos (Objetivo 2.3.2). A regra no uso da engenharia simultânea é antecipar para as etapas iniciais o máximo possível as atividades de mudanças presentes em etapas posteriores (Regra 17). E para ampliar a validação digital dos produtos (Objetivo 2.3.4) a regra é investir em softwares para auxiliar a montar os protótipos (Regra 18).

O Modelo de Processos de Negócios começa com as ações da Diretoria (ProcExt 1) produzindo estratégias que irão orientar a prospecção de oportunidades no mercado pela área de marketing (Processo 1). A próxima etapa é transformar os inputs de marketing (ideias sobre design, funcionalidades e características de desempenho) em especificações técnicas (Processo 2). Com essas especificações definidas pode-se realizar estudos de viabilidade técnica, financeira, industrial e ambiental (Processo 3) que serão submetidos à aprovação da Diretoria (Processo 4). Na sequência é preparada uma lista discriminando sistemas, subsistemas e componentes (Processo 5) a qual serve de apoio para a definição de quais componentes serão terceirizados (Processo 6). Isso permite prospectar os parceiros de desenvolvimento (Processo 7) e a definição de quais recursos serão compartilhados com os parceiros/terceiros (Processo 8). Na sequência é realizado um estudo financeiro considerando a participação das parcerias (Processo 9). Após a aprovação dos resultados dos estudos é realizada a definição da arquitetura do produto (Processo 10) e desenvolvido o protótipo virtual (Processo 11) que permitirá que sejam conduzidos de forma mais precisa estudos de viabilidade técnica, financeira e industrial (Processo 12). O próximo passo é integrar os principais parceiros ao PDP (Processo 13) para depois desenvolver o protótipo físico (Processo 14). Com resultados dos testes, mais 
informações da lista técnica e os ajustes necessários é feita a especificação do processo de produção (Processo 15), e depois é realizado o fase out com a manufatura, SAC e autorizadas (Processo 16).

O Modelo de Atores e Recursos mostra que a equipe de projeto (Unidade Organizacional 6) acessa vários recursos na condução do projeto: diretrizes, normas e procedimentos (Recurso 1); ferramentas, máquinas e equipamentos (Recurso 2); ERP, CAD, documentos de projetos (Recurso 3). Esses recursos são fornecidos pela gerência de qualidade (Unidade Organizacional 1), gerência comercial (Unidade Organizacional 2), gerência de processos (Unidade Organizacional 3), e gerência de manufatura (Unidade Organizacional 4). Essas unidades organizacionais também fornecem as unidades individuais que compõem a equipe de projeto: gerente de projetos (Unidade Individual 1), engenheiro de produto (Unidade Individual 2), analista de vendas (Unidade Individual 3), engenheiro de manufatura (Unidade Individual 4), engenheiro de processo (Unidade Individual 5), engenheiro de qualidade (Unidade Individual 6), analista de marketing (Unidade Individual 7). A coordenação do projeto (Papel 1) é compartilhada dentro da própria equipe de projeto. Através desse papel ela acessa a orientação estratégica (Recurso 11) elaborada pelo diretor comercial (Unidade Individual 8) e pelo diretor industrial (Unidade Individual 9) com apoio de uma parceiro especializado em mercado (Unidade Organizacional 8) que assume as atribuições de Broker (Papel 3). Acessando os recursos e as orientações a equipe de projetos elabora os contratos (Recurso 5) que controlam os fornecedores de peças (Unidade Organizacional 6) e o DIP (Documento de Identificação do Produto - Recurso 4). O DIP é composto pela lista de componentes, sistemas e subsistemas (Recurso 6); pelas informações das simulações (Recurso 7); pelas especificações de desempenho (Recurso 8); por estudos de viabilidade financeira, técnica e industrial (Recurso 9); e pelo custo do ferramental e dos componentes (Recurso 10). A equipe de projeto busca a certificação do produto (Recurso 12) que é concedida pelo INMETRO (Unidade Organizacional 7).

No Modelo de Conceitos a participação no mercado (Conceito 1) recebe apoio de vários conceitos: valor (Conceito 8), velocidade para inovar (Conceito 9), custos operacionais (Conceito 10), integração entre áreas (Conceito 11), mudanças (Conceito 12), e engenharia simultânea (Conceito 12). O conceito de usar a inovação para beneficiar os stakeholders (Conceito 2) apoia o conceito de participação no mercado (Conceito 1), recebe apoio do conceito de prioridades (Concito 14), e requer apoio das parcerias (Conceito 3). Alguns conceitos importantes fazem parte do universo das parcerias como contratos (Conceito 4), Broker (Conceito 5), compartilhamento de recursos (Conceito 6), e premiação de parceiros (Conceito 7). 


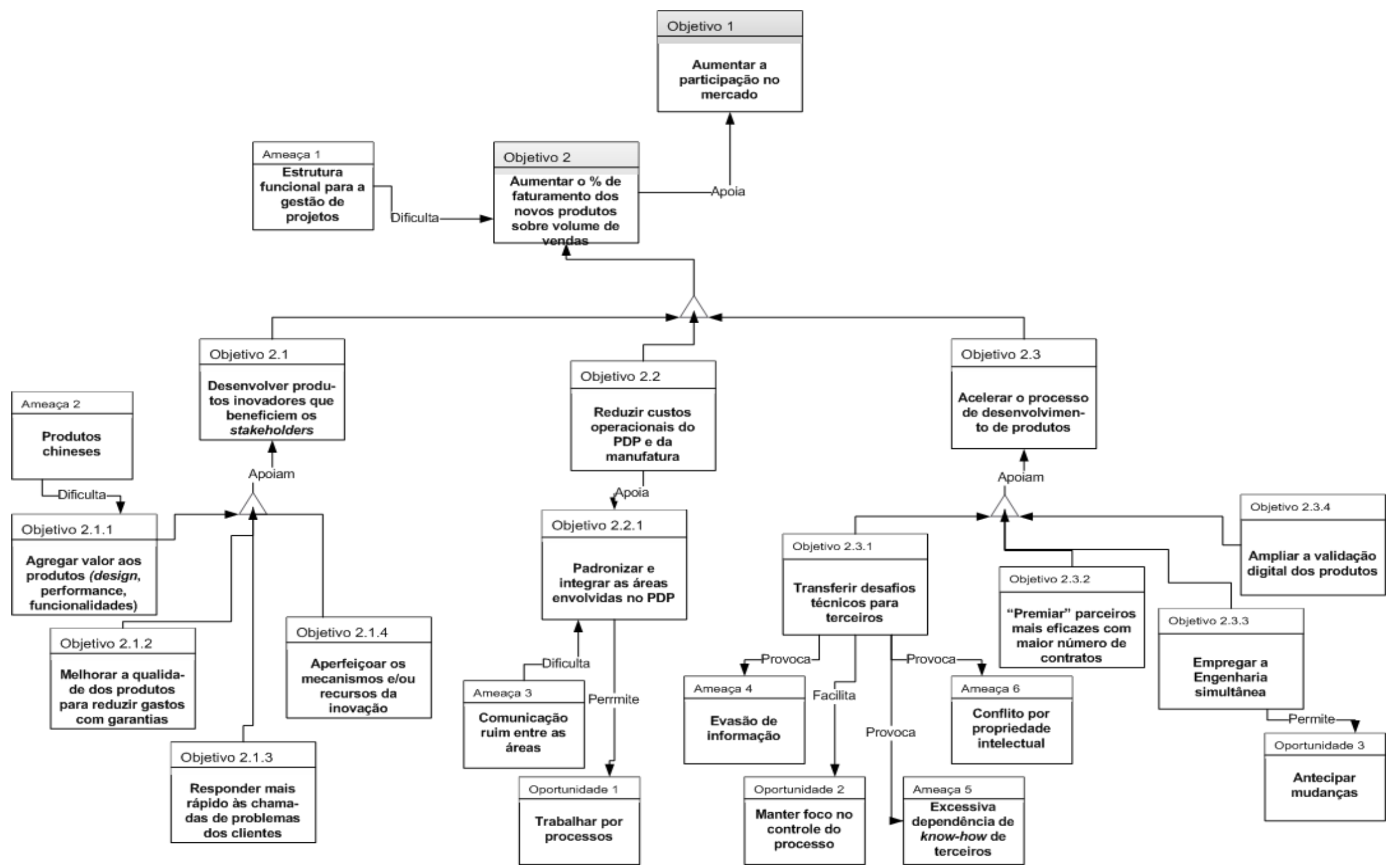

Figura 54: Modelo de Objetivos (as-is) - unidade de análise número 7 

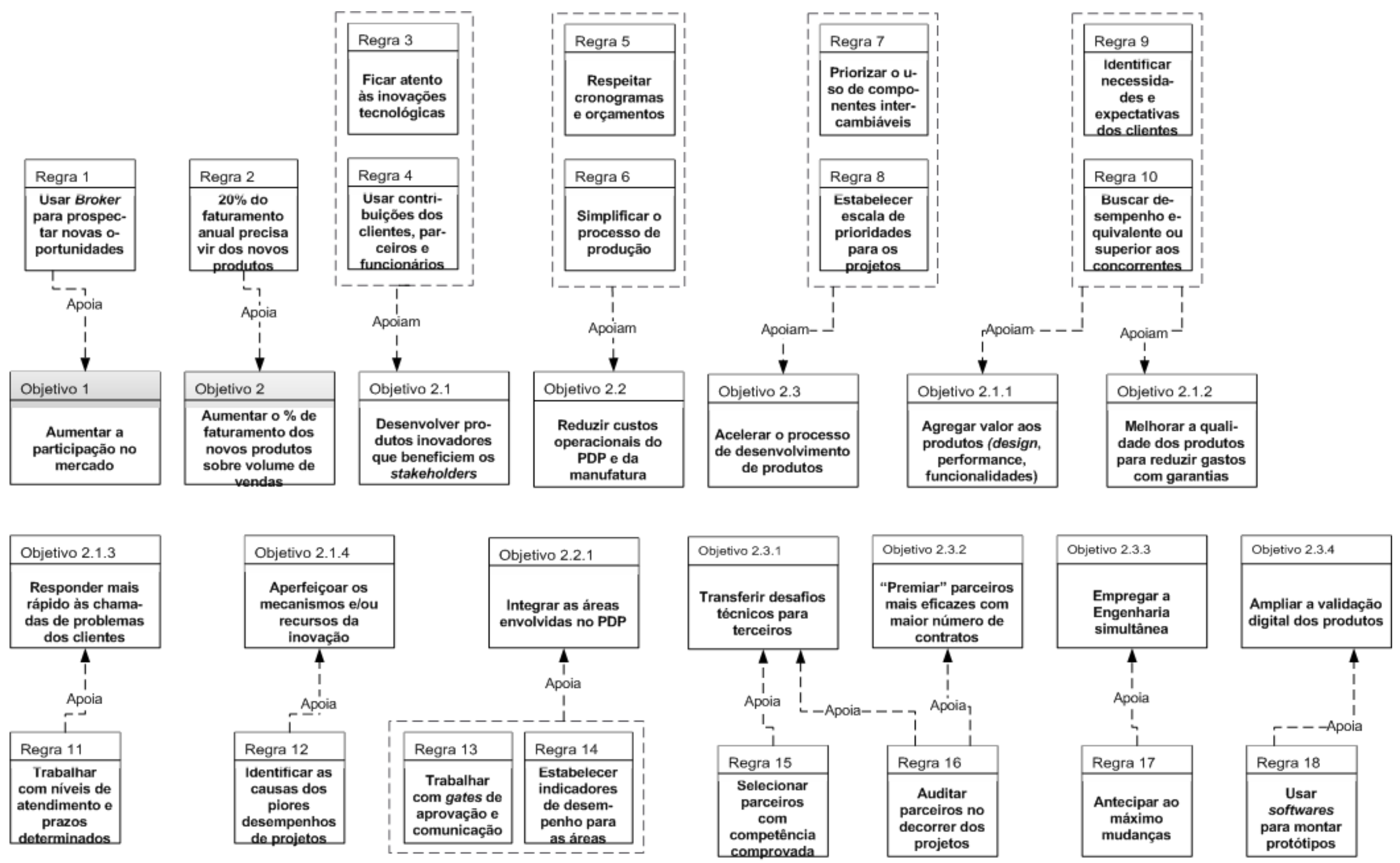

Figura 55: Modelo de Regras de Negócios (as-is) - unidade de análise número 7. 


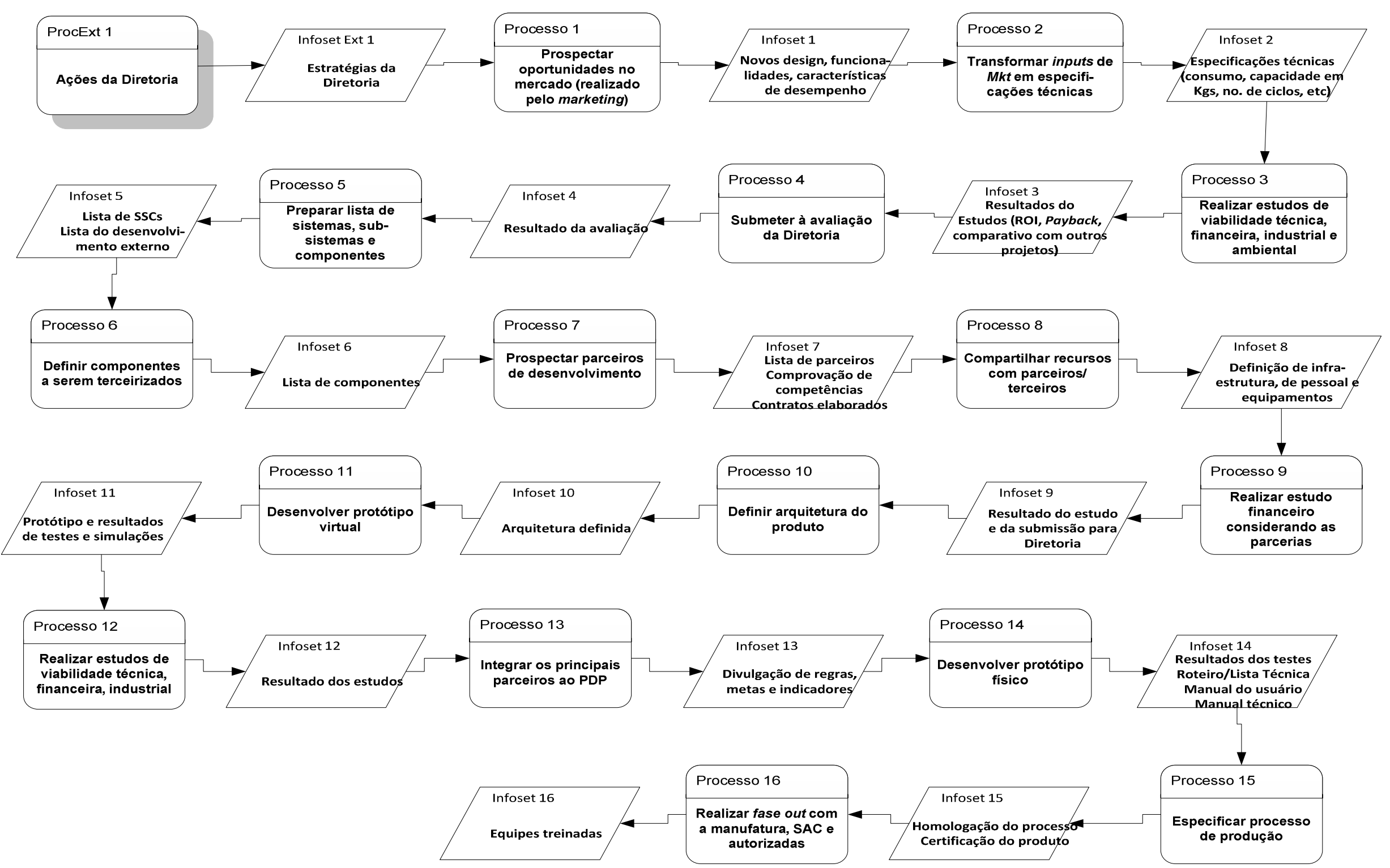

Figura 56: Modelo de Processo de Negócios (as-is) - unidade de análise número 7. 


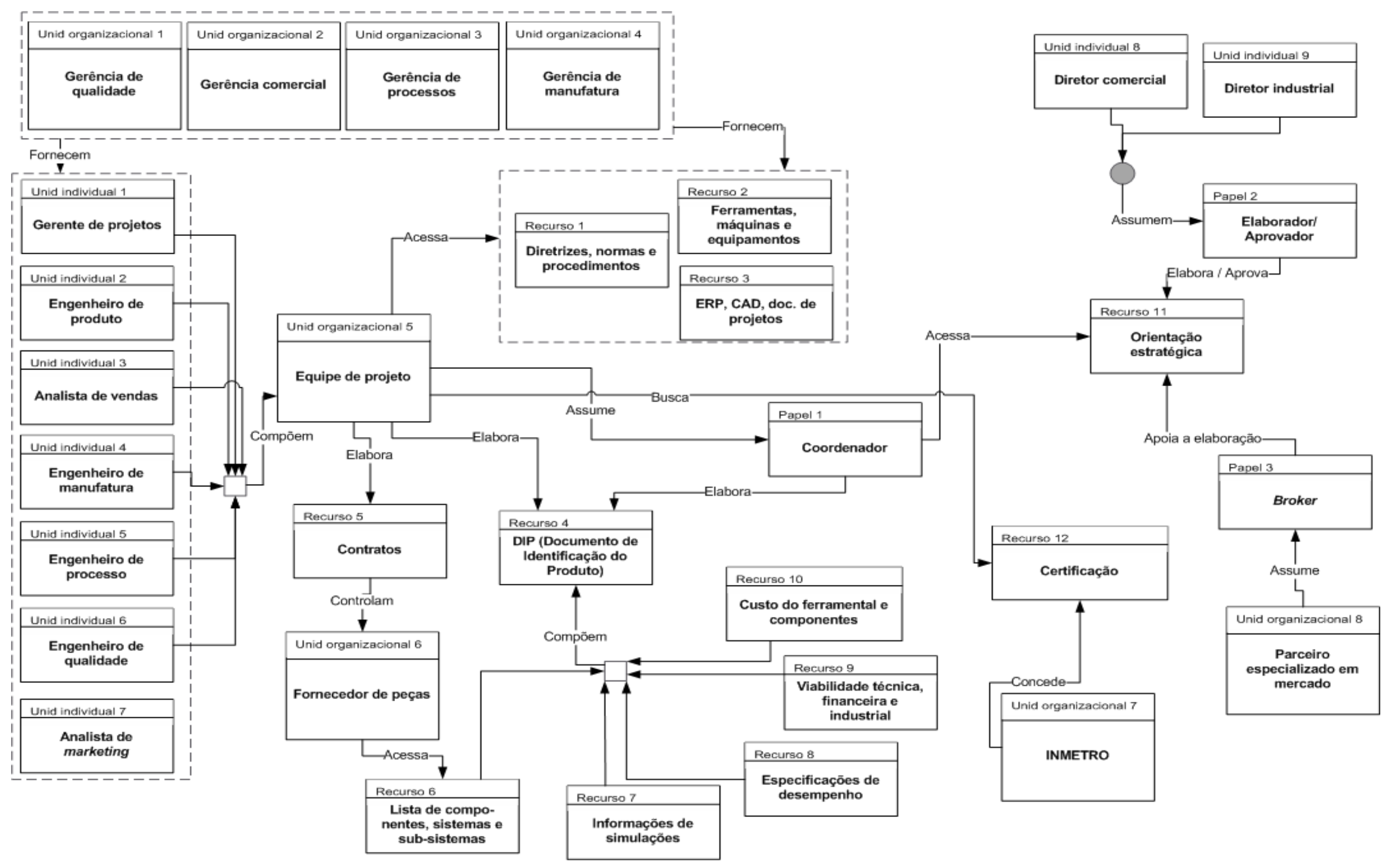

Figura 57: Modelo de Atores e Recursos (as-is) - unidade de análise número 7. 


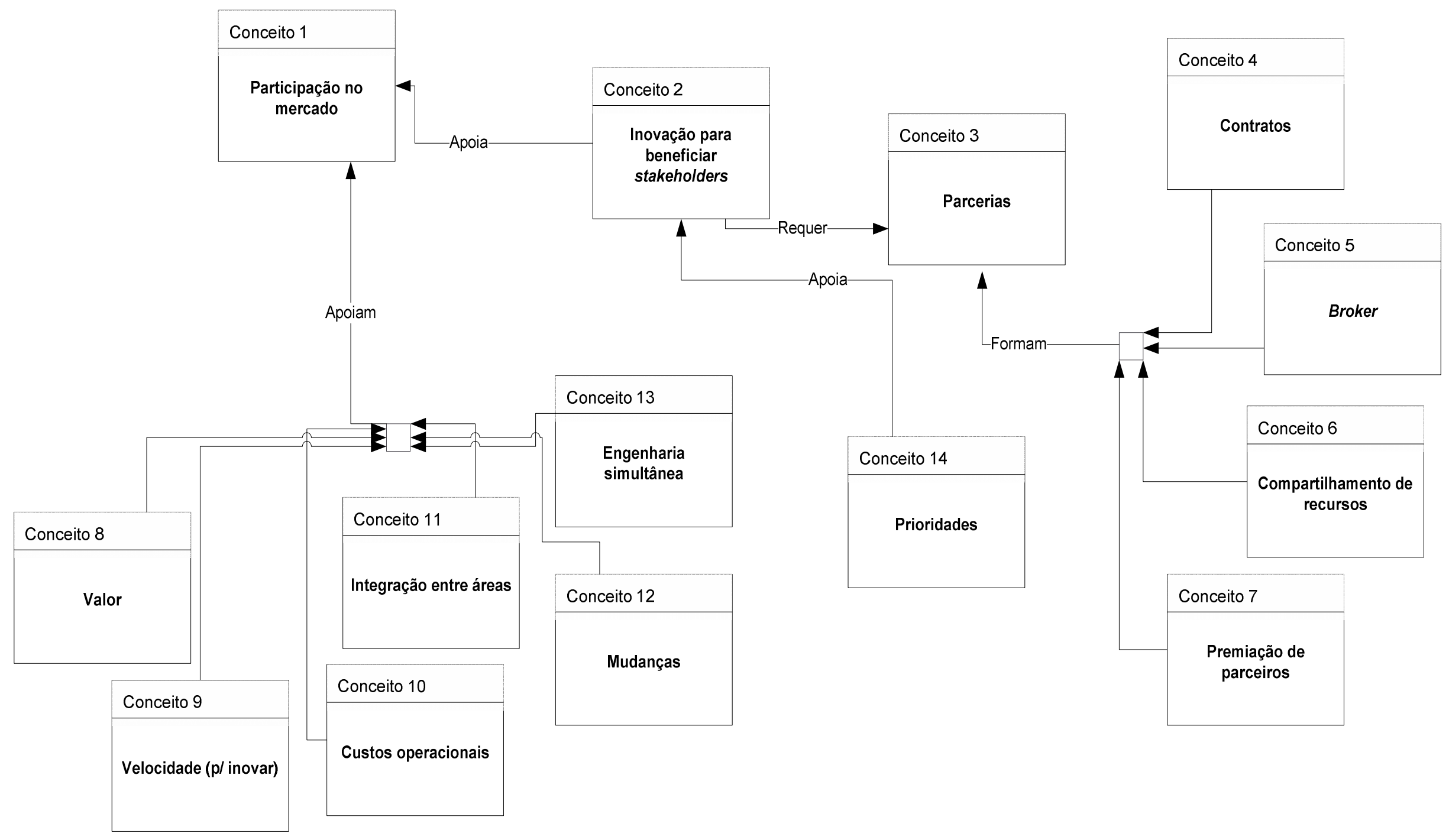

Figura 58: Modelo de Conceitos (as-is) - unidade de análise número 7. 
8. Unidade de análise Número 8

O Modelo de Objetivos está orientado pela determinação de ampliar a liderança no segmento de eletrodomésticos (Objetivo 1), cujo esforço permite aproveitar o conhecimento e as práticas dispersos pela planta (Oportunidade 1). Esse objetivo recebe apoio de outros quatro objetivos: agregar valor aos produtos (Objetivo 2), o que permite trabalhar classificar e priorizar os projetos mais importantes (Oportunidade 2); antecipar as necessidades dos clientes (Objetivo 2), o que possibilita melhorar a imagem da empresa (Oportunidade 2); desenvolver produtos ecologicamente corretos (Objetivo 4), que muitas vezes esbarra na necessidade de reduzir custos (Ameaça 2); e melhorar a cadeia de fornecedores (Objetivo 5), que sofre com as diferenças culturais e de objetivos estratégicos entre os parceiros (Ameaças 3 e 4). Uma das formas de agregar valor aos produtos é desenvolver tecnologias novas e originais (Objetivo 2.1), mas que pode esbarrar em custo e prazo envolvidos (Ameaça 1). A determinação de antecipar as necessidades dos clientes começa com os objetivos de diminuir as reclamações dos clientes (Objetivo 3.1) e de acelerar a resolução de conflitos e oferecer respostas/soluções (Objetivo 3.2). Para apoiar o objetivo de desenvolver produtos ecologicamente corretos temos: obter novos conhecimentos a partir do relacionamento com os fornecedores (Objetivo 4.1), e desenvolver campanha publicitária para desenvolver esse valor (Objetivo 4.2). Para melhorar a cadeia de fornecedores temos três objetivos de apoio: tornar os fornecedores mais confiáveis (Objetivos 5.1), compartilhar custos (Objetivo 5.2), e compartilhar riscos (Objetivo 5.3).

No Modelo de Regras de Negócios fica evidente que ampliação da liderança no segmento de eletrodomésticos (Objetivo 1) requer o alinhamento do PDP com as diretrizes estratégicas da empresa (Regra 1), e como exemplo temos a regra que determina que os projetos top-ten sejam priorizados dentro do portfólio de novos produtos (Regra 2). Para agregar valor aos produtos temos duas regras de apoio: usar métricas eficazes para avaliar o desempenho dos novos produtos (Regra 3) e fazer o levantamento detalhado das necessidades dos clientes (Regra 4). Para antecipar as necessidades dos clientes (Objetivo 3) é preciso usar o CRM para prospectar novas oportunidades (Regra 5). Para desenvolver produtos ecologicamente corretos é necessário realizar benchmarking com empresas concorrentes e não concorrentes (Regra 6) a fim de identificar novas técnicas, tecnologias, materiais, e processos. Melhorar a cadeia de fornecedores (Objetivo 5) requer o desenvolvimento de novas parcerias (Regra 7), que recebe apoio da regra que determina que a empresa priorize o desenvolvimento com terceiros (Regra 8). Para ser possível desenvolver novas tecnologias originais (Objetivo 2.1) é preciso priorizar investimentos em projetos que envolvam inovação tecnológica (Regra 9). Para diminuir reclamações dos clientes (Objetivo 3.1) é importante focar na etapa de testes laboratoriais de 
desempenho (Regra 10). Para acelerar a resolução de conflitos (Objetivo 3.2) deve-se treinar o $\mathrm{SAC}$ e fornecer os meios para ele responder com eficácia (Regra 11). O objetivo de obter novos conhecimentos a partir do relacionamento com os fornecedores (Objetivo 4.1) requer que seja documentada a colaboração dos fornecedores (Regra 12). É importante informar o público do esforço da empresa e dos benefícios obtidos pelo desenvolvimento de produtos ecologicamente corretos (Regra 13). Para tornar os produtos mais confiáveis (Objetivo 5.1) temos três regras de apoio: estabelecer contratos rigorosos sobre obrigações e confidencialidade (Regra 14), assegurar que o acesso do fornecedor ao projeto seja apenas parcial (Regra 15), e evitar fornecedor de concorrente (Regra 16). Quanto ao compartilhamento de custos e de riscos (Objetivos 5.2 e 5.3), a análise do resultado das parcerias precisa mostrar redução nos custos (Regra 17) e nos riscos (Regra 18).

O Modelo de Processos de Negócios evidencia que o PDP nasce a partir do estabelecimento das diretrizes estratégicas da empresa (ProcExt 1). As estratégias e metas estabelecidas permitem que se compare o portfólio de produtos com o mercado (ProcExt 2) e a partir das oportunidades e ameaças identificadas sejam concebidas novas ideias (Processo 1). O próximo passo é a realização da análise de viabilidade técnica e financeira (Processo 2) considerando essas novas ideias. Uma vez aprovado o resultado desse passo inicia-se o desenvolvimento dos modelos funcionais (Processo 3), das soluções alternativas (Processo 4) e é selecionada a arquitetura definitiva do produto (Processo 5). O próximo passo é verificar no mercado as possíveis parcerias (Processo 6) para depois montar o protótipo virtual/físico (Processo 7) inclusive com apoio dos eventuais parceiros. Na sequência é realizada a análise de viabilidade técnica e financeira (Processo 8), cujo resultado é submetido à aprovação da diretoria. A seguir é definida a embalagem e o armazenamento (Processo 9) inclusive com os testes necessários. O processo de produção passa a ser desenvolvido na próxima etapa (Processo 10) e é produzido um lote piloto (Processo 11). Na sequência é realizado o fase out com a área de manufatura (Processo 12), tanto em termos de treinamento como de acompanhamento.

O Modelo de Atores e Recursos mostra que algumas unidades organizacionais ajudam a oferecer a estrutura necessária ao PDP, são elas: gerência de marketing (Unidade Organizacional 1), gerência de qualidade (Unidade Organizacional 2), gerência de processos (Unidade Organizacional 3), e gerência de manufatura (Unidade Organizacional 4). Elas oferecem diretrizes, planos de vendas e normas (Recurso 1); ferramentas, máquinas e equipamentos (Recurso 2); ERP, CAD, documentos de FMEA e de QFD (Recurso 3). Também oferecem gerente de projeto (Unidade Individual 1), engenheiro de qualidade (Unidade Individual 2), analista de vendas (Unidade Individual 3), engenheiro de manufatura (Unidade Individual 4), 
técnico de laboratório (Unidade Individual 5), analista de mercado (Unidade Individual 6). Todas essas unidades ajudam a formar a equipe de projeto (Unidade Organizacional 5) que tem o papel de elaborar os contratos (Recurso 5) que controlam os fornecedores de componentes (Unidade Organizacional 6) e elaborar o plano principal do projeto (Recurso 4), composto por: especificações sobre componentes (Recurso 6), especificações de desempenho do produto (Recurso 7), estudo de impacto ambiental (Recurso 8), informação sobre processo (Recurso 9), desenhos técnicos e artes (Recurso 10), e cronogramas e orçamentos (Recurso 11). A equipe de projeto recebe apoio de um coordenador (Papel 1) que normalmente é um gerente de produtos (Unidade Individual 1). Ele recebe as orientações estratégicas (Recurso 12) elaboradas pelo conselho internacional (Unidade Individual 7), pela diretoria comercial (Unidade Individual 8), e pela diretoria industrial (Unidade Individual 9). Também há a participação de um especialista em mercado (Unidade Organizacional 7) que assume o papel de Broker (Papel 3) para ajudar a elaborar as orientações estratégicas (Recurso 12).

No Modelo de Conceitos a Inovação (Conceito 1) recebe apoio de outros cinco conceitos: projetos top ten (Conceito 2), mudança (Conceito 3), benchmarking (Conceito 4), ecologicamente correto (Conceito 5), e CRM (Conceito 6). A inovação normalmente agrega valor (Conceito 7) e isso apoia a liderança comercial (Conceito 8). O conceito de inovação recebe apoio do conceito de redes de parceiros (Conceito 9), o qual recebe apoio de outros três conceitos: confiança (conceito 10), contratos (Conceito 11) e internalização do conhecimento (Conceito 12). 


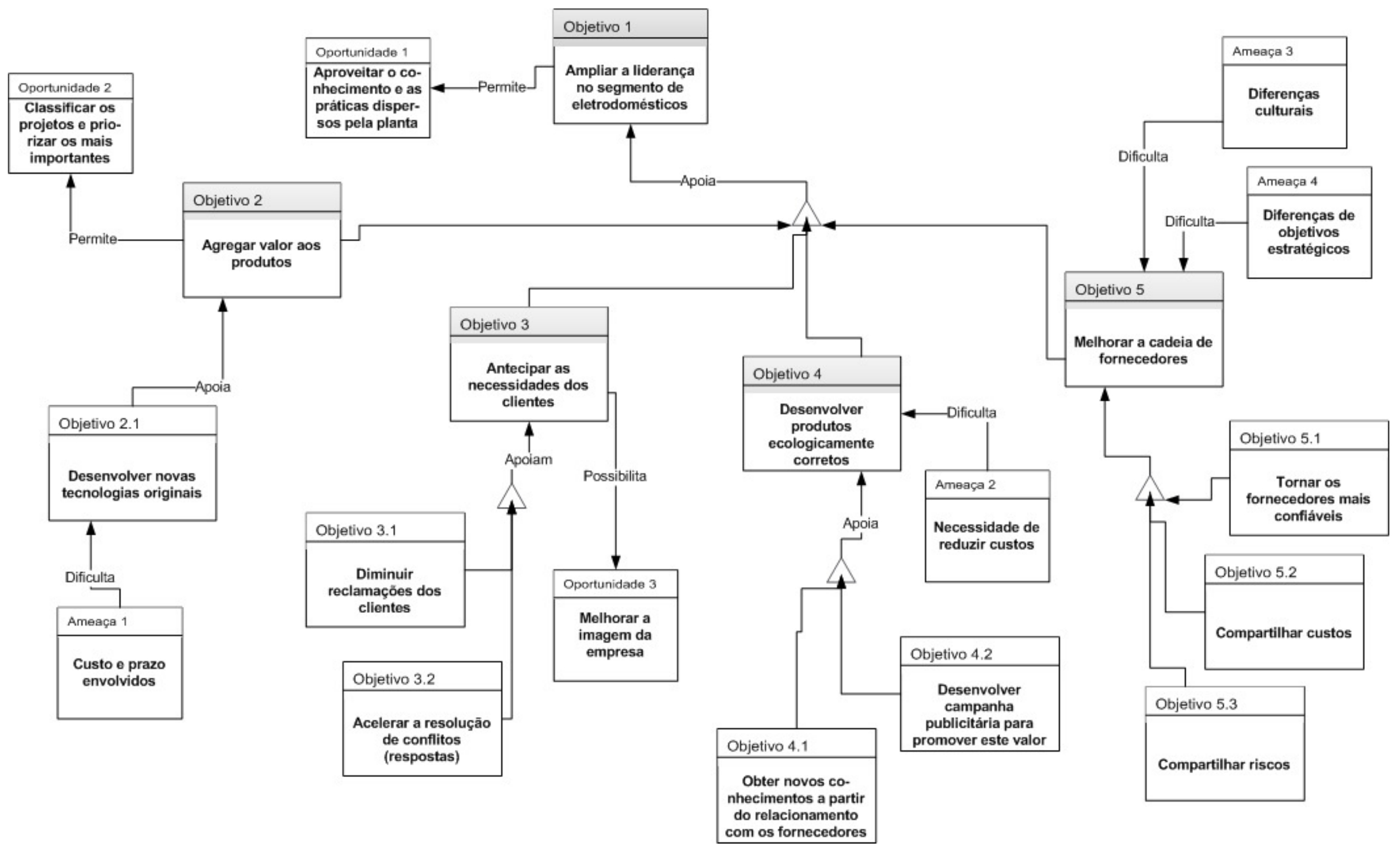

Figura 59: Modelo de Objetivos (as-is) - unidade de análise número 8 

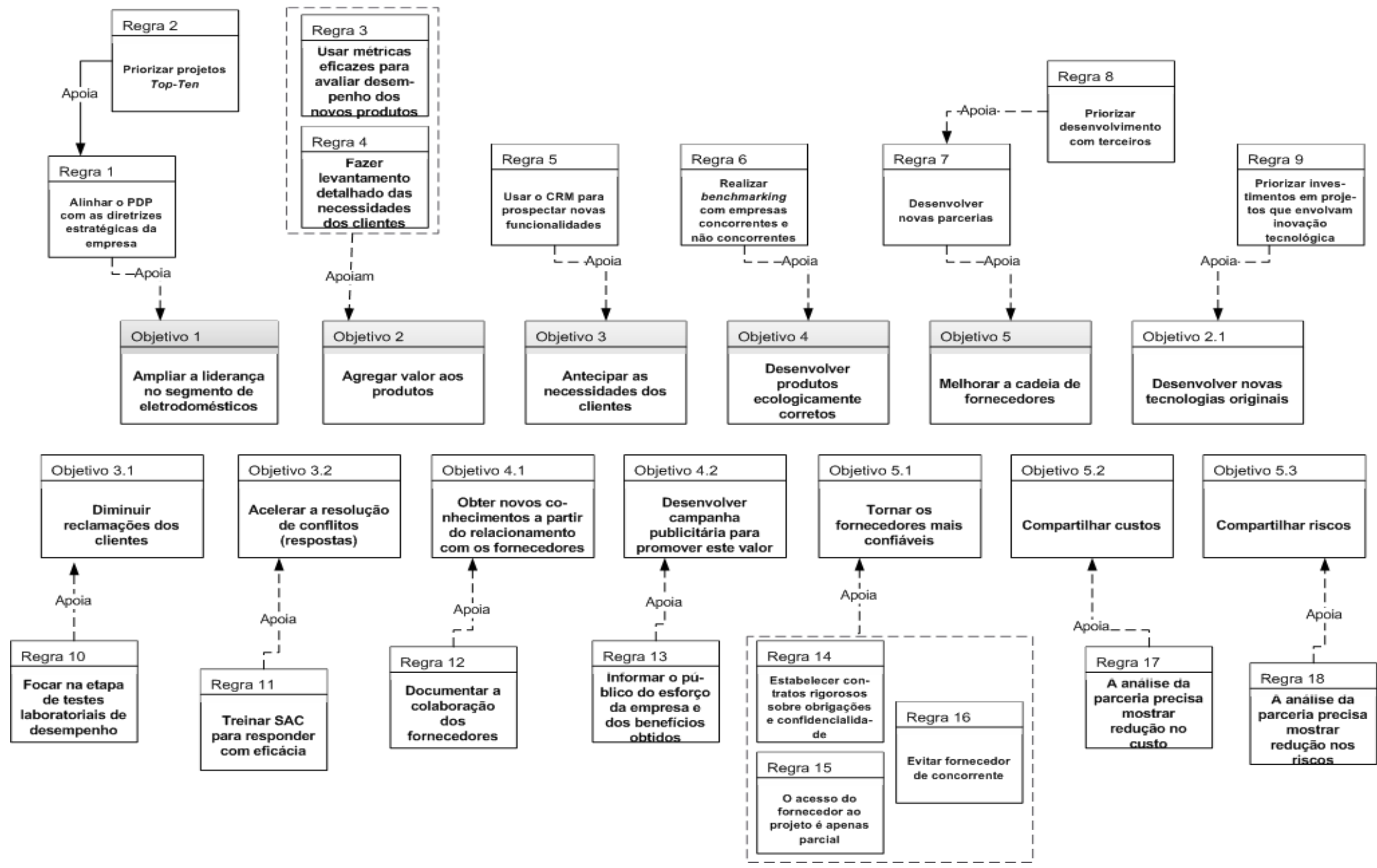

Figura 60: Modelo de Regras de Negócios (as-is) - unidade de análise número 8. 


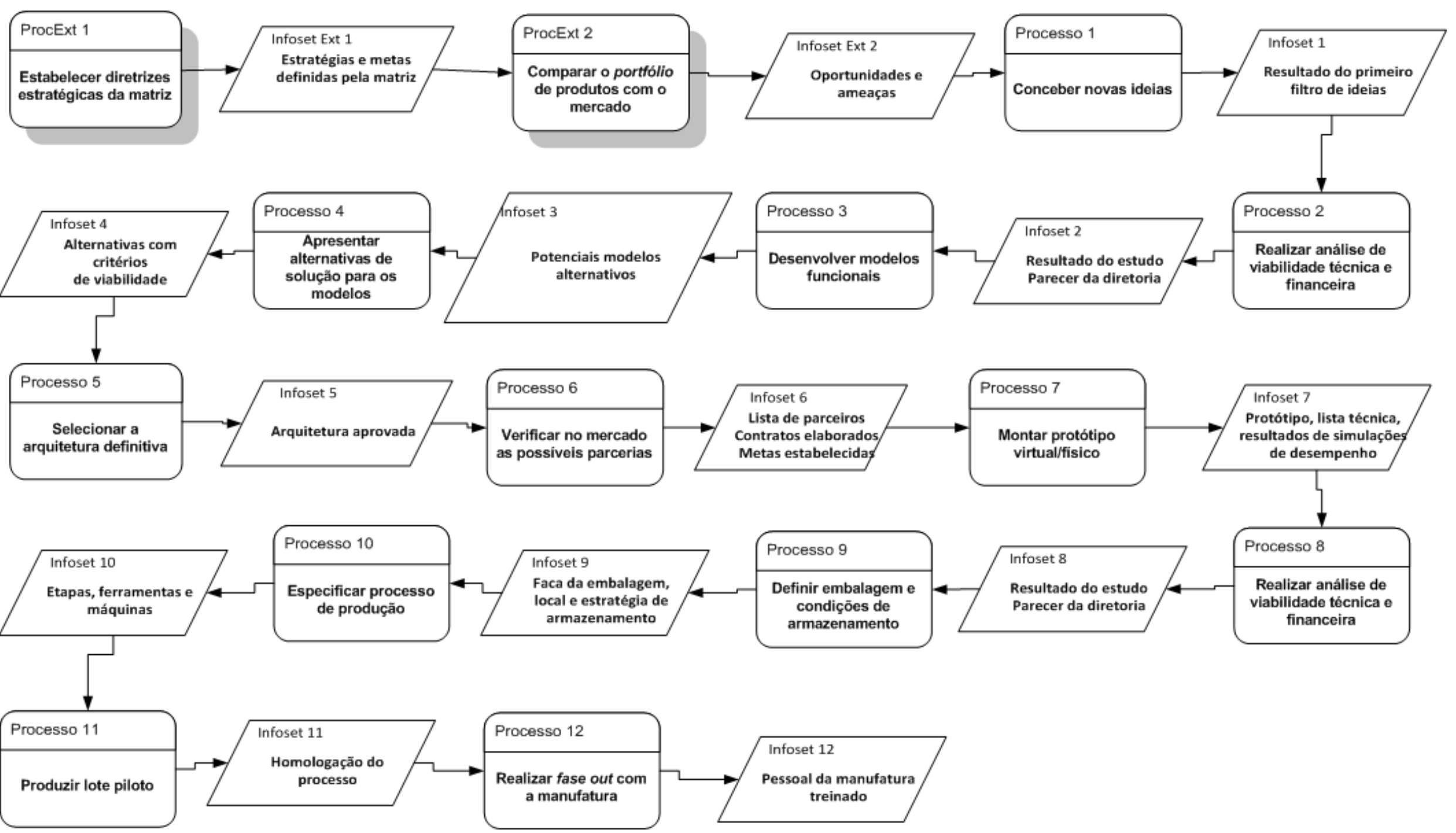

Figura 61: Modelo de Processo de Negócios $(a s-i s)$ - unidade de análise número 8. 


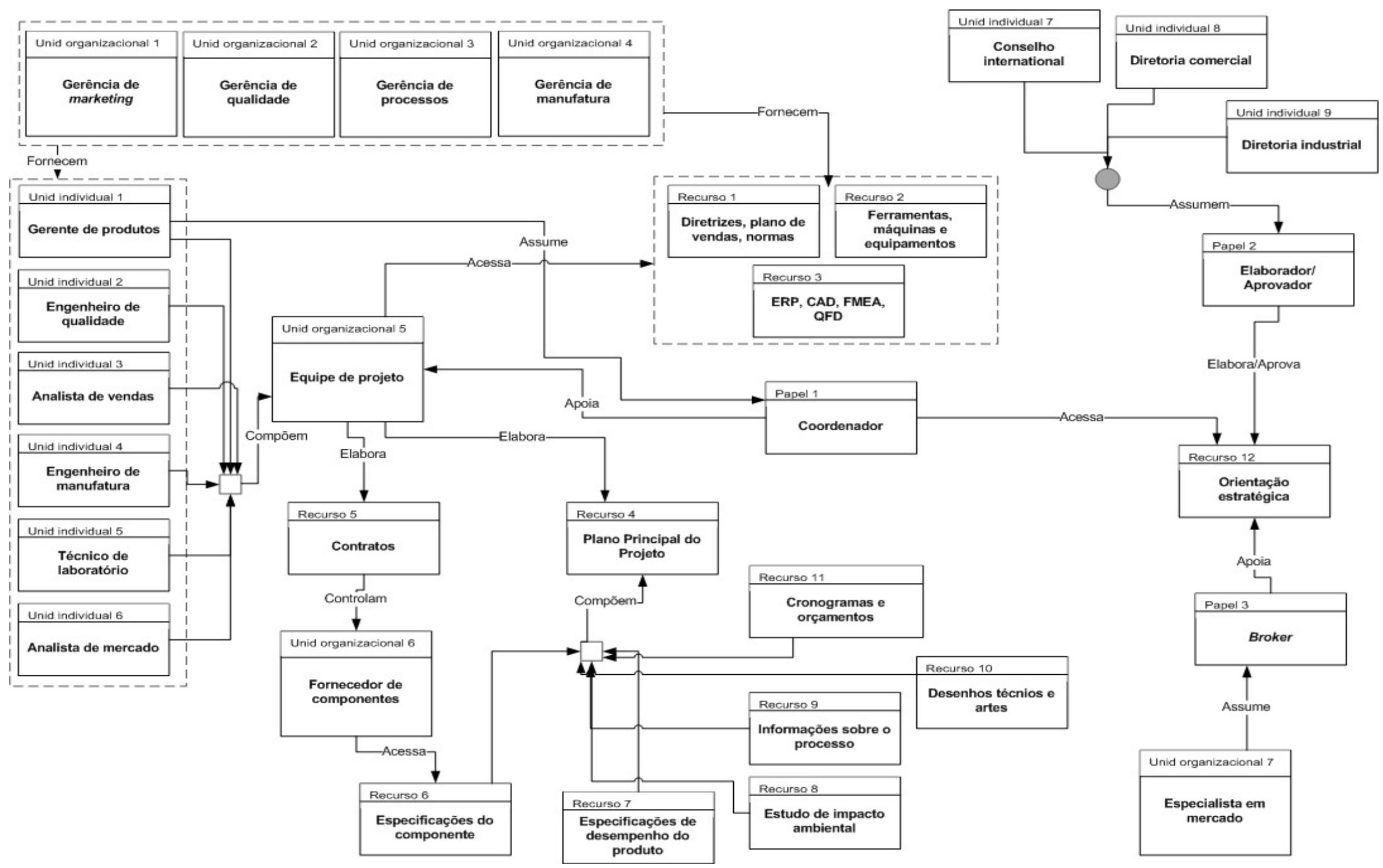

Figura 62: Modelo de Atores e Recursos (as-is) - unidade de análise número 8. 


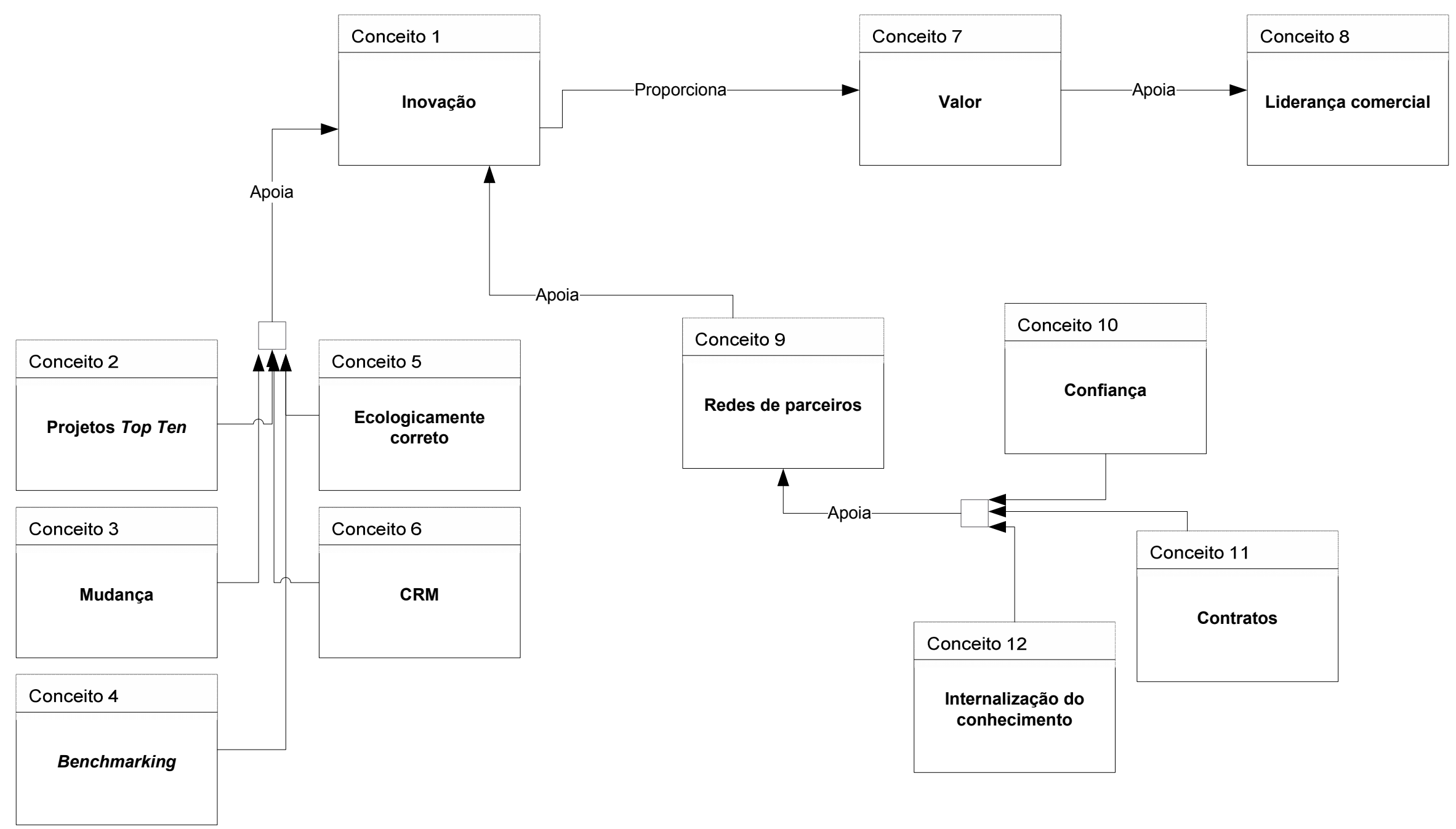

Figura 63: Modelo de Conceitos (as-is) - unidade de análise número 8. 


\section{APÊNDICE D - Questionário de validação do modelo de referência}

Os quadros abaixo mostram os questionários submetidos aos especialistas de cada unidade de análise para a validação do modelo de referência proposto. O primeiro quadro referese a uma visão geral da pesquisa e procura verificar se o entrevistado considera o trabalho relevante e exequiível. As opções disponíveis estão pontuadas da seguinte forma: discordo totalmente (1 ponto); discordo ( 2 pontos); não concordo nem discordo ( 3 pontos); concordo (4 pontos); concordo totalmente (5 pontos). Foi solicitado aos especialistas justificar apenas as avaliações negativas.

Quadro 16: formulário relativo à validação geral da pesquisa.

\begin{tabular}{|l|l|l|l|l|l|}
\hline & $\begin{array}{l}\text { Discordo } \\
\text { totalmente }\end{array}$ & Discordo & $\begin{array}{l}\text { Não concordo } \\
\text { nem discordo }\end{array}$ & Concordo & $\begin{array}{l}\text { Concordo } \\
\text { totalmente }\end{array}$ \\
\hline $\begin{array}{l}\text { 1. A auto-organização é uma } \\
\text { propriedade que pode contribuir } \\
\text { para o alcance das metas nos } \\
\text { projetos de inovação. }\end{array}$ & & & & & \\
\hline $\begin{array}{l}\text { 2. O modelo de referência } \\
\text { apresentado pode contribuir para } \\
\text { apoiar o processo de auto- } \\
\text { organização. }\end{array}$ & & & & & \\
\hline $\begin{array}{l}\text { 3. O modelo de referência pode ser } \\
\text { instanciado na sua unidade de } \\
\text { análise. }\end{array}$ & & & & & \\
\hline
\end{tabular}


Os quadros 17 a 21 mostram a avaliação da importância de cada elemento que foi inserido no modelo de referência, assim com das demais modificações propostas. O modelo foi segmentado nos seus sub-modelos a fim de facilitar a avaliação pelos entrevistados.

Quadro 17: formulário relativo à validação do Modelo de Objetivos.

\begin{tabular}{|l|l|l|l|l|l|}
\hline MODELO DE OBJETIVOS & $\begin{array}{l}\text { Discordo } \\
\text { totalmente }\end{array}$ & Discordo & $\begin{array}{l}\text { Não concordo } \\
\text { nem discordo }\end{array}$ & Concordo & $\begin{array}{l}\text { Concordo } \\
\text { totalmente }\end{array}$ \\
\hline $\begin{array}{l}\text { 1. Usar um controle descentraliza- } \\
\text { do e indireto. }\end{array}$ & & & & & \\
\hline $\begin{array}{l}\text { 2. Direcionar foco para os relacio- } \\
\text { namentos. }\end{array}$ & & & & & \\
\hline $\begin{array}{l}\text { 3. Incentivar o comprometimento } \\
\text { das partes. }\end{array}$ & & & & & \\
\hline $\begin{array}{l}\text { 4. Motivar a participação voluntá- } \\
\text { ria. }\end{array}$ & & & & & \\
\hline $\begin{array}{l}\text { 5. Incentivar o aprendizado } \\
\text { enquanto geração e uso do } \\
\text { conhecimento. }\end{array}$ & & & & & \\
\hline 6. Apoiar a interdependência. & & & & & \\
\hline 7. Apoiar movimentos bottom up. & & & & & \\
\hline $\begin{array}{l}\text { 8. Promover o alinhamento dos } \\
\text { parceiros. }\end{array}$ & & & & & \\
\hline 9. Fomentar o compartilhamento. & & & & & \\
\hline
\end{tabular}

Quadro 18: formulário relativo à validação do Modelo de Regras de Negócios.

\begin{tabular}{|l|l|l|l|l|l|}
\hline $\begin{array}{l}\text { MODELO DE REGRAS DE } \\
\text { NEGÓCIOS }\end{array}$ & $\begin{array}{l}\text { Discordo } \\
\text { totalmente }\end{array}$ & Discordo & $\begin{array}{l}\text { Não concordo } \\
\text { nem discordo }\end{array}$ & $\begin{array}{l}\text { Concordo } \\
\text { 1. Compartilhar o planejamento do } \\
\text { projeto e a resolução de conflitos. }\end{array}$ & $\begin{array}{l}\text { Concordo } \\
\text { totalmente }\end{array}$ \\
\hline $\begin{array}{l}\text { 2. Avaliar o tipo e a intensidade } \\
\text { dos relacionamentos. }\end{array}$ & & & & & \\
\hline $\begin{array}{l}\text { 3. Estabelecer política de } \\
\text { governança clara. }\end{array}$ & & & & & \\
\hline $\begin{array}{l}\text { 4. Manter canais de comunicação } \\
\text { sempre abertos. }\end{array}$ & & & & & \\
\hline
\end{tabular}




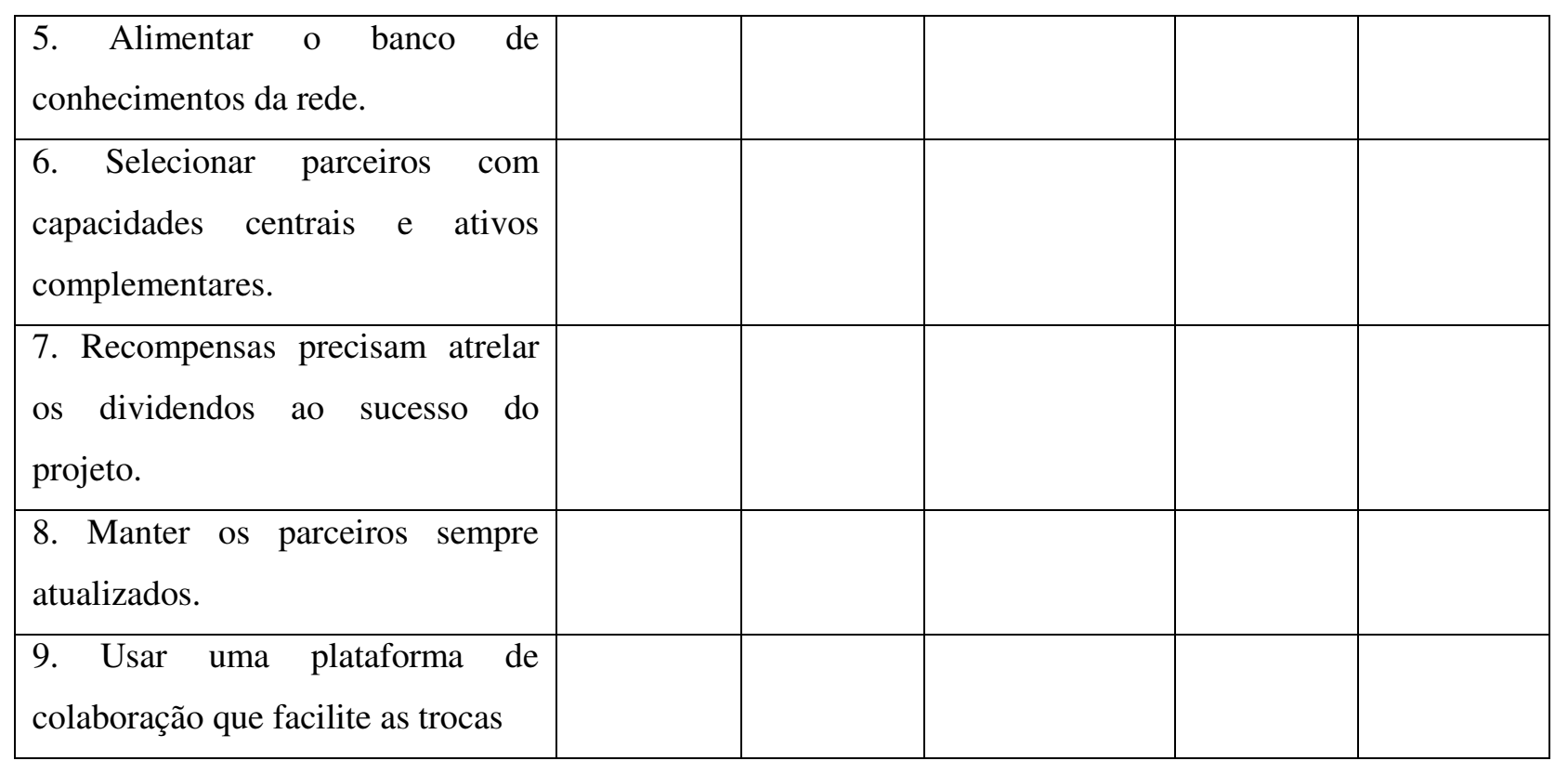

Quadro 19: formulário relativo à validação do Modelo de Atores e Recursos.

\begin{tabular}{|l|l|l|l|l|l|}
\hline $\begin{array}{l}\text { MODELO DE ATORES E } \\
\text { RECURSOS }\end{array}$ & $\begin{array}{l}\text { Discordo } \\
\text { totalmente }\end{array}$ & Discordo & $\begin{array}{l}\text { Não concordo } \\
\text { nem discordo }\end{array}$ & Concordo & $\begin{array}{l}\text { Concordo } \\
\text { totalmente }\end{array}$ \\
\hline $\begin{array}{l}\text { 1. Integração do parceiro à equipe } \\
\text { de projeto. }\end{array}$ & & & & & \\
\hline 2. Gestor de relacionamentos. & & & & & \\
\hline $\begin{array}{l}\text { 3. Gestor da mobilidade do } \\
\text { conhecimento. }\end{array}$ & & & & & \\
\hline $\begin{array}{l}\text { 4. Gestor da apropriação da } \\
\text { inovação. }\end{array}$ & & & & & \\
\hline 5. Selecionador de empresas. & & & & & \\
\hline 6. Plataforma de colaboração & & & & & \\
\hline 7. Relação de benefícios & & & & & \\
\hline $\begin{array}{l}\text { 8. Capacidades centrais e ativos } \\
\text { complementares. }\end{array}$ & & & & & \\
\hline 9. Relação de metas estabelecidas. & & & & & \\
\hline
\end{tabular}

Quadro 20: formulário relativo à validação do Modelo de Processos de Negócios.

\begin{tabular}{|c|c|c|c|c|c|}
\hline $\begin{array}{l}\text { MODELO DE PROCESSOS DE } \\
\text { NEGÓCIOS }\end{array}$ & $\begin{array}{l}\text { Discordo } \\
\text { totalmente }\end{array}$ & Discordo & $\begin{array}{l}\text { Não concordo } \\
\text { nem discordo }\end{array}$ & Concordo & $\begin{array}{l}\text { Concordo } \\
\text { totalmente }\end{array}$ \\
\hline $\begin{array}{l}\text { 1. Gerar colaborativamente a } \\
\text { concepção do produto (antecipar a } \\
\text { participação dos parceiros). }\end{array}$ & & & & & \\
\hline
\end{tabular}




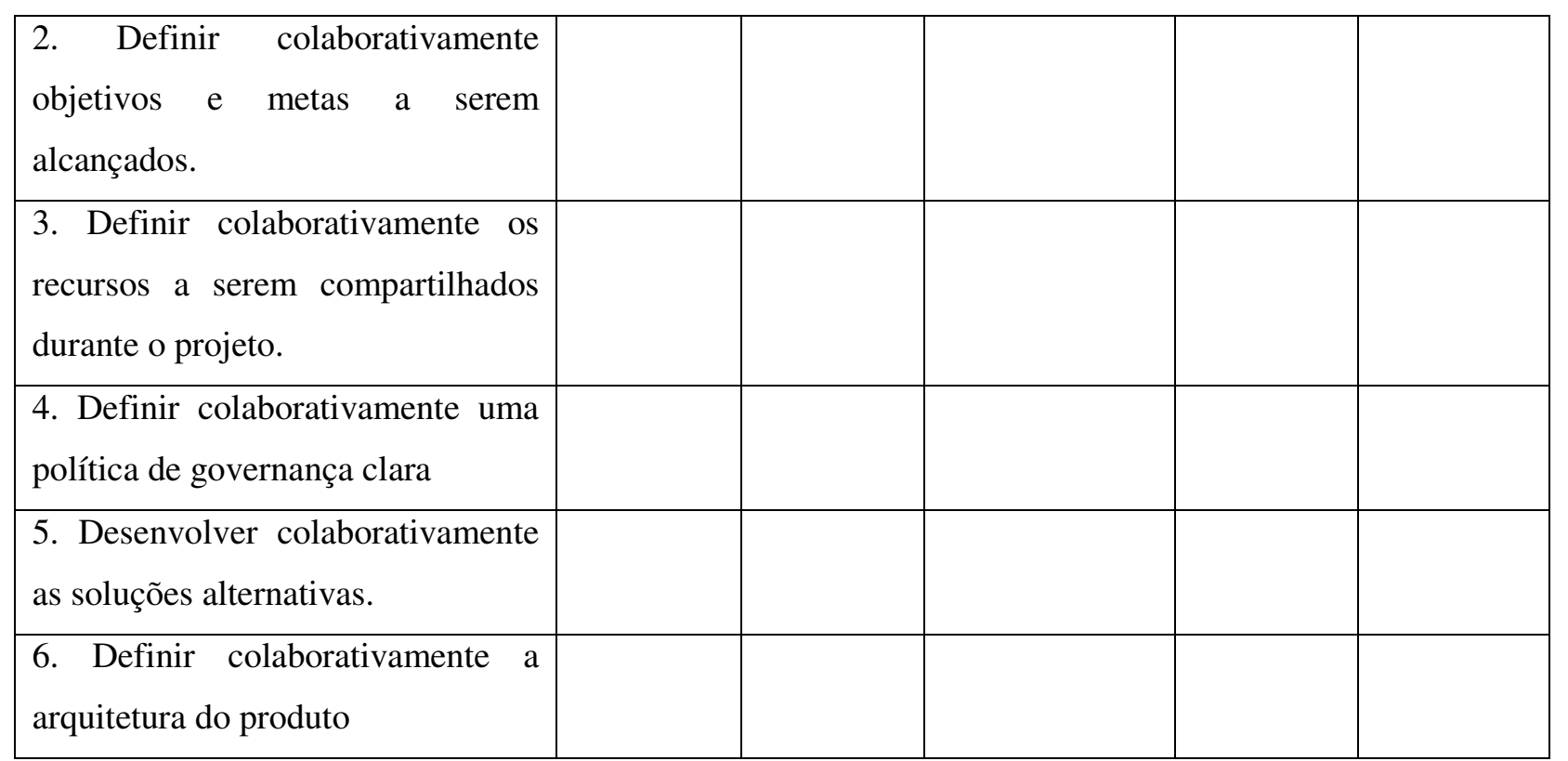

Quadro 21: formulário relativo à validação do Modelo de Componentes e Requisitos Técnicos.

\begin{tabular}{|l|l|l|l|l|l|}
\hline $\begin{array}{l}\text { MODELO DE COMPONENTES } \\
\text { E REQUISITOS TÉCNICOS }\end{array}$ & $\begin{array}{l}\text { Discordo } \\
\text { totalmente }\end{array}$ & Discordo & $\begin{array}{l}\text { Não concordo } \\
\text { nem discordo }\end{array}$ & $\begin{array}{l}\text { Concordo } \\
\text { 1. O sistema precisa permitir a } \\
\text { descentralização do controle. }\end{array}$ & $\begin{array}{l}\text { Concordo } \\
\text { totalmente }\end{array}$ \\
\hline $\begin{array}{l}\text { 2. O sistema precisa gerenciar a } \\
\text { colaboração entre as partes. }\end{array}$ & & & & \\
\hline $\begin{array}{l}\text { 3. O sistema precisa gerenciar a } \\
\text { mobilidade do conhecimento. }\end{array}$ & & & & \\
\hline $\begin{array}{l}\text { 4. O sistema precisa gerenciar a } \\
\text { apropriação da inovação }\end{array}$ & & & & \\
\hline $\begin{array}{l}\text { 5. O sistema precisa promover o } \\
\text { alinhamento dos parceiros. }\end{array}$ & & & & & \\
\hline $\begin{array}{l}\text { 6. O sistema precisa permitir o } \\
\text { registro e o compartilhamento das } \\
\text { práticas. }\end{array}$ & & & & & \\
\hline $\begin{array}{l}\text { 7. O sistema precisa monitorar o } \\
\text { desempenho dos parceiros. }\end{array}$ & & & & \\
\hline
\end{tabular}

Os elementos presentes no Modelo de Conceitos foram retirados dos demais modelos, portanto, já foram avaliados nos quadros acima. 